\title{
Manmade Organic Compounds in the Surface Waters of the \\ United States-A Review of Current Understanding
}

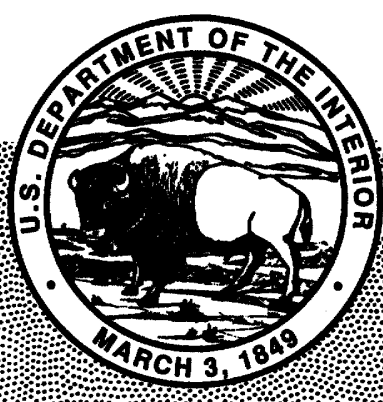



Manmade Organic Compounds

in the Surface Waters of the

United States-A Review of

Current Understanding

By JAMES A. SMITH, PATRICK J. WITKOWSKI and THOMAS V. FUSILLO 


\title{
U.S. DEPARTMENT OF THE INTERIOR BRUCE BABBITT, Secretary
}

\author{
U.S. GEOLOGICAL SURVEY
}

GORDON P. EATON, Director

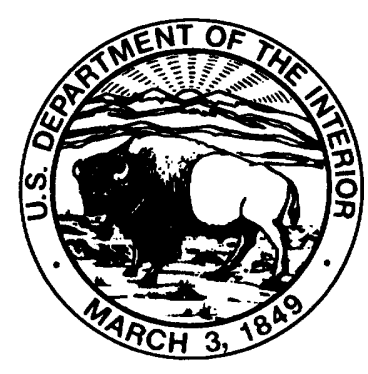

Any use of trade, product, or firm names

in this publication is for descriptive purposes only

and does not imply endorsement by the U.S. Government

First printing 1988

Second printing 1993

Third printing 1996

UNITED STATES GOVERNMENT PRINTING OFFICE: 1988

Free on application to the Books and Open-File Reports Section, U.S. Geological Survey, Federal Center, Box 25425, Denver, CO 80225

Library of Congress Cataloging in Publication Data

Smith, James A. (James Albert)

Manmade organic compounds in the surface waters of the United States.

(U.S. Geological Survey circular ; 1007)

Bibliography: $p$.

Supt. of Docs. no.: | 19.4/2:1007.

1. Organic water pollutants-United States. 2. Organic compounds. I. Witkowski, P.J. (Patrick J.) II. Fusillo,

Thomas V. III. Title. IV. Series.

$\begin{array}{llll}\text { TD427.07S55 } & 1988 & 363.7^{\prime} 394 & 87-600258\end{array}$ 


\section{CONTENTS}

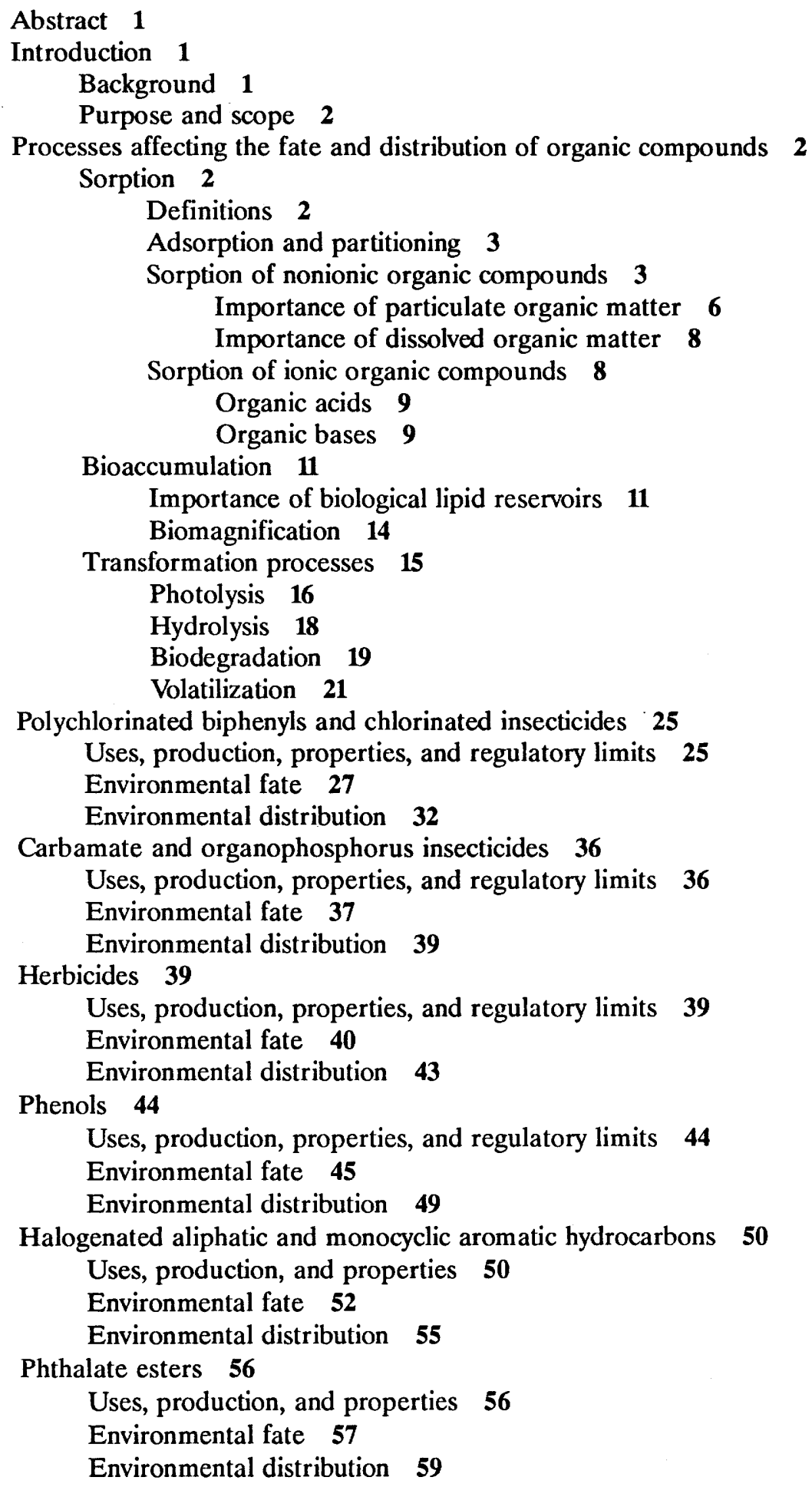

Polychlorinated biphenyls and chlorinated insecticides 25

Uses, production, properties, and regulatory limits 25

Environmental fate 27

Environmental distribution $\mathbf{3 2}$

Carbamate and organophosphorus insecticides 36

Uses, production, properties, and regulatory limits 36

Environmental fate 37

Environmental distribution 39

Herbicides 39

Uses, production, properties, and regulatory limits 39

Environmental fate $\mathbf{4 0}$

Environmental distribution $\mathbf{4 3}$

Phenols 44

Uses, production, properties, and regulatory limits 44

Environmental fate $\mathbf{4 5}$

Environmental distribution 49

Halogenated aliphatic and monocyclic aromatic hydrocarbons $\mathbf{5 0}$

Uses, production, and properties $\mathbf{5 0}$

Environmental fate $\mathbf{5 2}$

Environmental distribution $\mathbf{5 5}$

Phthalate esters $\mathbf{5 6}$

Uses, production, and properties $\mathbf{5 6}$

Environmental fate $\mathbf{5 7}$

Environmental distribution $\mathbf{5 9}$ 
Polychlorinated dibenzo-p-dioxins 60

Uses, production, and properties

Environmental fate 62

Environmental distribution 63

Polycyclic aromatic hydrocarbons 64

Uses, production, and properties 64

Environmental fate 66

Environmental distribution $\mathbf{7 0}$

Summary 73

Selected references

\section{FIGURES}

1-10. Plots showing:

1. Correlation of octanol-water partition coefficient with water solubility for selected aromatic liquids and solids at $25^{\circ} \mathrm{C} \quad 4$

2. Soil-water equilibrium isotherms of some neutral organic compounds at $20^{\circ} \mathrm{C} 4$

3. Typical soil-water equilibrium isotherms for 1,3-dichlorobenzene and 1,2,4-trichlorobenzene as single solutes and as binary solutes on a Woodburn silt loam soil at $20^{\circ} \mathrm{C} 5$

4. Soil organics-water sorption coefficients plotted as a function of the aqueous solubilities of selected neutral organic compounds 5

5. Sorption coefficient normalized for organic-carbon content as a function of compound water solubility and octanol-water partition coefficient 7

6. Adsorption isotherms of paraquat in soils $\mathbf{1 0}$.

7. Correlation of bioconcentration factor versus octanol-water partition coefficient showing the correlations of Veith and others (1979), Neely and others (1974), and Mackay (1982a) 12

8. Relation between $\log$ water solubility of pesticides and $\log$ bioconcentration factor for Triaenodes tardus egg masses 13

9. Correlation of $\log$ bioconcentration factor on the basis of fish lipid content with log triolein-water partition coefficient for a variety of nonionic organic compounds 14

10. Relation between microbial specific growth rate and substrate concentration 20

11. Structural diagrams of selected chlorinated insecticides and a polychlorinated biphenyl 25

12. Plot showing relation of summer mean polychlorinated biphenyl (PCB) concentrations in water and lipid-based PCB concentrations in fillets of whole yearling pumpkinseed collected September 1977-83 at Stillwater, N.Y. 35

13. Frequency of detection of organochlorine insecticides in water and bed-material samples from stations in the U.S. Geological Survey-U.S. Environmental Protection Agency Pesticide Monitoring Network, 1975-80 35

14. Structural diagrams of selected carbamate and organophosphorus insecticides 36 
15, 16. Plots showing:

15. Cumulative ${ }^{14} \mathrm{CO}_{2}$ (percentage of added ring-labeled

${ }^{14} \mathrm{C}$-insecticide) evolved in a soil planted to rice under flooded and nonflooded conditions 38

16. Trends in national use of herbicides and insecticides on major crops, 1964-82 40

17, 18. Structural diagrams of:

17. Selected herbicides $\mathbf{4 0}$

18. Selected phenolic compounds 44

19. Structural diagrams showing degradation pathway of pentachlorophenol in soils 48

20. Structural diagrams of selected halogenated aliphatic and monocyclic aromatic hydrocarbons 51

21. Graph of predicted volatilization rates of methylene chloride and dichlorobenzene in the Rio Grande River, N. Mex. 55

22. Structural diagrams of some common phthalate esters $\mathbf{5 7}$

23, 24. Structural diagrams showing:

23. Degradation of di-n-butyl phthalate, mono-n-butyl phthalate, and phthalic acid by different microorganisms: organisms isolated with di-n-butyl phthalate as carbon source for enrichment, stock cultures, and bacteria isolated from phthalic acid enrichment medium 59

24. Formation of 2,3,7,8-tetrachlorodibenzo-p-dioxin as a byproduct in the synthesis of 2,4,5-trichlorophenoxyacetic acid 60

25. Structural diagrams of selected polycyclic aromatic hydrocarbons 66

26. Structural diagrams showing proposed degradation pathway of phenanthrene by soil pseudomonads $\mathbf{7 0}$

\section{TABLES}

1. Contrasting characteristics of adsorption and partition processes 3

2. Selected anionic and cationic organic compounds of environmental significance 9

3. Approximate molecular composition of some Aroclor mixtures 26

4. Some uses of polychlorinated biphenyls suggested by the manufacturer 27

5. Detection limits, water-quality criteria, and use data for selected organochlorine insecticides 28

6. Experimentally determined octanol-water partition coefficients, solubilities, and vapor pressures of selected polychlorinated biphenyls and chlorinated insecticides at room temperature 29

7. Experimentally determined sorption coefficients for some polychlorinated biphenyls and organochlorine insecticides 30

8. Experimentally determined bioconcentration factors for some polychlorinated biphenyls and organochlorine insecticides 31

9. Means and ranges of detectable sediment residues of polychlorinated biphenyls and organochlorine insecticides 33

10. Detectable residues of polychlorinated biphenyls and organochlorine insecticides in biota 34

11. Experimentally determined octanol-water partition coefficients, solubilities, and vapor pressures of selected organophosphorus and carbamate insecticides at room temperature 36 
12. Detection limits, water-quality criteria, and use data for selected organophosphorus insecticides 37

13. Characteristics of selected carbamate insecticides 38

14. Approximate persistence of pesticides in soils $\mathbf{3 8}$

15. Detection limits, water-quality criteria, and use data for some common herbicides $\mathbf{4 0}$

16. List of and magnitude of application of herbicides in $\mathbf{1 1}$ agricultural watersheds in Ontario, $1975 \quad \mathbf{4 1}$

17. Experimentally determined aqueous solubilities and vapor pressures of selected herbicides at room temperature 41

18. Structural groupings of selected herbicides $\mathbf{4 1}$

19. Herbicide residues in North American surface waters 43

20. World production of phenol in 197845

21. Experimentally determined physicochemical properties of selected phenolic compounds at room temperature 46

22. Phenol bacteria present during the winter and (or) summer season in St. Lawrence River water and maximum phenol levels that could be tolerated 47

23. Time required for bacteria to use 95 percent of parent substrate 48

24. Photolysis of phenols and their degradation products 48

25. Experimentally determined sorption coefficients of nonionized chlorinated phenols for different natural sorbents 49

26. Concentration of phenol and some of its chlorinated derivatives in municipal and industrial wastewater $\mathbf{5 0}$

27. U.S. production of selected halogenated aliphatic and monocyclic aromatic hydrocarbons 51

28. Uses of selected halogenated aliphatic and monocyclic aromatic hydrocarbons $\mathbf{5 2}$

29. Experimentally determined octanol-water partition coefficients, solubilities, and vapor pressures of selected halogenated aliphatic and monocyclic aromatic hydrocarbons at room temperature $\mathbf{5 3}$

30. Evaporation times for 50 and 90 percent removal of chlorinated aliphatic hydrocarbons ( 1 milligram per liter) at $25^{\circ} \mathrm{C}, 200$ revolutions per minute of stirring, and a depth of 6.5 centimeters 54

31. Ratios of overall transfer coefficients for selected aliphatic and monocyclic aromatic hydrocarbons to overall transfer coefficients for oxygen $\mathbf{5 4}$

32. Uses of phthalate esters in the United States $\mathbf{5 7}$

33. Solubilities and vapor pressures of selected phthalate esters $\mathbf{5 8}$

34. Selected bioconcentration factors of phthalate esters in aquatic systems $\mathbf{5 8}$

35. Chlorinated dibenzo-p-dioxins found in commercial pesticides 61

36. Single oral doses of dioxins necessary to kill 50 percent of exposed animals 62

37. Bioconcentration factors of 2,3,7,8-tetrachlorodibenzo-p-dioxin for a variety of aquatic organisms 62

38. Estimated annual inputs of polychlorinated dibenzo-p-dioxins to the Canadian environment from major sources 64

39. Residues of chlorodibenzo-p-dioxins in soil samples from various locations in the United States $\mathbf{6 5}$

40. Mean and maximum concentrations of detected residues of $2,3,7,8-$ tetrachlorodibenzo-p-dioxin in a variety of freshwater and marine fish 65 
41. Residues of polycyclic aromatic hydrocarbons in oils, gasoline, bitumen, and sludge 67

42. Estimated annual benzo(a)pyrene emissions to the atmosphere 68

43. Experimentally determined octanol-water partition coefficients, solubilities, and vapor pressures of selected polycyclic aromatic hydrocarbons 68

44. Calculated and experimental sediment-water sorption coefficients normalized for organic carbon for a variety of polycyclic aromatic hydrocarbons 69

45. Bioconcentration factors for selected polycyclic aromatic hydrocarbons 69

46. Sediment residues of polycyclic aromatic hydrocarbons 71

47. Residues of polycyclic aromatic hydrocarbons in biota $\mathbf{7 2}$ 


\section{ABBREVIATIONS}

\begin{tabular}{|c|c|c|c|}
\hline $\begin{array}{l}\text { A } \\
\text { atm-m } \mathrm{m}^{3} / \mathrm{mol}\end{array}$ & $\begin{array}{l}\text { Angstroms } \\
\text { Atmosphere-cubic meter }\end{array}$ & $\begin{array}{l}\mathrm{mg} / \mathrm{L} \\
\mathrm{Mg} / \mathrm{yr}\end{array}$ & $\begin{array}{l}\text { Milligrams per liter } \\
\text { Megagrams per year } \\
\text { Miles }\end{array}$ \\
\hline${ }^{\circ} \mathrm{C}$ & Degrees Celsius & $\min$ & Minutes \\
\hline $\mathrm{cm}$ & Centimeters & $\mathrm{mm}$ & Millimeters \\
\hline $\mathrm{m} / \mathrm{h}$ & Centimeters per hour & mo & Months \\
\hline & Days & $\mathrm{mol} / \mathrm{L}$ & Moles per liter \\
\hline$g / d$ & Grams per day & $\mathrm{mol} / \mathrm{m}^{3}$ & Moles per cubic meter \\
\hline $\mathrm{g} / \mathrm{L}$ & Grams per liter & $\mathbf{m} / \mathbf{s}$ & Meters per second \\
\hline & Hours & $\mathrm{ng} / \mathrm{L}$ & Nanograms per liter \\
\hline $\mathrm{kcal} / \mathrm{mol}$ & Kilocalories per mole & $\mathrm{nm}$ & Nanometers \\
\hline & Kilograms & $\mathrm{pg} / \mathrm{L}$ & Picograms per liter \\
\hline $\mathrm{kg} / \mathrm{d}$ & Kilograms per day & $\mathrm{ppb}$ & Parts per billion \\
\hline kg/ha & Kilograms per hectare & ppm & Parts per million \\
\hline $\mathbf{k g} / \mathbf{y r}$ & Kilograms per year & ppt. & Parts per trillion \\
\hline km & Kilometers & rpm & Revolutions per minute \\
\hline lb & Pounds & & Metric tons \\
\hline $\mathrm{lb} / \mathrm{yr}$ & Pounds per year & torr $-\mathrm{L} / \mathrm{mol}$ & Torr-liters per mole \\
\hline L-torr $/ K-1$ & $\begin{array}{l}\text { Liter-torr per degree Kelvin- } \\
\text { mole }\end{array}$ & $\begin{array}{l}\text { torr } / \text { molar } \\
\mathrm{yr}\end{array}$ & $\begin{array}{l}\text { Torr-liters per mole } \\
\text { Years }\end{array}$ \\
\hline $\mathbf{m}$ & Meter & $\mu \mathrm{g}$ & Micrograms \\
\hline & Square meters per hour & $\mu \mathrm{g} / \mathrm{g}$ & Micrograms per gram \\
\hline & Cubic meters & $\mu \mathrm{g} / \mathrm{kg}$ & Micrograms per kilogra \\
\hline ng & Milligrams per kilogram & $\mu \mathrm{g} / \mathrm{L}$ & Micrograms per liter \\
\hline
\end{tabular}




\title{
Manmade Organic Compounds in the Surface Waters of the United States- A Review of Current Understanding
}

\author{
By James A. Smith, Patrick J. Witkowski, and Thomas V. Fusillo
}

Abstract

This report reviews the occurrence and distribution of manmade organic compounds in the surface waters of the United States. On the basis of their aqueous solubilities, nonionic organic compounds partition themselves among water, dissolved organic matter, particulate organic matter, and the lipid reservoirs of aquatic organisms. lonized organic compounds can be adsorbed to sediments, thereby reducing their aqueous concentrations. Transformation processes of photolysis, hydrolysis, biodegradation, and volatilization can attenuate organic compounds, and attenuation rates commonly follow a first-order kinetic process.

Eight groups of manmade organic compounds are discussed:

1. Polychlorinated biphenyls and organochlorine insecticides,

2. Carbamate and organophosphorus insecticides,

3. Herbicides,

4. Phenols,

5. Halogenated aliphatic and monocyclic aromatic hydrocarbons,

6. Phthalate esters,

7. Polychlorinated dibenzo-p-dioxins, and

8. Polycyclic aromatic hydrocarbons.

For each compound group, data pertaining to use, production, and properties are presented and discussed. Processes that influence the environmental fate of each group, as determined primarily through laboratory studies, are reviewed, and important fate processes are identified. Environmental concentrations of compounds from each group in water, biota, and sediment are given to demonstrate representative values for comparison with concentrations determined during ongoing research. Finally, where data are sufficient, regional and temporal contamination trends in the United States are discussed.

\section{INTRODUCTION}

\section{Background}

Because of the dramatic increase in the production and use of manmade (anthropogenic) organic compounds in the United States over the past $50 \mathrm{yr}$, the quality of our Nation's surface-water systems has gradually deteriorated. Organic contaminants have been detected in the water, sediments, and biota of rivers, estuaries, and lakes throughout the United States. Shackelford and Keith (1976) documented the occurrence of 1,258 organic compounds in 5,720 observations in 33 water types from 1970 to 1976 . Gilliom (1985) reported the detection of one or more pesticides in almost 20 percent of sediment samples collected from more than 150 river sites in the United States. Residues of persistent organochlorine compounds have been detected around the world, including in antarctic snow (Peterle, 1969) and fish from depths of $2,500 \mathrm{~m}$ in the Atlantic Ocean (Barber and Warlen, 1979).

Manmade organic compounds enter surface-water systems in point-source discharges, nonpoint-source runoff, atmospheric deposition, and ground-water discharges. The discharge of polychlorinated biphenyls (PCB's) into the Hudson River (N.Y.) by two capacitor-manufacturing plants is a notorious example of point-source contamination. Over a $30-y r$ period, these plants combined to discharge PCB's to the Hudson at an average rate of 14 $\mathrm{kg} / \mathrm{d}$ (Brown and others, 1985). Although the discharge of PCB's to the Hudson by these plants was stopped by 1977 , significant residues of the persistent organochlorine contaminants remain in both the sediment and the biota. Nonpoint-source discharges also can contribute to surface-water contamination (Novotny, 1980), particularly with regard to pesticides applied to farmland and forests. In many areas, sediment resulting from eroded soil contains elevated concentrations of sorbed pesticides and is regarded as the primary source of contamination of 
the surface-water system. Based on land-use data, greater than 97 percent of land area in the United States is a potential source of nonpoint contaminant discharges (McElroy and others, 1975). Atmospheric deposition of organic contaminants into surface waters also has been documented. Heit and others (1984) determined that PCB contamination of four remote lakes in Rocky Mountain National Park (Colo.) was attributable to the atmospheric transport and subsequent deposition of the organic contaminants. They found that surficial sediments in the lakes had total PCB concentrations as high as $540 \mu \mathrm{g} / \mathrm{kg}$ dry weight. Finally, ground water also can supply a surface-water system with organic contaminants (Frank and others, 1981), but the persistence of soluble groundwater contaminants in surface waters is typically not great because of their volatility (Connor, 1984b).

\section{Purpose and Scope}

The increasing production and use of manmade organic compounds coupled with their ease of transport into surface-water systems makes knowledge of their environmental behavior essential to the management of the Nation's freshwater resources. The purpose of this report is to provide an interpretative, critical review of the scientific literature with regard to the occurrence, distribution, and fate of manmade organic compounds in the surface-water systems of the United States. More specifically, the review examines organic-contaminant interactions with bottom and suspended sediment, the water column, and the biota of rivers, estuaries, and lakes. Both laboratory and field studies are reviewed, and, where applicable, their results are compared and contrasted. Examples of organic-contaminant concentrations reported in field studies are given to serve as a means of comparison with ongoing research. Special emphasis is given to the environmental variables and the physicochemical properties of the organic compounds that are intrinsic to the distribution and fate of the contaminant. Finally, where data are sufficient, the regional and temporal distribution patterns of manmade organic compounds in the surfacewater systems of the United States are discussed.

\section{PROCESSES AFFECTING THE FATE AND DISTRIBUTION OF ORGANIC COMPOUNDS}

This section is divided into three main parts. The first part reviews sorption interactions between sediments and organic contaminants, the second discusses bioaccumulation of organic contaminants, and the third reviews transport and transformation processes affecting organic contaminants in surface-water systems.

\section{Sorption}

Water quality has traditionally been assessed in terms of concentrations of dissolved constituents. However, certain organic contaminants can be sorbed to suspended and bottom sediment and may be present in sediment at concentrations that are orders of magnitude higher than their dissolved concentrations. Sediments can be a reservoir for many persistent organic compounds, causing the compounds to remain in the surface-water system years after input of the contaminant has stopped. Additionally, the sorbed organic contaminant may represent a large fraction of the total mass of contaminant transported downstream. The ability to predict the extent of sorption for a contaminant in a surface-water system may, therefore, be extremely important in assessing water quality.

\section{Definitions}

Unlike aqueous concentrations, concentrations of anthropogenic organic compounds sorbed to sediment or soil are expressed as a ratio of the mass of contaminant to the mass of sediment or soil (for example, $\mu \mathrm{g} / \mathrm{g}, \mu \mathrm{g} / \mathrm{kg}$, $\mathrm{mg} / \mathrm{kg}$ ). The extent to which an organic contaminant is sorbed to a given sediment at equilibrium is quantified by its distribution (sorption) coefficient, $K_{d}$, which is defined as

$$
\mathrm{K}_{\mathrm{d}}=\frac{\mathrm{C}_{\mathrm{s}}}{\mathrm{C}_{\mathrm{e}}}
$$

where $\mathrm{C}_{\mathrm{s}}$ is the concentration of a contaminant sorbed to a specific weight of sediment and $C_{e}$ is the concentration of the same contaminant dissolved in an equal weight of water (Olsen and others, 1982).

For a given contaminant-sediment combination, $\mathrm{C}_{\mathrm{s}}$ is a function of $C_{e}$ and commonly is related to $C_{e}$ by the empirical Freundlich isotherm, given by

$$
\mathrm{C}_{\mathrm{s}}=\mathrm{KC}_{\mathrm{e}}^{(1 / \mathrm{n})} \text {, }
$$

where $\mathrm{K}$ and $\mathrm{n}$ are empirical constants that are a function of the sorbent and sorbate. If $\mathbf{n}$ has a value of unity, a plot of $\mathrm{C}_{s}$ versus $\mathrm{C}_{e}$ will be linear and $\mathrm{K}$ will equal the previously defined sorption coefficient.

The sorption coefficient commonly is expressed on an organic-matter basis and is defined as

$$
\mathrm{K}_{\mathrm{om}}=\frac{\mathrm{K}_{\mathrm{d}}}{\mathrm{f}_{\mathrm{om}}},
$$

where $f_{o m}$ is the fractional mass of organic matter in the sediment. Similarly, the sorption coefficient expressed on an organic-carbon basis is defined as 


$$
K_{o c}=\frac{K_{d}}{f_{o c}}
$$

where $f_{o c}$ is the fractional mass of organic carbon in the sediment. The values of $f_{o m}$ and $f_{o c}$ can be related by the Van Bemmelen factor of 1.724 (Allison, 1965), which assumes that soil or sediment organic matter is composed of 58 percent carbon. This conversion factor is, however, only an approximation, and determinations of $f_{o c}$ and $f_{o m}$ typically are obtained by laboratory analyses.

An organic compound's octanol-water partition coefficient, $\mathrm{K}_{\mathrm{ow}}$, is defined as the ratio of the compound's concentration in a known volume of n-octanol to its concentration in a known volume of water after the octanol and water have reached equilibrium.

\section{Adsorption and Partitioning}

Sorption of organic compounds by sediments can be accomplished by either an adsorption or a partition process. Adsorption is a surface phenomenon that involves formation of either a physical or a chemical bond between the organic compound and a site on the sediment particle's surface. Physical adsorption is caused by van der Waal's forces, whereas chemical adsorption (chemisorption) is the result of formation of a chemical bond between the organic compound and the sediment (Khan, 1978). Ion exchange is an example of chemical adsorption. For a partition process, the organic compound distributes itself between water and the sediment organic matter by molecular forces common to solution, similar to the distribution between water and an organic solvent such as octanol (Chiou and others, 1979; Hassett and others, 1980; Chiou, 1981; Chiou, Schmedding, and Manes, 1982; Chiou, Porter, and Schmedding, 1983).

Table 1 contrasts the characteristics of partition and adsorption processes (Chiou and others, 1979; Chiou, Porter, and Schmedding, 1983). Adsorption is a surfacecondensation process that occurs with high exothermic heat in compensation for losses in entropy. The enthalpy change for adsorption of a solute from water must be greater than the solute's heat of condensation from water (except when adsorption is very weak). For a partition process, the heat of sorption equals the difference between the molar enthalpies of solution of the solute in the organic and water phases and typically is less exothermic than the solute's heat of condensation. Adsorption processes are characterized by nonlinear isotherms, whereas partition processes yield linear isotherms over a wide range of solute solubility. An adsorption process is also characterized by a competitive effect between solutes for a fixed number of surface sites, while a partition process involves independent sorption between individual solutes. Finally, the magnitude of the partition coefficient of an organic solute between an organic phase and water is
Table 1. Contrasting characteristics of adsorption and partition processes

Characteristics

\begin{tabular}{lr}
\hline Adsorption & Rartition \\
High heats of sorption & Low heats of sorption \\
Nonlinear isotherms & Linear isotherms \\
Competitive sorption & Noncompetitive sorption \\
& Solubility dependence
\end{tabular}

determined primarily by the solute's solubility in water. The dependence of the octanol-water partition coefficient on solute-water solubility has repeatedly been demonstrated for various organic solutes (Chiou and others, 1977; Chiou and Freed, 1977; Mackay, 1977; Chiou, Schmedding, and Manes, 1982; Miller and others, 1985); water solubility was found to be the major factor affecting the partition coefficient. In analogy to the solvent-water system, Chiou, Porter, and Schmedding (1983) demonstrated that solute solubility also was the primary factor influencing the partitioning of 12 nonionic organic compounds between water and soil organic matter. The relation between aqueous solubility and $\mathrm{K}_{\text {ow }}$ developed by Chiou, Schmedding, and Manes (1982) is given in figure 1.

Because of significant differences between the adsorption and partition processes, it is important to determine the mechanism responsible for the sorption of manmade organic compounds to sediments in surfacewater systems. Although the issue was considered unsettled by some investigators (Kyle, 1981; Mingelgrin and Gerstl, 1983; Curl and Keoleian, 1984; MacIntyre and Smith, 1984), there is strong evidence that sorption of nonionic and acidic organic compounds from water by soil or sediment is caused primarily by the partitioning of the solute into the soil/sediment organic matter (Chiou and others, 1979, 1985; Chiou, Porter, and Schmedding, 1983; Witkowski and others, 1987). Sorption of organic bases, on the other hand, appears to occur primarily by adsorption.

\section{Sorption of Nonionic Organic Compounds}

The sorptive behavior of nonionic organic compounds characteristic of a partitioning process has been repeatedly observed. Chiou and others (1979) calculated low heats of sorption for 1,2-dichlorobenzene and 1,1,1trichloroethane sorbed to a Willamette silt loam. Pierce and others (1974) calculated low isosteric heats of sorption for dichlorodiphenyltrichloroethane (DDT) sorbed 


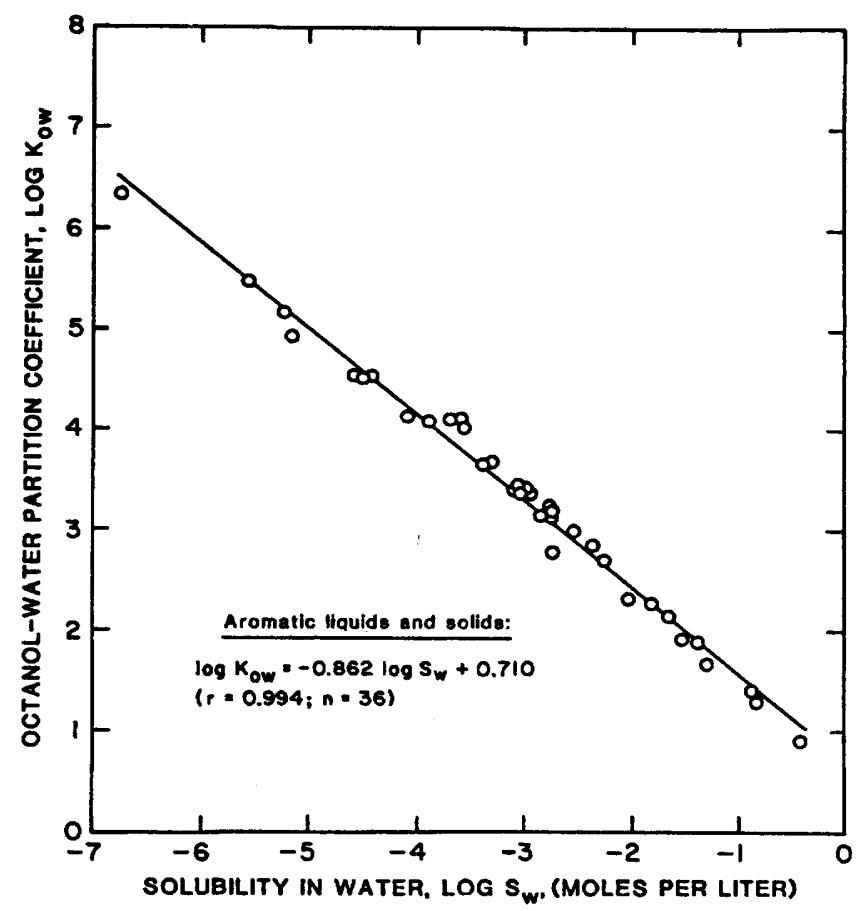

Figure 1. Correlation of octanol-water partition coefficient with water solubility for selected aromatic liquids and solids at $25^{\circ} \mathrm{C}$. The solubilities of solid compounds in the plot are those of their supercooled liquids at $25^{\circ} \mathrm{C}$. [Reprinted with permission from Environmental Science and Technology, v. 16, 9 (1982). Copyright 1981 by the American Chemical Society.] to several types of particulate matter ranging from -2 to $+4 \mathrm{kcal} / \mathrm{mol}$. Because the heat of condensation for DDT is approximately $10 \mathrm{kcal} / \mathrm{mol}$, an adsorption process would require at least $10 \mathrm{kcal} / \mathrm{mol}$ (exothermic). The low heats calculated by Pierce and others (1974) are in keeping with a partition process. Khan (1974b) also witnessed low isosteric heats of sorption of the weakly acidic herbicide 2,4-D when sorbed to a fulvic acid-clay complex, again indicating a partition process.

Figure 2 presents sorption isotherms for a variety of nonionic organic compounds partitioned between water and a Willamette silt loam (Chiou and others, 1979). All the isotherms are linear, and, for 1,2-dichloropropane and 1,2-dichloroethane, the isotherms are linear up to equilibrium aqueous concentrations that are 75 and 95 percent of the solute's solubility. This observation, along with the low exothermic heat, cannot be reconciled by an adsorption model. Lotse and others (1968) observed approximately linear sorption isotherms for lindane sorbed to lake sediments. Karickhoff and others (1979) observed isotherm linearity for the sorption of pyrene and methoxychlor to natural sediments. Pierce and others (1974) and Picer and others (1977) witnessed linear Freundlich isotherms for DDT sorption to natural sediments. Hassett and others (1980) reported linear isotherms for dibenzothiophene sorption to a variety of soils and sediments. Finally, Herbes (1977) also observed

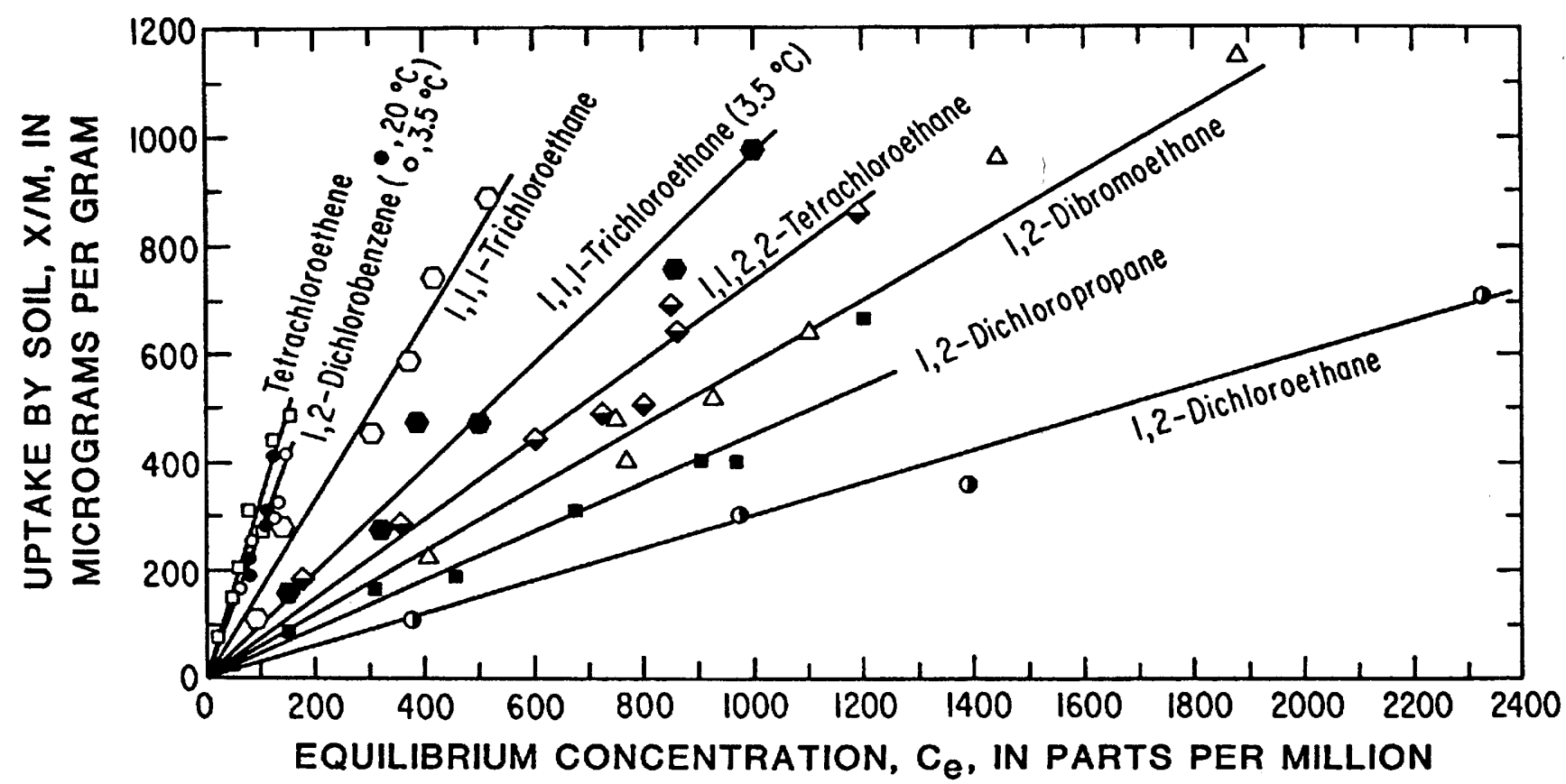

Figure 2. Soil-water equilibrium isotherms of some neutral organic compounds at $20^{\circ} \mathrm{C}$. The soil used is a Willamette silt loam with 1.6 percent organic matter, 26 percent clay, 3.3 percent sand, and 69 percent silt. [Reprinted with permission from Science, v. 206, p. 831 (1979). Copyright 1979 by the American Association for the Advancement of Science.] 
linear isotherms for anthracene sorption to particulate organic matter. All these examples of linear isotherms are indicative of a partition process rather than an adsorption process.

The noncompetitive effect of binary nonionic solutes on sorption isotherms was demonstrated by Chiou, Porter, and Schmedding (1983), Chiou and others (1985), and Chiou and Shoup (1985). Figure 3 presents soil-water isotherms for single and binary solutes (Chiou, Porter, and Schmedding, 1983). No competitive effects are observed. Instead, the data indicate independent sorption that is characteristic of a partition process. Additionally, both isotherms are linear up to 60 to 90 percent of solute saturation.

The solubility dependence of the sorption process also has been observed. Senesi and Testini (1980) noted increased sorption of some nitrogenated herbicides with decreasing solubility. Sharom and others (1980a) noted that the sorption of 12 insecticides by three types of soil was inversely correlated with the insecticides' solubilities. Figure 4 presents data from Chiou and others (1979) showing the linear log-log relation between solubility and the soil organic matter-water distribution coefficient $\left(\mathrm{K}_{\mathrm{om}}\right)$ for a variety of nonionic organic compounds. The data demonstrate that the distribution coefficient decreases with increasing solubility. The observed solubility depend-

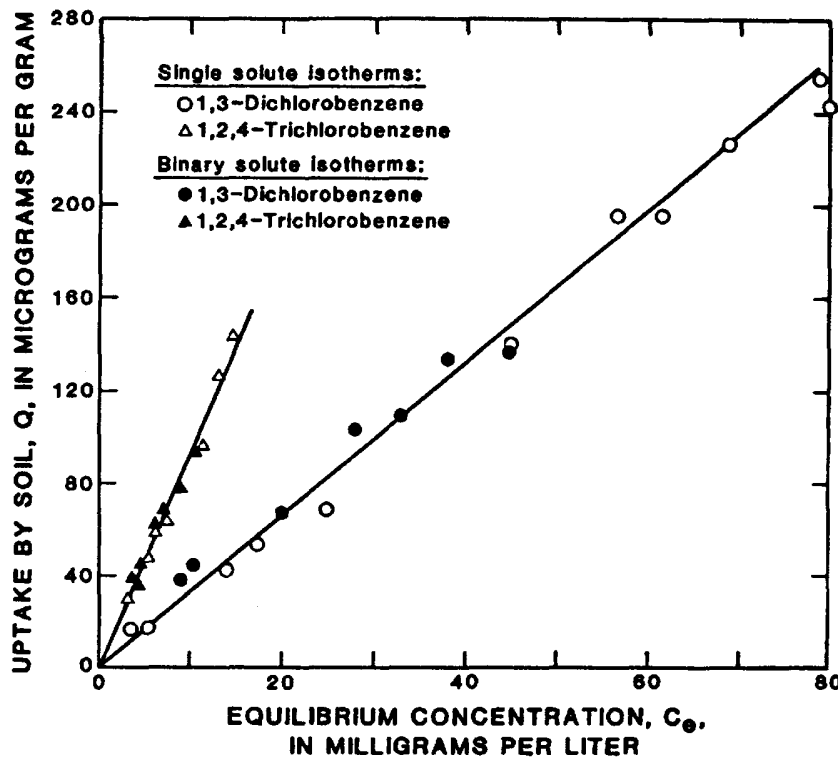

Figure 3. Typical soil-water equilibrium isotherms for 1,3dichlorobenzene and 1,2,4-trichlorobenzene as single solutes and as binary solutes on a Woodburn silt loam soil at 20 ${ }^{\circ} \mathrm{C}$. [Reprinted with permission from Environmental Science and Technology, v. 17, p. 229 (1983). Copyright 1983 by the American Chemical Society.]

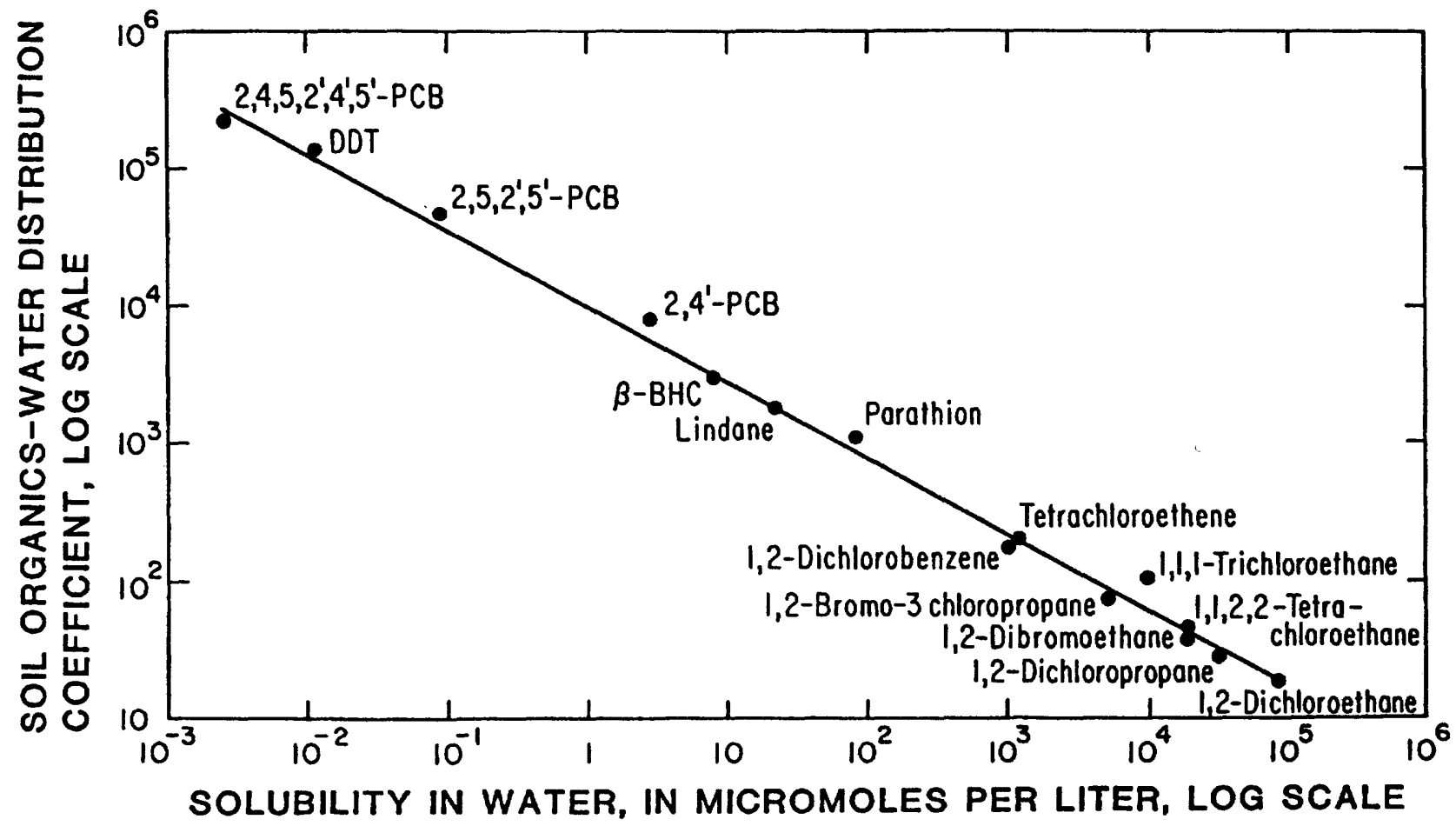

Figure 4. Soil organics-water sorption coefficients plotted as a function of the aqueous solubilities of selected neutral organic compounds. [Reprinted with permission from Science, v. 206, p. 831 (1979). Copyright 1979 by the American Association for the Advancement of Science.] 
ence of the sorption process again lends support to the hypothesis that partitioning between water and sediment organic matter is primarily responsible for the sorption of nonionic organic compounds by sediments.

Adsorption of nonionic organic compounds appears not to be a significant mechanism in sediment-water systems because of the ability of polar water molecules to compete successfully with nonionic organic solutes for mineral adsorption sites (Yaron, 1978; Chiou, Peters, and Freed, 1981; Chiou, Schmedding, and Block, 1981; Chiou and Shoup, 1985; Chiou and others, 1985). On the other hand, sorption of nonionic organic compounds in the absence of water may result primarily from an adsorption mechanism. Yaron and Saltzman (1972) found that parathion sorption from a hexane solution decreased with increasing soil-moisture content. Chiou and others (1985), when observing parathion and lindane sorption from hexane onto dry and partially hydrated Woodburn soil, observed nonlinear isotherms, strongly exothermic heats of sorption, competitive sorption effects, and dependence on clay content. Additionally, increased soil-moisture content decreased sorption. In the absence of the competitive effects of water for surface adsorption sites, the two nonionic insecticides were apparently adsorbed to the mineral surfaces. In hexane solution, little solute would partition into the soil organic matter because of its high solubility in the organic solvent. A slight increase in the soil-moisture content, however, resulted in a sharp decline in sorption owing to adsorptive competition by the water molecules. Similar moisture-content effects have also been observed by Yaron (1978) for the sorption of organophosphorus insecticides to soils. Strong sorption of organic vapors by dry soils has also been attributed to adsorption by minerals since water is not present to compete with the nonionic organic molecules for adsorption sites (Chiou and Shoup, 1985).

The above hypothesis explains the results of Walker and others (1975), who observed greater extraction efficiencies for petroleum hydrocarbons from dry sediment when a more polar solvent was used. Polar solvents, such as methylene chloride, can replace nonionic organic compounds that are weakly adsorbed to the sediment mineral surfaces more effectively than can nonpolar solvents, such as hexane (Chiou and Shoup, 1985). Likewise, the sorption of a nonionic organic compound from a polar solvent, such as methanol or methylene chloride, onto dry soil or sediment would likely be insignificant (Chiou and others, 1985). The compound's high solubility in the solvent would greatly limit partitioning into the soil or sediment organic matter, and the polar solvent would successfully compete with the solute for surface-adsorption sites. This observation is in agreement with the data of Nkedi-Kizza and others (1985), who observed decreased sorption of anthracene, atrazine, and diuron from water onto soil when methanol or acetone was added as a cosolvent. The cosolvent enhanced solute solubility (thus reducing the partition of solute into organic matter), while significant adsorption by minerals was prevented by the polar mixed solvents. In surface-water systems, however, sorption of nonionic organic compounds will always occur from water. Therefore, adsorption processes are likely to be insignificant compared with the partition of the organic compound into the sediment organic matter.

\section{Importance of particulate organic matter}

Because sorption of nonionic organic compounds appears to be caused by partition between water and sediment organic matter, sediments having large organicmatter contents would be expected to sorb greater amounts of solute than sediments having small organicmatter contents. A correlation between organic-matter content and sorption has been observed by numerous investigators (Pierce and others, 1974; Spencer and others, 1974; Choi and Chen, 1976; Herbes, 1977; Rao and Davidson, 1979; Hassett and others, 1980; Sharom and others, 1980a; Abdullah and Ringstad, 1982; Banwart and others, 1982; Hassett and Anderson, 1982; NkediKizza and others, 1983; Glotfelty and others, 1984; Oliver and Charlton, 1984; Brown and others, 1985; Stamer and others, 1985) and is an important consideration when comparing sorption data obtained from different sediments. Two sediment samples collected from the same river cross section may have significantly different contaminant concentrations if their organic-matter contents are dissimilar.

To allow comparisons of sorption coefficients obtained from different sediments, Karickhoff and others (1979) normalized experimentally determined sedimentwater sorption coefficients by dividing by the organiccarbon content of the sediment. The resulting organiccarbon sorption coefficient, $\mathrm{K}_{\mathrm{oc}}$, differed little from sediment to sediment. Rao and Davidson (1979) measured soil-water sorption coefficients for several pesticides using three soil types. The sorption coefficients varied greatly with soil type, but when the coefficients were adjusted to reflect the organic-carbon content of the soils used, the resulting $K_{o c}$ values showed much greater independence from soil type. Similarly, Nkedi-Kizza and others (1983) observed that soil-water sorption coefficients obtained using six particle-size fractions of a Webster soil differed by a factor of 7 , while calculated $K_{o c}$ values differed by a factor of only 1.5 . In a field study of atrazine and simazine sorption, Glotfelty and others (1984) also observed much less variability in $\mathrm{K}_{\mathrm{oc}}$ values than in sorption coefficients not normalized for the organic-carbon effect. The results of these studies indicate that sorption coefficients normalized for sediment organic-carbon content will best reflect spatial contamination trends by eliminating much of the variability caused 
by different concentrations of organic matter in sediments.

Because solute solubility in water (S) is the primary factor affecting both the soil organic-matter sorption coefficient (Chiou, Porter, and Schmedding, 1983) and the octanol-water partition coefficient (Chiou, Schmedding, and Manes, 1982), a relation can be established between $S$ or $\mathrm{K}_{\mathrm{ow}}$ and the sediment organic-carbon sorption coefficient. Such a relation is depicted in figure 5 for 10 nonionic organic compounds partitioned between water and the coarse-silt fractions of two sediments (Karickhoff and others, 1979). Sorption differences caused by different solute types are accounted for by $S$ or $\mathrm{K}_{\mathrm{ow}}$, and differences caused by different sediment types are accounted for by organic-carbon content. Similar relationships have been developed by Banwart and others (1982) and Oliver and Charlton (1984). Chiou and others (1979), Chiou, Porter, and Schmedding (1983) also have developed such relations, but they have normalized the sediment-water sorption coefficient by the organic-matter content rather than the organic-carbon content.

Relations such as the one depicted in figure 5 potentially are very useful because they allow prediction of the sediment-water sorption coefficient for a multitude of nonionic organic contaminants with a knowledge of only the sediment organic-matter content and the solute's solubility or octanol-water partition coefficient. The $\mathrm{K}_{\mathrm{om}}$ (or $\mathrm{K}_{\mathrm{oc}}$ ) value for a given compound will likely show some variation from sediment to sediment because of variations in the composition of the sediment organic matter (Means and others, 1982; Chiou, Porter, and Schmedding, 1983; Chiou and others, 1984). However, this variation is small compared with variations in the sediment-water sorption coefficient prior to normalization for organic-matter content.

In general, sediment organic-matter content has been shown to increase with decreasing particle size (Choi and Chen, 1976; Frank and others, 1979; Scott and others, 1982; Simmons and Kotz, 1982; Ricci and others, 1983; Stamer and others, 1985). Therefore, the highest sorbed contaminant concentrations are commonly found in the silt and clay fractions of surface-water sediments. Bottom sediments containing large percentages of silts and clays typically accumulate in areas of low water velocity, such as along the banks of rivers or lakes. Hunter and others (1980), in a study of an Oklahoma stream, observed the highest PCB concentrations in areas of sediment deposition. Routh (1972) likewise detected elevated DDT concentrations in Salinas River (Calif.) sediments in areas of low velocity.

It should be noted that although the highest contaminant concentrations are usually found in the silt- and clay-size fractions of a sediment (because of their usually high organic-carbon content), numerous exceptions have been documented. Stainken and Rollwagen (1979) found
LOG WATER SOLUBILITY (MOLE FRACTION $\times 10^{9}$ )

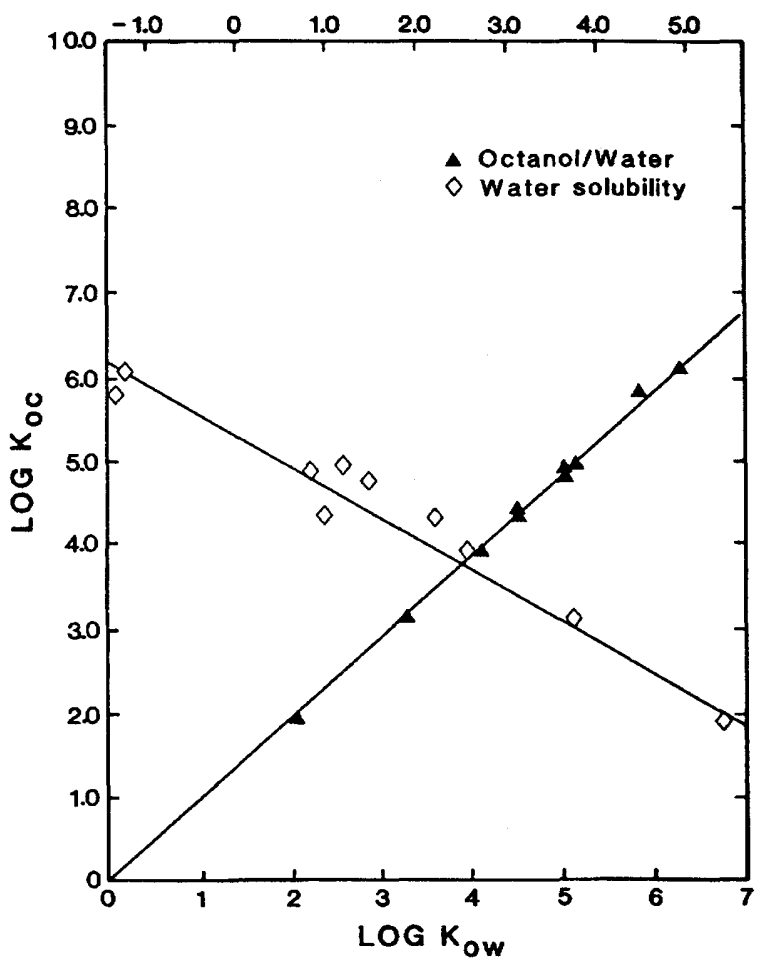

Figure 5. Sorption coefficient normalized for organiccarbon content $\left(\mathrm{K}_{\mathrm{oc}}\right)$ as a function of compound water solubility and octanol-water partition coefficient $\left(K_{\mathrm{ow}}\right)$. [Reprinted with permission from Water Research, v. 13, p. 247 (1979). Copyright 1979 by Pergamon Press Ltd.]

no correlation between percent silt-clay and PCB concentrations in sediment samples from Raritan Bay (N.J.). Van Luik (1984) similarly found no correlation between percent silt-clay and either PCB or polycyclic aromatic hydrocarbon (PAH) concentrations in sediment samples from the Calumet Sag Channel (Ill.). In a laboratory study of dibenzothiophene sorption to soils and sediments, Hassett and others (1980) observed no relation between the partition coefficient and either the cation-exchange capacity, the clay mineralogy, the percentage of clay, or the surface area of the soil-sediment. However, a positive correlation was observed between the partition coefficient and the organic-matter content of the soil-sediment. Organic-matter content, therefore, seems to be the most important indicator of a sediment's sorptive capacity for nonionic organic solutes.

Frank and others (1979, 1981), Frank, Thomas, Braun, and others (1980), and Frank, Thomas, Holdrinet, and Damiani (1980), after observing the relatively low sorptive capacity of the sand-size fraction of Great Lakes' sediment compared with the silt- and clay-size fractions, corrected their sorption data for the variable content of sand in the different samples. Although this correction was an improvement, the approach depended on the 
relation between organic-carbon content and particle size and did not consider differences in the organic-carbon contents of the different sediment samples. The studies by Frank and others dealt with nonionic sorbates, such as PCB's and organochlorine insecticides, that will likely sorb by partition into the sediment organic matter. Therefore, a better normalization approach might have been to divide the sorbed contaminant concentration by the organic-matter content of the sediment sample, as illustrated by Smith and others (1987). This approach does not depend on the organic-matter content to increase with decreasing particle size. It also accounts for differences in the organic-matter contents of the silt-clay fractions of the different sediment samples.

Importance of dissolved organic matter

Although the sorption coefficient is strongly influenced by sediment organic-matter content, the presence of dissolved organic matter (DOM) also can influence the sorption coefficient by serving as an additional organic phase into which a solute can partition. In this manner, DOM increases the apparent solubility of the solute in water while the amount of solute partitioned into the sediment organic matter may remain relatively unchanged because of low concentrations of DOM. The resulting net effect will be a decrease in the sediment-water sorption coefficient. Chiou and others (1986) have demonstrated that the apparent aqueous solubilities of DDT and two PCB isomers increase linearly with DOM content, with no indication of competitive effects. They attribute the solubility enhancement of highly water insoluble organic solutes by DOM to a partitionlike interaction of the compounds with the microscopic organic environment of the high-molecular-weight DOM. The solubility enhancement caused by DOM has also been observed by other researchers for DDT (Wershaw and others, 1969; Carter and Suffet, 1982; Caron and others, 1985), phthalate esters (Matsuda and Schnitzer, 1971), and the alkanes, hexadecane and eicosane (Boehm and Quinn, 1973). For more soluble compounds such as lindane, however, DOM concentrations up to $100 \mathrm{mg} / \mathrm{L}$ have been shown to have no significant enhancement effect on solute solubility (Caron and others, 1985; Chiou and others, 1986), which is in agreement with the proposed partition interaction between solute and DOM. Therefore, only relatively insoluble organic compounds, such as DDT or PCB's, are likely to exhibit enhanced solubility and reduced sorption coefficients in the presence of sufficient concentrations of DOM.

The ability of DOM to affect the sorption coefficient helps to explain the phenomenon known as the "solids effect," or the observed decrease in sorption coefficients with increasing sediment concentration. This effect has been studied by numerous researchers (Lotse and others, 1968; Grover and Hance, 1970; Herbes, 1977; O'Connor and Connolly, 1980; Horzempa and Di Toro, 1983b; Koskinen and Cheng, 1983; Voice and others, 1983; Curl and Keoleian, 1984; Bowman and Sans, 1985a; Gschwend and Wu, 1985; Voice and Weber, 1985), and in some cases an order of magnitude increase in the sediment concentration resulted in a decrease of comparable magnitude in the sorption coefficient. Voice and others (1983) and Gschwend and Wu (1985) have found that increased sediment concentrations result in increased DOM concentrations. Because increased DOM can reduce the apparent sorption coefficients of relatively insoluble organic compounds, the relation between the sediment concentration and the sorption coefficient can be at least partially attributed to the solubility-enhancing effect of DOM (Voice and others, 1983; Chiou and others, 1984; Gschwend and Wu, 1985; Voice and Weber, 1985).

DOM, therefore, may be very important in determining the environmental fate of extremely hydrophobic organic pollutants. Sorption coefficients may differ greatly between bottom sediments and suspended sediments because of the large variation in sediment concentration and, consequently, DOM concentration (Voice and Weber, 1985); organic compounds that partition strongly to DOM may not exhibit the same bioavailability as they would if they existed in a free, solubilized state. Similarly, other fate-influencing processes such as volatilization, hydrolysis, or photolysis also may be substantially affected by the partitioning of organic compounds into DOM. However, available data suggest that under typical environmental conditions the solubilities of only the least soluble organic compounds will be enhanced by DOM, and that the extent to which these compounds partition into DOM will depend on the polarity and size of the dissolved organic molecules along with the solute's solubility (Chiou and others, 1986).

\section{Sorption of Ionic Organic Compounds}

Herbicides and phenolic compounds represent the majority of environmentally significant ionic organic compounds. Compared with nonionic organic compounds, such as PCB's and chlorinated insecticides, they generally have much higher aqueous solubilities, and, as a result, solute partitioning into sediment organic matter is greatly reduced. Their solubilities are functions of system $\mathrm{pH}$, so sorption can be expected also to vary with $\mathrm{pH}$. Ionic organic compounds dissociate to either cations or anions, and, based on the surface charge of sediment particles, the ionized organic compound may be able to compete successfully with water molecules for surface adsorption sites. Table 2 lists some of the environmentally important anionic and cationic organic compounds. 
Table 2. Selected anionic and cationic organic compounds of environmental significance

Anionic

Cationic

\section{Dalapon}

Dicamba

2, 4-D

$2,4,5-T$

Glyphosate

Picloram

Phenol

Chlorophenols

Nitrophenols

Cresols
Ametryn

Atrazine

Cyperquat

Difenzoquat

Diquat

Paraquat

Benzidine

Prometon

Prometryn

\section{Organic acids}

The solubility of organic acids increases with $\mathrm{pH}$ as a result of increased deprotonation and the resulting anion formation. The organic anion presumably does not displace polar water molecules (or other inorganic cations) bound to surface adsorption sites inasmuch as particle surfaces, like the organic anion, generally are negatively charged (Khan, 1974c, 1980; Hayes and others, 1975; Jackson, 1975; Wang, 1975; Mulholland, 1981; Davis, 1982; Olsen and others, 1982). Therefore, because increased dissociation of the organic acid will not cause increased adsorption and because increased solute solubility will reduce solute partitioning into the sediment organic matter, the sorption of organic acids will be reduced at elevated $\mathrm{pH}$.

Schellenberg and others (1984) noted decreased sorption coefficients for chlorinated phenols when $\mathrm{pH}$ was increased from 6.5 to 8.5 . The sorption isotherms were linear even at the higher $\mathrm{pH}$ values, indicating that solute adsorption was small compared with solute partitioning into the sediment organic matter despite the presence of the phenolate anion. This is consistent with the hypothesis that organic anions are repelled from negatively charged particle surfaces. Linear isotherms for phenolic compounds also have been determined by Scott and others (1982). Khan (1974b) observed nearly linear isotherms and low isosteric heats of sorption for 2,4-D sorption by a fulvic acid-clay complex, despite the fact that more than 50 percent of the 2,4-D was present in its anionic form. Nkedi-Kizza and others (1983) observed approximately linear isotherms for 2,4-D sorption to different soil particle-size fractions and noted the dependence of the sorption coefficient on the soil's organic-matter content. Linear isotherms also have been observed for 2,4,5-T sorption onto soil from water (Koskinen and Cheng, 1983). These results indicate that the organic anions present in solution generally do not exhibit appreciable adsorption owing to their negative charge, and that any sorption that does occur is attributable primarily to partitioning of the undissociated organic acid into the sediment organic matter (Chiou, 1981). Sorption of organic acids as influenced by partitioning will be reduced at higher $\mathrm{pH}$ because of increased solute solubility and decreased undissociated solute concentration in accordance with the results of Schellenberg and others (1984).

\section{Organic bases}

Sorption of organic bases to sediment also will be largely controlled by $\mathrm{pH}$, but, in contrast to organic acids, adsorption of the protonated organic cation to particle surfaces (presumably by ion exchange or ion pairing) can be a significant sorption mechanism. Khan (1972a) has noted that sorption of basic herbicides is greatest at $\mathrm{pH}$ values close to the herbicides' $\mathrm{pK}_{\mathrm{b}}(-\log$ base dissociation constant) values. At $\mathrm{pH}>>\mathrm{pK}_{\mathrm{b}}$, the basic herbicides are almost completely in their neutral form and will be unable to compete with water molecules for mineral adsorption sites of the sediment because of their neutral charge. Partitioning into the sediment organic matter may also be low owing to the generally high solubility of the basic herbicides. At $\mathrm{pH}<<\mathrm{pK}_{\mathrm{b}}$, the organic base will be almost completely in its cationic form, but adsorption will be retarded because of the high hydrophilicity of the cations in combination with the increased protonation of many of the acidic functional groups on the sediment organic matter. This counteracting effect makes the efficiency of the adsorption process a maximum at $\mathrm{pH}$ around $\mathrm{pK}_{\mathrm{b}}$.

Zierath and others (1980) found that system $\mathrm{pH}$ controlled the sorption of benzidine to soils and sediments by varying the amount of benzidine present in the cationic form. Benzidine sorption increased as $\mathrm{pH}$ was lowered to values approaching the compound's $\mathrm{pK}_{\mathrm{b}}$. Sorption of the ionized species also was correlated with the surface area of the soil-sediment used. Narine and Guy (1982) observed diquat sorption to humic acid to increase as $\mathrm{pH}$ was raised from 2.0 to 9.0 . Because diquat is essentially 100 percent in its cationic form within this experimental $\mathrm{pH}$ range, the increased diquat sorption at high $\mathrm{pH}$ can be attributed to a charge interaction (ion exchange or ion pairing) of diquat with the negatively charged acidic phenolic and carboxylic functional groups (having $\mathrm{pK}_{\mathrm{a}}$ ( $-\log$ acid dissociation constant) values of about 10 and 4 , respectively) of the humic acid. The increased protonation of the functional groups at low $\mathrm{pH}$ decreases the availability of adsorption sites for the organic cations. The importance of the adsorption process to the sorption of organic bases is demonstrated by the data in figure 6 (Juo and Oginni, 1978), which presents sorption isotherms for paraquat using a variety of soils. The nonlinear isotherms are indicative of an adsorption process. Distinctly nonlinear isotherms also have been reported by Karickhoff and 


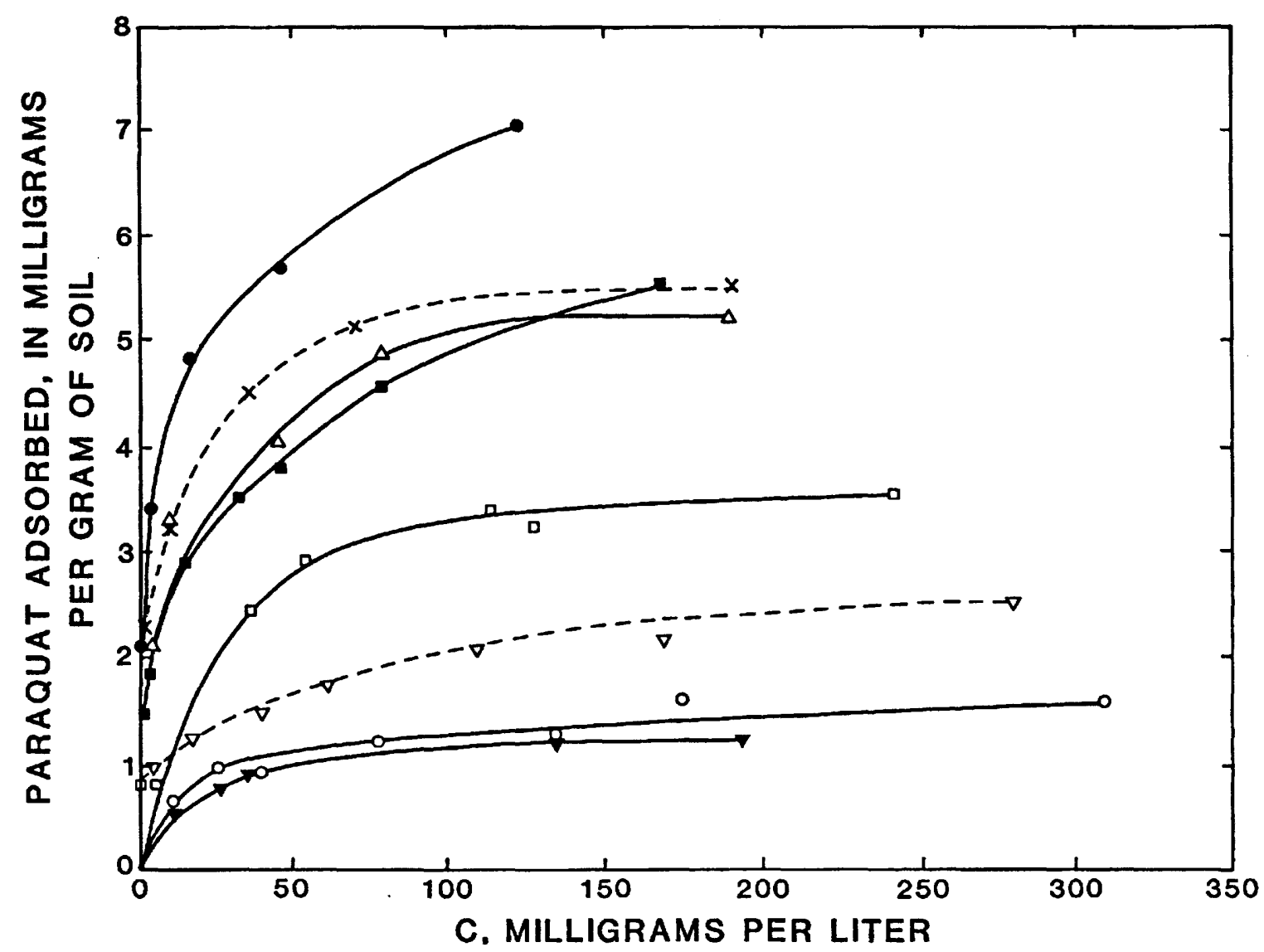

Figure 6. Adsorption isotherms of paraquat in soils. The $\mathrm{X}$-axis denotes the paraquat concentration, $\mathrm{C}$, in water. [Reprinted with permission from Journal of Environmental Quality, v. 7, p. 11 (1978). Copyright 1978 by the American Society of Agronomy, Crop Science Society of America, and Soil Science Society of America.]

Brown (1978) for the sorption of paraquat by sediment and by Khan (1974a) for the sorption of paraquat and diquat.

Organic cations appear to be adsorbed primarily by an ion-exchange mechanism, as is evidenced by the infrared spectroscopic analyses of Khan (1974a) and Senesi and Testini (1980). The adsorption process is, therefore, sensitive to both the charge and atomic radius of the saturating cation associated with the sediment. Khan (1974c) stated that the sediment-associated cations that enhanced adsorption of both diquat and paraquat to a humic acid followed the sequence $\mathrm{Al}^{+3}<\mathrm{Fe}^{+3}<\mathrm{Cu}^{+2}<$ $\mathrm{Ni}^{+2}<\mathrm{Zn}^{+2}<\mathrm{Co}^{+2}<\mathrm{Mn}^{+2}<\mathrm{H}^{+}<\mathrm{Ca}^{+2}<\mathrm{Mg}^{+2}$. This relation is inversely related to the stability of the element when complexed with humic acid (Khan, 1974c). The stability of an element typically increases with both valence and ionic radius. Strongly bound cations, such as $\mathrm{Al}^{+3}$ or $\mathrm{Fe}^{+3}$, are more resistant to displacement by an organic cation than are weakly bound cations, such as $\mathrm{Ca}^{+2}$ or $\mathrm{Mg}^{+2}$. The variation in organic-cation sorption as a function of the type of inorganic cation saturating the soil or sediment also has been observed by El-Dib and Aly (1976b) and Hayes and others (1975). Hayes and others (1975) also noted that while different saturating inorganic cations may influence the sorption of bipyridylium herbicides, this influence will also depend on the type of clay mineral present. Karickhoff and Brown (1978) observed sorption coefficients for paraquat to be correlated with the cation-exchange capacity of different particle-size fractions of a natural sediment. Zierath and others (1980) similarly noted that benzidine sorption increased directly with particle surface area.

Because sorption of organic bases, such as the bipyridylium herbicides, is due primarily to an adsorption process, solute solubility and sediment organic-matter content may not be sufficient parameters to predict sorption coefficients. As described above, the solute's $\mathrm{pK}_{\mathrm{t}}$ and sediment factors, such as cation exchange capacity, surface area, or the charge or atomic radius of the saturating inorganic cation, also may be important in determining a sorption coefficient. System parameters, such as $\mathrm{pH}$ and ionic strength (Narine and Guy, 1982), may also influence sorption. For these reasons, predictive sorption modeling is more complex for organic bases than for organic acids or nonionic organic compounds. However, the environmentally significant compounds that 
exhibit the greatest tendency to sorb to surface-water sediments are the hydrophobic, nonionic organic compounds, such as the organochlorine insecticides and PCB's.

\section{Bioaccumulation}

Bioaccumulation (or bioconcentration) is the uptake of organic compounds by biota from either water or food. Many toxic organic chemicals attain concentrations in biota several orders of magnitude greater than their aqueous concentrations, and, therefore, bioaccumulation poses a serious threat to both the biota of surface waters and the humans that feed on these surface-water species. The extent to which an organic compound tends to accumulate in an aquatic organism is quantified by the bioconcentration factor (BCF). Chiou (1981) defines $\mathrm{BCF}$ as the ratio of the concentration of a contaminant in an organism or the tissue of an organism to the concentration in water. $\mathrm{BCF}$ also can be defined as the ratio of an organism's accumulation rate to its depuration rate (Neely and others, 1974). BCF's have been applied to quantify organic-contaminant concentrations in a variety of surface-water organisms. Agarwal and others (1982) documented the accumulation of DDT isomers by the freshwater ciliate Tetrahymena pyriformis. Barker (1984) noted the bioconcentration of organochlorine compounds at four different trophic levels in the Schuylkill River (Pa.) Belluck and Felsot (1981) observed pesticide bioaccumulation by caddisfly egg masses. Birmingham and Colman (1983) documented diquat accumulation by freshwater plants. Microorganisms also have been shown to accumulate organic compounds (Grimes and Morrison, 1975; Paris and others, 1977; Blair and others, 1982). Additionally, numerous examples of organic-compound bioaccumulation have been documented for fish and shellfish (Biddinger and Gloss, 1984).

\section{Importance of Biological Lipid Reservoirs}

Hamelink and others (1971) first proposed that the uptake of hydrophobic compounds by fish is accomplished primarily by exchange equilibria between the water and blood followed by storage in the fish's lipid reservoirs. Since then, researchers have investigated the importance of lipid-water partitioning with regard to bioaccumulation.

Hansch and others (1968) implied that the bioaccumulation of organic contaminants from water is comparable to the partitioning of the contaminant between water and an organic solvent such as octanol. In surfacewater systems, hydrophobic organic contaminants will partition themselves between water and the lipid reservoirs of biological organisms, with solute solubility in water being a primary factor affecting the magnitude of the BCF for any given organism. However, unlike a solvent-water system, biological lipid-water systems do not attain rapid equilibrium. Slow solute diffusion to the lipid reservoir, combined with metabolic breakdown or aqueous phase transformation processes, can delay or even prevent the attainment of an equilibrium condition (Chiou, 1981). Generally, stable organic compounds having low aqueous solubility exhibit the longest equilibration times. Sanders and Chandler (1972) did not observe an equilibrium condition for PCB uptake from water by crayfish even after $21 \mathrm{~d}$ of exposure. Similarly, DDT uptake by goldfish did not result in steady-state concentrations even after $50 \mathrm{~d}$ (Rhead and Perkins, 1984). Oliver and Niimi (1983) monitored the bioconcentration of a variety of chlorinated benzenes by rainbow trout and noted that, as compound solubility decreased, the time to reach equilibration generally increased. Dichlorobenzene isomers attained equilibrium after $10 \mathrm{~d}$, but pentachlorobenzene did not reach a steady-state concentration after $119 \mathrm{~d}$. The tri- and tetrachlorobenzenes reached equilibrium after about 15 and $50 \mathrm{~d}$, respectively. For the more soluble organic compounds, such as the herbicides alachlor and dinoseb, bioaccumulation by fathead minnows has been observed to reach equilibrium after only $24 \mathrm{~h}$ (Call and others, 1984).

The time required to reach equilibrium has also been shown to be a function of fish size. Murphy (1971), in a laboratory bioaccumulation study using female mosquito fish, observed that the larger fish accumulated DDT from the water at a slower rate than smaller fish exposed to the same aqueous concentration. Similar results have been observed for the bioaccumulation of dieldrin (Reinert, 1972).

The hypothesis that bioaccumulation is caused primarily by partition into the lipid reservoirs of aquatic organisms is supported by the repeated observation of increased BCF's with increased lipid content. Canton and others (1977) noted that the greatest accumulation of hexachlorocyclohexane occurred in Chlamydomonas cells having the greatest lipid contents. Helwig and Hora (1983) confirmed the lipophilicity of PCB's by quantifying the compound's elevated concentration in fat tissue relative to meat tissue in Minnesota snapping turtles. Niimi (1979) measured the concentrations of hexachlorobenzene (HCB) in lake trout, rainbow trout, and coho salmon from Lake Ontario. The mean fat contents of each species of fish were proportional to their whole-body $\mathrm{HCB}$ concentrations. Additionally, $\mathrm{HCB}$ concentrations in fish samples within each species increased with fish size. Similar lipid-content effects were observed by Rudling (1970) with pentachlorophenol accumulation, by Ryan and others (1984) for dioxin and PCB accumulation, and by Seguchi and Asaka (1981) for diazinon accumulation. Skea and others (1979) placed fish in submerged cages in the Hudson River (N.Y.) to quantify the bioaccumulation 


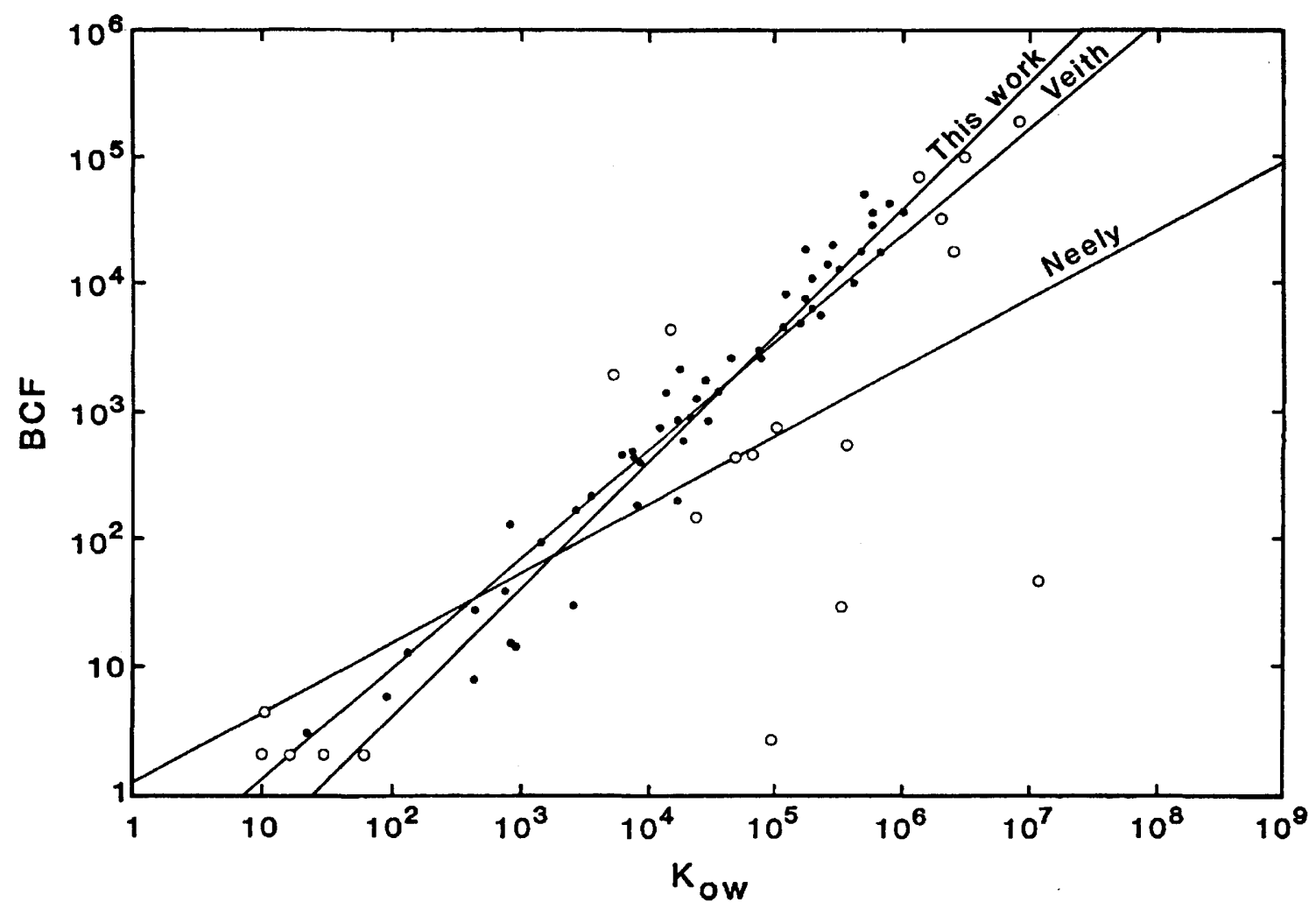

Figure 7. Correlation of bioconcentration factor (BCF) versus octanol-water partition coefficient $\left(K_{\text {ow }}\right)$ showing the correlations of Veith and others (1979), Neely and others (1974), and Mackay (1982a) (labeled "this work"). Only solid points are included in the regression. [Reprinted with permission from Environmental Science and Technology, v. 16, p. 277 (1982). Copyright 1982 by the American Chemical Society.]

of PCB's. Again, the highest PCB concentrations were found in the largest fish (which possessed the highest lipid contents). The results of these studies indicate the importance of lipid content to the bioaccumulation of organic compounds. For a given exposure level, organisms having the highest lipid contents can be expected to accumulate the greatest amount of organic solute on a concentration basis. Similarly, the accumulated contaminant will likely concentrate itself in an organism's lipid reservoirs.

The extent to which an organic compound is bioaccumulated by a given aquatic organism depends largely on its aqueous solubility. As discussed earlier, decreasing solubility correlates with increasing $\mathrm{K}_{\mathrm{ow}}$. Because bioaccumulation appears to be a partitioning process, the $\mathrm{BCF}$ can be expected to vary inversely with solubility. Also, the $B C F$ can be expected to vary with $K_{\text {ow }}$ such that increasing $\mathrm{K}_{\mathrm{ow}}$ yields increasing BCF. Examination of the scientific literature reveals that these relations have been demonstrated in the laboratory. Mackay (1982a) compiled data from a variety of sources to develop figure 7 , in which the BCF's based on whole-fish mass are used. The majority of the data are from the work of Veith and others (1979); their plot of $\log \mathrm{K}_{\mathrm{ow}}$ versus $\log \mathrm{BCF}$ is labeled in the figure along with the plot developed by Neely and others (1974). By selectively disregarding some of the data in figure 7, Mackay (1982a) developed his own relation (labeled "this work" in the figure), having the equation

$$
\log \mathrm{BCF}=\log \mathrm{K}_{\mathrm{ow}}-1.32
$$

with a correlation coefficient of 0.95 . The data of Neely and others (1974), not included in the above correlation, resulted in the following relation:

$$
\log \mathrm{BCF}=0.52 \log \mathrm{K}_{\mathrm{ow}}+0.124
$$

with a correlation coefficient of 0.948 . Casserly and others (1983) also correlated $\mathrm{K}_{\mathrm{ow}}$ with $\mathrm{BCF}$ for the green alga Selenastrum capricornutum and established the equation

$$
\log \mathrm{BCF}=0.46 \log \mathrm{K}_{\mathrm{ow}}+2.36
$$

with a correlation coefficient of 0.83 . Similar correlations have been reported by Oliver and Niimi $(1983,1985)$, Könemann and van Leeuwen (1980), and Southworth and others (1978a, 1978b). Figure 8 presents a plot of BCF as a function of aqueous solubility for a variety of pesticides 


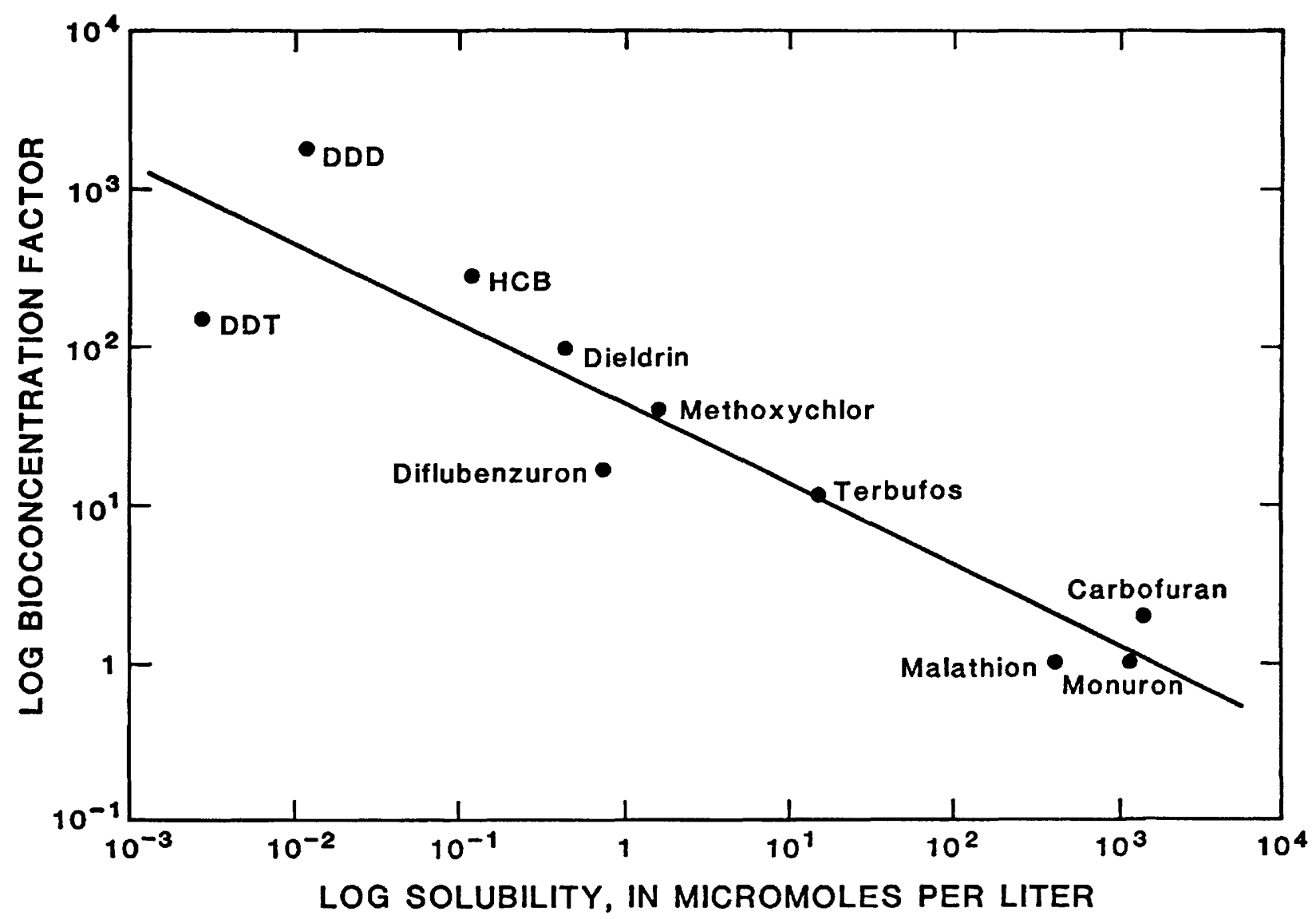

Figure 8. Relation between log water solubility of pesticides and log bioconcentration factor (BCF) for Triaenodes tardus egg masses. HCB is hexachlorobenzene. [Reprinted with permission from Bulletin of Environmental Contamination and Toxicology, v. 26, p. 304 (1981). Copyright 1981 by Springer-Verlag New York, Inc.]

accumulated by caddisfly egg masses (Belluck and Felsot, 1981). Again, a linear log-log relationship is assumed and defined by the equation

$$
\log \mathrm{BCF}=-0.52 \log \mathrm{S}+1.67 \text {. }
$$

Other solubility-BCF relations have been demonstrated by Chiou and others (1977) and Metcalf and others (1975). These relations indicate the dependence of the BCF on organic compound solubility and on $\mathrm{K}_{\mathrm{ow}}$. The BCF tends to increase with decreasing solubility and (or) increasing octanol-water partition coefficient.

Although numerous researchers have successfully performed regression analyses for BCF's as a function of either solubility or octanol-water partition coefficient, the BCF's for a given compound predicted by many of the correlation equations are significantly different, sometimes by orders of magnitude. Chiou $(1981,1985)$ has suggested that these differences are accounted for largely by differences in the lipid contents of the aquatic organisms used to develop the different correlations. To account for this effect, Chiou (1985) normalized BCF values obtained from the work of Könemann and van Leeuwen (1980) and Oliver and Niimi (1983) by dividing them by the fraction of lipid present in the organism. Figure 9 presents a log-log plot of the lipid-normalized BCF's for rainbow trout and guppies versus the triolein-water partition coefficients $\left(\mathrm{K}_{\mathrm{tw}}\right)$ for a variety of organic compounds. The parameter $\mathrm{K}_{\mathrm{tw}}$ was used instead of $\mathrm{K}_{\mathrm{ow}}$ because triolein more closely resembles the fish lipid than does octanol. The data are well correlated, and the regression equation takes the form

$$
\log B C F=0.957 \log K_{t w}+0.245
$$

with $n=18$ and a correlation coefficient $=0.915$. Unlike previous regressions, no systematic differences between the two fish species are evident. Just as sorption coefficients can be estimated from sediment organic-matter content and a compound's solubility, or $\mathrm{K}_{\mathrm{ow}}$, the above correlation allows the prediction of the BCF from only a knowledge of the organism's lipid content and the compound's $K_{t w}$. Chiou (1985) also related $K_{t w}$ to $K_{o w}$, so the $B C F$ can also be determined from the compound's $K_{o w}$ 


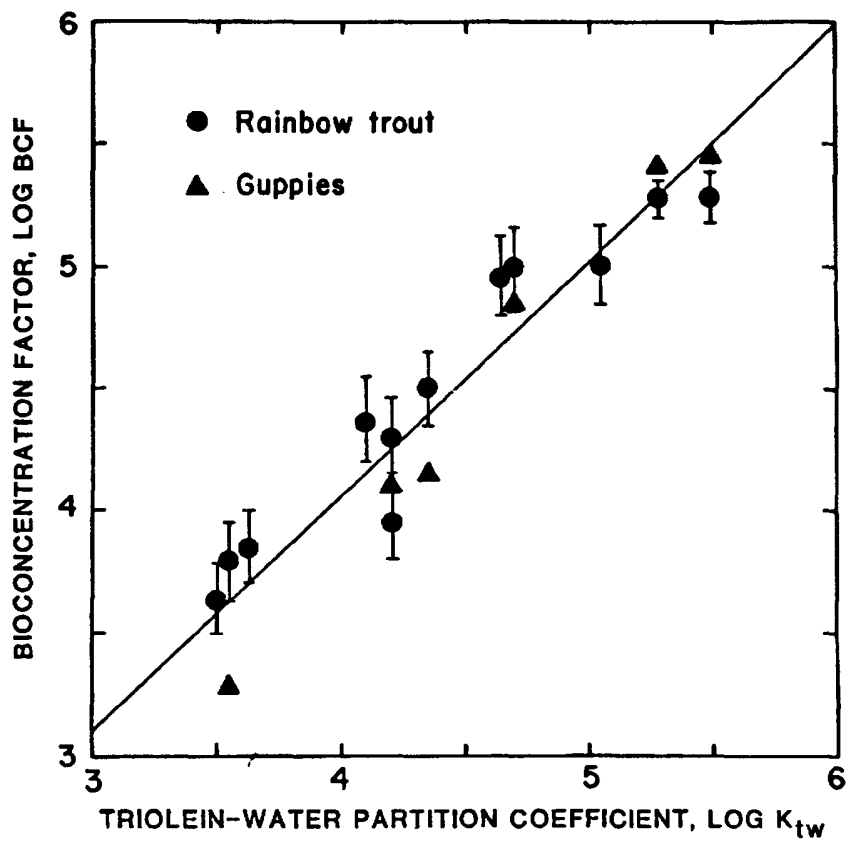

Figure 9. Correlation of log bioconcentration factor (BCF) on the basis of fish lipid content with log triolein-water partition coefficient $\left(K_{t w}\right)$ for a variety of nonionic organic compounds. Vertical limits of bars for rainbow trout are the minimum and maximum BCF's reported. [Reprinted with permission from Environmental Science and Technology, $v$. 19, p. 61 (1985). Copyright 1984 by the American Chemical Society.]

using the following equation:

$$
\log \mathrm{BCF}=0.893 \log \mathrm{K}_{\mathrm{ow}}+0.607
$$

with $\mathrm{n}=18$ and a correlation coefficient $=0.904$.

Differences between predicted and actual BCF's can arise because of a variety of factors (Chiou, 1985). The BCF's determined in figure 9 are assumed to be at an equilibrium condition. If a compound is unstable in water or is metabolized at a rate greater than the rate of equilibration with the organism's lipid reservoir, actual BCF's will be lower than predicted values. Also, partitioning of an organic compound into the nonlipid phases of an organism may be significant for compounds of high aqueous solubility. Third, dissolved organic matter may enhance the solubility of organic compounds, which in turn would result in lower apparent BCF's than predicted by a compound's $\mathrm{K}_{\mathrm{ow}}$. Finally, Niimi and McFadden (1982) and Oliver and Niimi (1983) have observed that BCF's increase slightly with increasing solute concentration (although Isensee and Jones (1975) and Canton and others (1977) did not observe variance of BCF's with the solute's aqueous concentration). Despite these possible sources of variation in the prediction of BCF's, consider- ation of the lipid contents of different aquatic organisms will likely result in better comparability of BCF's.

\section{Biomagnification}

There has been considerable debate as to whether bioaccumulation of organic compounds in aqueous systems is based on the physicochemical properties of the compound acting in combination with the physiology of the aquatic organism or is attributable to the trophic transfer of these compounds through the food chain (Biddinger and Gloss, 1984). The latter concept of aqueous-system biomagnification, or the accumulation of organic compounds through trophic transfer, is not well substantiated by the scientific literature.

Previous assumptions of biomagnification have been based on data that neglected to account for physiological differences between organisms. In most cases, reports of aqueous system biomagnification were confused with the concept of bioaccumulation resulting from the uptake of organic chemicals directly from water. To determine if biomagnification is an important process in aqueous systems, recent studies have been conducted to isolate the relative importance of food and water to the uptake of organic compounds by aquatic organisms. The results of these studies have indicated that the uptake of contaminants through food has only a small effect on the accumulation of organic contaminants by aquatic organisms relative to uptake resulting from exchange equilibria with water.

Canton and others (1975) studied the bioaccumulation of hexachlorocyclohexane $(\mathrm{HCH})$ using the following food chain combinations: algae-daphnia, daphnia-guppy, and guppy-trout. When compared with contamination by water alone, the transfer of $\mathrm{HCH}$ through the food chain was minimal, and the authors concluded that uptake of $\mathrm{HCH}$ from water was much more important than uptake through food. In a study of atrazine uptake by freshwater mollusks and fish, Gunkel and Streit (1980) illustrated that the feeding of contaminated food to the organisms did not increase their equilibrium whole-body atrazine concentration above the level obtained by exposure to contaminated water only. Additionally, by noting that the highest BCF's were occurring in the organs of the fish that had high blood circulation, they postulated that atrazine is taken in by the gills and transported in the blood to the organs. They went on to use tritiated-waterbalance calculations to determine that the swallowing of water and the exchange of water through the skin are of little importance to either the fish's water balance or its accumulation of atrazine. Niimi and Cho (1983) analyzed fish from Lake Ontario representing two trophic levels and noted that pentachlorophenol (PCP) levels in the fish from the different trophic levels were not significantly different. In an earlier study, Niimi and McFadden (1982) 
illustrated that rainbow trout exposed to aqueous PCP concentrations of $35 \mathrm{ng} / \mathrm{L}$ and $660 \mathrm{ng} / \mathrm{L}$ accumulated $9 \mu \mathrm{g}$ and $115 \mu \mathrm{g}$ of PCP, respectively, after an exposure period of $115 \mathrm{~d}$. Although the fish's diet had a PCP concentration of $3 \mu \mathrm{g} / \mathrm{kg}$, the authors estimated that no more than $2 \mu \mathrm{g}$ of PCP were accumulated through diet. Southworth and others (1979) also confirmed the importance of the uptake of organic contaminants from water. They showed that the uptake rates of acridine by freshwater fish via ingestion of contaminated invertebrates $(0.02 \mu \mathrm{g} / \mathrm{g} / \mathrm{h})$ or by ingestion of contaminated sediment $(0.01 \mu \mathrm{g} / \mathrm{g} / \mathrm{h})$ were insignificant relative to the rate of direct uptake from water $(1.40 \mu \mathrm{g} / \mathrm{g} / \mathrm{h})$.

In further support of the hypothesis that aqueous solute concentrations control the extent of bioaccumulation are the data of Canton and others (1977) and Paris and others (1977). The former study determined that the accumulation of $\mathrm{HCH}$ by the marine algae Chlamydomonas was the same for both living and dead cells. The study of Paris and others (1977) reported the same results for the bioaccumulation of toxaphene by a variety of aquatic microorganisms. The metabolic processes of the aquatic organisms, therefore, had no measurable effect on the equilibria established between the water and the lipid reservoirs of the microbes.

Some laboratory studies have noted that the uptake of organic contaminants from food has significantly contributed to the bioaccumulation of the compound in the aquatic organism. However, many of these studies did not allow an equilibrium condition (essentially zero change of contaminant concentration in the aquatic organism with time) to be established. Rhead and Perkins (1984) found that either dietary exposure or solution exposure of DDT to goldfish could be the dominant source of accumulation, depending on their relative concentrations. However, equilibrium conditions were apparently not obtained in any of their experiments. Therefore, their experiments demonstrated only that dietary exposure to DDT can significantly enhance the rate of DDT bioaccumulation. It did not demonstrate that dietary exposure could increase the magnitude of an equilibrium BCF determined from water exposure only. In a similar study, Shannon (1977) observed the relative importance of food versus water uptake to the bioaccumulation of dieldrin by channel catfish. Catfish exposed to $2 \mathrm{mg} / \mathrm{kg}$ of dieldrin through their diets combined with exposure to $75 \mathrm{ng} / \mathrm{L}$ of aqueous dieldrin accumulated significantly more of the compound than catfish exposed only to aqueous dieldrin. Here again, however, an equilibrium condition was not attained in either of the exposure experiments. Skea and others (1981) fed brook trout a mirex-contaminated diet for 100 days and noted a substantial accumulation of the compound in the fish. Equilibrium conditions were not attained, and no comparison was made with mirex exposure through water only. These studies indicate that prior to equilibrium, uptake of organic contaminants by aquatic organisms can occur through both dietary and aqueous exposures, but they do not support the concept of biomagnification.

In some cases, increases in BCF's are mistakenly attributed to biomagnification when, in fact, they are caused by differences in lipid content. In a study of four different trophic levels in the Schuylkill River (Pa.), Barker (1984) reported PCB levels of $56 \mu \mathrm{g} / \mathrm{kg}$ in the primary producers, $125 \mu \mathrm{g} / \mathrm{kg}$ in the primary consumers, and 650 to $700 \mu \mathrm{g} / \mathrm{kg}$ in the secondary and tertiary consumers. Although data such as these commonly are attributed to biomagnification, Barker attributes the variations primarily to differences in the lipid contents of the trophic levels along with other physiological factors such as age, sex, sex cycle, and diet. Of the aquatic organisms examined by Barker, the highest organochlorine residues were detected in the American eels, which typically have very high lipid contents relative to other aquatic organisms.

The studies discussed above indicate that the popular concept of biomagnification in aquatic systems is not well supported by the scientific literature. Future studies need to take into account physiological differences between aquatic species (and even different specimens), and BCF's should be compared only if the values are obtained at an equilibrium condition. The available data suggest that accumulation of organic contaminants by aquatic organisms is caused primarily by solute partitioning between water and the lipid reservoirs of the organism.

\section{Transformation Processes}

This section reviews the following four transformation processes that remove organic contaminants from aqueous solution:

1. Photolysis,

2. Hydrolysis,

3. Biodegradation, and

4. Volatilization.

Each process attenuates the concentration of an organic compound in solution by a different chemical, physical, or biological mechanism. The magnitude of the attenuation depends on the combination of physicochemical properties of the compound and the environmental conditions of the water body in which the compound is present. The removal mechanism, as well as the environmental and compound-specific properties influencing the rate of removal, are reviewed for each of the four processes.

In addition to detailing the environmental and physicochemical factors influencing the removal of contaminants by these four processes, this section also examines the kinetics of the removal processes. Each transformation process can be represented, mathematically, by a 
first-order rate law. Other representations, such as higher order rate laws, also are reviewed where appropriate. The first-order rate law is emphasized because it is the simplest kinetic description and is applicable to all four processes. The rate law for each process is described by a constant whose magnitude reflects the influence of both environmental factors and physicochemical properties. Consequently, the rate constant is useful as a relative measure for determining which of the four competing processes dominates the organic-contaminant removal under a specific set of environmental conditions.

\section{Photolysis}

The study of photochemistry in natural waters is a relatively new and emerging field. Only in the last decade has the knowledge obtained about atmospheric photochemistry during the last century been extended to the photochemical processes in marine and fresh waters (Miller, 1983; Zafiriou and others, 1984). The environmental photolysis of organic compounds is a complicated series of processes that depends on

1. Properties of the particular organic molecule,

2. Characteristics of the water body, and

3. Input of sunlight.

This subsection reviews the component factors from these three categories that appear to have the greatest influence on the process of photolysis in surface-water systems.

Photolysis is the degradation of compounds by the action of light. The aqueous photochemical reactions collectively referred to as photolysis can be further categorized as direct and indirect (or "sensitized") photolysis (Zepp and Cline, 1977). Direct photolysis is defined as the absorption of light by a compound causing a chemical reaction involving the energized molecule. The absorbed radiation causes the molecule to become excited, and it has a tendency to react in order to return to a more stable ground-state configuration. The possible resulting reaction mechanisms can include, but are not limited to, molecular rearrangement, dissociation, and oxidation.

Indirect photolysis refers to those photochemical reactions in which an organic compound interacts with other previously energized molecules rather than directly with solar radiation. Natural waters provide an abundance of potential reactive species that can absorb radiation and then react with organic contaminants by indirect photolytic mechanisms. These light-absorbing species (called chromophores) include humic substances, transitionmetal ions, organic-free radicals, and oxidizing species, such as peroxides, singlet oxygen, and ozone (Miller, 1983). Because it is difficult to separate and isolate the dominant photochemical mechanisms in natural waters, most studies do not attempt to differentiate between the different types of photolytic reactions (Callahan and others, 1979). Much of the available laboratory data and the remainder of the current discussion focuses on the physicochemical properties and environmental variables that influence the direct photolysis of organic contaminants.

The importance of photolysis to the degradation of organic compounds in surface-water systems is measured by the photolysis-rate constant, which is a measure of an organic compound's photodecomposition over time. The magnitude of the photolysis-rate constant depends on the amount and wavelength of the solar radiation that reaches a particular compound and on the ability of the compound to absorb that energy source. Environmental variables determine the intensity and spectral distribution of wavelengths of light available to a compound. Physicochemical properties, such as the light-absorption coefficient, determine the efficiency of the conversion of the energy into the photochemical transformation of the compound.

The intensity and spectral distribution of solar radiation is attenuated in the atmosphere through absorption by gases-for example, ozone-and scattering by molecules and aerosols. The degree of attenuation varies with time of day, season, geographic location, and thickness of the ozone layer. At the air-water interface, the two sources of radiation originating from the atmosphere are direct radiation and sky radiation. The latter type of radiation is derived from the scattering of direct radiation into the water body. The radiation reaching the air-water interface either is reflected back into the atmosphere (generally less than 10 percent) or is refracted into the water body at an angle different from the angle of incidence. Once in the bulk solution, light is further attenuated by absorption and scattering. Light is absorbed by water molecules, dissolved solids, and suspended sediment. Absorption of light also occurs as a result of the biological activity of photosynthetic organisms. Attenuation by scattering in the water column has a smaller impact than absorption on the penetration of light and is generally ignored in obtaining first-order approximations of light intensity (Zepp and Cline, 1977).

In addition to the environmental variables, the photolysis rate also depends on certain characteristics of the organic contaminant. Of the light that reaches the compound, only light absorbed by the chemical can cause photolytic degradation. The percentage of available light absorbed by the contaminant depends on its molar extinction coefficient and its concentration. In other words, the presence of the solute changes the value of the absorption coefficient of the solution from the value attributable solely to pure water. Based on the fundamental law of photochemistry, the average photolysis rate, at a specific wavelength in a completely mixed water body, is directly proportional to the rate of light absorption by the solute per unit volume (Zepp and Cline, 1977). To obtain the actual, average photolysis rate, this relation is summed over all the wavelengths in the ultraviolet- and visible-light 
range and multiplied by a constant. The constant, called the quantum yield of the reaction, represents the efficiency of usage of the absorbed radiation by the solute for the particular photochemical reaction. From the intensity of radiation at a particular depth in a water body, the average photolysis rate is estimated from the properties of the solute-namely, the molar extinction coefficient, the concentration, and the quantum yield for the photochemical reaction.

The most commonly used representation for a direct photolytic process is a first-order kinetic expression,

$$
\mathrm{d}[\mathrm{C}] / \mathrm{dt}=-\mathrm{k}_{\mathrm{p}}[\mathrm{C}]
$$

In this expression, the rate of change $(d / d t)$ of a compound's concentration (C) (resulting from photolysis) is directly proportional to the concentration of the compound multiplied by a first-order rate constant, $k_{p}$, with units of reciprocal time.

The first-order rate constant is the product of the rate constant for the absorption of light by the chemical, $k_{a}$, and the quantum yield (Q) (the efficiency of energy conversion for the photochemical reaction), or

$$
\mathrm{k}_{\mathrm{p}}=\left(\mathrm{k}_{\mathrm{a}}\right)(\mathrm{Q}) \text {. }
$$

The determination of the absorption-rate constant takes into account the environmental variables for a specific system, such as time of day, season, latitude, ozone thickness, and depth in the water body, as well as the absorption characteristics, such as the molar extinction coefficient, of the particular compound.

The influence of the compound's absorption properties on the rate of direct photolysis is illustrated by the following example. Zepp and Cline (1977) calculated the direct photolysis rates for carbaryl (a carbamate insecticide) and trifluralin (a dinitroaniline herbicide). The compounds have similar quantum yields for reactions in air-saturated water, but their peak absorption of radiation occurs in different parts of the ultraviolet- and visiblelight ranges. Consequently, for the same set of environmental conditions (midday, midsummer, latitude $40^{\circ} \mathrm{N}$.), the absorption rate for trifluralin is 400 times larger than that for carbaryl, and the direct photolysis of trifluralin is two orders of magnitude more rapid than that of carbaryl (Zepp and Cline, 1977).

The intensity and spectral distribution of light are as important as the absorption properties of the compound in determining the photolysis rate. The data of Zepp and Cline (1977) illustrate the difference that chemical properties can have on the photolysis rate. This difference is not constant, but varies with environmental conditions. Different combinations of time of day, season, latitude, and ozone thickness will selectively filter out different wavelengths of light. Because the two compounds absorb radiation of different wavelengths, this filtering process may alter the intensity of usable radiation available to the compounds. Thus, for the same set of environmental conditions, two compounds can photolyze at different rates because of differences in the energy content of the range of solar radiation (the specific set of wavelengths) they absorb.

Using the first-order rate equation for direct photolysis, an expression can be derived for a compound's half life. The half life (originally devised to measure the decay of radioactive material) refers to the time required for one-half of the initial concentration of a compound to be removed solely by direct photolysis. The half-life expression for a first-order, direct photolysis process is

$$
t_{1 / 3}=0.693 / k_{p} \text {, }
$$

and it is dependent on only the quantum yield and the absorption coefficient for a particular compound. Compounds that have high absorption coefficients and high quantum yields will have low half-life values, indicating rapid removal of the compound by photochemical processes. Because the half-life concept provides an indication of the rate of reaction in units of time (as opposed to rate constants in units of reciprocal time), it is a tangible measure for comparing photolysis with other first-order rate processes, such as hydrolysis, volatilization, and biodegradation.

Although estimates of the photolytic half-lives of certain organic chemicals account for many environmental and compound-specific properties, additional factors should be considered to improve the approximation of the photolytic degradation of an organic contaminant. For example, cloud cover can reduce the intensity of ultraviolet radiation by as much as 50 percent and thereby alter the degradation kinetics of an organic compound. In contrast, variations in the elevation of a stream within a geographical area can increase light intensity by $15-20$ percent for every kilometer increase in elevation. Also, the thickness of the ozone layer can vary daily as much as $\mathbf{3 0}$ percent, causing changes in atmospheric scattering and absorption.

The influence of other factors on the photolysis process has not been well quantified. For example, it has yet to be determined how varying concentrations of chromophores, such as dissolved and particulate organic matter, affect the rate and extent of indirect photolysis reactions. In many studies, the effect of light scattering in the water column is ignored, but it may be significant in turbid lakes and rivers. Finally, the mixing of water continually changes the temporal and spatial distribution of available sunlight and chemical concentrations. Current photolysis models still assume a spatially homoge- 
neous distribution of the contaminant throughout the depth of the water column.

Although laboratory protocols and kinetic representations for direct photolysis have been fairly well established, similar procedures for indirect photolysis are only beginning to be understood. Indirect photolysis is a much more complicated phenomenon, and it is mediated by any one of a variety of natural compounds. The chemical kinetics are represented by a second-order process where the rate of removal depends on both the compound's concentration and the concentration of the reactive intermediate (U.S. Environmental Protection Agency, 1979b). The difficulty encountered in applying this kinetic approach is in experimentally measuring the concentrations of the reactive intermediates, which frequently have half-lives on the order of microseconds or less (Zafiriou and others, 1984). Nevertheless, Miller (1983) states that the contribution of indirect photolytic processes to the overall photolysis rate may be significant. The increasing ability of researchers to isolate, monitor, and measure the chromophores present in natural waters (for example, humic substances, transition metal ions, and free radical and other oxidizing species) will likely result in an increased understanding of both indirect and direct photolysis of anthropogenic organic compounds in surface-water systems.

\section{Hydrolysis}

Hydrolysis is a transformation process that changes the chemical speciation of an organic contaminant. Like photolysis, biodegradation, and volatilization, the extent of contaminant removal by hydrolysis depends on both the chemical properties of the organic compound and the aqueous medium. Also, like other transformation processes, the hydrolysis of organic contaminants is mathematically represented by a first-order kinetic process. This subsection summarizes some of the equations and physicochemical factors influencing the rate and extent of the hydrolysis reaction for different classes of organic compounds.

Hydrolysis is the reaction of a compound with water resulting in an exchange of some functional group, $\mathrm{X}^{-}$, from the organic molecule with a hydroxyl group, $\mathrm{OH}^{-}$, from the aqueous medium. The overall mechanism can be represented by the following reaction sequence

$$
\mathrm{RX}+\mathrm{H}_{2} \mathrm{O} \rightarrow \mathrm{ROH}+\mathrm{HX}
$$

where $\mathrm{RX}$ is the organic molecule and $\mathrm{X}$ is a particular functional group. The individual reaction steps involve the formation of one or more intermediates which combine to transform the compound by the simplified mechanism given above. On the basis of this mechanism, the hydrolysis rate is expressed by a first-order rate law such that

$$
-\mathrm{d}[\mathrm{RX}] / \mathrm{dt}=\mathrm{K}_{\mathrm{h}}[\mathrm{RX}]
$$

where

$$
\begin{aligned}
-\mathrm{d}[\mathrm{RX}] / \mathrm{dt}= & \text { rate of hydrolysis of compound } \mathrm{RX} \\
& \left(\text { mass volume } \mathrm{e}^{-1} \text { time }^{-1}\right), \\
\mathrm{K}_{\mathrm{h}}= & \text { hydrolysis rate }\left(\mathrm{time}^{-1}\right), \text { and } \\
{[\mathrm{RX}]=} & \text { concentration of compound } \mathrm{RX} \text { (mass } \\
& \text { volume } \left.\mathrm{e}^{-1}\right) .
\end{aligned}
$$

In a manner similar to other transformation processes, the rate of contaminant removal by hydrolysis depends on the chemical structure of the compound, the influence of $\mathrm{pH}$, temperature, and ionic strength, and the presence of other compounds, such as humic substances. The contribution of each factor to the overall rate of hydrolysis is accommodated by modification of the firstorder rate law, given above, to explicitly account for the additional variable. For example, the rate of hydrolysis depends on the $\mathrm{pH}$ of the aqueous solution. Depending on the particular organic compound, the hydrolysis rate is increased by the addition of acid or base to the system. In this case, the rate expression is rewritten to reflect the explicit dependence of the reaction rate on the concentration of acid, $\left[\mathrm{H}^{+}\right]$, and base, $\left[\mathrm{OH}^{-}\right]$:

$$
\begin{aligned}
-\mathrm{d}[\mathrm{RX}] / \mathrm{dt} & =\mathrm{K}_{\mathrm{a}}\left[\mathrm{H}^{+}\right][\mathrm{RX}]+\mathrm{K}_{\mathrm{b}}\left[\mathrm{OH}^{-}\right][\mathrm{RX}]+\mathrm{K}_{\mathrm{n}}[\mathrm{RX}] \\
& =\mathrm{K}_{\mathrm{h}}[\mathrm{RX}],
\end{aligned}
$$

where $K_{a}$ and $K_{t}$ are second-order rate constants (mass volume $e^{-1}$ time $^{-1}$ ). This relation shows that the rate of hydrolysis depends on the product of the acid or base concentration and the contaminant concentration. $\mathrm{K}_{\mathrm{n}}$ is the first-order rate constant for the $\mathrm{pH}$-independent reaction.

Incorporation of the effects of acid- or basepromoted catalysis increases the order of the overall hydrolysis expression from first to second order. The rate now depends, explicitly, on the concentration of two components, $[\mathrm{RX}]$ and $\left[\mathrm{OH}^{-}\right]$or $\left[\mathrm{H}^{+}\right]$. Rearranging the rate equation to express it solely in terms of $\left[\mathrm{H}^{+}\right]$is done using the expression for the dissociation of water, $\mathrm{K}_{\mathrm{w}}=\left[\mathrm{OH}^{-}\right]\left[\mathrm{H}^{+}\right]$, and by canceling the $[\mathrm{RX}]$ in each term. From the above equation, this gives

$$
\mathrm{K}_{\mathrm{h}}=\mathrm{K}_{\mathrm{b}} \mathrm{K}_{\mathrm{w}} /\left[\mathrm{H}^{+}\right]+\mathrm{K}_{\mathrm{a}}\left[\mathrm{H}^{+}\right]+\mathrm{K}_{\mathrm{n}}
$$

From this expression, it is apparent that at elevated $\mathrm{pH}$, the overall rate constant is controlled by the first term on the right side of the equation (assuming $\mathrm{K}_{\mathrm{b}} \mathrm{K}_{\mathrm{w}}$ is sufficiently large). Under acidic conditions, the elevated $\mathrm{H}^{+}$ concentration makes the second term on the right side dominate in the determination of the overall rate constant (assuming $\mathrm{K}_{\mathrm{a}}$ is sufficiently large). At neutral $\mathrm{pH}$, the last 
term on the right side controls the rate of reaction. Thus, for a particular reaction, the rate depends on the $\mathrm{pH}$ of the aqueous medium as well as on the relative magnitude of the three rate constants, $K_{a}, K_{b}$, and $K_{n}$. Because the order of the reaction varies with $\mathrm{pH}$ (second order for acid or base conditions and first order at neutral $\mathrm{pH}$ ), the overall hydrolysis rate constant, $K_{h}$, is sometimes termed a pseudo-first-order constant (Mabey and Mill, 1978). It is the observed or estimated rate constant for hydrolysis at a constant $\mathrm{pH}$.

In addition to $\mathrm{pH}$, other factors influence the rate of hydrolysis of organic contaminants; these include temperature, ionic strength of the solution, and presence of other natural organic compounds, such as humic substances. In general, the rate of hydrolysis increases with temperature, and this observation follows the commonly cited Arrhenius equation. This equation relates the rate constant of a chemical reaction to the absolute temperature of the system and, for a specific reaction, takes the form

$$
\mathbf{k}=\mathbf{A} \exp [-\mathrm{E} / \mathrm{RT}]
$$

where $\mathrm{k}$ is the rate constant, $\mathrm{A}$ is a constant, $\mathrm{E}$ is the activation energy, $R$ is the universal gas constant, and $T$ is the absolute temperature.

The presence of dissolved ions in solution also can increase or decrease the rate of hydrolysis. The extent of this effect depends on the organic contaminant and specific ions and their concentrations. In some natural waters, the total concentration of dissolved anions and cations is low (less than 0.01 molar) and the influence of ionic strength on the rate of reaction is small (Mabey and Mill, 1978). In other types of waters, such as brackish, estuarine, and marine, the significance of the effect increases with dissolved-ion concentration.

Many of the recent investigations of dissolved organic matter, including humic substances, show that these substances collectively play an important role in the kinetics of contaminant hydrolysis. Humic substances can increase or decrease the rate of hydrolysis depending on the concentration of organic matter and the $\mathrm{pH}$ of the solution (Purdue, 1983). In general, humic substances will inhibit base-catalyzed hydrolysis reactions (for example, 2,4-D ester; Purdue, 1983) and accelerate acid-catalyzed hydrolysis reactions (for example, atrazine; $\mathrm{Li}$ and Felbeck, 1972). The ability of humic substances to partition certain organic contaminants affects the rate of hydrolysis, because the reactivity of the humiccontaminant mixture differs from that of the free dissolved contaminant in solution (Purdue, 1983). Consequently, whether the contaminant is free or partitioned influences the overall rate of hydrolysis as well as the extent of catalysis of the reaction based on changes in $\mathrm{pH}$.

\section{Biodegradation}

Microorganisms decompose organic compounds through enzymatically mediated reactions. The driving force behind these reactions is the microorganisms' need for energy, carbon, and other essential nutrients. Some manmade organic compounds can serve as organic substrates which are degraded by enzymes and used for cellular growth. Consequently, the degradation of an organic contaminant can be monitored by examining the growth of a microbial population that uses the compound as a substrate. In addition to the chemical structure of the organic compound and the type of microbial population, certain environmental factors influence the biodegradation process. Among the most important are temperature, $\mathrm{pH}$, and amount of oxygen present in the system. These factors are discussed in this subsection, along with the kinetics of the biodegradation process.

The rate of biodegradation is a function of the size of the microbial population and the concentration of the organic contaminant. To achieve a noticeable amount of contaminant degradation, a sufficiently large microbial population must be present. In addition, for a single substrate system, sufficient contaminant must be present to result in enough cell growth to sustain the microbial population. Under ideal conditions (a large resident population and ample substrate for growth), the rate of growth is limited by the cellular metabolic and reproductive systems of the microbial population.

The rate of biodegradation of an organic contaminant is examined in terms of the rate of microbial growth, assuming all of the consumed contaminant is converted into mass for biological growth and no other competing substrates are available. The relation between growth rate and substrate concentration is represented by the Monod equation for microbial growth:

where

$$
\mu=\mu_{\max } \frac{[\mathrm{C}]}{\mathrm{K}_{\mathrm{s}}+[\mathrm{C}]},
$$

$\mu=$ specific growth rate, which represents the rate of growth per unit amount of biomass $\left(\right.$ time $\left.^{-1}\right)$,

$\mu_{\max }=$ maximum specific growth rate $\left(\right.$ time $\left.^{-1}\right)$,

$[C]=$ contaminant or substrate concentration (mass volume ${ }^{-1}$ ), and

$\mathrm{K}_{\mathrm{s}}$ = concentration of contaminant corresponding to a growth rate, $\mu$, equal to $\mu_{\max } / 2$ (mass volume ${ }^{-1}$ ).

Figure 10 graphically depicts the relation between substrate concentration and specific growth rate (Benefield and Randall, 1980). At low substrate concentrations, the specific growth rate increases linearly with an increase in substrate concentration. At high substrate concentrations, the growth rate approaches and maintains a limiting growth rate that is independent of substrate concentration. 


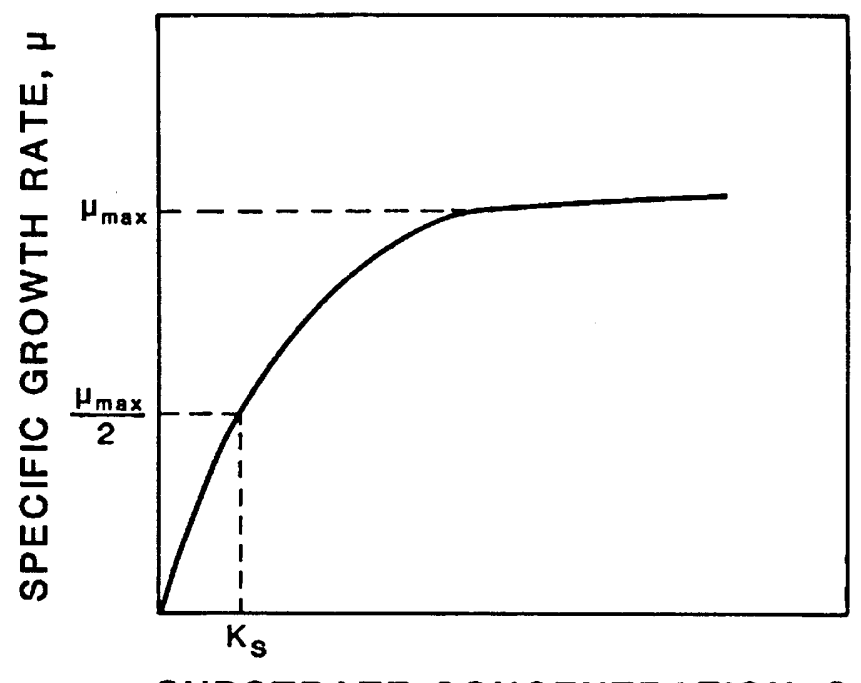

SUBSTRATE CONCENTRATION, S

Figure 10. Relation between microbial specific growth rate $\mu$, and substrate concentration. $K_{B}$ is the contaminant concentration corresponding to a growth rate equal to one-half the maximum specific growth rate.

Because the rate of biodegradation and consequently the rate of microbial growth is the result of many enzymecatalyzed processes, the Monod equation is sometimes replaced by the analagous Michaelis-Menten equation for enzymatic reactions (Banerjee, Howard, and others, 1984). The mathematical forms of the Monod and Michaelis-Menten equations are the same. The difference lies in the scale of observation used to interpret the equation parameters and variables. The Monod equation applies specifically to microbial growth, whereas the more general Michaelis-Menten equation applies to any biochemical process whose rate of substrate reaction is catalyzed by enzymes.

Using the Monod equation for microbial growth, an expression for the rate of contaminant removal is formulated in terms of the contaminant concentration and the size of the microbial population. This expression is written as

where

$$
-d[C] / d t=\mu \frac{X}{Y}=\mu_{\text {max }} \frac{[C]}{K_{s}+[C]} \frac{X}{Y}=K_{b} \frac{[C] X}{K_{s}+[C]},
$$

$$
\begin{aligned}
\mathrm{X}= & \text { biomass per unit volume (mass volume } \mathrm{m}^{-1} \text { ), } \\
\mathrm{Y}= & \text { the growth yield, equal to the biomass pro- } \\
& \text { duced per unit amount of chemical con- } \\
& \text { sumed, and } \\
\mathrm{K}_{\mathrm{b}}= & \text { biodegradation rate constant }\left(\text { time }^{-1}\right) .
\end{aligned}
$$

The constants $\mu_{\max }, K_{s}$, and $Y$ depend on the characteristics of the microbes, $\mathrm{pH}$, temperature, and the presence of other nutrients. For example, the amount of biomass produced for a unit amount of contaminant consumed, Y, depends on the ease of assimilation and conversion of that substrate into cellular components. Values of $Y$ vary with the species of microbes, the chemical structure of the contaminant, and the environmental conditions of the system.

The above kinetic equation for the rate of contaminant removal simplifies under a number of specific environmental conditions. For example, at high contaminant concentration, $[C]>>K_{s}$, the equation reduces to the following form:

$$
-d[C] / d t=K_{b} X
$$

In this case, the rate of degradation is first order and depends only on biomass concentration. Another possible and more likely case is that the contaminant concentration is very low, $[\mathrm{C}]<<\mathrm{K}_{\mathrm{s}}$. In this case the equation becomes

$$
-d[C] / d t=K_{b}[C] X / K_{s}=K_{b 2}[C] X,
$$

where $\mathrm{K}_{\mathrm{t} 2}$ is the second-order rate constant. The rate of degradation depends on both the contaminant concentration and the biomass population size. A third possibility is commun to many surface waters and occurs when the biomass population is relatively large and constant. In addition, the contaminant concentration is relatively low, so that the consumption of contaminant will not radically alter the population concentration. These conditions represent the specific case in which microbes are acclimated to the chemical and actively use the compound. In this case, the degradation rate is termed pseudo-first order and is represented mathematically as

$$
-\mathrm{d}[\mathrm{C}] / \mathrm{dt}=\mathrm{K}_{\mathrm{b}}{ }^{\prime}[\mathrm{C}],
$$

where

$$
\mathrm{K}_{\mathrm{b}}{ }^{\prime}=\mathrm{K}_{\mathrm{b} 2} \mathrm{X} \text {. }
$$

The above equations show that the two primary factors influencing the rate of biodegradation of an organic contaminant are microbial-population density and concentration of the contaminant (substrate). Different combinations of substrate concentration and population density can significantly alter the shapes of substratedisappearance curves that are functions of time (Simkins and Alexander, 1984; Alexander, 1985). Additional factors are embedded within the biodegradation rate constant. These include differences in assimilability between contaminants as well as differences between various species of microbes responsible for converting the contaminants into biomass. Microbial populations are sensitive to variations in environmental conditions, and different combinations of temperature, $\mathrm{pH}$, and oxygen content of the water may provide an advantage to one species competing with another species for the same substrate. The contributions of these environmental variables to the rate of biodegradation commonly are significant. 
A change in temperature can alter the balance of competition between microbial species using a contaminant as substrate. Each class of bacteria has an optimum temperature range within which a maximum growth rate is attainable assuming a sufficient supply of all other essential nutrients. Bacteria are commonly classified on the basis of the temperature range within which their optimum growth occurs. Psychrophilic bacteria grow best at temperatures ranging from -5 to $30^{\circ} \mathrm{C}$. Mesophiles grow best at temperatures between 15 and $45^{\circ} \mathrm{C}$. Thermophilic (heat-loving) bacteria grow best at temperatures ranging from 45 to $75^{\circ} \mathrm{C}$ (Benefield and Randall, 1980). Within the temperature range of each group of bacteria, the rate of biochemical reaction approximately doubles for every increase of $10^{\circ} \mathrm{C}$. However, this relation, known as the van't Hoff rule, is valid over only a limited range for bacteria, because further increases in temperature eventually break down the cellular growth and reproductive mechanisms (Benefield and Randall, 1980). Other, more complicated relations describing the influence of temperature on the rate of reaction are based on the Arrhenius equation. These relations include correction factors that show how temperature affects the microbial-growth and decay rate, the dominant organism groups, and the availability of nutrients-factors that contribute to alteration of the rate of contaminant removal (Novak, 1974).

Like temperature, the oxygen content of a water system contributes to the determination of which class of microbes can best degrade a particular organic contaminant. Depending on the mechanism by which microorganisms obtain their energy, different classes of organisms can exist under aerobic, anaerobic, or anoxic conditions. Thus, the oxygen content of the water-sediment system determines which group of microorganisms competes for the contaminant as a substrate and, ultimately, the rate of the contaminant's degradation.

In summary, the biodegradation of an organic compound is primarily determined by two components of the system: the microorganisms and their substrate (the organic contaminant). The microorganisms are sensitive and responsive to the condition of their immediate environment, including temperature and oxygen content, as well as to the chemical nature of the organic substrate. For rapid removal and conversion into biomass, the substrate must be readily decomposable and more assimilable than other available organic compounds. For this system, the rate of biodegradation depends largely on the density of the microbial population and the concentration of the contaminant. The reaction dynamics are approximated by a kinetic relation that is limited by the maximum growth rate of the microbial population. The order of the reaction rate for the degradation of the contaminant depends on the abundance of the microorganisms and the organic substrate. For many environmental cases, characterized by a stable microbial population and a small contaminant concentration, the equation simplifies to a pseudo-first-order expression: Only one parameter-the biodegradation rate constant - is needed to parameterize this kinetic representation. In this approach, the rate constant is specific for a single organic compound, a particular population of microorganisms, and the temperature and oxygen content characterizing the aqueous system.

\section{Volatilization}

Volatilization and.condensation are two complementary processes contributing to the exchange of organic compounds across the air-water interface. Both processes involve phase changes of the organic compound, either from gas to liquid or from liquid to gas, and are driven by concentration gradients between the respective bulk phases. Volatilization, in the present context, refers to the evaporation and vapor-phase transport of an organic compound from aqueous solution into the atmosphere. This subsection examines only volatilization, even though condensation and volatilization of organic compounds are controlled by many of the same chemical properties and environmental variables.

A number of compound properties and system variables combine to determine the extent of volatilization of an organic chemical. The most important chemical properties are vapor pressure and water solubility. Commonly, the ratio of these two properties is expressed as the Henry's law constant, where the constant, $\mathrm{H}$, is equal to vapor pressure divided by water solubility. The Henry's law constant represents the equilibrium distribution of concentrations of the organic chemical between the air and water phases at equilibrium. Air and water temperatures are important environmental variables controlling volatilization. In addition, the degree of air turbulence caused by the wind and the amount of subsurface mixing generated by velocity gradients in the water have a significant influence on the rate of volatilization. This subsection discusses the relative contributions of these chemical and environmental factors and examines some models currently used to represent the volatilization process.

From a physical standpoint, the potential volatility of an organic compound in a pure solution is related to its vapor pressure. In a natural water body, the actual rate of volatilization depends on the extent to which the environmental conditions attenuate the potential volatility of the compound. Competing processes, such as sorption with water-column particulates, act to suppress the vapor pressure attainable if all of the compound remained in a dissolved and unassociated state. In general, however, the greater the vapor pressure of a compound, the greater its mass loss rate (flux). Other factors also influence the volatilization rate, but most do so through their effect on vapor pressure or on the movement of the compound 
away from the air-water interface. Vapor pressure, for example, increases with temperature and thereby increases the rate of volatilization. In addition, increasing the temperature also increases the rate of diffusion, which serves to enhance the movement of organic molecules away from the interfacial boundaries.

Volatilization is a transformation process that acts to establish an equilibrium between the concentrations of a compound in the bulk phases of air and water. The driving force behind this process is the difference in concentrations (more precisely, the chemical potentials) of the compound in the two bulk phases. The retarding forces that prevent the instantaneous attainment of an equilibrium state are those that reduce the chemical potential difference of the compound between the two bulk phases. The overall resistance can be considered to be the sum of the resistance experienced in a different part of the entire physical system. The greatest of the component resistances serves to control the rate for the overall movement of a compound from the water to the air.

If the physical system is assumed to consist of two bulk phases--air and water-separated by a stagnant near-surface water layer and a stagnant near-surface air layer, the component resistances in the system can be examined. These include the resistance to diffusion in the (1) water column, (2) near-surface water layer, (3) surface-film layer (if any), (4) near-surface air layer, and (5) air column. Ignoring the presence of surface films (such as oil spills) for now, the majority of the resistance occurs in the near-surface gas and liquid layers (Smith and others, 1980). The magnitude of the resistance in these interfacial layers varies with the thickness of the two interfacial layers; layer thickness, in turn, depends on such factors as temperature, wind and water turbulence, and the specific properties of the compound of interestfor example, diffusivity and (or) molecular weight.

Many investigators use a first-order process as a mathematical representation of volatilization (Mackay and Leinonen, 1975; Dilling, 1977; Mackay and others, 1979, 1983; Southworth, 1979; Chiou and others, 1980; Smith and others, 1980, 1981, 1983; Rathbun and Tai, 1982, 1984; Chiou, Kohnert, and others, 1983). For this representation, the rate of removal of a compound from the water phase by volatilization depends on the concentration of the compound in solution and on the volatilization rate constant. An expression for this relation is

$$
\mathrm{d}[\mathrm{C}] / \mathrm{dt}=\mathrm{K}_{\mathrm{v}}[\mathrm{C}]
$$

where [C] is the dissolved concentration of the compound in solution and $\mathrm{K}_{\mathrm{v}}$ is the volatilization rate constant. The usefulness of this approach depends on the ability to obtain an accurate estimate of the volatilization rate constant for a particular compound and a given set of environmental conditions.

Initial attempts to estimate volatilization rates were based on the belief that organic compounds codistill with water into the atmosphere (Acree and others, 1963; Mackay and Wolkoff, 1973). The codistillation hypothesis implies that the simultaneous evaporation of water and organic compounds somehow enhances the volatility of the organic compound to rates not normally expected solely on the basis of the chemical's physical properties. From a theoretical standpoint, it has been shown that the volatilization of organic compounds and water are mechanistically independent processes, and no evidence for a thermodynamic coupling has yet been presented (Spencer and others, 1973; Chiou and Manes, 1980). In addition, Chiou and Manes (1980) have reported experimental resuits demonstrating that, under certain conditions, organic solutes evaporate while water vapor condenses. The use of the term "codistillation" should be avoided because it incorrectly implies that water loss enhances volatilization of organics by codistillation and that water loss is necessary for volatilization of significant quantities of organic compounds (Spencer and others, 1973).

Estimation of the volatilization-rate constant is based on a two-film-layer model because, for many compounds, the resistance to volatilization occurs in either the gas or the liquid near-surface layer. This approach is based on the two-film, mass-transfer model originally proposed by Whitman (1923). The model assumes uniformly mixed air and water phases separated by thin films of air and water in which transport is by molecular diffusion. The model's volatilization-rate constant is expressed in terms of the mass-transfer rates of the organic compound across the liquid-phase and gas-phase boundary layers. The general expression for the volatilization rate constant is

$$
\mathrm{K}_{\mathrm{v}}=\frac{1}{\mathrm{~L}}\left(\frac{1}{\mathrm{k}_{1}}+\frac{\mathrm{RT}}{\mathrm{Hk}_{\mathrm{g}}}\right)^{-1},
$$

where $K_{v}$ is the volatilization-rate constant $\left(h^{-1}\right), L$ is the depth $(\mathrm{cm})$, which equals the interfacial area divided by the liquid volume, $\mathrm{k}_{1}$ is the liquid-film mass-transfer coefficient $(\mathrm{cm} / \mathrm{h}), \mathrm{R}$ is the gas constant (L-torr $/ \mathrm{K}-\mathrm{mol})$, $\mathrm{T}$ is the absolute temperature $(\mathrm{K}), \mathrm{H}$ is the Henry's law constant (torr- $\mathrm{L} / \mathrm{mol}$ ), and $\mathrm{k}_{\mathrm{g}}$ is the gas-film mass-transfer coefficient $(\mathrm{cm} / \mathrm{h})$. The first term within parentheses represents the liquid-film resistance, and the second term represents the gas-film resistance. An important assumption behind the two-film-layer model is that the organic solute is at equilibrium between the water and air phases at the interface (Smith and others, 1983). This equilibrium is described by the Henry's law constant, which is the organic-solute concentration in the air $\left(\mathrm{mol} / \mathrm{m}^{3}\right)$ divided by the organic-solute concentration in water. Because 
atmospheric concentrations are frequently expressed in partial pressures, $\mathrm{P}$, they can be converted to $\mathrm{mol} / \mathrm{m}^{3}$ by using the ideal-gas law (n/V=P/RT).

From the above expression, it is seen that the volatilization-rate constant depends on the Henry's law constant for the organic : ompound as well as on the liquid and gas mass-transfer coefficients. The Henry's law constant is a function of the compound properties, whereas the mass-transfer coefficients are a function of both the compound properties and environmental variables. The liquid-film, mass-transfer coefficient is expressed as the diffusion coefficient ( $D$, in $\mathrm{m}^{2} / \mathrm{h}$ ) for the given organic solute divided by the thickness of the stagnant liquid film. The diffusion coefficient in a particular phase is related to the molecular weight of the organic solute. Transport in the boundary layer is by molecular diffusion, because the air and liquid films are considered stagnant. The thickness of the liquid film depends on the level of water turbulence in the system. In other words, the thickness of the stagnant water layer decreases with increasing water velocities (turbulence). The same relations hold true for the gasfilm, mass-transfer coefficient except that they apply to the gas phase and air turbulence imparts the windshearing force. Consequently, the rate of volatilization depends on the diffusion properties of the organic compound in the respective stagnant film phases. Diffusion, in turn, is related to the molecular weight of the organic molecule, the concentration or vapor density of the organic compound, and temperature, which influences both the vapor density and the diffusion process.

The difficulty in applying the two-film model is trying to measure or estimate the liquid and gas masstransfer coefficients accurately in actual water bodies. The overall mass-transport rate of a substance may depend on liquid-phase and (or) gas-phase resistance, based on the relative magnitude of $\mathrm{k}_{1}$ and $\mathrm{Hk}_{\mathrm{g}}$. A simplifying approach is to determine, from the two-film equation, which film-phase resistance dominates for particular values of the Henry's law constant (Dilling, 1977; Mackay, 1979; Mackay and others, 1979; Smith and others, 1980, 1981, 1983). Smith and others (1980) found that, for compounds having Henry's law constants greater than 3,500 torr $/ \mathrm{molar}\left(4.4 \times 10^{-3} \mathrm{~atm}-\mathrm{m}^{3} / \mathrm{mol}\right)$, the liquidphase resistance controlled approximately 95 percent of the mass transfer for alkanes and benzene. The compounds having constants above the 3,500-torr/molar demarcation are considered highly volatile. For compounds having constants below 10 torr/molar $\left(1.2 \times 10^{-5}\right.$ atm- $\mathrm{m}^{3} / \mathrm{mol}$ ), the gas-phase resistance controls mass transfer, and these compounds are considered to be of low volatility. For compounds having Henry's law constants between 10 and 3,500 torr/molar, the liquid- and gasphase resistances are significant, and both terms in the two-film equation must be included in the calculation of the volatilization-rate constant. These compounds are considered to have intermediate volatility-for example, DDT (Mackay, 1979). These three groupings, based on Henry's law constants, provide a convenient way to categorize the potential volatility of organic substances so that experimental methods can be devised to measure masstransfer coefficients for the phase (air, water, or both) imparting the dominant resistance to volatilization.

Smith and others (1980) have proposed a method of predicting the volatilization rate of highly volatile organic compounds in streams on the basis of laboratory measurements. Highly volatile compounds experience resistance to mass transport, primarily in the liquid-film phase, whereas resistance in the gas film is considered negligible. Consequently, estimation of the volatilizationrate constant simplifies to estimation of only the liquidphase, mass-transfer coefficient. Using oxygen as a highvolatility reference compound, Smith and others (1980) used results of previous studies to show that the ratio of the liquid-film, mass-transfer coefficient of an organic compound to the reaeration coefficient for oxygen is constant over a wide range of turbulence levels. If this ratio is measured in the laboratory, and if the oxygen reaeration constant is measured in an actual water body, the corresponding field liquid-phase, mass-transfer coefficient can then be calculated for the organic compound. Theoretical justification for the constancy of the masstransfer coefficient ratio for the organic compound and oxygen as well as a test of the method of predicting volatilization of benzene and six other chlorinated hydrocarbons is reported in Smith and others (1980).

The rate of mass transfer of low-volatility compounds is controlled by resistance in the gas film, whereas resistance in the liquid film is relatively small. Smith and others $(1981,1983)$ suggest the use of water as a reference compound, because its rate of evaporation is controlled entirely by gas-phase, mass-transfer resistance. The ratio of the mass-transfer coefficients for water and the organic compound is constant, and any effect of gas-phase turbulence is equal for the two compounds (and therefore is canceled). Based on the ratio, the gas-film, mass-transfer coefficient is estimated from field measurements of the water evaporation flux, relative humidity, and air temperature. Smith and others (1981, 1983) demonstrated this approach for two organic compounds of low volatility and two organic compounds of intermediate volatility. For compounds of intermediate volatility, estimates are required for both the gas-film and liquid-film, mass-transfer coefficients. These cannot be estimated by a single experiment; independent measurements of each coefficient are required. Methods of obtaining these estimates are described by Southworth (1979) and Smith and others $(1981,1983)$.

Despite the fact that the two-film theory is commonly used to model volatilization, it has several important limitations. One of the basic assumptions of the 
two-film theory is that the surface layer of the solvent (water) is stationary and is not evaporating, so that a solute has to move to the liquid surface by diffusion to evaporate. This assumption applies only to solutes that are evaporating much faster than the solvent; it breaks down when the loss rate of the solvent is comparable to or greater than the loss rate of the solute. For the latter case, the solute is not required to diffuse to the liquid surface to evaporate, inasmuch as the solvent at the old surface is gone. Therefore, even if no diffusion occurred, the solute would then be at the newly generated surface and would evaporate. The failure of the two-film theory to account for solvent evaporation may make the model somewhat inaccurate for describing the evaporative behavior of solutes that are relatively nonvolatile. Another possible weakness of the two-film theory is its emphasis on the diffusion of the solute and lack of consideration that the solvent also is diffusing. Because the solvent is the dominant component of the mixture, its diffusive motion may cause additional movement of the solute to the surface. Therefore, the size of the solute molecule may not have a strong influence on solute diffusion in water; in other words, the solute may be "pushed" by the solvent's diffusive motion. Finally, the two-film theory treats the concentration gradient of the solute in the liquid film as the driving force for evaporation. In fact, the concentration gradient is merely the result of uneven evaporative loss rates between solute and solvent and should not be treated as the driving force for evaporation of the solute.

Chiou and others (1980; Chiou, Kohnert, and others, 1983) have presented an alternative first-order model for volatilization that explicitly accounts for the effects of solute concentration and system turbulence. The model differs from the previously described two-film approach in that it explicitly treats the influence of air turbulence and subsurface mixing on the evaporative behavior of organic solutes of different volatility. In addition, although the two-film model gives only relative resistances, the model proposed by Chiou and others (1980; Chiou, Kohnert, and others, 1983) gives relative as well as absolute resistances. The absolute liquid-phase and airphase resistances are based on pure liquid and vacuum as the reference states.

Chiou and others (1980; Chiou, Kohnert, and others, 1983) report that for compounds that have small Henry's law constants (low volatility and gas-phasecontrolled diffusion), the rate of volatilization is enhanced by air turbulence but not by subsurface mixing. On the other hand, the volatilization rate of volatile solutes increases with air turbulence and subsurface mixing. The degree of enhancement by liquid mixing is a function of the magnitude of the Henry's law constant. In addition, Chiou, Kohnert, and others (1983) examined the influence of system conditions on the ratio of mass-transfer coefficients for different organic-solute combinations in water. They found that the ratios of mass-transfer coefficients for organic solutes are constant with respect to changes in air turbulence and water mixing if the organic compounds have similar or low Henry's law constants. The ratios are not constant for compounds that have vastly different or high Henry's law constants. These results show that careful examination of compound properties and system conditions is necessary before reference compounds, such as oxygen, can be used to estimate volatilization rates for organic compounds in natural waters.

A number of statistical approaches have been proposed to estimate mass-transfer coefficients (either liquid or gas, or both) of organic compounds from field properties that characterize the degree of air and water turbulence. For example, Rathbun and Tai (1982) measured liquid-film, mass-transfer coefficients for ethylene and propane and correlated their magnitudes with a number of hydraulic and geometric properties of streams (stream energy, depth of flow, average velocity, and stream slope). The regression equations derived for ethylene and propane are then used to estimate mass-transfer coefficients for other highly volatile organic compounds, after the proper adjustment is made on the basis of molecular diffusivity, molecular weight, or molecular diameter. Mackay and Yeun (1983) used a similar statistical approach but chose for their correlation studies stream and compound properties different from those used by Rathbun and Tai. Mackay and Yeun (1983) developed separate regression equations for the gas- and liquid-film, mass-transfer coefficients. They used friction velocity as the hydrodynamic parameter and the Schmidt number to characterize differences between organic solutes. The Schmidt number (viscosity divided by density multiplied by diffusivity) incorporates the solute-diffusion properties as well as a temperature dependence, whereas the friction velocity is related to the windspeed. The correlations were found to yield reasonable results for 11 organic compounds under a number of windspeed conditions. Although these correlations do allow estimates of masstransfer coefficients necessary to apply the two-film model to the process of volatilization, they also show that more research needs to be conducted to increase understanding of factors that control the mass-transfer coefficients in the gas and liquid films.

In summary, the current approach to representing the volatilization of organic compounds from surfacewater bodies is through the use of a first-order-rate expression. In this form, the rate of volatilization depends on the concentration of the compound in solution and on the volatilization-rate constant. The most common way to represent the volatilization-rate constant is by the two-film resistance model. This model is parameterized by the Henry's law constant and a gas-film and liquid-film, mass-transfer coefficient. In some cases, depending on the 
magnitude of the Henry's law constant of the compound of interest, the resistance to volatilization can be approximated by the gas-film resistance and (or) the liquid-film resistance. Generally, the Henry's law constant is obtainable from independent measurements of the organic compound's water solubility and vapor pressure. Vapor pressures can be estimated from correlation equations based on boiling or melting points (Mackay and others, 1982 ) or by experimental procedures. Burkhard and others (1985) review and assess the predictive ability of 11 methods as they are applied to 15 chlorinated biphenyl isomers. Because of the large number of existing approaches to estimating the Henry's law constant, the usefulness of the two-film model depends on obtaining values for the gas- and liquid-film, mass-transfer coefficients.

The difficulty in estimating the gas- and liquid-film, mass-transfer coefficients stems from their dependence on system conditions (such as temperature, wind turbulence, and water mixing) and compound properties (such as diffusivity and molecular weight). Statistical approaches have tried to correlate mass-transfer coefficients with system variables for organic compounds for which some experimental data are available. These correlation equations are extrapolated to other organic solutes of similar volatility by making corrections on the basis of diffusivity, molecular weight, or molecular diameter. Experimental approaches derive estimates by the use of reference compounds-for example, oxygen, carbon dioxide, radon, or other organic solutes-whose variation in parameter values is constant relative to the organic compound of interest over a particular range of conditions. These studies indicate that no entirely satisfactory method has been developed to estimate the different mass-transfer resistances (gas or liquid) over the full range of volatilities exhibited by the organic solutes.

Although the two-film model is a promising approach to quantifying the volatilization rate of organic compounds, a number of other factors still need to be incorporated in the model. The presence of natural or manmade organic films (or surface-active agents) creates another layer that acts to further retard volatilization. This surface film possesses a characteristic thickness and a resistance to diffusion that has to be considered in addition to the air- and water-boundary layers already treated in the two-film model (Smith and others, 1980; Mackay, 1982b). The two-film model gives the theoretical maximum volatilization rate for a given set of environmental conditions. Other water and atmospheric phenomena (such as stratification and aerosol formation) as well as competing processes (such as sorption, photolysis, hydrolysis, and biodegradation) reduce the amount of organic solute available for volatilization. For some of these processes, relative comparisons of first-order rate con-<smiles>C=C(c1ccc(Cl)cc1)c1ccc([Po](=O)[O-])cc1</smiles>

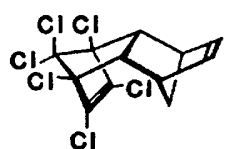

Aldrin

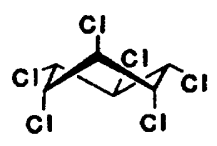

Lindane

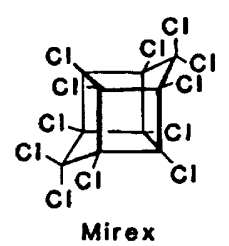

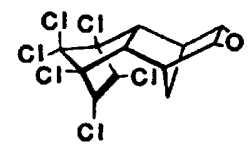

Dieldrin

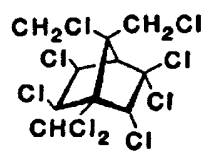

Toxaphene

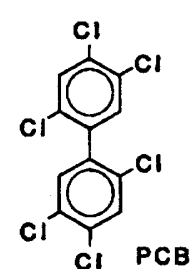

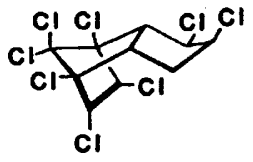

chlordane

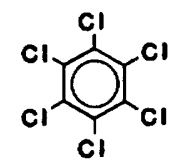

HCB
Figure 11. Structural diagrams of selected chlorinated insecticides and a polychlorinated biphenyl (PCB). HCB is hexachlorobenzene.

stants can be used to determine the transformations that control the aquatic fate of an organic compound.

\section{POLYCHLORINATED BIPHENYLS AND CHLORINATED INSECTICIDES}

\section{Uses, Production, Properties, and Regulatory Limits}

Polychlorinated biphenyls (PCB's) and chlorinated insecticides have been grouped together in this section because of their similar behavior in surface-water systems. As a group, they are the most persistent anthropogenic organic compounds introduced into the environment since the lead and arsenic pesticides of the early 1900 's. Although the use of many of these contaminants has been banned in the United States for more than a decade, significant residues contaminate the sediment, water, and biota of the country's surface waters. Figure 11 shows the structural diagrams of $2,2^{\prime}, 4,4^{\prime}, 5,5^{\prime}$-PCB and some of the more common chlorinated insecticides.

PCB's are synthetically produced by the catalyzed chlorination of biphenyl. Because of their chemical and thermal stability, inertness, and dielectric nature, they 
Table 3. Approximate molecular composition of some Aroclor mixtures [nd, not detected. From Hutzinger and others, 1974]

\begin{tabular}{|c|c|c|c|c|c|c|c|c|c|}
\hline \multirow[b]{2}{*}{$\begin{array}{c}\text { Empirical } \\
\text { formula }\end{array}$} & \multirow[b]{2}{*}{$\begin{array}{l}\text { Molecular } \\
\text { weight }\end{array}$} & \multirow[b]{2}{*}{$\begin{array}{l}\text { Percent } \\
\text { chlorine }\end{array}$} & \multicolumn{6}{|c|}{ Percentage in each Aroclor mixture } & \multirow[b]{2}{*}{1260} \\
\hline & & & 1016 & 1221 & 1232 & 1242 & 1248 & 1254 & \\
\hline $\mathrm{C}_{12}{ }^{\mathrm{H}} 10$ & 154.21 & 0 & $<0.1$ & 11 & $<0.1$ & $<0.1$ & nd & $<0.1$ & nd \\
\hline $\mathrm{C}_{12} \mathrm{H}_{9} \mathrm{Cl}$ & 188.65 & 18.79 & $I$ & 51 & 31 & 1 & nd & $<.1$ & nd \\
\hline $\mathrm{C}_{12} \mathrm{H}_{8} \mathrm{Cl}_{2}$ & 223.10 & 31.77 & 20 & 32 & 24 & 16 & 2 & .5 & nd \\
\hline $\mathrm{c}_{12} \mathrm{H}_{7} \mathrm{C}_{3}$ & 257.54 & 41.30 & 57 & 4 & 28 & 49 & 18 & 1 & nd \\
\hline $\mathrm{C}_{122^{\mathrm{H}}} \mathrm{Cl}_{4}$ & 291.99 & 48.56 & 21 & 2 & 12 & 25 & 40 & 21 & 1 \\
\hline $\mathrm{C}_{12} \mathrm{H}_{5} \mathrm{Cl}_{5}$ & 326.43 & 54.30 & 1 & $<.5$ & 4 & 8 & 36 & 48 & 12 \\
\hline $\mathrm{C}_{12} \mathrm{H}_{4} \mathrm{Cl}_{6}$ & 360.88 & 58.93 & $<.1$ & nd & $<.1$ & 1 & 4 & 23 & 38 \\
\hline $\mathrm{C}_{12} \mathrm{H}_{3} \mathrm{Cl}_{7}$ & 395.32 & 62.77 & nd & nd & nd & $<.1$ & nd & 6 & 41 \\
\hline \multicolumn{3}{|c|}{ Average molecular weight } & 257.9 & 200.7 & 232.2 & 266.5 & 299.5 & 328.4 & 375.7 \\
\hline
\end{tabular}

have been used as plasticizers, as hydraulic lubricants in gas turbines and vacuum pumps, in heat-transfer systems, and as dielectric fluids in electrical capacitors and transformers. Aroclor ${ }^{1}$ is the trade name for one manufacturer's PCB's. Aroclors are mixtures of a variety of polychlorinated bi- and terphenyls that are identified by a four-digit number. The first two numbers refer to the type of molecule primarily used in the mixture (12- refers to biphenyl, 54- refers to terphenyl), and the second two numbers specify the percent chlorine (by weight) in the mixture. Aroclor 1016 was marketed more recently in response to the environmental problems associated with the persistence of the other Aroclor mixtures. This product contains predominantly mono-, di-, and trichlorobiphenyl isomers. The approximate molecular compositions of Aroclor mixtures are given in table 3. Additionally, some uses of PCB's suggested by the manufacturer are detailed in table 4.

PCB's were first synthesized in 1929 , with production escalating in the United States during the 1960's. Production reached a peak in 1970 , when $38,600 \mathrm{t}$ were produced (Moore and Ramamoorthy, 1984). The manufacturer voluntarily decreased and eventually ceased pro-

\footnotetext{
${ }^{1}$ Use of trade names in this report is for identification purposes only and does not constitute endorsement by the U.S. Geological Survey.
}

duction of PCB's during the 1970's. Because of the environmental persistence and toxicity of PCB's, their production, sale, distribution, and disposal were first regulated under the provisions of the Toxic Substances Control Act of 1976. In the same year, the U.S. Environmental Protection Agency (USEPA) set $0.001 \mu \mathrm{g} / \mathrm{L}$ as the water-quality criterion for PCB's to protect freshwater and marine aquatic life (U.S. Environmental Protection Agency, 1976). In 1977, PCB use was restricted by the USEPA, and in 1979, all manufacture, sale, and distribution of PCB's in the United States was prohibited (Haley, 1984). Despite the cessation of production, PCB's are estimated to be present in 2 million transformers and 2.8 million capacitors currently in use in the United States (Moore and Ramamoorthy, 1984).

The use of organochlorine insecticides began with the discovery of the insecticidal properties of DDT by Paul Müller in 1939. In that year, DDT was chosen as the most promising new synthetic organic insecticide. Müller was awarded the Nobel Prize for his discovery $9 \mathrm{yr}$ later (Reutergardh, 1980). Technical-grade DDT contains approximately 80 percent p,p'-DDT and 15-20 percent o,p'-DDT (Verschueren, 1983). The metabolicdegradation products of $\mathrm{p}, \mathrm{p}^{\prime}-\mathrm{DDT}$ are $\mathrm{p}, \mathrm{p}^{\prime}$-DDE and $\mathrm{p}, \mathrm{p}^{\prime}-\mathrm{DDD}$, and their residues are commonly found in the environment.

Following the discovery of DDT, numerous other organochlorine insecticides were developed and used. 
Table 4. Some uses of polychlorinated biphenyls suggested by the manufacturer [From Moore and Ramamoorthy, 1984]

\begin{tabular}{|c|c|c|}
\hline Base material & $\begin{array}{l}\text { Type of Aroclor } \\
\text { used and lts } \\
\text { percent content } \\
\text { in final product }\end{array}$ & $\begin{array}{l}\text { Purpose of Aroclor use } \\
\text { and beneficial result }\end{array}$ \\
\hline Polyvinyl chloride & $1248,1254,1260(7-88)$ & $\begin{array}{l}\text { Secondary plasticlzers to } \\
\text { increase flame retardance } \\
\text { and chemical resistance }\end{array}$ \\
\hline Polyvinyl acetate & $1221,1232,1242(118)$ & $\begin{array}{l}\text { Improved quick-track and } \\
\text { fiber-tear properties }\end{array}$ \\
\hline Polyester resins & $1260(10-208)$ & $\begin{array}{l}\text { Stronger fiberglass; } \\
\text { reinforced resins and } \\
\text { economical fire retardants }\end{array}$ \\
\hline Polystyrene & $1221(28)$ & Plasticizer \\
\hline Epoxy resins & 1221,1248 (208) & $\begin{array}{l}\text { Increased resistance to } \\
\text { oxidation and chemical } \\
\text { attack; better adhesive } \\
\text { properties }\end{array}$ \\
\hline $\begin{array}{l}\text { Styrene-butadiene } \\
\text { co-polymer }\end{array}$ & $1254(88)$ & Better chemical resistance \\
\hline Neoprene & $\begin{aligned} 1268 & (408) \\
& (1.58)\end{aligned}$ & $\begin{array}{l}\text { Fire retardant } \\
\text { injection moldings }\end{array}$ \\
\hline $\begin{array}{l}\text { Crepe rubber } \\
\text { Nitrocellulose } \\
\text { lacquers }\end{array}$ & $\begin{array}{l}1262(5-508) \\
1262(78)\end{array}$ & $\begin{array}{l}\text { Plasticizer in paints } \\
\text { Co-plasticlzer }\end{array}$ \\
\hline $\begin{array}{l}\text { Ethylene vinyl } \\
\text { acetates }\end{array}$ & $1254(418)$ & Pressure-sensitive adhesives \\
\hline Chlorinated rubber & $1254(5-108)$ & $\begin{array}{l}\text { Enhances resistance, flame } \\
\text { retardance, electrical } \\
\text { insulation properties }\end{array}$ \\
\hline Varnish & 1260 (258 of o11) & $\begin{array}{l}\text { Improved water and alkali } \\
\text { resistance }\end{array}$ \\
\hline Wax & $1262(58)$ & $\begin{array}{l}\text { Improved moisture and flame } \\
\text { resistance }\end{array}$ \\
\hline
\end{tabular}

Lindane, the gamma isomer of hexachlorocyclohexane $(\mathrm{HCH})$, was found to be an effective insecticide in 1942, followed by chlordane in 1945, and heptachlor, aldrin, dieldrin, and toxaphene in 1948. Toxaphene is produced by the chlorination of terpene derivatives and is a mixture of more than 170 components. Endrin and endosulfan were first introduced in the 1950's. Mirex was first prepared in 1946 but was not used extensively until 1969, when it was used to control fire ants in the Southern United States. The degradation product of mirex is kepone. Methoxychlor also became widely used in 1969 in response to the ban of DDT in the United States. In the past $10 \mathrm{yr}$, it has been estimated that the quantities of insecticides applied has decreased owing to the use of more potent insecticides, such as the pyrethroids permethrin and fenvalerate, which require much lower application rates than older organochlorine insecticides, such as toxaphene (Gilliom, 1985).

The production of organochlorine insecticides in the United States has been greatly curtailed over the last $15 \mathrm{yr}$ owing to their environmental persistence, toxic effects, and lipophilic nature. DDT and aldrin/dieldrin use peaked in the mid-1960's at annual values of 70,000 and $9,000 \mathrm{t}$, respectively. By 1970 , these values had decreased to 36,000 and $5,000 \mathrm{t}$, respectively. Currently (1987), production of these compounds in the United States is negligible. The use of other organochlorine insecticides currently applied to crops (such as toxaphene) is being restricted (Moore and Ramamoorthy, 1984). Additional use data for these and other chlorinated insecticides, along with detection limits and water-quality criteria, are presented in table 5 .

\section{Environmental Fate}

Organochlorine insecticides and PCB's are characterized by relatively low aqueous solubilities and high octanol-water partition coefficients (table 6). Because low solute solubility correlates with high sediment-water sorption coefficients for nonionic organic compounds, it is expected that PCB's and organochlorine insecticides would strongly partition into sediment organic matter and 
Table 5. Detection limits, water-quality criteria, and use data for selected organochlorine insecticides $[\mu \mathrm{g} / \mathrm{L}$, micrograms per liter; lb/yr, pounds per year. From Gilliom, 1985]

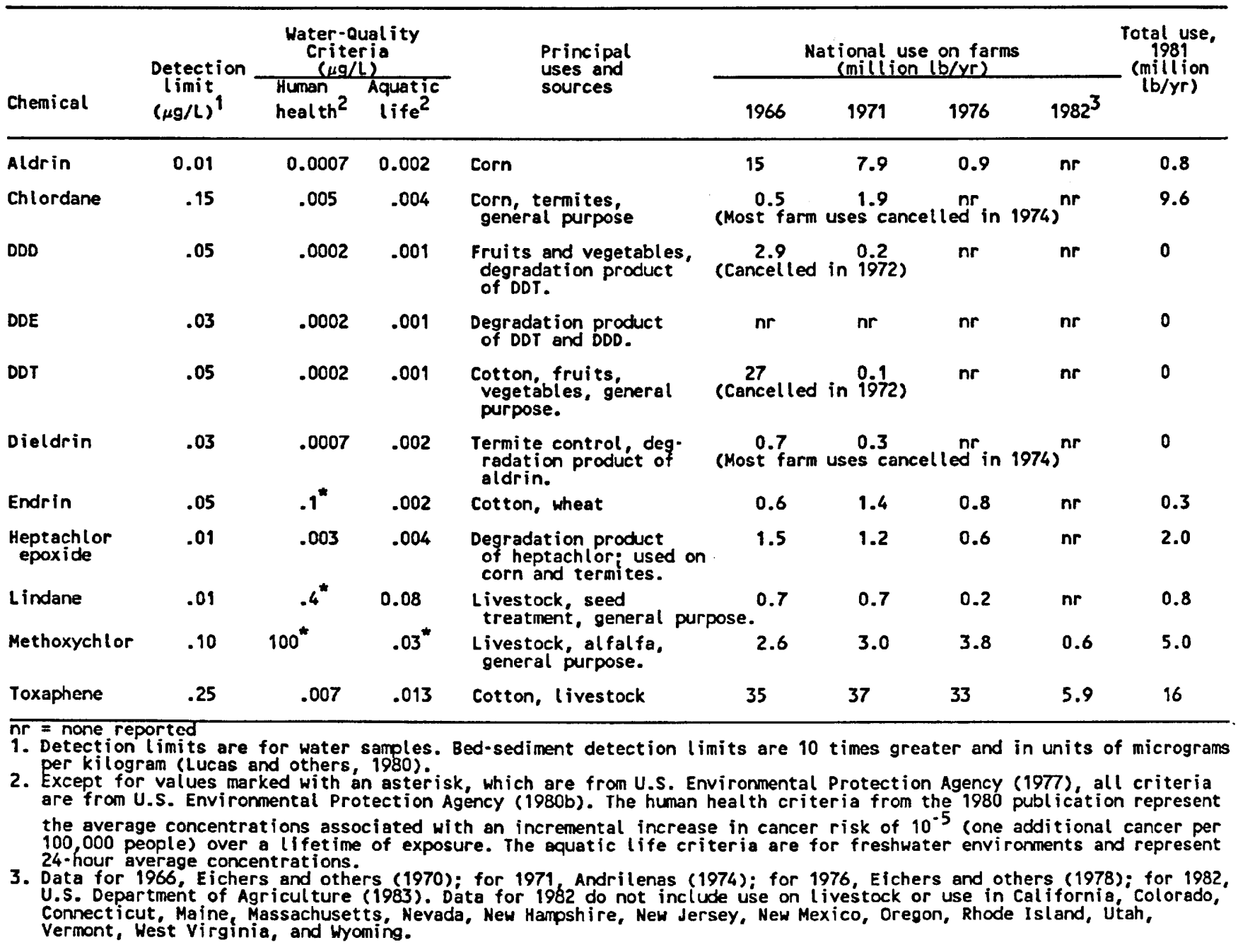

dissolved organic matter. Laboratory and field studies have corroborated this hypothesis.

Table 7 presents some partition coefficients that have been determined for PCB's and chlorinated insecticides in laboratory and field studies. The values for the distribution coefficient, $K_{d}$, and the distribution coefficients normalized for organic carbon, $\mathrm{K}_{\mathrm{oc}}$, or organic matter, $\mathrm{K}_{\mathrm{om}}$, are very high, especially for DDT, DDE, and the PCB's. These high sorption coefficients indicate the strong tendency of these compounds to partition into the sediment organic matter. Even lindane, one of the more soluble of the organochlorine insecticides, has been documented as having $\mathrm{K}_{\mathrm{om}}$ values greater than 800 (Sharom and others, 1980a).

As a result of their high sorption coefficients, insecticides and PCB's having low dissolved concentrations in water (in the parts-per-trillion range) can still have very high concentrations in sediment (up to the parts-per-million range). In an Oklahoma stream, Hunter and others (1980) determined that PCB concentrations in sediment ranged from 0.23 to $7.2 \mathrm{ppm}$, yet the concentration of PCB's in the water was undetectable. Likewise, at one location in the Hudson River (N.Y.), Nadeau and Davis (1976) detected PCB concentrations in sediment of almost $3,000 \mathrm{ppm}$, even though the aqueous concentration in the overlying water was only $3.0 \mathrm{ppb}$. These studies indicate the importance of sorption to the transport, fate, and distribution of organochlorine insecticides and PCB's in surface-water systems.

In addition to their affinity for sediment organic matter, these chlorinated organic compounds also tend to partition strongly into the lipid reservoirs of aquatic organisms. The resulting concentration of the compound in the biota can be as much as 1 million times greater than the compound's aqueous concentration. Table 8 presents bioconcentration factors (BCF's) for a variety of PCB's 
Table 6. Experimentally determined octanol-water partition coefficients $\left(\mathrm{K}_{\text {ow }}\right)$, solubilities, and vapor pressures of selected polychlorinated biphenyls (PCB's) and chlorinated insecticides at room temperature

[mg/L, milligrams per liter, $\mathrm{mm}$, millimeters. Dash indicates no data available]

\begin{tabular}{|c|c|c|c|c|}
\hline Compound & $\log _{\text {ow }}$ & $\begin{array}{l}\text { Solubility } \\
(\mathrm{mg} / \mathrm{L})\end{array}$ & $\begin{array}{l}\text { Vapor pressure } \\
(\mathrm{mm} \text { of } \mathrm{Hg})\end{array}$ & Reference \\
\hline $\begin{array}{l}\text { Biphenyl } \\
2,4^{\circ}-\mathrm{PCB}\end{array}$ & $\begin{array}{l}4.09 \\
5.10\end{array}$ & 7.5 & $\begin{array}{l}1.8 \\
0.28\end{array}$ & $\begin{array}{r}1,2,3 \\
4,3\end{array}$ \\
\hline $4,4^{\circ}-\mathrm{PCB}$ & 5.58 & 0.062 & $8.99 \times 10^{-3}$ & $5,2,3$ \\
\hline $\begin{array}{l}2,5,2^{\prime}, 5^{\prime}-\mathrm{PCB} \\
2,4,5,2^{\prime} 5^{\prime}-\mathrm{PCB}\end{array}$ & $\begin{array}{l}5.81 \\
6.11\end{array}$ & $\begin{array}{l}0.016 \\
0.010\end{array}$ & $4.27 \times 10^{-3}$ & $\begin{array}{r}5,2,3 \\
5,2\end{array}$ \\
\hline $2,4,5,2^{\prime}, 4^{\prime}, 5^{\prime}-\mathrm{PCB}$ & 6.72 & 0.00095 & $4.57 \times 10^{-4}$ & $5,2,3$ \\
\hline$p, p^{\prime}-D D T$ & 6.36 & 0.0031 & $1.9 \times 10^{-7}$ & $1,2,6$ \\
\hline $0, \mathrm{P}^{\prime}-\mathrm{DDT}$ & - & 0.026 & $5.5 \times 10^{-6}$ & 6 \\
\hline$P, P^{\prime}-D D D$ & 5.99 & 0.020 & $10.2 \times 10^{-7}$ & 6 \\
\hline $0, p^{\prime}-D D D$ & 6.08 & - & $18.9 \times 10^{-7}$ & 6 \\
\hline$p, p^{\prime}-D D E$ & 5.69 & 0.040 & $6.5 \times 10^{-6}$ & 6 \\
\hline $0, p^{\prime}-D D E$ & 5.78 & - & $6.2 \times 10^{-8}$ & 6 \\
\hline Lindane & 3.70 & 7.87 & $1.6 \times 10^{-4}$ & $7,7,6$ \\
\hline Aldrin & - & 0.017 & $6.0 \times 10^{-8}$ & 6 \\
\hline Dieldrin & - & 0.195 & $1.8 \times 10^{-7}$ & 6,2 \\
\hline $\begin{array}{l}\text { Chlordane } \\
\text { Toxaphene }\end{array}$ & $5.48^{*}$ & $\begin{array}{l}0.056 \\
0.74\end{array}$ & $\begin{array}{l}1.0 \times 10^{-5} \\
0.2-0.4\end{array}$ & $\begin{array}{r}8,6,6 \\
6\end{array}$ \\
\hline Endrin & - & 0.26 & $2 \times 10^{-7}$ & 6 \\
\hline Heptachlor & - & 0.056 & $3 \times 10^{-4}$ & 6 \\
\hline$\alpha$-Endosulfan & - & 0.53 & $1 \times 10^{-5}$ & 6 \\
\hline
\end{tabular}

* - Value calculated from structural parameters according to Mabey and others (1982)

1. Chiou, Schmedding, and Manes (1982) 5. Chiou and others (1985)

2. Verschueren (1983) 6. Callahan and others (1979)

3. Burkhard and others (1985) 7. Chiou and others (1986)

4. Chiou, Porter, and Schmedding (1983) 8. Mabey and others (1982)

and chlorinated insecticides and for a variety of aquatic organisms ranging from microorganisms to fish. Differences in the BCF values among different compounds result largely from differences in each compound's solubility in water. For a given compound, the BCF can be expected to vary with the lipid contents of the different organisms. BCF's greater than 10,000 have been observed, and even the more soluble insecticides such as lindane have been bioconcentrated to values hundreds of times greater than the compound's aqueous concentration. Therefore, even low aqueous concentrations of organochlorine insecticides and PCB's can produce environmentally significant concentrations of these compounds in aquatic organisms.
In addition to their typically low solubilities and high octanol-water partition coefficients, PCB's and chlorinated insecticides also are characterized by relatively low vapor pressures (table 6). Compounds that have low vapor pressures typically have low mass-loss rates (fluxes) from solution. However, PCB's and some of the chlorinated insecticides in water are relatively volatile, because their low water solubilities cause relatively high rates of loss from water. The rate of volatilization for a given compound depends on such factors as suspendedsediment concentration and the compound's organicmatter content, the concentration of dissolved organic matter, temperature, and water turbulence. Increased concentrations of organic matter result in increased sorp- 
Table 7. Experimentally determined sorption coefficients for some polychlorinated biphenyls (PCB's) and organochlorine insecticides

[OC, organic carbon; OM, organic matter; $K_{d}$ distribution coefficient; $K_{o c}$ and $K_{o m}$. distribution coefficients normalized for organic carbon and organic matter, respectively. Dash indicates no data available]

\begin{tabular}{|c|c|c|c|c|c|}
\hline Compound & So11/sediment & OC or OM (8) & $\mathbf{k}_{\mathbf{d}}$ & $\mathrm{K}_{\mathrm{oc}}$ or $\mathrm{K}_{\mathrm{om}}$ & Reference \\
\hline $2,4,4^{\prime}-\mathrm{PCB}$ & silt loam & $1.9(\mathrm{om})$ & 460 & 24,000 & 1 \\
\hline $2,5,2^{\prime}-\mathrm{PCB}$ & $\begin{array}{l}\text { Suspended river } \\
\text { gediment }\end{array}$ & $4.1(\mathrm{Oc})$ & 10,000 & 250,000 & 2 \\
\hline $\begin{array}{l}\text { Hexachloro- } \\
\text { biphenyl }\end{array}$ & $\begin{array}{l}\text { Lake Michigan } \\
\text { sediment }\end{array}$ & $2.9(\mathrm{oc})$ & 9.000 & 310,000 & 3 \\
\hline $\begin{array}{l}\text { Hexachloro- } \\
\text { biphenyl }\end{array}$ & $\begin{array}{l}\text { Suspended river } \\
\text { sediment }\end{array}$ & $4.1(\mathrm{oc})$ & 13,000 & 300,000 & 2 \\
\hline Aroclor 1254 & $\begin{array}{l}\text { Lake Michigan } \\
\text { sediment }\end{array}$ & $1.7(\mathrm{oc})$ & 7,000 & 410,000 & 4 \\
\hline DDT & Marine sediment & 2.7 (oc) & 48,000 & $1,800,000$ & 5 \\
\hline DDT & So11 samples & $-(o m)$ & - & 140.000 & 6 \\
\hline $\mathbf{p}, \mathbf{P}^{\prime}-\mathrm{DDE}$ & $\begin{array}{l}\text { Suspended river } \\
\text { sediment }\end{array}$ & 4.1 (oc) & 41,000 & $1,000,000$ & 2 \\
\hline Lindane & silt loam & $1.9(\mathrm{om})$ & 14 & 740 & 7 \\
\hline Lindane & Creek sediment & $2.8(\mathrm{om})$ & 24 & 860 & 8 \\
\hline$\alpha$-chlordane & $\begin{array}{l}\text { Suspended river } \\
\text { sediment }\end{array}$ & 4.1 (oc) & 13,000 & 300,000 & 2 \\
\hline$\beta$-chlordane & $\begin{array}{l}\text { Suspended river } \\
\text { sediment }\end{array}$ & 4.1 (oc) & 10,000 & 250,000 & 2 \\
\hline Endrin & Sand & $0.7(\mathrm{om})$ & 58 & 8,300 & 8 \\
\hline Kepone & Estuarine sediment & - & 1,700 & - & 9 \\
\hline Methoxychlor & Clay & $1.2(o c)$ & 1,100 & 90,000 & 10 \\
\hline
\end{tabular}

1. Chiou, Porter, and Schmedding (1983) 6. Chiou and others (1979)

2. Oliver and Charlton (1984) 7. Chiou and others (1985)

3. Volce and others (1983) 8. Sharom and others (1980a)

4. Voice and Weber (1985) 9. Huggett and others (1980)

5. Pierce and others (1974) 10. Karickhoff and others (1979)

tion and, consequently, decreased volatilization (Haque and others, 1974; Callahan and others, 1979). Increases in temperature or turbulence, however, will increase the rate of volatilization.

Volatilization from solution and other atmospheric discharges (such as incineration) combine with atmospheric transport to contribute to the widespread distribution of PCB's and some of the chlorinated pesticides. Munson (1976) detected both toxaphene and PCB's in rainwater collected at Sollers Point, Md. Heit and others (1984) have determined PCB concentrations up to 194 $\mu \mathrm{g} / \mathrm{kg}$ in the sediments of remote Rocky Mountain lakes that had not been directly affected by point source discharges of PCB's. They concluded that PCB's present in the lakes were due to atmospheric deposition of the contaminants. Similarly, atmospheric deposition has been considered the primary source of PCB contamination to the Great Lakes (Murphy and Rzeszutko, 1977; Eisenreich and others, 1979). Haines (1983) found residues of a variety of organochlorine insecticides in brook trout taken from six remote lakes in New England. Because the lakes were surrounded by forested land that had not been treated with pesticides for at least $80 \mathrm{yr}$, it was concluded that the contaminant residues were atmospherically deposited. Volatilization, atmospheric transport, and subsequent deposition, therefore, partly explain the numerous detections of PCB's and organochlorine insecticides around the globe. 
Table 8. Experimentally determined bioconcentration factors for some polychlorinated biphenyls (PCB's) and organochlorine insecticides

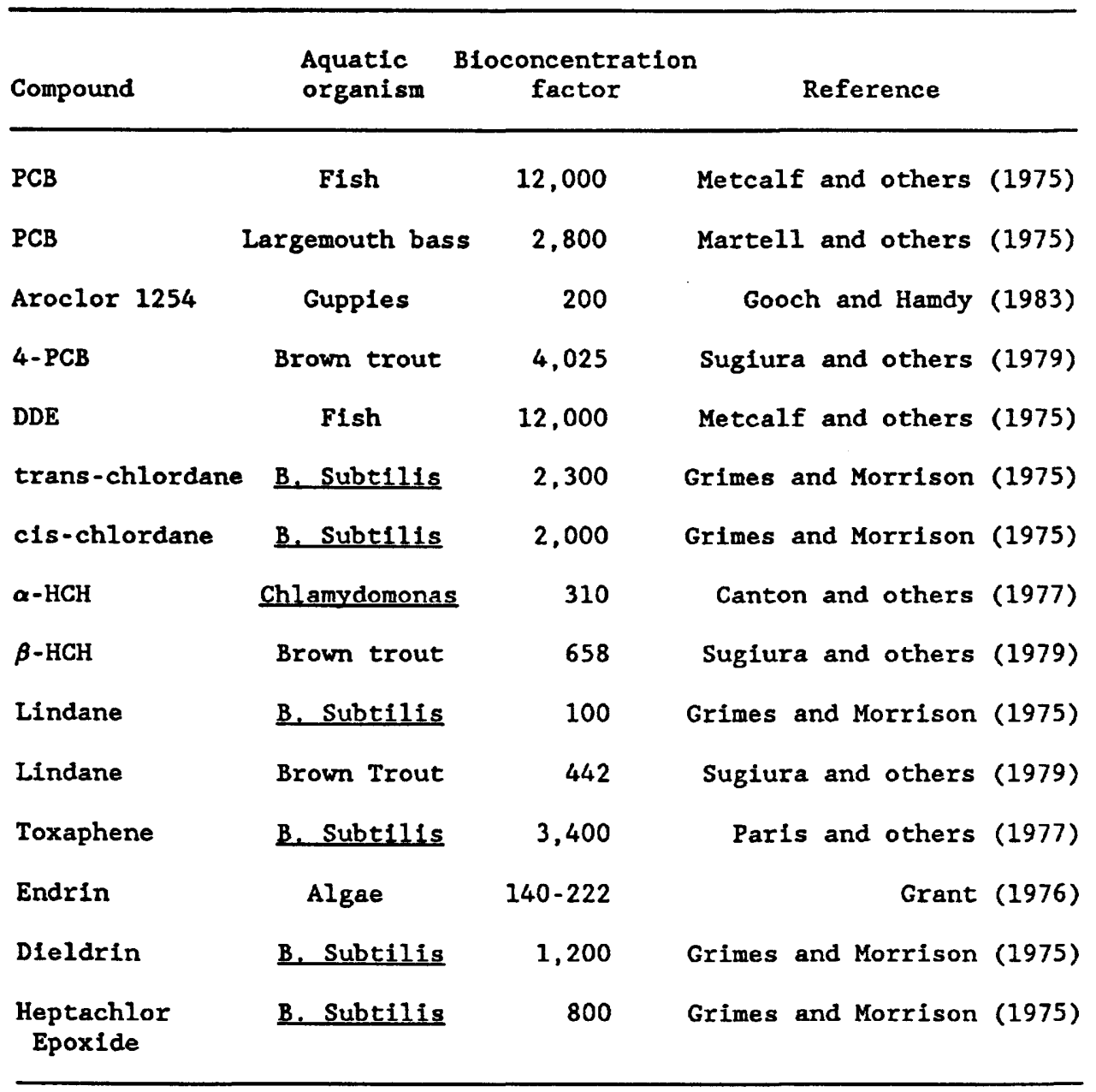

In addition to their ability to partition into organic matter and biological lipid reservoirs and their tendency to volatilize and be transported atmospherically, the chlorinated insecticides and PCB's are, in general, highly resistant to chemical or biological transformation. As a result, they are extremely persistent environmental contaminants whose residues commonly remain years after use at the source of contamination has ceased.

The biodegradability of PCB's decreases with increased chlorination of the molecule, with the more highly chlorinated biphenyls being extremely resistant to biodegradation (Sayler and others, 1977). The biotransformation of PCB's is enhanced by an increase in the number of $\mathrm{C}-\mathrm{H}$ bonds available for hydroxylation by microbial enzymes (Haley, 1984). Increased chlorination decreases the number of $\mathrm{C}-\mathrm{H}$ bonds and, therefore, inhibits biodegradation. PCB's also are extremely resistant to oxidation and to both acidic and basic hydrolysis (Callahan and others, 1979). Neither oxidation nor hydrolysis are likely to transform PCB's significantly in the environment. There is some evidence that PCB's can be partially dechlorinated by photolysis, particularly when exposed to short-wave ultraviolet light. Bunce and Kumar (1978) calculated that highly chlorinated biphenyl molecules would lose one chlorine molecule per year in shallow waters. In the same $1-y r$ period, however, they predicted that only 5 percent of the lesser chlorinated biphenyls would lose a chlorine molecule photolytically. Although both biodegradation and photolysis transform PCB's at a very slow rate, they may be the most significant long-term transformation processes because of the negligible degradative affects of hydrolysis and oxidation.

The chlorinated insecticides also are relatively resistant to biodegradation. Aldrin has been shown to be biotransformed to dieldrin, but this product is strongly resistant to further degradation (Callahan and others, 1979). Likewise, DDT has been biotransformed to both DDD and DDE in natural systems, with the latter compound being highly resistant to continued biodegradation. Microbial decomposition of DDT occurs primarily 
through DDD formation by reductive dechlorination under anaerobic conditions (Johnsen, 1976). Other chlorinated insecticides such as chlordane, endosulfan, heptachlor, toxaphene, and mirex do not appear to biodegrade at significant rates in natural surface-water systems (Callahan and others, 1979; Aslanzadeh and Hedrick, 1985). Lindane is one of the few chlorinated insecticides that has been shown to biodegrade at significant rates in natural systems, with documented degradation products being penta- and tetrachloro-1-cyclohexanes and penta- and tetrachlorobenzenes (Moore and Ramamoorthy, 1984).

Oxidation of the organochlorine insecticides is not an important factor affecting their fate, with the possible exception of the oxidation of aldrin to dieldrin in the presence of oxygen or ozone (Callahan and others, 1979). Hydrolytic half-lives for the chlorinated insecticides typically are greater than $1 \mathrm{yr}$, with the exception of heptachlor, which is rapidly hydrolyzed to 1-hydroxychlordene. Photolytic reactions degrade the chlorinated insecticides in laboratory experiments, and this process may be important to the long-term fate of these compounds. Moore and Ramamoorthy (1984) state that sunlight reaching the Earth may have enough energy to cleave aromatic $\mathrm{C}-\mathrm{Cl}$ bonds or an aliphatic alcohol's $\mathrm{C}-\mathrm{H}$ bonds but not aromatic $\mathrm{C}-\mathrm{C}$ and $\mathrm{H}-\mathrm{OH}$ bonds.

\section{Environmental Distribution}

Because of the tendency of PCB's and chlorinated insecticides to partition into sediment organic matter and biological lipid reservoirs, elevated concentrations of these contaminants have been reported in soils, sediments, and aquatic organisms throughout the United States and other parts of the world. Tables 9 and 10 present some of the documented residues of PCB's and organochlorine insecticides in sediments and biota, respectively. The highest sediment $\mathrm{PCB}$ residues have been observed in the Hudson River (N.Y.) near the former discharges of two capacitormanufacturing plants. It has been estimated that more than $150,000 \mathrm{~kg}$ of PCB's were discharged to the Hudson River from these two plants over a 30 -yr period ending in 1976 (Brown and others, 1985). Sediment residues have been reported to be greater than $2,000 \mathrm{mg} / \mathrm{kg}$ (Nadeau and Davis, 1976). The sediments of Los Angeles Harbor have also been grossly contaminated with high concentrations of organochlorine compounds, including dieldrin $(1,800 \mu \mathrm{g} / \mathrm{kg})$, total DDT $(770 \mu \mathrm{g} / \mathrm{kg})$, and PCB's (140 $\mu \mathrm{g} / \mathrm{kg}$ ) (Choi and Chen, 1976).

Biota from diverse locations across the United States also have been contaminated with organochlorine residues (table 10). Again, the Hudson River serves as an example of the "worst-case" PCB contamination, with concentrations approaching $100 \mathrm{mg} / \mathrm{kg}$ found in the livers of Atlantic tomcods (Klauda and others, 1981). Brown and others (1985) have documented lipid-based PCB concentrations greater than $1,000 \mathrm{mg} / \mathrm{kg}$ in the fillets of whole yearling pumpkinseeds in the Hudson River. The 8-yr discharge of kepone into the James River estuary in Virginia also caused extreme contamination of biota, with concentrations as high as $10 \mathrm{mg} / \mathrm{kg}$ in the muscle of white perch (Huggett and others, 1980). Concentrations of organochlorine insecticides and PCB's commonly are highest in American eels, inasmuch as this species has a relatively high lipid content (Zitko, 1971; Barker, 1984).

In contrast to sediment and biological residues, aqueous concentrations of PCB's and chlorinated insecticides are typically low, with values typically in the partsper-trillion range. In a study of a Tennessee river, Jaffe and others (1982) detected the insecticides hexachlorobenzene, heptachlor, aldrin, chlordane, dieldrin, and endrin in water samples at mean concentrations of 5.3, 3.2, 5.1, $16.7,0.8$, and $1.2 \mathrm{ppt}$, respectively. Rihan and others (1978) similarly detected aqueous concentrations of aldrin (0.01 to $0.49 \mathrm{ppt}$ ), lindane (0.02 to $0.16 \mathrm{ppt}$ ), p,p'-DDT (2.73 to $12.31 \mathrm{ppt}$ ), and heptachlor (undetectable to 0.18 ppt) in the surface waters of northern Mississippi. These concentrations are typical of contaminated surface waters, and their low magnitudes are consistent with the low solubilities of the contaminants.

PCB's and chlorinated insecticides have been shown in field studies to be extremely persistent and ubiquitous environmental contaminants. Nevertheless, increased restrictions on the use and production of these compounds generally have resulted in a slow but steady decline of their environmental residues over the last 10 to $15 \mathrm{yr}$.

Several researchers have noted decreases in biological residues of PCB's and chlorinated insecticides over time. Wszolek and others (1979) determined that DDE concentrations in 12-yr-old fish from Cayuga Lake in central New York had decreased from 11.7 to 3 to $4 \mathrm{ppm}$ over an 8-yr period. Over the same timespan, PCB residues exhibited less of a decline, with concentrations decreasing only from 15.7 to $13 \mathrm{ppm}$. As a result of an accidental discharge of PCB's to Escambia Bay, Fla., in 1969, Wilson and Forester (1978) monitored PCB concentrations in the bay's oysters from 1969 to 1976. Despite the fact that no known point-source discharges of PCB's contaminated the bay after 1969, residues in the oysters showed only a slight decline over the study period, with an apparent equilibrium PCB concentration of about 0.5 ppm recorded in 1976. Sullivan and others (1983) reported that PCB concentrations in fish of the lower Fox River, Wis, had declined steadily from 1976 to 1981. Figure 12 presents some of the temporal trends in PCB contamination in water and fish of the Hudson River at a site approximately $50 \mathrm{~km}$ below two capacitormanufacturing plants that had formerly discharged PCB's 
Table 9. Means and ranges of detectable sediment residues of polychlorinated biphenyls (PCB's) and organochlorine insecticides

$[\mu \mathrm{g} / \mathrm{kg}$, micrograms per kilogram]

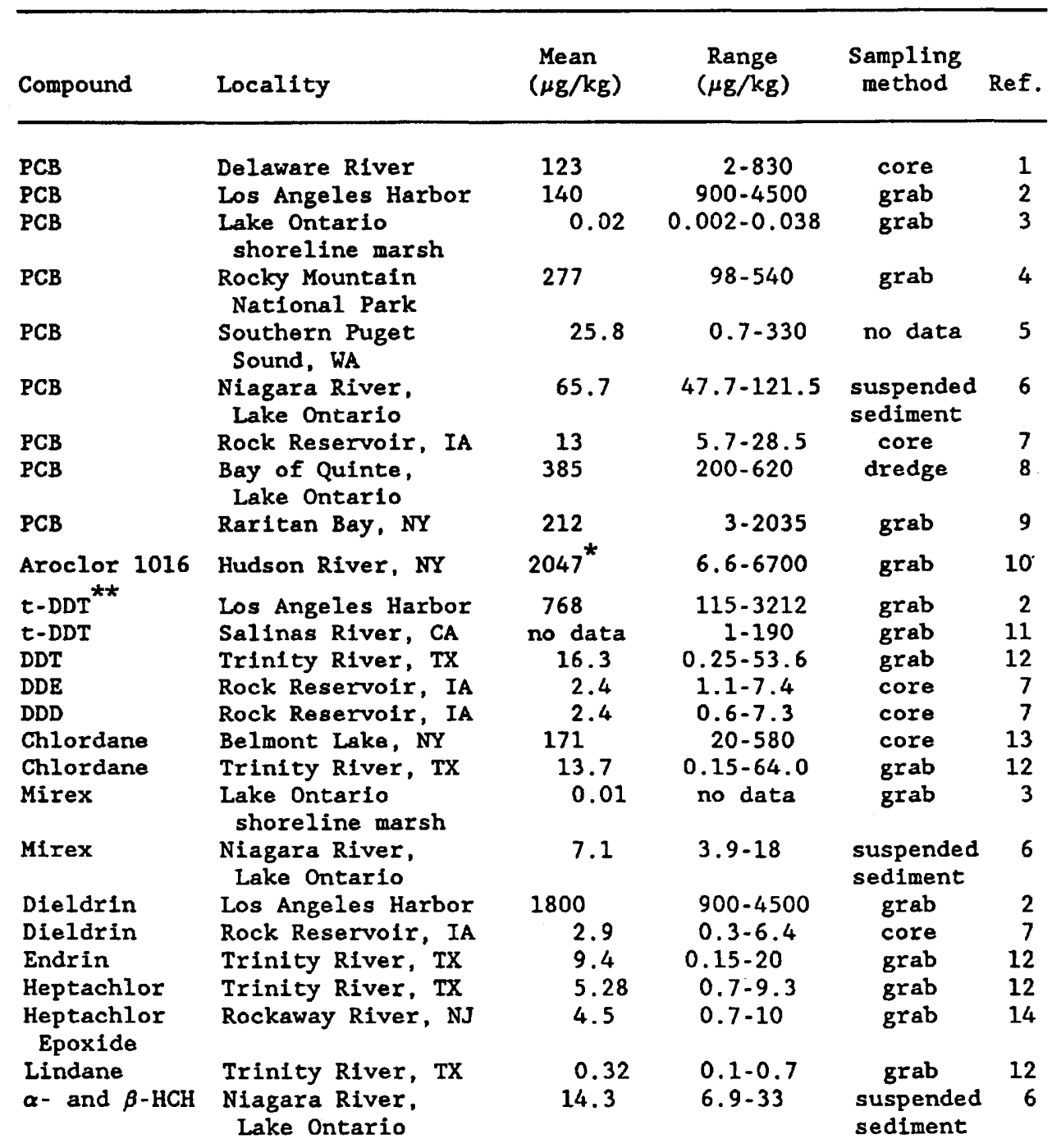

* Concentrations for mean and range in units of milligrams per kilogram

** Denotes total DDT (includes all DDT, DDE, and DDD 1somers)

1. Hochreiter (1982)

8. Scott (1980)

2. Choi and Chen (1976)

9. Stainken and Rollwagen (1979)

3. Glooschenko and others (1981) 10. Nadeau and Davis (1976)

4. Heit and others (1984)

11. Routh (1972)

5. Mowrer and others (1977)

6. Oliver and Charlton (1984)

12. Qasim and others (1980)

13. Wood and others (1986)

7. Ricci and others (1983)

14. Smith and others (1987)

(Brown and others, 1985). The data demonstrate a distinct decline in aqueous and lipid concentrations of PCB's with time.

Organochlorine residues in sediments have also shown a general decline over time. Gilliom (1985) reported the results of the U.S. Geological Survey-U.S. Environmental Protection Agency Pesticide Monitoring Network, which monitored selected pesticides in the water and bottom sediments of more than 150 river sites across the United States. The number of detections of chlorinated insecticides in bed sediment decreased steadily from 1976 through 1978, but increased slightly in 1979 (fig. 13). In the monitoring network, 36 station-chemical combinations exhibited statistically significant trends in pesticide concentration; 29 trends decreased with time. Five of the seven increasing trends occurred in the Black River in Kingstree, S.C., and most of these trends involved either DDD, DDE, DDT, chlordane, or dieldrin. 
Table 10. Detectable residues of polychlorinated biphenyls (PCB's) and organochlorine insecticides in biota

$[\mu \mathrm{g} / \mathrm{kg}$, micrograms per kilogram. Dash indicates no data available]

\begin{tabular}{|c|c|c|c|c|c|}
\hline Compound & Locality & $\begin{array}{l}\text { Aquatic } \\
\text { organism }\end{array}$ & $\begin{array}{l}\text { Mean } \\
(\mu \mathrm{g} / \mathrm{kg})\end{array}$ & $\begin{array}{l}\text { Maximum } \\
(\mu \mathrm{g} / \mathrm{kg})\end{array}$ & Reference \\
\hline PCB & $\begin{array}{l}\text { Schuylkill River } \\
\text { Reading, PA }\end{array}$ & American eel & 3,700 & 8,100 & 1 \\
\hline PCB & $\begin{array}{l}\text { Milwaukee River, } \\
\text { WI }\end{array}$ & $\begin{array}{l}\text { Red horse } \\
\text { sucker }\end{array}$ & 6,630 & $\cdot$ & 2 \\
\hline PCB & $\begin{array}{l}\text { New Bedford } \\
\text { Harbor }\end{array}$ & Musse1 & - & 17,000 & 3 \\
\hline PCB & Huds on River & $\begin{array}{l}\text { Atlantic } \\
\text { tomcod liver }\end{array}$ & 37,500 & 98,200 & 4 \\
\hline PCB & New York Harbor & Lobster & 230 & 410 & 5 \\
\hline PCB & Utah Lake & Carp & 115 & - & 6 \\
\hline PCB & $\begin{array}{l}\text { Long Island } \\
\text { Sound }\end{array}$ & $\begin{array}{l}\text { Windowpane } \\
\text { flounder liver }\end{array}$ & 1,500 & 2,300 & 7 \\
\hline$t-D D T^{*}$ & Atlantic Ocean & Deep sea fish & 7,100 & 27,000 & 8 \\
\hline$t-D D T$ & $\begin{array}{l}\text { Milwaukee River, } \\
\text { WI }\end{array}$ & $\begin{array}{l}\text { Red horse } \\
\text { sucker }\end{array}$ & 150 & - & 2 \\
\hline t-DDT & Lake Superior & Lake trout & 3,250 & 9.780 & 9 \\
\hline$P, P^{\prime}-D D E$ & $\begin{array}{l}\text { New England } \\
\text { lakes }\end{array}$ & Brook trout & 18 & 34 & 10 \\
\hline Dieldrin & Atlantic Ocean & Deep sea fish & 20 & 30 & 8 \\
\hline Dieldrin & $\begin{array}{l}\text { New England } \\
\text { lakes }\end{array}$ & Brook trout & 4 & 7 & 10 \\
\hline$\alpha-\mathrm{HCH}$ & $\begin{array}{l}\text { New England } \\
\text { lakes }\end{array}$ & Brook trout & 11 & 19 & 10 \\
\hline$\beta-\mathrm{HCH}$ & $\begin{array}{l}\text { Milwaukee River, } \\
\text { WI }\end{array}$ & $\begin{array}{l}\text { Red horse } \\
\text { sucker }\end{array}$ & 60 & - & 2 \\
\hline Lindane & Lake Superior & Lake trout & 190 & - & 9 \\
\hline Heptachlor & Lake Superior & Lake trout & 1,630 & 2,770 & 9 \\
\hline $\begin{array}{l}\text { Heptachlor } \\
\text { epoxide }\end{array}$ & $\begin{array}{l}\text { Milwaukee River, } \\
\text { WI }\end{array}$ & $\begin{array}{l}\text { Red horse } \\
\text { sucker }\end{array}$ & 20 & - & 2 \\
\hline Chlordane & $\begin{array}{l}\text { Schuylkill River, } \\
\text { Reading, PA }\end{array}$ & American eel & 180 & 270 & 1 \\
\hline Endrin & $\begin{array}{l}\text { Schuylkill River, } \\
\text { Reading, PA }\end{array}$ & American eel & 9 & 19 & 1 \\
\hline Aldrin & Lake Superior & Lake trout & 120 & 220 & 9 \\
\hline Endosulfan & $\begin{array}{l}\text { Milwaukee River, } \\
\text { WI }\end{array}$ & $\begin{array}{l}\text { Red horse } \\
\text { sucker }\end{array}$ & 20 & - & 2 \\
\hline Toxaphene & Louisiana lakes & Spotted gar & 410 & 800 & 11 \\
\hline \multicolumn{6}{|c|}{$\begin{array}{l}\text { * Denotes total DDT (includes al } \\
\text { 1. Barker (1984) } \\
\text { 2. DeVault (1985) } \\
\text { 3. Farrington and others (1983) } \\
\text { 4. Klauda and others (1981) } \\
\text { 5. Roberts and others (1982) } \\
\text { 6. Smith and others (1974) }\end{array}$} \\
\hline
\end{tabular}

PCB contamination trends in sediment generally have been constant or have slowly declined over the last 10 yr. Ricci and others (1983) collected sediment cores from an Iowa reservoir and determined that PCB residues were greatest in the deepest sections of the core, indicating that the more recently deposited sediments were less contaminated with PCB's. They observed similar trends for DDE and DDD. Van Luik (1984), on the other hand, found no correlation between PCB concentration and core depth for sediment cores collected from the Calumet Sag Channel (Ill.). Sediment PCB concentrations in the
Hudson River have gradually decreased since the mid1970 's, but much of this decrease can be attributed to substantial dredging operations that have removed an estimated $500,000 \mathrm{~m}^{3}$ of sediment over a $25-\mathrm{yr}$ period (Brown and others, 1985). Also, some of the Hudson River's contaminated sediment has been transported into Raritan Bay and is believed to be accumulating (Stainken and Rollwagen, 1979). Sullivan and others (1983), although observing a decline in PCB concentrations in fish from the Fox River, Wis., observed no significant decline in the sediment PCB concentrations in the river 


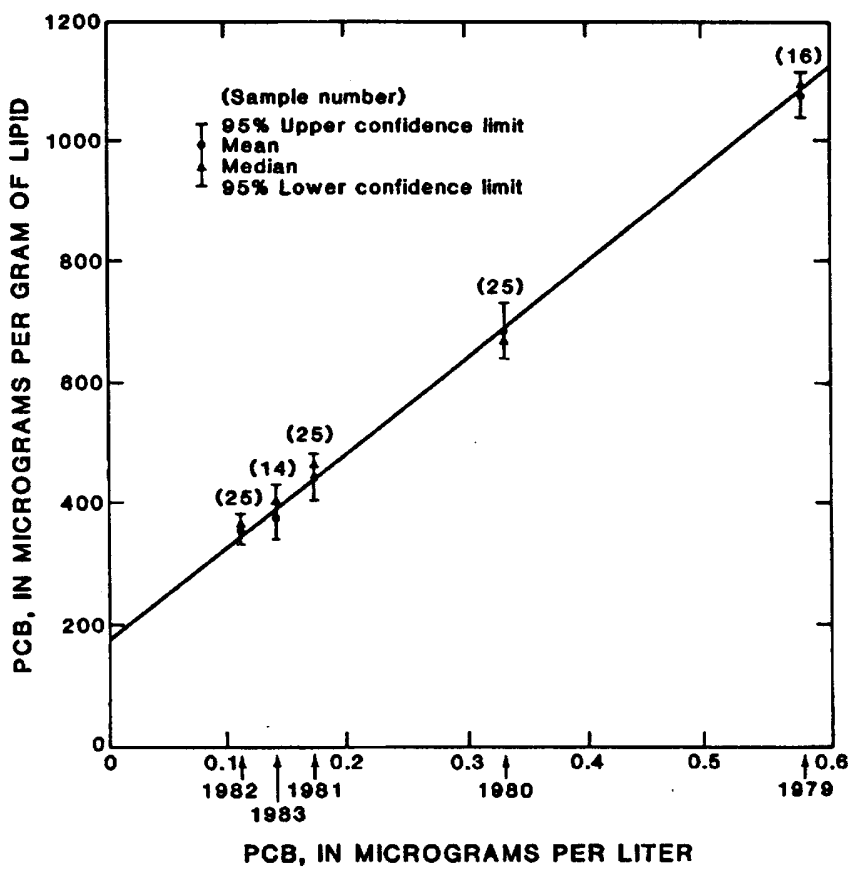

Figure 12. Relation of summer mean polychlorinated biphenyl (PCB) concentrations in water and lipid-based PCB concentrations in fillets of whole yearling pumpkinseed collected in September 1977-83 at Stillwater, N.Y.

[Reprinted with permission from Environmental Science and Technology, v. 19, p. 659 (1985). Copyright 1985 by the American Chemical Society.]

from 1976 to 1981 . These studies indicate the extreme persistence of PCBs and also may indicate that, despite the cessation of their production, PCB residues in capacitors and transformers throughout the United States may still be contaminating surface waters.

Regionally, the highest PCB concentrations typically are found near industrial areas. Martel and others (1975), in a study of a northern Virginia watershed, observed that the highest sediment PCB concentrations in the watershed were near the most industrialized areas. Similarly, Mowrer and others (1977) found the highest PCB residues in sediments and mussels of Puget Sound, Wash., in industrialized and heavily populated areas and the lowest concentrations in sparsley populated areas surrounding the bay. Farrington and others (1983) analyzed mussels from 62 locations in the eastern and western coastal waters of the United States from 1976 to 1978. In all $3 \mathrm{yr}$ of the study, mussels from water near urbanized areas had PCB concentrations at least an order of magnitude greater than mussels from water near rural areas. Nationally, PCB concentrations were generally highest along the northeastern coast from Chesapeake Bay to Cape Ann, Maine.

Residues of chlorinated insecticides are not necessarily highest in industrialized regions. Gilliom (1985) described pesticide use as being "strongly regional, with

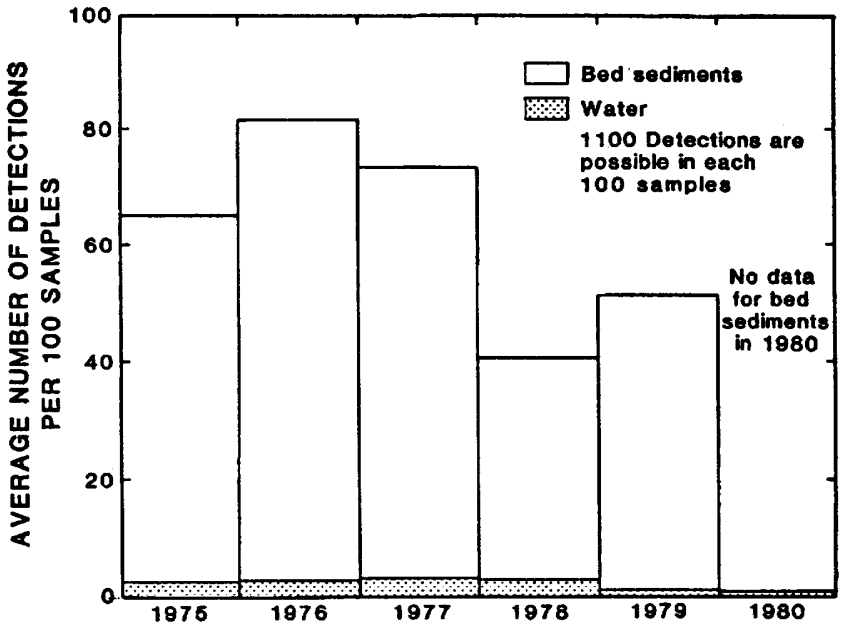

Figure 13. Frequency of detection of organochlorine insecticides in water and bed-material samples from stations in the U.S. Geological Survey-U.S. Environmental Protection Agency Pesticide Monitoring Network, 1975-80. (Reprinted from Gilliom, 1985.)

most use of each chemical occurring in only one or two regions of the country." Because compounds such as DDT and toxaphene are applied primarily in cottongrowing areas, their residues are likely to be highest in these areas. Compounds such as aldrin and chlordane are applied principally to corn and, therefore, are expected to be found in corn-producing areas. However, residues in industrial areas also can be high, as evidenced by the data of Qasim and others (1980). They determined that aqueous pesticide concentrations in the Trinity River, Tex., were highest in the central reach of the river, which drained cropland, pasture, and forest. However, sediment pesticide concentrations were highest in the upper reaches of the river, which drains the metropolitan areas of Dallas and Fort Worth. The authors attribute the latter contamination to numerous point-source discharges of wastewater-treatment plants. When surface-water contamination can be attributed to runoff from cropland, the highest concentrations are likely to be observed after a heavy rain (Pfaender and others, 1977).

PCB's and chlorinated insecticides have severely affected our environment, and, despite their drastically declining use over the last 10 to $20 \mathrm{yr}$, their residues are likely to persist in the sediment, water, and biota of the Nation's surface-water systems for many years to come. At present, these compounds are being replaced by less persistent organic compounds. New insecticides, such as the carbamate and organophosphorus insecticides discussed in the next section, have found increasing use. PCB's have similarly been replaced by such compounds as phenylxylylethanes, di-isopropylnaphthalenes, and isopropylbiphenyls (Addison and others, 1983). 
CARBAMATE AND

ORGANOPHOSPHORUS INSECTICIDES

\section{Uses, Production, Properties, and Regulatory Limits}

In response to the environmental concern over the persistence of the chlorinated insecticides, the carbamate and organophosphorus insecticides have seen increasing use over the last $20 \mathrm{yr}$ because of their relatively short half-lives in the environment. In addition, they have been increasingly recommended for the control of pests that are not specifically controlled by the organochlorine insecticides. Figure 14 presents the structural diagrams of some of the more common carbamate and organophosphorus insecticides. The octanol-water partition coefficients, solubilities, and vapor pressures of some of these compounds are given in table 11 .

Table 12 presents usage data for some of the organophosphorus insecticides (Gilliom, 1985). Of the group, malathion and parathion have probably seen the most widespread use. The use of parathion, although it is relatively nonpersistent in the environment, has decreased considerably in recent years because of its high toxicity to mammals. The compound inhibits the activation of the acetylcholinesterase enzyme in the nervous systems of animals (Baum, 1982), and its use has resulted in numerous deaths of humans involved in its manufacture and application. Decline in the use of parathion is evidenced by its production decrease from 50.6 million $\mathrm{lb}$ in 1969 to 15 million $\mathrm{lb}$ in 1971 (Mulla and others, 1981). In contrast, malathion is the least toxic of the organo-
CARBAMATE INSECTICIDES

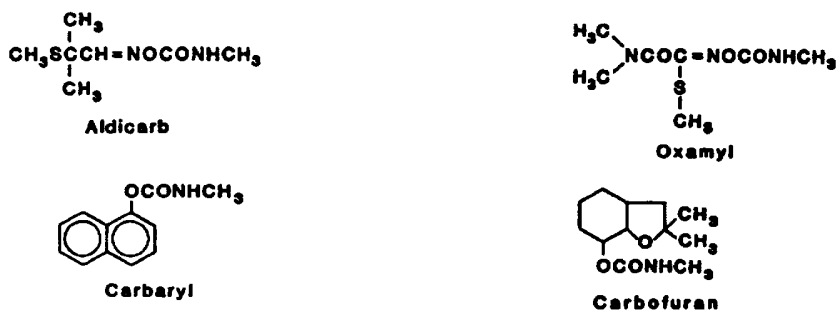

ORGANOPHOSPHORUS INSECTICIDES

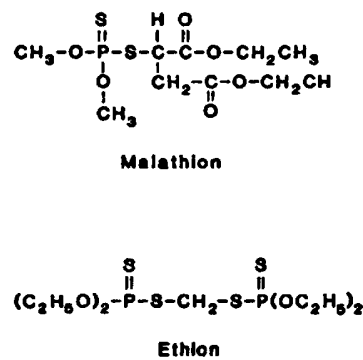<smiles>CCOP(=O)(OCC)Oc1ccc([N+](=O)[O-])cc1</smiles><smiles></smiles>

Fenitrothion<smiles>CCOP(=S)(OCC)Oc1nc(C)nc(C(C)C)n1</smiles>

Figure 14. Structural diagrams of selected carbamate and organophosphorus insecticides.

phosphorus insecticides and has been used to protect livestock, to control fleas in kennels, and to control other household and garden pests (Baum, 1982). Its low toxic-

Table 11. Experimentally determined octanol-water partition coefficients $\left(\mathrm{K}_{\mathrm{ow}}\right)$, solubilities, and vapor pressures of selected organophosphorus and carbamate insecticides at room temperature

[mg/L, milligrams per liter; $\mathrm{mm}$, millimeter. Numbers in parentheses indicate references; dashes indicate no data available]

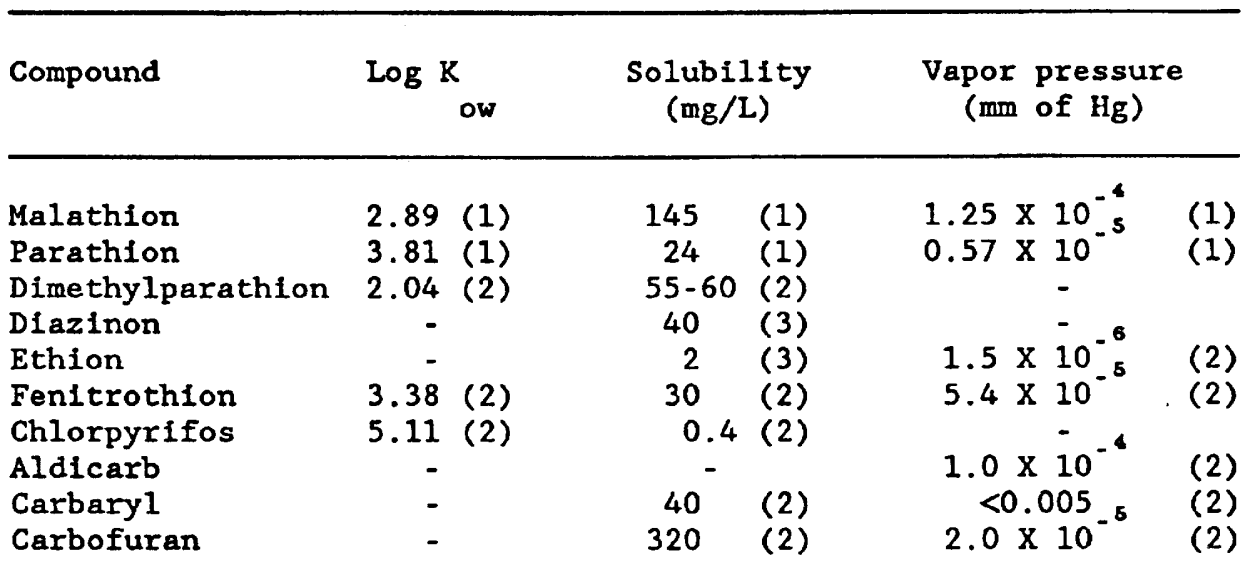

1. Mulla and others (1981)

2. Verschueren (1983)

3. Gilliom (1985) 
Table 12. Detection limits, water-quality criteria, and use data for selected organophosphorus insecticides $[\mu \mathrm{g} / \mathrm{L}$, micrograms per liter, lb/yr, pounds per year. From Gilliom, 1985]

\begin{tabular}{|c|c|c|c|c|c|c|c|c|c|}
\hline \multirow[b]{2}{*}{ Chemical } & \multirow{2}{*}{$\begin{array}{l}\text { Detection } \\
\text { timit }^{\text {imion }} \\
(\mu g / L)^{1}\end{array}$} & \multicolumn{2}{|c|}{$\begin{array}{l}\text { Water-quality } \\
\text { criteria } \\
(\mu g / L)\end{array}$} & \multirow{2}{*}{$\begin{array}{l}\text { Principel } \\
\text { uses and } \\
\text { sources }\end{array}$} & \multicolumn{4}{|c|}{$\begin{array}{c}\text { National use on farms } \\
\text { (million (b/yr) }\end{array}$} & \multirow{2}{*}{$\begin{array}{r}\text { Total use } \\
1981 \\
-(m i l l i o n \\
\text { (b/yr) }\end{array}$} \\
\hline & & heal th ${ }^{2}$ & life & & 1966 & 1971 & 1976 & 1982 & \\
\hline Diazinon & 0.10 & nd & nd & $\begin{array}{l}\text { Corn, general } \\
\text { purpose }\end{array}$ & 5.6 & 3.2 & 1.6 & 0.3 & 9.0 \\
\hline Ethion & 0.25 & nd & nd & Citrus fruits & 2.0 & 2.3 & $\mathrm{nr}$ & $\mathrm{nr}$ & 2.0 \\
\hline Malathion & 0.25 & nd & 0.1 & General purpose & 5.2 & 3.6 & 2.8 & 1.6 & 28 \\
\hline $\begin{array}{l}\text { Dimethyl } \\
\text { parathion }\end{array}$ & 0.25 & nd & nd & cotton, wheat & 8.0 & 28. & 23. & 11. & 20 \\
\hline $\begin{array}{l}\text { Methyl } \\
\text { trithion }\end{array}$ & 0.50 & nd & nd & Not identified & $n r$ & $n r$ & $\mathrm{nr}$ & $\mathrm{nr}$ & 0.1 \\
\hline Parathion & 0.25 & nd & 0.04 & Wheat, corn, sorghum & 8.5 & 9.5 & 6.6 & 4.0 & 5.0 \\
\hline Trithion & 0.50 & nd & nd & General purpose & $\mathrm{nr}$ & $\mathrm{nr}$ & $\mathrm{nr}$ & $\mathrm{nr}$ & 0.1 \\
\hline
\end{tabular}

nr $=$ none reported; nd $=$ no data available

1. Detection limits are for water samples. Bed-sediment detection limits are 10 times greater and in units of micrograms per kilogram (Lucas and others, 1980).

2. U.S. Envirommental Protection Agency (1977).

3. Dat: for 1966, Eichers and others (1970); for 1971, Andrilenas (1974); for 1976, Eichers and others (1978); for 1982, U.S. Department of Agriculture (1983). Data for 1982 do not include use on livestock.

ity to animals is attributed to carboxyesterases that degrade malathion to nontoxic metabolites in birds, mammals, and resistant insects (Mulla and others, 1981). The production of malathion in the United States reached a high in 1971 of 30 million lb (Mulla and others, 1981).

Table 13 presents some usage data for the carbamate insecticides. Carbaryl, first synthesized in 1953 and introduced in 1958, is the most widely used of the carbamate insecticides and has been shown to control more than 150 major pests (Rajagopal and others, 1984).

\section{Environmental Fate}

As is evidenced from the half-lives in table 14, the carbamate and organophosphorus insecticides are among the least environmentally persistent pesticides. This is primarily attributable to their relatively rapid chemical and biological degradation in both soil and surface-water systems.

Several researchers have documented the chemical and biological attenuation of the organophosphorus insecticides. Walker (1976) determined that 97 percent of malathion added to sterile and nonsterile river water was degraded after $18 \mathrm{~d}$ incubation in the dark. Parathion was more persistent, with only a 16- to 23-percent loss after $40 \mathrm{~d}$. Microorganisms capable of degrading both compounds were isolated. Sudhakar-Barik and Sethunathan (1978) noted the biological hydrolysis of parathion in soils, water, and sediments and the formation of a degradation product, p-nitrophenol, within $6 \mathrm{~h}$ after the second or third additions of the insecticide. Sharom and others (1980b) found that 40 percent of the ethion and leptophos and essentially 100 percent of the diazinon and mevinphos added to natural water samples was degraded within 16 weeks. In a study of malathion degradation in soil, Gibson and Burns (1977) observed malathion half-lives of about $1 \mathrm{~d}$. When the soil's organic matter was removed, however, degradation was three to six times slower. The authors hypothesized that the organic matter has a catalytic effect (by acting as a stable enzyme) on the degradation of malathion. Wolfe and others (1977) modeled the chemical degradation of malathion as a function of $\mathrm{pH}$ and temperature. Acid degradation was slow (malathion half-life of 4 yr at $\mathrm{pH}=4$ ), but alkaline degradation was fast enough to be a competitive degradation pathway in the environment (malathion half-life of $22 \mathrm{~h}$ at $\mathrm{pH}=8.2$ ). Weinberger and others (1982) documented both hydrolytic and photolytic decomposition of fenitrothion in aquatic microcosms. Eidt and others (1984) applied fenitrothion formulations to two Canadian streams and observed that the compound's aqueous concentration was rapidly attenuated in both streams. These studies indicate that the organophosphorus insecticides are generally susceptible to rapid chemical and microbial degradation in natural systems.

Numerous studies also have documented the chemical and biological degradation of the carbamate insecticides. Carbaryl is rapidly hydrolyzed at alkaline $\mathrm{pH}$ (Wolfe and others, 1978), and it has been biologically degraded to 1-naphthol in the laboratory (Rajagopal and others, 1984). Aldicarb has similarly been observed to have hydrolytic half-lives of 55 and $6 \mathrm{~d}$ at $\mathrm{pH}$ values of 
Table 13. Characteristics of selected carbamate insecticides

\begin{tabular}{|c|c|c|c|}
\hline Compound & Type & Uses & Trade name (s) \\
\hline Aldicarb & Oxime carbamate & $\begin{array}{l}\text { Insects, mice, } \\
\text { nematodes }\end{array}$ & Temik \\
\hline Oxamyl & Oxime carbamate & Insects, nematodes & Vydate \\
\hline $\begin{array}{l}\text { Arprocarb } \\
\text { (propoxur) }\end{array}$ & $\mathrm{N}$-methylcarbamate & Insects & $\begin{array}{l}\text { Baygon, Unden, } \\
\text { Sendran, Suncide, } \\
\text { Blatanex }\end{array}$ \\
\hline Carbaryl & N-methylcarbamate & Insects & Sevin \\
\hline Carbofuran & $\mathrm{N}$-methylcarbamate & Soil insects & Furadan \\
\hline
\end{tabular}

Table 14. Approximate persistence of pesticides in soils [From Metcalf, 1972]

\begin{tabular}{lc}
\hline Pesticide & $\begin{array}{c}\text { Approxinate half-life, } \\
\text { years }\end{array}$ \\
\hline Lead, arsenic, copper, mercury & $10-30$ \\
Chlorinated Insecticides & $2-4$ \\
Triazine herbicides & $1-2$ \\
Benzoic acid herbicides & $0.2-1$ \\
Urea herbicides & $0.3-0.8$ \\
Chlorinated herbicides & $0.1-0.4$ \\
Organophosphorus insecticides & $0.02-0.2$ \\
Carbamate insecticides & $0.02-0.1$ \\
\hline
\end{tabular}

8.85 and 9.95, respectively (Given and Dierberg, 1985). Sharom and others (1980b) determined that essentially 100 percent of the carbofuran added to sterile and nonsterile natural water was degraded after 16 weeks incubation. Carbaryl was degraded even more rapidly, with almost 100 percent removal after only 4 weeks. Comparison of the sterile-water and nonsterile-water degradation data revealed that, for both compounds, chemical degradation appeared to be of primary importance to the attenuation, with biological processes playing only a secondary role. Figure 15 compares the ${ }^{14} \mathrm{CO}_{2}$ evolved from three ring-labeled ${ }^{14} \mathrm{C}$-insecticides (parathion, carbaryl, and carbofuran) applied to flooded and nonflooded soils (Rajagopal and others, 1984). These data in combination with the results of Sharom and others (1980b) indicate that while the initial chemical or biological transformation step of carbaryl or carbofuran may be rapid, ring cleavage of the molecules may be slow (less than 3 percent of

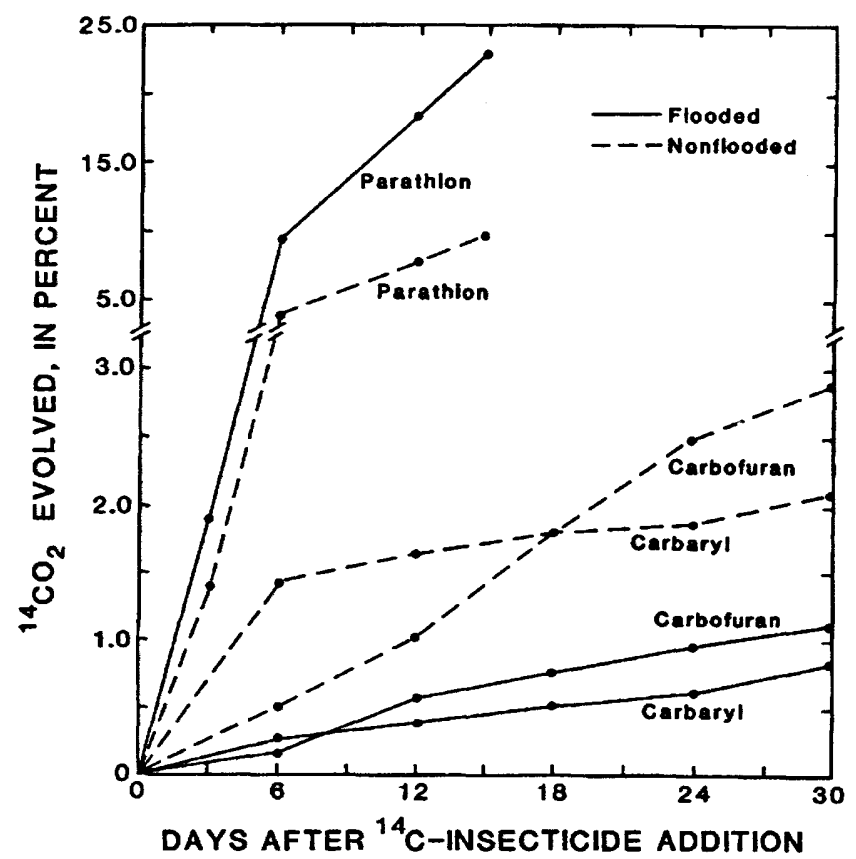

Figure 15. Cumulative ${ }^{14} \mathrm{CO}_{2}$ (percentage of added ringlabeled ${ }^{14} \mathrm{C}$-insecticide) evolved in a soil planted to rice under flooded and nonflooded conditions. [Reprinted with permission from Residue Reviews, v. 93, p. 113 (1984). Copyright 1984 by Springer-Verlag New York, Inc.]

ring-labeled ${ }^{14} \mathrm{C}$ evolved as ${ }^{14} \mathrm{CO}_{2}$ for either carbaryl or carbofuran after $30 \mathrm{~d}$ ).

Sorption to sediments and bioaccumulation generally are not significant fate processes for most of the carbamate and organophosphorus insecticides because of their relatively high solubilities and low octanol-water partition coefficients. However, sediments having high organic-matter contents or aquatic organisms having high lipid contents may accumulate significant residues if 
aqueous concentrations are high. Aquatic plants exposed to $10 \mathrm{ppm}$ fenitrothion for $5 \mathrm{~d}$ accumulated between 216 and $286 \mathrm{ppm}$ of the contaminant on a dry-weight basis (Weinberger and others, 1982). These residues decreased rapidly, however, as the fenitrothion was chemically and biologically degraded in the water column. Sharom and others (1980a) observed the sorption of a variety of organophosphorus and carbamate insecticides to soils and sediments and noted that increased sorption correlated with both decreased solubility and increased soil or sediment organic matter. The order of sorption to soil was leptophos $>$ ethion $>$ chlorpyrifos $>$ parathion $>$ diazinon $>$ carbaryl $>$ carbofuran $>$ mevinphos. Sorption coefficients $\left(\mathrm{K}_{\mathrm{d}}\right)$ for the sediment (2.8 percent organic carbon) ranged from 158 (ethion) to less than unity (mevinphos). Belluck and Felsot (1981) measured BCF's between 1 and 10 for carbofuran and malathion partitioned between water and caddisfly egg masses, indicating that bioaccumulation was minimal.

Bioaccumulation and sorption of the carbamate and organophosphorus insecticides, therefore, will vary with such factors as compound solubility and aqueous concentration, sediment and dissolved organic matter concentration, and lipid contents of the aquatic organisms. Because the partitioning of these solutes into sediment organic matter and biological lipid reservoirs are reversible processes, biological and sediment residues are likely to be short-lived as a result of the rapid chemical and biological attenuation of these compounds in surface-water systems.

\section{Environmental Distribution}

Despite extensive use of carbamate and organophosphorus insecticides in the United States, they are not detected frequently in surface waters. Additionally, because they have relatively high solubilities (and therefore a low tendency to partition into organic matter and biological lipid reservoirs), their residues are even less frequently detected in sediment and biota.

The U.S. Geological Survey-U.S. Environmental Protection Agency Pesticide Monitoring Network monitored the occurrence of several of the organophosphorus insecticides at 161 surface-water stations throughout the United States from 1975 to 1980 (Gilliom and others, 1985). Compared with chlorinated insecticide residues, which also were monitored, organophosphorus insecticides were only occasionally detected in water samples. Methyl parathion, the organophosphorus insecticide used most heavily on farms, was detected in only 3 of almost 3,000 water samples. The low number of detections of organophosphorus insecticides was attributed to their relatively low persistence and high aqueous detection limits (table 12). Diazinon was detected most frequently (34 detections in 2,861 water samples), and this was likely related to the fact that, of the organophosphorus insecti- cides included in the analysis, diazinon is the most persistent and has the lowest detection limit. For all the organophosphorus insecticides monitored, the number of sediment detections was less than the number of aqueous detections, which agrees with laboratory data demonstrating that the organophosphorus insecticides do not strongly partition into sediment organic matter. Because of the small number of detections of organophosphorus insecticides by the Pesticide Monitoring Network, no regional trends were observed for either water or sediment samples.

No studies documenting regional or temporal trends of carbamate-insecticide contamination in the United States were found in the reviewed literature. However, because the behavior and persistence of the carbamate and organophosphorus insecticides are similar, it is expected that contamination of surface waters of the United States by these compounds will not be widespread, and that any existing residues will rarely persist for more than several weeks. Carbamate and organophosphorus insecticide residues are expected to be highest in shallow ground water beneath agricultural areas and in streams draining these areas.

\section{HERBICIDES}

\section{Uses, Production, Properties, and Regulatory Limits}

In contrast to the declining use of insecticides in recent years, herbicide use on major crops in the United States has been steadily increasing, as is evidenced by the data in figure 16 (Gilliom and others, 1985). Herbicides also are applied extensively to surface waters to control aquatic vegetation that may impede water flow, navigation, and recreation. The majority of herbicide use in the United States can be attributed to atrazine and 2,4-D. From 1971 to 1976 , they accounted for 50 percent of all herbicide use (Gilliom, 1985). Since 1976, however, their share of total herbicide application has decreased slightly. Atrazine use, for example, declined from 41 percent of the total amount of herbicide applied to corn in 1976 to 33 percent by 1980 (Gilliom, 1985).

Detection limits, water-quality criteria, and U.S. farm usage data for some of the most common herbicides are presented in table 15 (Gilliom, 1985). Table 16 lists the quantities of herbicides applied in 11 agricultural watersheds in Ontario during 1975 (Frank and others, 1982). Both tables indicate that atrazine and 2,4-D are the most heavily applied herbicides in those areas.

The herbicides are characterized by high aqueous solubilities and low vapor pressures (table 17). As a result, they generally do not bioconcentrate, sorb to sediments, or volatilize from solution to an appreciable 


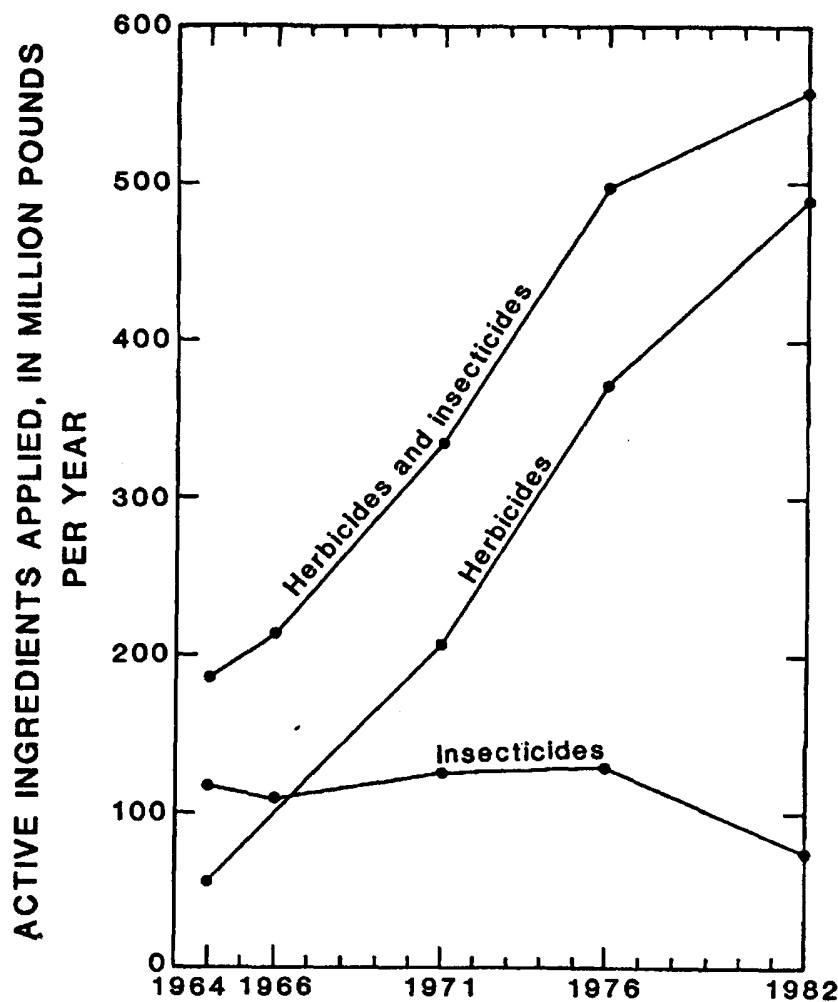

Figure 16. Trends in national use of herbicides and insecticides on major crops, 1964-82. [Reprinted from Gilliom and others, 1985).]

extent. Figure 17 presents the structural diagrams of some of the more common terrestrial and aquatic herbicides. Based on their structural characteristics, the herbicides are broken down into four groups. The organochlorine herbicides have phenoxy, acetic, or benzoic acid functional groups attached to an aromatic ring. The other three groups are the nitrogen-substituted, urea-substituted, and dinitroaniline herbicides. Table 18 lists the four groups<smiles>O=C(O)COc1ccc(Cl)cc1Cl</smiles><smiles>O=C(O)COc1cc(Cl)c(Cl)cc1Cl</smiles>

$2,4,6-T$

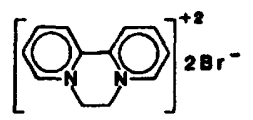

Dlquat<smiles></smiles><smiles>CN(C)C(=O)Nc1ccc(Cl)c(Cl)c1</smiles><smiles></smiles>

Atrazine

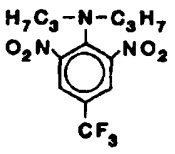

Trifluralln

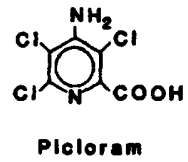<smiles>CC(Oc1cc(Cl)c(Cl)cc1Cl)C(=O)O</smiles>

Figure 17. Structural diagrams of selected herbicides.

along with some of their associated herbicides. Paraquat and diquat, commonly referred to as the bipyridylium herbicides, are highly potent salts that exist in solution as divalent organic cations with associated chloride or bromide.

\section{Environmental Fate}

The herbicides are, in general, nonpersistent environmental contaminants. Their high solubilities greatly

Table 15. Detection limits, water-quality criteria, and use data for some common herbicides [ $\mu \mathrm{g} / \mathrm{L}$, micrograms per liter; lb/yr, pounds per year. From Gilliom, 1985]

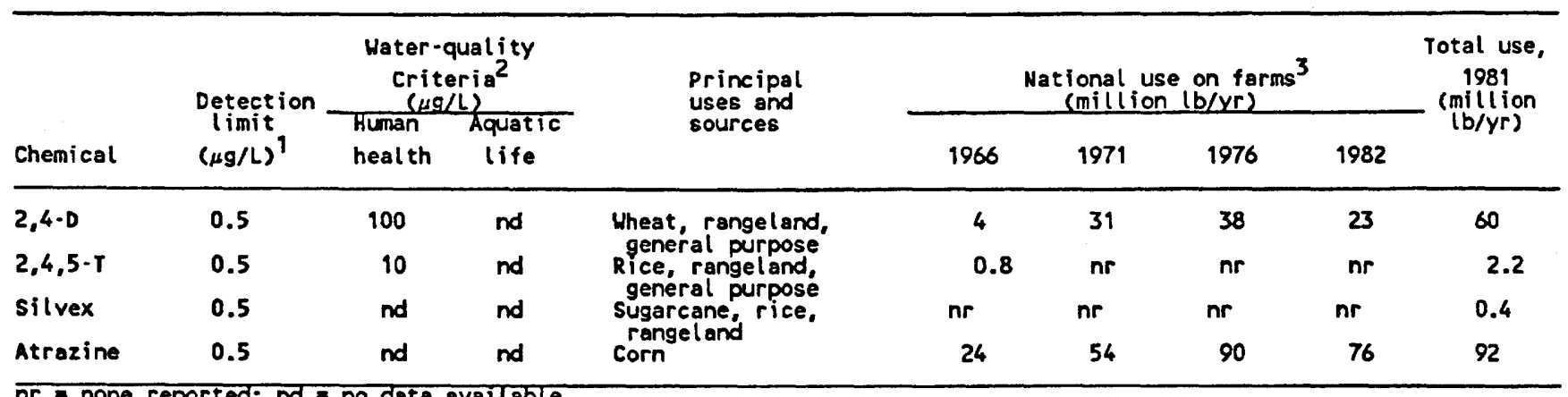

1. Detection limits ore for water samples. Bed-sediment detection limits are 10 times greater and in units of micrograms

2. Per ki logram (Lucos and others, 1980 ) (1977).

3. Data for 1966, Eichers and others (1970); for 1971, Andrilenas (1974); for 1976, Eichers and others (1978); for 1982, U.S. Department of Agricul ture (1983). 
Table 16. List of and magnitude of application of herbicides in 11 agricultural watersheds in Ontario, 1975

[kg, kilograms. From Frank and others, 1982]

\begin{tabular}{|c|c|c|c|c|}
\hline \multicolumn{5}{|c|}{ Amounts applied } \\
\hline $1.10 \mathrm{~kg}$ & $11-100 \mathrm{~kg}$ & $101-1000 \mathrm{~kg}$ & $1001-10,000 \mathrm{~kg}$ & $>10,000 \mathrm{~kg}$ \\
\hline $\begin{array}{l}\text { Bromacil } \\
\text { Monuron } \\
\text { Nitrofen } \\
\text { Picloram }\end{array}$ & $\begin{array}{l}\text { Amitrole } \\
\text { Cyprazine } \\
\text { DCPA } \\
\text { Diallate } \\
\text { Dicamba } \\
\text { Dinitramine } \\
\text { Dinoseb } \\
\text { Mecoprop } \\
\text { Monolinuron } \\
\text { Naptalam } \\
\text { Pebulate } \\
\text { Prometon } \\
\text { Terbacil }\end{array}$ & $\begin{array}{l}\text { Bentazon } \\
2,4-D B \\
\text { Diphenamid } \\
\text { EPTC } \\
\text { IInuron } \\
\text { MCPA } \\
\text { Metribuzin } \\
\text { Paraquat } \\
2,4,5-T \\
\text { Trifluralin }\end{array}$ & $\begin{array}{l}\text { Alachlor }(2755)^{1} \\
\text { Butylate }(1708) \\
\text { Chloramben (1979) } \\
\text { Cyanazine (2468) } \\
\text { 2,4-D (3098) } \\
\text { Metobromuron (1012) } \\
\text { Simazine (1389) }\end{array}$ & $\begin{array}{c}\text { Atrazine } \\
(10,570)\end{array}$ \\
\hline
\end{tabular}

Table 17. Experimentally determined aqueous solubilities and vapor pressures of selected herbicides at room temperature

[mg/L, milligrams per liter, $\mathrm{mm}$, millimeter. Dash indicates no data available]

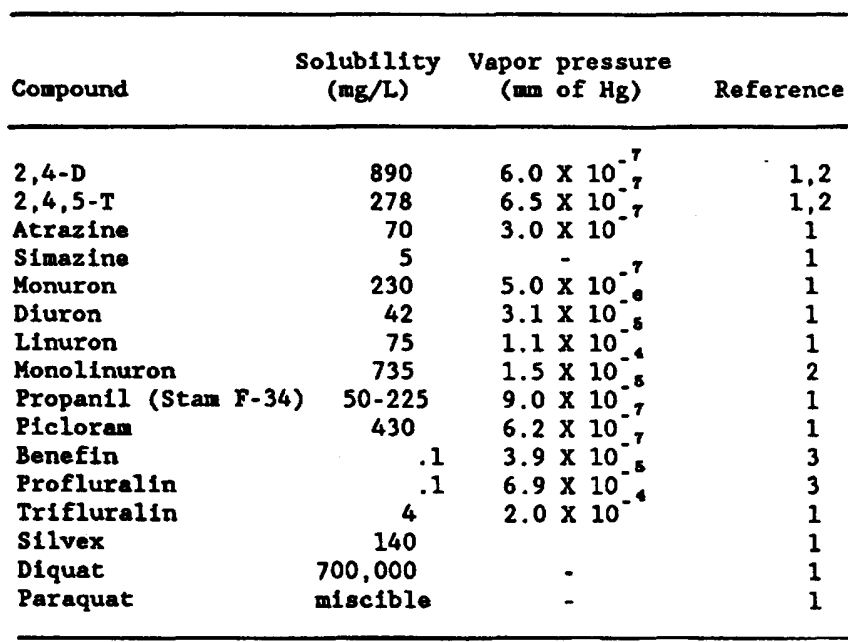

1. Verschueren (1983)

2. Bailey and others (1968)

3. Helling (1976)

reduce solute partitioning into sediment organic matter or biological lipid reservoirs. Although their low vapor pressures and high solubilities combine to make volatilization an insignificant fate process, many of the herbicides are rapidly biodegraded by microbial populations or are chemically attenuated by photolytic or hydrolytic reactions.

Documented sediment-water sorption coefficients $\left(K_{d}\right)$ for the herbicides are small relative to such compounds as the organochlorine insecticides, indicating that
Table 18. Structural groupings of selected herbicides

\begin{tabular}{ll}
$\begin{array}{l}\text { Organochlorine (phenoxy, } \\
\text { acetic, and benzoic acid) }\end{array}$ & $\begin{array}{l}\text { Dinitroaniline } \\
\text { herbicides }\end{array}$ \\
\cline { 2 - 2 } Amiben & Benefin \\
2,4-D & Butralin \\
Dalapon & Dinitramine \\
Dicamba & Ethalfluralin \\
DNBP & Fluchloralin \\
Fenac & Isopropalin \\
MCPA & Nitralin \\
Methoxy fenac & Oryzalin \\
Picloram & Penoxalin \\
Silvex & Profluralin \\
2,4,5-T & Prosulfalin \\
$2,3,6-$ TBA & Trifluralin \\
TCA &
\end{tabular}

TCA

Tricamba

\section{Organonitrogen (triazines)}

Substituted urea

Atrazine

Alachlor

Ametryn

Atraton

Prometone

Prometryne

Propazine

Secbumeton

Simazine

Simetryn

Terbutryn
Buturon

Cycluron

Diuron

Fenuron

Linuron

Monuron

Neburon

Norea (Herban) 
sorption generally is not an important fate process. Bovey and others (1974) applied a 1:1 mixture of picloram and $2,4,5-\mathrm{T}$ at a rate of $1.12 \mathrm{~kg} / \mathrm{ha}$ to pastureland and then analyzed soil and runoff water for both compounds. Concentrations in runoff water (400 to $800 \mathrm{ppb}$ ) were significantly higher than concentrations in soil (undetectable to $238 \mathrm{ppb}$ ). El-Dib and Aly (1976b) studied the use of bentonite clays to remove the herbicides IPC, CIPC, linuron, and monuron from contaminated surface waters and concluded that the clay minerals would be unable to remove significant amounts of the herbicides from solution. Endothall, an aquatic herbicide, was shown to have a sorption coefficient of 0.958 in a sediment-water system investigated by Reinert and Rodgers (1984). Similarly, Muir and others (1980) determined that distribution coefficients for fluridone sorption to pond and river sediments were relatively low, ranging from 20 to 137 . Wauchope and Myers (1985) observed atrazine and linuron sorption to freshwater sediments to be rapid and reversible. Once again, sorption coefficients were low, ranging from 1.3 to 18 for atrazine and 1.5 to 24 for linuron.

Although the majority of herbicides do not sorb appreciably to sediments, there are some exceptions. The dinitroaniline and bipyridylium herbicides have demonstrated a strong tendency to sorb to sediments. Juo and Oginni (1978) observed that sorption maximums for paraquat sorbed to a variety of tropical soils ranged from 1,200 to $7,500 \mathrm{mg} / \mathrm{kg}$ of soil. Karickhoff and Brown (1978) reported similar paraquat concentrations for the silt- and clay-size fractions of five natural sediments, with the extent of sorption increasing with the sediment fraction's cation exchange capacity. Distribution coefficients were greater than 1,000 for the clay fraction of one of the sediments. Khan (1974c) noted that paraquat and diquat sorb by ion exchange and that their magnitudes of sorption are comparable. LaFleur (1979) noted that sorption of trifluralin to several model soils was extensive and rapid, with practically 100 percent of the applied herbicide being sorbed to the soil within $100 \mathrm{~min}$ of batch mixing. Therefore, the low solubilities of the dinitroaniline herbicides (relative to the other herbicides) and the strongly cationic nature of the bipyridylium herbicides cause them to strongly sorb to natural sediments.

The herbicides are not readily bioaccumulated because of their high solubilities and the ability of biota to metabolize them easily. Muir and others (1980) observed that BCF's for minnows exposed to fluridone in small ponds ranged from less than 1 to 64 . BCF's for duckweed in the ponds were also low, ranging from 19 to 85 . Hoeppel and Westerdahl (1983) noted only minor accumulations of 2,4-D by fish in a Georgia lake treated with the dimethylamine (DMA) and butylethanol (BEE) salts of 2,4-D. All fish collected $13 \mathrm{~d}$ after application of the herbicide contained nondetectable residues of 2,4-D.
However, fish subjected to the 2,4-D BEE treatment initially appeared to accumulate greater amounts of 2,4-D than fish subjected to the treatment with 2,4-D DMA. In a laboratory study documenting the BCF's of a variety of pesticides by caddisfly egg masses, Belluck and Felsot (1981) observed that monuron had the lowest BCF of the group, having a value of approximately unity. Monuron's low BCF was attributed to its high solubility relative to the other pesticides studied. With regard to the herbicides as a group, bioconcentration varies inversely with herbicide solubility, with some of the dinitroaniline herbicides probably exhibiting the greatest ability to bioconcentrate.

The majority of the herbicides are rapidly degraded in surface-water systems and, therefore, are not persistent environmental contaminants. Averitt and Gangstad (1976) observed the dissipation of 2,4-D in static water as a function of water depth, temperature, and time. Using a treatment rate of $4.48 \mathrm{~kg}$ acid equivalent per hectare, they observed a 58-ppb residue decrease for each $0.61 \mathrm{~m}$ increase in water depth, a 115-ppb residue decrease for each $7{ }^{\circ} \mathrm{C}$ increase in temperature, and a 53-ppb concentration decrease for every 7-d interval after treatment. Delaune and Salinas (1985) found that anaerobic conditions retard microbial degradation of 2,4-D and that rapid degradation is most likely to occur in the oxidized surface layer of sediments. Complete degradation of 2,4-D to $\mathrm{CO}_{2}$ has been reported, with interim soil degradation products of 2,4-dichlorophenol and 2,4-dichloroanisole being detected (Smith, 1985). Jones and others (1982) documented half-lives of atrazine in an aqueous estuarine environment to range from 3 to $12 \mathrm{~d}$, with the major metabolite being hydroxyatrazine. In contrast to 2,4-D degradation, oxygen levels had little effect on atrazine degradation. Humic substances have been shown to inhibit base-catalyzed hydrolytic reactions and to accelerate acidcatalyzed hydrolytic reactions (Purdue, 1983). For example, Li and Felbeck (1972) have shown that the hydrolytic half-life of atrazine decreases with decreasing $\mathrm{pH}$ and increasing humic acid concentration. Muir and others (1980) reported fluridone half-lives in pond water ranging from 4 to $7 \mathrm{~d}$. Similarly, Bovey and others (1974) observed that picloram and 2,4,5-T applied to pastureland dissipated rapidly with no evidence of accumulation.

Some herbicides have demonstrated greater persistence than such compounds as atrazine and 2,4-D. Anderson (1985) determined that residues of chlorsulfuron and metsulfuron (two sulfonylurea herbicides applied to winter wheat and barley) were persistent in soils for as long as $500 \mathrm{~d}$. Their ultimate attenuation was attributed to hydrolysis and biodegradation, the rates of which decreased with decreasing temperature. El-Dib and Aly (1976a, 1976c) investigated hydrolysis and biodegradation of some of the phenylamide herbicides. They found that hydrolysis was a significant degradation process only at $\mathrm{pH}$ values 
Table 19. Herbicide residues in North American surface waters [ppb, parts per billion]

\begin{tabular}{|c|c|c|c|c|c|}
\hline Compound & Locality & & $\begin{array}{l}\text { Mean, } \\
\text { ppb }\end{array}$ & $\begin{array}{l}\text { Maximum, } \\
\text { ppb }\end{array}$ & Reference \\
\hline Atrazine & Rhode River, Maryland & & 0.13 & 3.3 & 1 \\
\hline Atrazine & Ontario surface waters & & 5.5 & 32 & 2 \\
\hline Atrazine & Saylorville Reservoir, & Iowa & .22 & .67 & 3 \\
\hline $2,4-D$ & New Iberia, Louistana & & 359 & - & 4 \\
\hline $2,4-D$ & Ontario surface waters & & 5.2 & 320 & 2 \\
\hline $2,4,5-T$ & Runoff; Reisel, Texas & & 26 & 287 & 5 \\
\hline Picloram & Runoff; Reisel, Texas & & 10 & 19 & 5 \\
\hline Diuron & Pearl Harbor, Hawali & & .33 & 1 & 6 \\
\hline Alachlor & Saylorville Reservoir, & Iowa & .08 & .41 & 3 \\
\hline Simazine & Ontarlo surface waters & & .37 & 3.4 & 2 \\
\hline Cyanazine & Saylorville Reservoir, & Iowa & .09 & .32 & 3 \\
\hline $\begin{array}{l}\text { 1. Wu and } \\
\text { 2. Frank a } \\
\text { 3. Leung a }\end{array}$ & $\begin{array}{l}\text { thers }(1980) \\
\text { d others }(1982) \\
\text { d others }(1982)\end{array}$ & $\begin{array}{l}4 . \\
5 . \\
6 .\end{array}$ & $\begin{array}{l}\text { ritt and } \\
\text { ey and o } \\
\text { en and o }\end{array}$ & $\begin{array}{l}\text { stad (197t } \\
(1974) \\
(1977)\end{array}$ & \\
\hline
\end{tabular}

above typical environmental levels. Additionally, the phenylamide herbicides were not significantly biodegraded by mixed microbial cultures taken from Nile River water. Biodegradation did occur, however, when Bacillus cereus was added to the aqueous system. Despite these examples, the herbicides are relatively nonpersistent contaminants of surface-water environments, with aquatic half-lives usually less than $60 \mathrm{~d}$.

\section{Environmental Distribution}

Because the herbicides do not readily partition into sediment organic matter or the lipid reservoirs of aquatic organisms, the highest environmental residues of these compounds are typically found in the aqueous phase of surface-water systems. Bovey and others (1974) observed that picloram and 2,4,5-T residues in runoff from pastureland were primarily in the aqueous phase, with only small amounts sorbed to soil particles. Green and others (1977) noted that diuron residues in Hawaiian estuaries were transported primarily in solution. In a study of an Iowa reservoir, Leung and others (1982) detected residues of only atrazine, alachlor, and cyanazine in the aqueous phase. In samples from more than 150 surfacewater stations across the United States during a 3-yr period, Gilliom and others (1985) reported that all herbicide detections were in water samples, with no detec- tions in bed-sediment samples. Table 19 presents some herbicide residues that have been detected in natural surface waters in the United States.

Herbicides enter surface-water systems in a variety of ways, including application of aquatic herbicides directly to a body of water to control aquatic vegetation. As a result, residues of aquatic herbicides will be greatest immediately following application. Terrestrial herbicides are carried into surface waters by runoff and base flow, and, consequently, surface-water residues are highest if a heavy rain immediately follows application of the herbicide. During the spraying season, residues are commonly the result of misuse of equipment which leads to accidental discharges of the herbicide into surface waters. Frank and others (1982) noted that 82 percent of the pesticides lost to water in 11 agricultural watersheds in Canada during the spraying season could be attributed to careless use of the pesticides near surface waters. On an annual basis, however, spills accounted for only 22 percent of the loss to water, while runoff accounted for 60 percent and base flow for 18 percent of the pesticide loss.

No definitive regional trends in contamination by herbicides in U.S. surface waters have been reported in the literature, but regional herbicide-contamination trends can be expected to parallel use patterns. For example, Gilliom and others (1985) noted that stations in the U.S. Geological Survey-U.S. Environmental Protection Agency 
Pesticide Monitoring Network where atrazine was detected more than once were all located downriver from large corn-producing areas in which atrazine is heavily applied. The low persistence of the herbicides coupled with relatively high analytical detection limits, however, prevented any other determinations of regional trends.

Aside from the fact that the highest herbicide residues in surface-water systems usually occur during spraying seasons, there are few data in the literature indicating temporal contamination trends in U.S. surface waters. Frequency-of-detection data for some of the chlorophenoxy and triazine herbicides monitored in the Pesticide Monitoring Network program were inconclusive with regard to temporal trends (Gilliom, 1985). This is primarily attributable to the relatively short persistence of the herbicides combined with the fact that herbicide data at most stations in the network were collected only during 1976, 1977, and 1978. Atrazine and 2,4-D were the most frequently detected herbicides; this can be explained by the heavy agricultural use of these two compounds. Atrazine also was the most frequently detected herbicide in the water of 11 Canadian agricultural watersheds from 1975 through 1977 (Frank and others, 1982). Although the available literature does not reveal any clear temporal trends in herbicide detection in the United States, the escalating use of herbicides over the last $20 \mathrm{yr}$ (fig. 16) indicates that the amount of herbicides in the Nation's surface waters is not likely to decrease in the near future.

\section{PHENOLS}

\section{Uses, Production, Properties, and Regulatory Limits}

Phenols are a widely used group of compounds characterized by a benzene ring with one or more hydroxyl groups. The dihydroxy phenols can have the second hydroxyl on the ortho, meta, or para position of the benzene ring, and these isomers are commonly referred to by their trivial names, catechol, hydroquinone, and resorcinol, respectively. Although phenols were first produced (in 1834) by the distillation of coal tar, most current production on a commercial scale employs the cumene (isopropylbenzene) process, the toluene oxidation process, or the benzene sulfonation process (U.S. Environmental Protection Agency, 1980a). The basic phenol molecule can then be amended with chlorine, nitro, or methyl groups. In addition to manufacturing processes, chlorophenols are produced by the chlorination of treated wastewaters and drinking waters containing phenol. In solutions containing as little as $10 \mathrm{mg} / \mathrm{L}$ phenol and 20 $\mathrm{mg} / \mathrm{L}$ chlorine, 2-chlorophenol has been synthesized in a 1-h period (Callahan and others, 1979). Similar results have been reported for di- and trichlorophenol isomers.

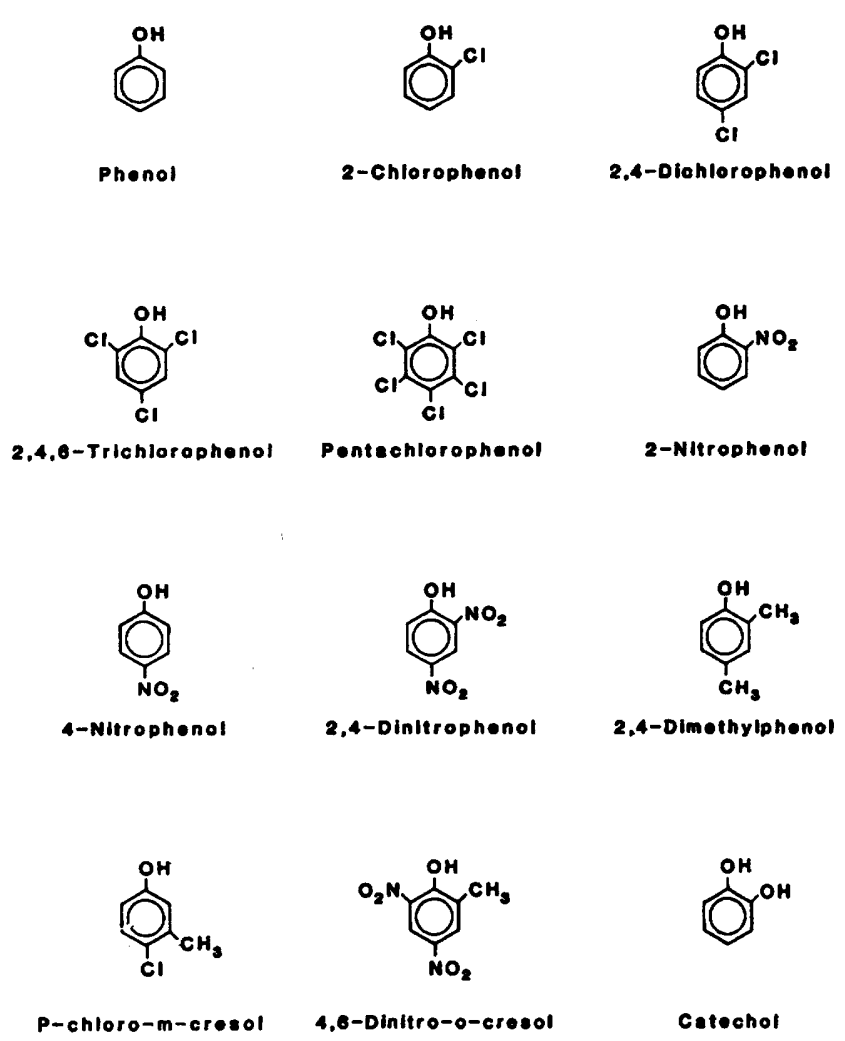

Figure 18. Structural diagrams of selected phenolic compounds.

Structural diagrams of some of the more common phenolic compounds are presented in figure 18.

Phenol, $\mathrm{C}_{6} \mathrm{H}_{5} \mathrm{OH}$, is a monohydroxybenzene that exhibits the properties of a weak acid $\left(\mathrm{pK}_{\mathrm{a}}=10\right)$ owing to the delocalization (via resonance) of the negative phenoxide ion throughout the benzene ring (Baum, 1982). It is this acidity that differentiates phenols from the alcohols. Phenol is a colorless, crystalline solid having a characteristic taste and odor. It is primarily an industrial chemical used as an intermediate in the production of other compounds such as phenolic resins, germicides, pharmaceuticals, fungicides, dyes, herbicides, plastics (such as Bakelite), explosives (such as picric acid or 2,4,6-trinitrophenol), antiseptic throat lozenges, and skin medications. Production data for phenol are presented in table 20.

Established U.S. Environmental Protection Agency criteria for phenol state that chronic toxicity to freshwater aquatic life will occur at a concentration of $2.56 \mathrm{mg} / \mathrm{L}$, and a limit of $3.5 \mathrm{mg} / \mathrm{L}$ is imposed as the maximum level allowable to ensure a lack of hazardous effects to humans (U.S. Environmental Protection Agency, 1980a). In addition, to avoid undesirable tastes and odors in stream water, phenol concentrations must not exceed $0.3 \mathrm{mg} / \mathrm{L}$.

Monochlorophenols are primarily used as intermediates in the production of more highly chlorinated 
Table 20. World production of phenol in 1978

[From Moore and Ramamoorthy, 1984]

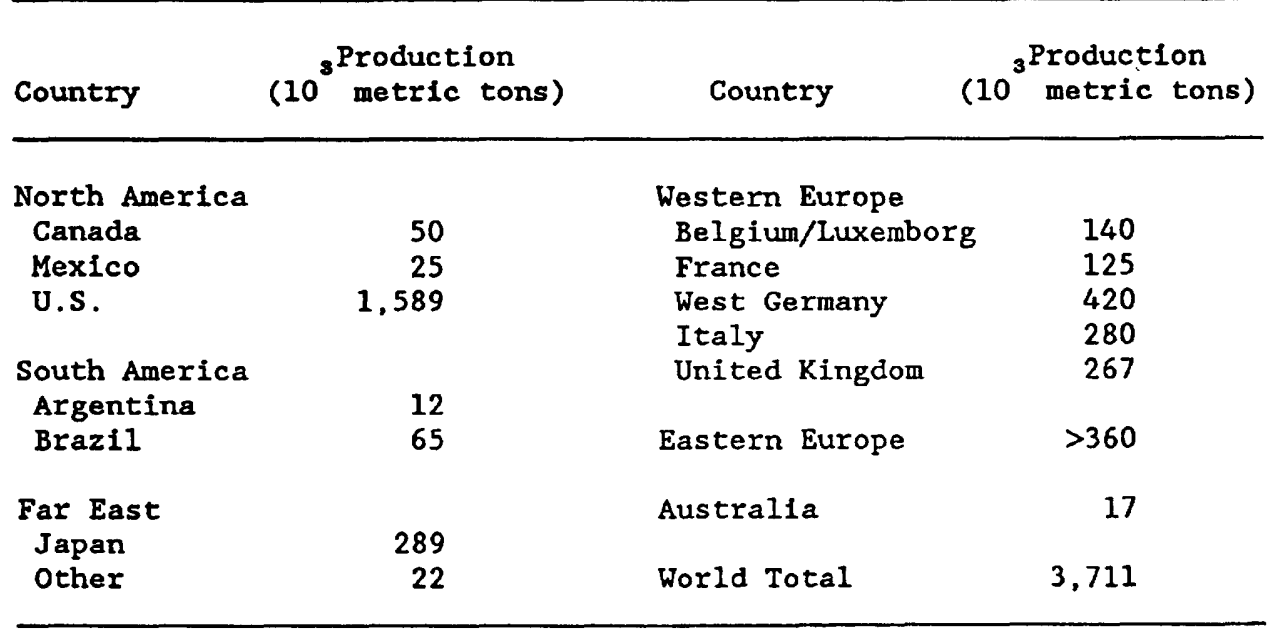

phenols, and their approximate annual production in the United States is $18,800 \mathrm{t}$-significantly less than the 39,000-t production of 2,4-dichlorophenol (Moore and Ramamoorthy, 1984). This compound is used extensively to manufacture the herbicide 2,4-D. Trichlorophenols are used as antimicrobial agents and as antimildew agents for textiles, and in the manufacture of wood and glue preservatives. More specifically, 2,4,5-trichlorophenol is used to manufacture 2,4,5-T and 2,4,6-trichlorophenol is used to produce tetrachlorophenol. The combined annual production of tri- and tetrachlorophenols in the United States is less than 7,000 t (Moore and Ramamoorthy, 1984).

Pentachlorophenol (PCP) has probably seen the most extensive use of all the chlorophenols, and it is manufactured primarily by the organic chemical and pesticide industries. PCP was the second most heavily used pesticide in the United States in 1977, when approximately 80 million $\mathrm{lb}$ were produced (Guthrie and others, 1984). As a herbicide in Japan, it accounted for 50 percent of all herbicide use in the country until its use was regulated in 1971 (Murthy and others, 1979). It is also used extensively as a wood preservative, as a fungicide and bactericide in cooling tower water, and as an additive in adhesives, construction materials, textiles, leather, paint, paper, and oil-well-drilling mud.

Annual U.S. production of 2-nitrophenol, 3-nitrophenol, 4-nitrophenol, and 2,4-dinitrophenol has been estimated to be 6,800 , less than $500,19,000$, and $500 \mathrm{t}$, respectively (Moore and Ramamoorthy, 1984). For the most part, the nitrophenols serve as intermediates in the production of pesticides, pharmaceuticals, dyes, explosives, and wood preservatives.

Only sparse production data were found for some of the other phenolic compounds. Moore and Ramamoorthy (1984) noted that annual U.S. production of 4-methyl-2,6-dibutyl phenol is about $16,000 \mathrm{t}$, and that annual U.S. production of nonylphenol was about 69,000 $t$ in 1981. The latter compound's uses include nonionic surfactants, phenolic resins and plasticizers, adhesives, lube oil additives, stabilizers, and petroleum demulsifiers (Verschueren, 1983).

Table 21 presents some physicochemical data for the phenols. In general, they have high solubility and relatively low vapor pressures and octanol-water partition coefficients. Among the chlorinated phenols, however, compound solubility decreases and octanol-water partition coefficient increases with increased chlorination of the aromatic ring. PCP, the most highly chlorinated phenol, has a solubility of only $14 \mathrm{mg} / \mathrm{L}$ and an octanolwater partition coefficient of 5.0 .

\section{Environmental Fate}

Primary fate mechanisms for phenolic compounds include biodegradation and photolysis. Sorption to natural sediments and bioaccumulation are generally minor, with the exception of the highly chlorinated phenols. Volatilization, hydrolysis, and nonphotolytic oxidation are also relatively insignificant fate processes.

Numerous researchers have documented biological degradation of the phenols. Studies by Baird and others (1974), Hickman and Novak (1984), and Tabak and others (1964) reported significant phenolic biodegradation in activated sludge systems. Other researchers (Chu and Kirsch, 1972; Knackmuss and Hellwig, 1978; Tabak and others, 1981; Banerjee, Howard, and others, 1984) have noted biodegradation of phenols by isolated bacterial cultures.

Biodegradation of phenol in surface waters has also been observed. Borighem and Vereecken (1978) used in 
Table 21. Experimentally determined physicochemical properties of selected phenolic compounds at room temperature

[mg/L, milligrams per liter, $\mathrm{K}_{\mathrm{ow}}$, octanol-water partition coefficient; $\mathrm{pK}_{\mathfrak{w}}$, $-\log$ acid dissociation constant. From Callahan and others, 1979]

\begin{tabular}{|c|c|c|c|c|}
\hline Compound & $\begin{array}{l}\text { Solub1lity } \\
(\mathrm{mg} / \mathrm{L})\end{array}$ & $\mathrm{K}_{\text {ow }}$ & $\begin{array}{c}\text { Vapor pressure } \\
\text { (torrs) }\end{array}$ & $\mathrm{pK}_{\mathrm{a}}$ \\
\hline Phenol & 93,000 & 1.46 & 0.53 & 10.02 \\
\hline 2-Chlorophenol & 28,500 & 2.17 & 2.2 & 8.52 \\
\hline 2,4-Dichlorophenol & 4,500 & 2.75 & 0.12 & 7.85 \\
\hline 2,4,6-Trichlorophenol & 800 & 3.38 & 1.0 & 5.99 \\
\hline Pentachloropheno1 & 14 & 5.01 & 0.00011 & 4.74 \\
\hline 2-Nitrophenol & 2,100 & 1.76 & 1.0 & 7.21 \\
\hline 4-Nitrophenol & 16,000 & 1.91 & 2.2 & 7.15 \\
\hline 2,4-Dinitrophenol & 5,600 & 1.53 & - & 4.09 \\
\hline 2,4-Dimethylphenol & 17,000 & 2.50 & 0.0621 & 10.60 \\
\hline p-Chloro-m-cresol & 3,850 & 2.95 & - & - \\
\hline 4,6-Dinitro-o-cresol & - & 2.85 & - & 4.35 \\
\hline
\end{tabular}

situ batch studies in both polluted and unpolluted reaches of the River Samber in Belgium to determine the effects of certain parameters on the degradation of phenol. They found that biodegradation rates increased with both increased oxygen transfer to the water and increased initial phenol concentration. Visser and others (1977) used in situ studies in the St. Lawrence River, Canada, to quantify phenol biodegradation. During summer, they observed that phenol concentrations as high as $125 \mathrm{ppb}$ were reduced to less than $10 \mathrm{ppb}$ within $4 \mathrm{~h}$. Phenol degradation was accompanied by a concurrent increase in the microbial population in the river-water sample. During the coldest part of winter, however, phenol biodegradation was negligible, probably owing to the absence of phenol-degrading bacteria. Table 22 lists the bacteria present in the St. Lawrence River water during the winter and summer months and the maximum phenol levels they tolerated after adaptation. Other microorganisms that have been shown to degrade phenol include Pseudomonas putida, Bacillus stearothernophilus, and yeast such as Oospora, Saccaromycetes, Candida, Debarymyces, and Trichosporon cutaneum (Callahan and others, 1979).

Most of the other phenols have been biodegraded under laboratory conditions. Using mixed microbial cultures obtained from soils and sediments, Tabak and others (1964) measured the biotransformation of 95 percent of a variety of parent phenolic compounds in 1 to $10 \mathrm{~d}$ (table 23). Knackmuss and Hellwig (1978) reported biodegradation of a variety mono- and dichlorophenols by a strain of 4-chlorophenol-grown cells. With the exception of 3,5and 2,4-dichlorophenol, all half-lives were less than $12 \mathrm{~d}$. Stanlake and Finn (1982) isolated a variety of PCPdegrading bacteria from soil, water, and sewage and noted that the length of the lag phase for bacterial growth on PCP decreased when $\mathrm{pH}$ was raised from 6.8 to 7.8 . Murthy and others (1979) examined PCP degradation in aerobic and anaerobic soils and noted that pentachloroanisole was a primary degradation product of PCP, along with 2,3,5,6- and 2,3,4,5-tetrachlorophenols and 2,3,6trichlorophenol. Their proposed degradation pathway of PCP is presented in figure 19.

The biodegradability of the chlorophenols differs with chlorine substitution. However, increased biodegradability does not always correlate with decreased chlorination of the phenolic molecule. In a study involving a variety of phenolic compounds, Alexander and Aleem (1961) found that chlorine substitution in the meta position of the aromatic ring increases the ring's resistance to biological cleavage. With the exception of these metachlorophenols, the authors observed virtually 100 percent ring cleavage of all the chlorophenols in a soil suspension within $47 \mathrm{~d}$. Under aerobic, room-temperature conditions, 
Table 22. Phenol bacteria present during the winter and (or) summer season in St. Lawrence River water and maximum phenol levels that could be tolerated [mg/, milligrams per liter. From Visser and others, 1977]

\begin{tabular}{|c|c|c|c|}
\hline Bacterial species & Winter & Summer & $\begin{array}{l}\text { Maximum phenol } \\
\text { levels tolerated } \\
\text { after adaptation } \\
(\mathrm{mg} / \mathrm{L})\end{array}$ \\
\hline Achromobacter eurydice & & $\mathbf{x}$ & 2,400 \\
\hline A. cycloclastes or guttatus & $\mathbf{x}$ & $\mathbf{x}$ & 1,200 \\
\hline A. iophagus & & $\mathrm{x}$ & 1,200 \\
\hline Arthrobacter terregens & & $\mathbf{x}$ & 1,200 \\
\hline Azotobacter agilis & & $\mathbf{x}$ & 2,400 \\
\hline Bacillus brevis & & $\mathbf{x}$ & 2,400 \\
\hline B. cereus & & $\mathbf{x}$ & 600 \\
\hline B. circulans & & $\mathbf{x}$ & 600 \\
\hline Brevibacterium maris & & $\mathbf{x}$ & 2,400 \\
\hline B. sulfureum & & $\mathbf{x}$ & 150 \\
\hline Brevibacterium sp. & $\mathbf{x}$ & $\mathbf{x}$ & 600 \\
\hline Clostridium carnis or tertium & & $\mathbf{x}$ & 300 \\
\hline Flavobacterium aquatile & $\mathbf{x}$ & $\mathbf{x}$ & 600 \\
\hline F. breve or peregrinum & & $\mathbf{x}$ & 1,200 \\
\hline F. lutescens & & $\mathbf{x}$ & 600 \\
\hline F. marinum & $\mathbf{x}$ & $\mathbf{x}$ & 300 \\
\hline F. solare & & $\mathbf{x}$ & 150 \\
\hline Flavobacterium (marinum ?) & $\mathbf{x}$ & $\mathbf{x}$ & 600 \\
\hline Flavobacterium sp. & & $\mathbf{x}$ & 1,200 \\
\hline Micrococcus conglomeratus & & $\mathbf{x}$ & 1,200 \\
\hline Micrococcus (?) & & $\mathbf{x}$ & 600 \\
\hline Mycobacterium phlei & & $\mathbf{x}$ & 600 \\
\hline Paracolobactrum coliforme & & $\mathbf{x}$ & 2,400 \\
\hline Pseudomonas fragi & $\mathbf{x}$ & $\mathbf{x}$ & 600 \\
\hline Pseudomonas sp. & & $\mathbf{x}$ & 150 \\
\hline Pseudomonas sp. & & $\mathbf{x}$ & 300 \\
\hline Pseudomonas sp. & & $\mathbf{x}$ & 600 \\
\hline Pseudomonas sp. & $\mathbf{x}$ & $\mathbf{x}$ & 1,200 \\
\hline Pseudomonas sp. & & $\mathbf{x}$ & 2,400 \\
\hline Sarcina flava & & $\mathbf{x}$ & 1,200 \\
\hline S. hansenil & & $\mathbf{x}$ & 2,400 \\
\hline
\end{tabular}

Banerjee, Howard, and others (1984) observed zeroorder biodegradation kinetics for a variety of phenolic compounds in natural water samples. They also stated that degradation rates decreased with increased chlorine substitution. However, biodegradation studies in their second collection of river water indicated that 2,4-dichlorophenol was more resistant to biodegradation than 2,4,5-trichlorophenol, which in turn was more resistant to degradation than PCP. Data indicating that decreased phenolic biodegradation rates do not strictly correspond to increasing chlorination of the aromatic ring have also been reported by Tabak and others (1964), Alexander and Aleem (1961), and Smith and Novak (1987).
Available data indicate that photolytic oxidation may also be a significant fate mechanism for many phenols. Phenol can be photolytically degraded to a reddish, high-molecular-weight material. Photolytic end products of phenol degradation include $4,4^{\prime}-, 2,4^{\prime}$-, and 2,2'-dihydroxybiphenyl, hydroquinone, and catechol (Joschek and Miller, 1966). Callahan and others (1979) have indicated that the absorption maximums of metalcoordinated phenols can be significantly extended. In the near-ultraviolet spectral region, the absorption maximum of phenol does not extend beyond $290 \mathrm{~nm}$. However, when phenol is complexed with metal cations such as Fe(III), the absorption maximum is extended to $600 \mathrm{~nm}$. Similarly, 
Table 23. Time required for bacteria to use 95 percent of parent substrate

[From Tabak and others, 1964]

\begin{tabular}{|c|c|c|}
\hline \multicolumn{3}{|c|}{ Compounds degraded in: } \\
\hline 1 to 2 days & 3 to 6 days & 7 to 10 days \\
\hline $\begin{array}{l}\text { Phenol } \\
\text { Catechol } \\
\text { Resorcinol } \\
\text { Quinol } \\
\text { Phloroglucinol } \\
\text { o-Cresol } \\
\text { m-Cresol } \\
\text { P-Cresol }\end{array}$ & $\begin{array}{l}\text { 0-Nitrophenol } \\
\text { n-Nitrophenol } \\
\text { p-N1trophenol } \\
\text { 2,4,6-Trinitrophenol } \\
\text { (250 ppm) } \\
\text { 2-Chloro-4-nitrophenol } \\
\text { 2,6-Dichloro- } \\
\text { 4-nitrophenol } \\
\text { m-Chlorophenol (150 ppm) } \\
\text { p-Chlorophenol } \\
\text { o-Phenylphenol (100 ppm) } \\
\text { Thymol (150 ppm) }\end{array}$ & $\begin{array}{l}\text { 2,4-Dinitrophenol } \\
\text { 2,6-Dimethylphenol } \\
\text { (200 ppm) } \\
\text { 2,4-Dichlorophenol } \\
\text { (200 ppm) } \\
\text { 2,4,6-Trichloro- } \\
\text { phenol }\end{array}$ \\
\hline
\end{tabular}

*Initlal concentration was 300 parts per million (Ppa) unless noted in parentheses.

the aqueous $\mathrm{Fe}(\mathrm{III})$ complex with 2-chlorophenol has an absorption maximum of about $550 \mathrm{~nm}$, which is significantly greater than the absorption maximum of the chlorophenolate anion (310) or undissociated 2-chlorophenol $(290 \mathrm{~nm})$. Table 24 details some of the photolytic degradation products of the phenols.

Based on their relatively high solubilities, low octanol-water partition coefficients, and anionic nature, most of the phenols do not strongly sorb to sediments or bioaccumulate. However, increased chlorination of the phenol molecule decreases compound solubility and increases octanol-water partition coefficients. Therefore, the more highly chlorinated phenols such as PCP or the tetrachlorophenols can exhibit significant sorption and bioaccumulation in surface-water systems.

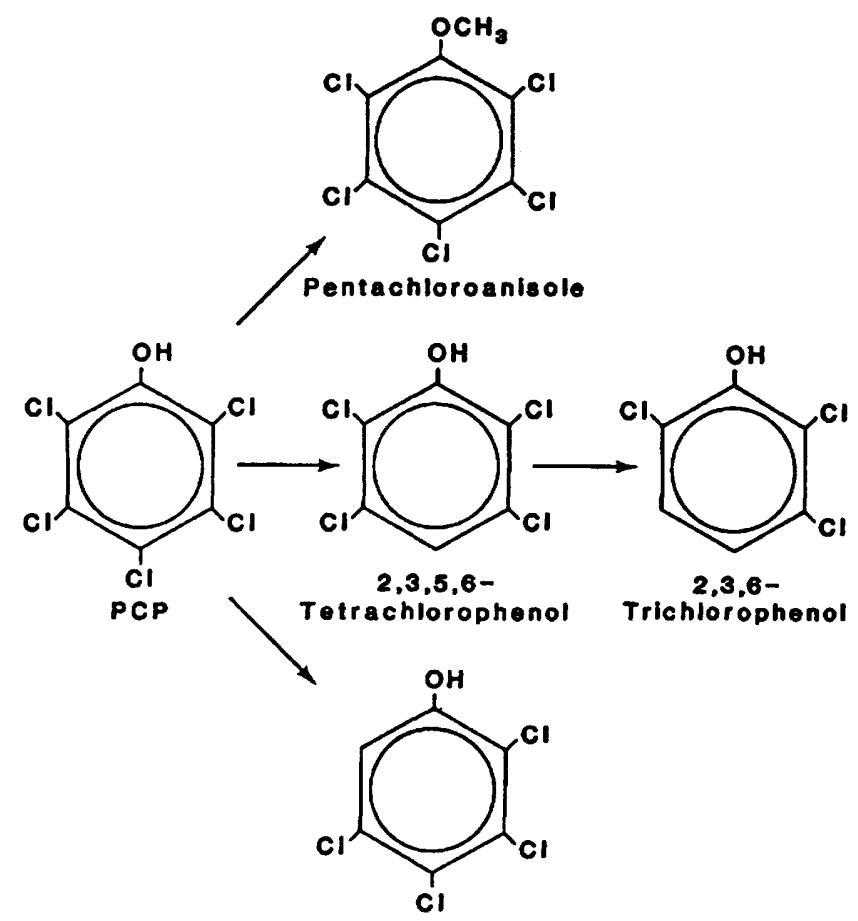

2,3,4,6-Tetrachlorophenol

Figure 19. Structural diagrams showing degradation pathway of pentachlorophenol (PCP) in soils. [Reprinted with permission from the Journal of Environmental Science and Health, v. B14, p. 13 (1979). Copyright 1979 by Marcel Dekker, Inc.]

Table 25 lists experimentally determined sorption coefficients $\left(\mathrm{K}_{\mathrm{d}}\right.$, equal to the equilibrium solute concentration in sediment divided by its equilibrium aqueous concentration) of nonionized chlorophenols sorbed to four different natural sediments (Schellenberg and others, 1984). The authors determined that in natural waters of

Table 24. Photolysis of phenols and their degradation products [nm, nanometer, ppm, parts per million. From Callahan and others, 1979]

\begin{tabular}{|c|c|c|c|}
\hline Compound & Light source & Experimental conditions & Products \\
\hline Phenol & $254 \mathrm{~mm}$ & Aqueous, oxygenated solutions & $\begin{array}{l}4,41-, 2,41-\text { and } 2,2^{\prime}-\text { dihydroxybiphenyl; } \\
\text { hydroquinone; catechol }\end{array}$ \\
\hline 2-Chl orophenol & $313 \mathrm{rm}$ & Aqueous alkali & Catechol \\
\hline 4-Chlorophenol & 254 and $>290 \mathrm{~mm}$ & Aqueous solution with cyanide & 4-cyanophenol \\
\hline 2,4-D ichlorophenol & Solar radiation & Aerated aqueous solution & $\begin{array}{l}\text { Complete disappearance ofter } 10 \text { days; } \\
\text { insoluble, dark, tarry substance produced }\end{array}$ \\
\hline 2,4,6-Trichlorophenol & $\cdot$ & In presence of electron acceptor & $\begin{array}{l}\text { 2,6-dichlorophenoxyl semiquinone radical } \\
\text { anion }\end{array}$ \\
\hline Pentachlorophenol & Sunlight & 2X solution of NePCP & $\begin{array}{l}50 \% \text { degradation after } 10 \text { days; products: } \\
\text { chloranilic acid, tetrachlororesorcinol, and } \\
\text { several complex chlorinated benzoquinones }\end{array}$ \\
\hline 4-Nitrophenal & Sunl ight & Aqueous solution of 200 ppm & $\begin{array}{l}\text { Degraded in } 1 \cdot 2 \text { month period to hydroquinone, } \\
4-\text { nitrocatechol, and a dark, acidic polymer }\end{array}$ \\
\hline
\end{tabular}


Table 25. Experimentally determined sorption coefficients of nonionized chlorinated phenols for different natural sorbents

[From Schellenberg and others, 1984]

\begin{tabular}{lcccc}
\hline & \multicolumn{3}{c}{ Sorption coefficient for sorbent } \\
\cline { 2 - 5 } Compound & 1 & 2 & 3 & 4 \\
\hline $2,3-\mathrm{DCP}$ & 21 & 12 & 5 & $<1$ \\
$2,4-\mathrm{DCP}$ & 25 & 17 & 6 & $<1$ \\
$2,4,6-\mathrm{TCP}$ & 78 & 34 & 9 & $<1$ \\
$2,4,5-\mathrm{TCP}$ & 165 & 74 & 20 & $<1$ \\
$3,4,5-\mathrm{TCP}$ & 276 & 115 & 31 & $<1$ \\
$2,3,4,6-\mathrm{TeCP}$ & 568 & 200 & 52 & $<3$ \\
$2,3,4,5-\mathrm{TeCP}$ & 1237 & 362 & 105 & 7 \\
PCP $^{* *}$ & 3670 & 930 & 200 & $<13$ \\
\hline
\end{tabular}

${ }^{*} 1$. Lake sediment; organic carbon content (OC) -9.48

2. River sediment; $O C=2.68$

3. Aquifer material; $O C=0.848$

4. Aquifer material; $O C=0.038$

Sorption coefficients for compound calculated from chromatographic data.

low ionic strength (less than $10^{3} \mathrm{~mol} / \mathrm{L}$ ) and of $\mathrm{pH}$ not more than one $\log$ unit greater than the phenolic compound's $\mathrm{pK}_{\mathrm{a}}$, sorption of the phenolate anion can be ignored. The data indicate that sorption coefficients increase with increasing chlorination of the phenolic compound and with increased sediment-organic-matter content. The less chlorinated phenols are not sorbed significantly to any of the soils. In soils having low organicmatter content, even sorption of PCP will not be substantial. Similarly, Scott and others (1982) observed that phenol did not sorb strongly to soils, with sorption coefficients ranging from 0.57 to 1.19. For the case of the higher chlorinated phenols such as PCP, sorption will likely be greatest in acidic soils and sediments having high organic-matter contents.

Similar to sediment sorption, phenols are not readily bioaccumulated in surface-water systems, but increased accumulation has been correlated with increased chlorination of the phenol molecule (Biddinger and Gloss, 1984). Few bioaccumulation data were found in the reviewed literature for the majority of the phenols, with the exception of PCP. Callahan and others (1979) cite several studies that found that PCP was accumulated to concentrations well beyond its aqueous concentration. An eel exposed to pulp-mill discharge bioaccumulated an aqueous PCP concentration of $3 \mu \mathrm{g} / \mathrm{L}$ to a tissue concen- tration of $3,000 \mu \mathrm{g} / \mathrm{L}$. Similarly, a 72-h exposure to 100 $\mu \mathrm{g} / \mathrm{L}$ PCP resulted in a 900 -fold concentration increase of the compound in goldfish, indicating that PCP can be bioaccumulated in substantial amounts. For the other phenols, bioaccumulation is likely to be an insignificant fate process owing to the compounds' generally low octanol-water partition coefficients.

Volatilization, nonphotolytic oxidation, and hydrolysis are not significant fate processes for the phenols. 2-Chlorophenol has the highest vapor pressure of the phenols, but its high solubility prevents any substantial volatilization losses. Phenol can be oxidized in aqueous solution by molecular oxygen, but the more highly chlorinated phenols are resistant to oxidation under typical environmental conditions (Moore and Ramamoorthy, 1984). The phenols also are resistant to hydrolysis, because the high negative charge density of the aromatic ring makes the covalent bonds relatively stable (Moore and Ramamoorthy, 1984).

\section{Environmental Distribution}

Phenols may enter surface-water systems directly as components of industrial effluents and indirectly as transformation products of other compounds. For example, pulp-mill effluents commonly contain elevated concentrations of phenolic compounds (Landner and others, 1977), and the chlorination of wastewaters can convert phenol to monochlorophenol, dichlorophenol, or even trichlorophenol (Callahan and others, 1979). Table 26 lists the concentrations of phenol and some of its chlorinated derivatives in municipal and industrial wastewater.

Because of their generally high solubilities, the phenols can be found in relatively high aqueous concentrations in natural surface waters. Sheldon and Hites (1979) detected isomers of bromochlorophenol, dibromophenol, dichlorobromophenol, and dibromochlorophenol in water of the Delaware River near Philadelphia. Yasuhara and others (1981) reported extremely high concentrations of PCP in the waters of the Hayashida River in Japan. Concentrations ranged from 306 to 895 $\mu \mathrm{g} / \mathrm{L}$ and were attributed to the unregulated discharge of leather-tannery wastewaters. Visser and others (1977) observed that ambient phenol concentrations in the waters of the St. Lawrence River, Canada, were approximately 10 to $15 \mu \mathrm{g} / \mathrm{L}$. Borighem and Vereecken (1978) noted that phenol levels in polluted stretches of the River Samber in Belgium were considerably higher, ranging from 0.2 to 0.7 $\mathrm{mg} / \mathrm{L}$. In a study of water and sediment quality in the Netherlands, Wegman and van den Broek (1983) detected all the isomers of mono-, di-, tri-, tetra-, and pentachlorophenol in water samples from the Ijssel River near Kampen. Maximum compound concentrations ranged from $0.02(2,3,4,5$-tetrachlorophenol) to $3.4 \mu \mathrm{g} / \mathrm{L} \mathrm{(3-}$ chlorophenol). Despite these detections, the ability of 
Table 26. Concentration of phenol and some of its chlorinated derivatives in municipal and industrial wastewater [ $\mu \mathrm{g} / \mathrm{L}$, micrograms per liter. From Moore and Ramamoorthy, 1984]

\begin{tabular}{|c|c|c|}
\hline Compound & $\begin{array}{l}\text { Concentration } \\
(\mu g / L)\end{array}$ & Source \\
\hline Phenol & $\begin{array}{l}0.03-20 \\
200-3,016,000 \\
3200 \\
38,000-1,240,000 \\
10-300\end{array}$ & $\begin{array}{l}\text { Treated sewage, European } \\
\text { clties } \\
3 \text { petroleum refineries (USA) } \\
2 \text { coal gasifacation plants } \\
\text { (USA) } \\
\text { Coke plant (USA) } \\
\text { specialty chemical plant } \\
\text { (USA) }\end{array}$ \\
\hline 2,4-DCP & $\begin{array}{l}220 \\
<0.1\end{array}$ & $\begin{array}{l}\text { Chemical plant (Vancouver) } \\
\text { Wood preservation plant } \\
\text { (British Columbia) }\end{array}$ \\
\hline \multirow[t]{2}{*}{$2,6-D C P$} & $\begin{array}{l}<0.1 \\
220 \\
2.4\end{array}$ & $\begin{array}{l}\text { Landfill leachate (Vancouver) } \\
\text { Chemical plant (Vancouver) } \\
\text { Wood preservation plant } \\
\text { (British Columbia) }\end{array}$ \\
\hline & $1.2-5.6$ & $\begin{array}{l}\text { Landfill leachate (British } \\
\text { Columbia) }\end{array}$ \\
\hline $2,4,5-\mathrm{TCP}$ & $\begin{array}{l}<0.05 \\
0.5-2400 \\
<0.05\end{array}$ & $\begin{array}{l}\text { Treated sewage, } 4 \text { plants } \\
\text { (Vancouver) } \\
2 \text { chemlcal plants (Vancouver) } \\
\text { Wood preservation plant } \\
\text { (British Columbia) }\end{array}$ \\
\hline \multirow[t]{2}{*}{$2,4,6-\mathrm{TCP}$} & $\begin{array}{l}0.05-2 \\
<0.05-1\end{array}$ & $\begin{array}{l}\text { Landfill leachate (Vancouver) } \\
\text { Treated sewage, } 4 \text { plants } \\
\text { (Vancouver) }\end{array}$ \\
\hline & $\begin{array}{l}<0.05-3120 \\
0.5-1\end{array}$ & $\begin{array}{l}3 \text { chemical plants (Vancouver) } \\
\text { Wood preservation plant } \\
\text { (British Columbia) }\end{array}$ \\
\hline \multirow[t]{3}{*}{$2,3,4,6-T e C P$} & $\begin{array}{l}0.4-1 \\
25-115 \\
0.6-28\end{array}$ & $\begin{array}{l}\text { Landfill leachate (Vancouver) } \\
\text { Pulpmill effluent (Vancouver) } \\
\text { Treated sewage, } 4 \text { plants } \\
\text { (Vancouver) }\end{array}$ \\
\hline & $1.2-8270$ & $\begin{array}{l}4 \text { wood preservation plants } \\
\text { (British Columbia) }\end{array}$ \\
\hline & $0.3-166$ & $\begin{array}{l}3 \text { chemical plants (Vancouver) } \\
\text { Landfill leachate (Vancouver) }\end{array}$ \\
\hline \multirow[t]{4}{*}{$\mathbf{P C P}$} & $0.5-4.7$ & $\begin{array}{l}\text { Treated sewage, } 4 \text { plants } \\
\text { (Vancouver) }\end{array}$ \\
\hline & $0.25-1.3$ & $\begin{array}{l}\text { Treated sewage, } 6 \text { cities } \\
\text { (Ontarlo) }\end{array}$ \\
\hline & $0.05-2760$ & $\begin{array}{l}\text { Wood preservation plants } \\
\text { (British Columbia) }\end{array}$ \\
\hline & $\begin{array}{l}5,400,000 \\
0.6-42\end{array}$ & $\begin{array}{l}\text { Chemical plant (Philadelphia) } \\
\text { Landfill leachate (Vancouver) }\end{array}$ \\
\hline
\end{tabular}

phenolic compounds to be biologically and photolytically attenuated makes them relatively nonpersistent contaminants. This is confirmed by data from the U.S. Environmental Protection Agency, which reported that of 110 raw-water samples taken throughout the United States, phenol was detected in only 2 (U.S. Environmental Protection Agency, 1980a).

Sediment residues of phenols rarely exceed the micrograms-per-kilogram range. However, higher residues have been reported occasionally. For example, Van Luik (1984) reported that phenol concentrations in the sediments of the Calumet Sag Channel (Ill.) ranged from 1 to $6.9 \mathrm{mg} / \mathrm{kg}$. Pierce and others (1977) documented sediment PCP concentrations in a small stream ranging from 1.1 to $1.3 \mathrm{mg} / \mathrm{kg}$ as a result of an accidental discharge of the compound. Concentrations typical of a phenol-contaminated surface-water system were reported by Wegman and van den Broek (1983). They determined that 100 percent of the sediment samples collected from Lake Ketelmeer in the Netherlands were contaminated with 2,5-dichlorophenol, 2,3,5- and 2,4,5-trichlorophenol, 2,3,4,5- and 2,3,4,6-tetrachlorophenol, and PCP. The respective median concentrations were $6.3,2.4,6.4,0.9$, 1.7 , and $8.4 \mu \mathrm{g} / \mathrm{kg}$. The authors also noted that areas of highest phenol contamination were near industrial areas. Biological phenolic residues also have been reported. DeVault (1985) found that fish from harbors and tributary mouths of the Great Lakes contained PCP concentrations ranging from $<0.08$ to $4.52 \mathrm{mg} / \mathrm{kg}$. In Lake Ontario, Niimi and Cho (1983) found lower PCP concentrations in a variety of sampled fish; mean residue levels ranged from 0.3 to $24 \mu \mathrm{g} / \mathrm{kg}$. Rudling (1970) analyzed fish from a lake into which PCP had been discharged and determined that concentrations in the tissues of pike, perch, and eel were $0.2,0.15$, and 3.0 $\mathrm{mg} / \mathrm{kg}$, respectively. The elevated PCP concentrations found in the eel were attributed to the relatively high lipid content of eels. Similarly, Landner and others (1977) analyzed perch and northern pike caught in the vicinity of a pulp mill. Phenolic residues were concentrated in the liver fat of the sampled fish, with mean concentrations of 2,4,6-trichlorophenol, trichloroguaiacol, and tetrachloroguaiacol of $1.2,5.0$, and $4.4 \mathrm{mg} / \mathrm{kg}$ fat, respectively. In general, biological residues of phenolic compounds depend on aqueous concentrations, biological lipid content, and the solubility of the phenolic compound.

\section{HALOGENATED ALIPHATIC AND MONOCYCLIC AROMATIC HYDROCARBONS}

\section{Uses, Production, and Properties}

The aliphatic hydrocarbons are straight-chain molecules composed of only hydrogen and carbon. The saturated aliphatic hydrocarbons, commonly referred to as the alkanes or paraffin hydrocarbons, are molecules in which each carbon atom is bonded covalently to four other atoms by single bonds. The general formula for alkanes is $\mathrm{C}_{n} \mathrm{H}_{2 n+2}$. Because of double and triple carboncarbon bonds, unsaturated aliphatic hydrocarbons contain fewer hydrogen atoms per carbon atom than the alkanes. The family of unsaturated aliphatic hydrocarbons containing carbon-carbon double bonds are called the alkenes, or olefins. The family of compounds containing carboncarbon triple bonds are called the alkynes, or acetylenes. The general formulas for the alkenes and alkynes are $\mathrm{C}_{n} \mathrm{H}_{2 n}$ and $\mathrm{C}_{n} \mathrm{H}_{2 n-2}$, respectively. The industrial halogenation of the aliphatic hydrocarbons results in the production of many toxic chemicals that are widely used as solvent degreasers, refrigerants, and fumigants and in dry-cleaning operations and the pharmaceutical industry. 
Benzene, first isolated in 1825 by Michael Faraday, exhibits the common structural feature of the aromatic hydrocarbons. The benzene molecule consists of six carbon atoms bound together in a cyclic structure. Each carbon atom also is bound to one hydrogen atom. X-ray diffraction analysis of benzene indicates that all the carbon-carbon bonds have a length of $1.39 \mathrm{~A}$, intermediate to the length of a carbon-carbon single bond (1.54 A) and a carbon-carbon double bond (1.34 A) (Baum, 1982). The molecule's stability and intermediate carbon-carbon bond length are attributable to a resonating electron structure within the molecule. Benzene and other aromatic compounds having halogens or other functional groups substituted for hydrogen atoms have found wide industrial use. Many of these compounds are highly toxic and, therefore, pose a serious threat to surface-water quality. Figure 20 gives the structural diagrams of some of the more common monocyclic aromatic hydrocarbons (MAH's), together with some of the halogenated aliphatic hydrocarbons.

Table 27 presents U.S. production data for the halogenated aliphatic and MAH's. Benzene, toluene, xylene, 1,2-dichloroethane, vinyl chloride, ethyl benzene, carbon tetrachloride, and nitrobenzene are among the compounds that have seen the largest production over the last $20 \mathrm{yr}$. Although production of some of the compounds in table 27 has slowed since 1979, the data indicate that production of both the halogenated aliphatic and MAH's was significantly greater in 1981-82 than production of these compounds from 1965 to 1969 . Table 28 documents<smiles>ClCCl</smiles>

Dichloromethane<smiles>C=CCl</smiles>

Vinyl chloride<smiles></smiles>

Toluene<smiles></smiles>

Ethyl benzene<smiles>ClC(Cl)Cl</smiles>

1,t-Dichloroethane<smiles>ClC(Cl)=C(Cl)I</smiles>

Tetrachloroethylene
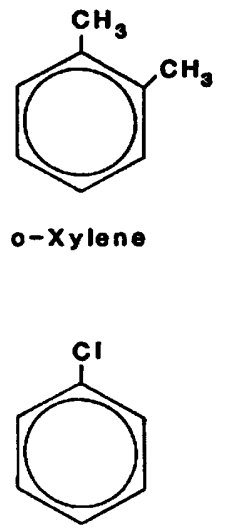

Chlorobenzene

Figure 20. Structural diagrams of selected halogenated aliphatic and monocyclic aromatic hydrocarbons.

Table 27. U.S. production of selected halogenated aliphatic and monocyclic aromatic hydrocarbons [In metric tons $\times 10^{4} .^{*}$ From Moore and Ramamoorthy, 1984]

\begin{tabular}{|c|c|c|c|c|c|c|c|c|c|c|}
\hline Compound & $1961-65^{x \hbar}$ & $1966-70^{\pi / 6}$ & $1971 \cdot 75^{k \pi}$ & 1976 & 1977 & 1978 & 1979 & 1980 & 1981 & 1982 \\
\hline $\begin{array}{l}\text { Chloromethane } \\
\text { Dichloromethane } \\
\text { Chloroform } \\
\text { Carbon tetrachloride } \\
\text { Chloroethane } \\
1,2-\text { dichloroethane } \\
1,1 \text { 1-trichloroethane } \\
\text { Chlorodifluoromethane } \\
\text { Trichlorofluoromethane } \\
\text { Dichlorodifluoromethane } \\
\text { vinyl chloride } \\
\text { Trichloroethylene } \\
\text { Tctrachlorocthylene } \\
\text { Bromoform } \\
\text { Ethylene dibromide } \\
\text { Benzene } \\
\text { Toluene } \\
\text { Xylene } \\
\text { Monochlorobenzene } \\
1,2-\text { dichlorobenzene } \\
\text { i, } 4 \text {-dichlorobenzene } \\
\text { Alkyl benzenes } \\
2,4+2,6-\text { dinitrotoluene } \\
\text { Ethyl benzene } \\
\text { Nitrobenzene }\end{array}$ & $\begin{array}{r}5.5 \\
6.9 \\
3.6 \\
21.8 \\
26.6 \\
82.1 \\
\text { nd } \\
\text { nd } \\
5.6 \\
9.6 \\
63.8 \\
13.9 \\
14.2 \\
0.6 \\
\text { nd } \\
62.6 \\
39.1 \\
31.9 \\
25.0 \\
1.9 \\
3.2 \\
28.3 \\
\text { nd } \\
106.1 \\
9.7\end{array}$ & $\begin{array}{r}14.9 \\
14.5 \\
9.1 \\
36.5 \\
23.1 \\
234.8 \\
14.0 \\
\text { nd } \\
10.4 \\
15.1 \\
142.1 \\
24.5 \\
27.0 \\
0.9 \\
13.8 \\
104.8 \\
70.2 \\
44.9 \\
25.0 \\
2.7 \\
2.9 \\
29.4 \\
12.6 \\
184.7 \\
19.1\end{array}$ & $\begin{array}{r}20.8 \\
19.0 \\
11.6 \\
45.9 \\
28.1 \\
379.2 \\
21.9 \\
\text { nd } \\
13.6 \\
19.9 \\
223.1 \\
18.8 \\
32.3 \\
1.2 \\
14.0 \\
125.8 \\
87.5 \\
53.2 \\
17.2 \\
2.7 \\
2.9 \\
23.6 \\
18.6 \\
246.9 \\
20.2\end{array}$ & $\begin{array}{r}17.1 \\
24.4 \\
13.2 \\
38.9 \\
30.4 \\
364.6 \\
28.6 \\
7.7 \\
11.6 \\
17.8 \\
257.5 \\
14.3 \\
16.3 \\
\text { nd } \\
9.1 \\
142.5 \\
99.9 \\
72.2 \\
14.9 \\
2.2 \\
1.7 \\
\text { nd } \\
18.0 \\
261.7 \\
18.6\end{array}$ & $\begin{array}{r}21.6 \\
21.7 \\
13.7 \\
36.7 \\
27.8 \\
498.7 \\
28.8 \\
8.1 \\
9.7 \\
16.2 \\
271.5 \\
13.5 \\
27.8 \\
1.6 \\
11.1 \\
143.5 \\
101.8 \\
81.1 \\
14.8 \\
2.1 \\
3.0 \\
23.6 \\
\text { nd } \\
376.9 \\
25.0\end{array}$ & $\begin{array}{r}20.6 \\
25.9 \\
15.8 \\
33.4 \\
24.5 \\
498.9 \\
29.2 \\
9.3 \\
8.8 \\
14.8 \\
315.8 \\
13.6 \\
32.9 \\
1.6 \\
10.4 \\
148.8 \\
105.4 \\
84.5 \\
13.4 \\
1.9 \\
1.9 \\
23.8 \\
29.8 \\
380.3 \\
26.1\end{array}$ & $\begin{array}{r}21.0 \\
28.7 \\
16.1 \\
32.4 \\
26.4 \\
534.9 \\
32.5 \\
9.6 \\
7.6 \\
13.3 \\
289.7 \\
14.5 \\
35.1 \\
\text { nd } \\
13.0 \\
167.2 \\
101.0 \\
97.2 \\
14.7 \\
2.6 \\
3.8 \\
28.4 \\
31.2 \\
383.1 \\
43.2\end{array}$ & $\begin{array}{r}16.4 \\
25.5 \\
16.0 \\
32.1 \\
17.9 \\
503.7 \\
31.4 \\
10.3 \\
10.3 \\
13.4 \\
293.4 \\
12.1 \\
34.7 \\
\text { nd } \\
8.8 \\
200.7 \\
101.7 \\
90.8 \\
12.8 \\
2.8 \\
3.4 \\
40.6 \\
\text { nd } \\
346.5 \\
27.7\end{array}$ & $\begin{array}{r}18.4 \\
26.8 \\
18.3 \\
32.9 \\
14.7 \\
452.3 \\
27.8 \\
11.4 \\
7.4 \\
14.7 \\
311.7 \\
11.7 \\
31.3 \\
\text { nd } \\
7.6 \\
133.9 \\
85.6 \\
88.2 \\
12.9 \\
2.3 \\
3.3 \\
24.2 \\
22.8 \\
354.3 \\
40.8\end{array}$ & $\begin{array}{r}16.0 \\
23.8 \\
13.5 \\
\text { nd } \\
13.1 \\
\text { nd } \\
25.0 \\
\text { nd } \\
\text { nd } \\
\text { nd } \\
\text { nd } \\
8.1 \\
\text { nd } \\
\text { nd } \\
\text { nd } \\
107.0 \\
105.2 \\
73.0 \\
\text { nd } \\
\text { nd } \\
\text { nd } \\
\text { nd } \\
\text { nd } \\
299.7 \\
\text { nd }\end{array}$ \\
\hline
\end{tabular}

\footnotetext{
For benzene, toluene, and xylene, units are $x 10^{7}$ gallons.

** Annual average

nd - no data available
} 
Table 28. Uses of selected halogenated aliphatic and monocyclic aromatic hydrocarbons

[From Verschueren, 1983]

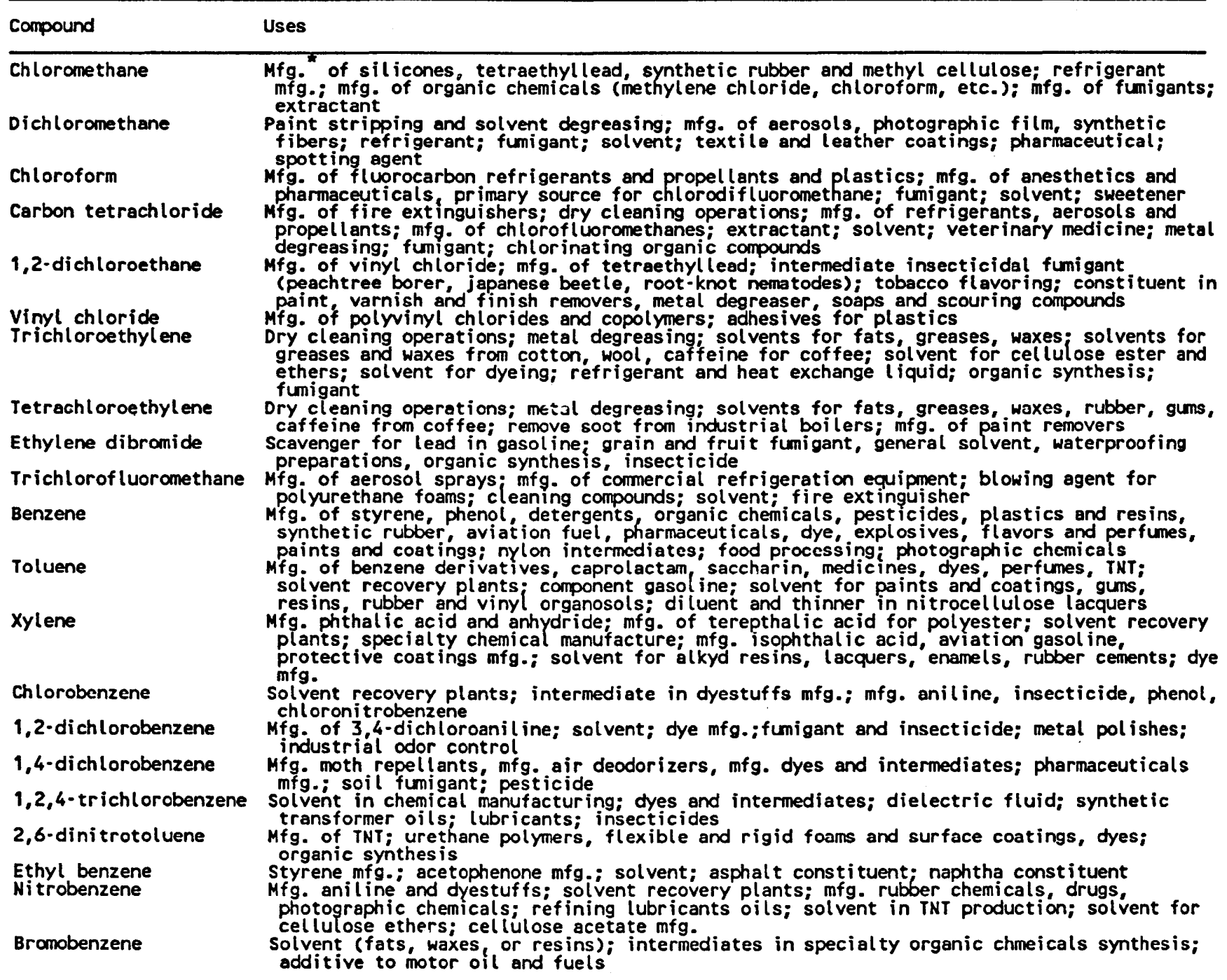

* manufacturing.

the numerous uses of the halogenated aliphatic and MAH's.

With the exception of the phenols discussed previously, the halogenated aliphatic and MAH's are characterized by high vapor pressures, high solubilities, and low octanol-water partition coefficients. Table 29 quantifies these physicochemical parameters.

\section{Environmental Fate}

The primary fate of most of the halogenated aliphatic and MAH's in surface-water systems is volatilization followed by photolytic degradation in the atmosphere. Dilling and others (1975) studied volatilization, sorption, and chemical degradation of five chlorinated aliphatic compounds at aqueous concentrations of $1 \mathrm{ppm}$. In water at $25{ }^{\circ} \mathrm{C}$ and stirred at $200 \mathrm{rpm}$, all five compounds (methylene chloride, chloroform, 1,1,1-trichloroethane, trichloroethylene, and tetrachloroethylene) demonstrated 50 percent volatilization in less than $30 \mathrm{~min}$ and 90 percent volatilization in less than $90 \mathrm{~min}$. Addition of other material (clay, limestone, sand, salt, peat moss, and kerosene) to the water had little effect on rate of volatilization, indicating that sorptive processes were unable to compete with solute evaporation. Furthermore, the authors determined that chemical degradation half-lives for the five compounds ranged from 6 to $18 \mathrm{mo}$. Table 30 presents the times for 50 and 90 percent removal of the five compounds from water, along with the evaporation times of 22 other chlorinated aliphatic hydrocarbons as determined by Dilling and others (1975). 
Table 29. Experimentally determined octanol-water partition coefficients $\left(K_{\text {ow }}\right)$, solubilities, and vapor pressures of selected halogenated aliphatic and monocyclic aromatic hydrocarbons at room temperature

[mg/L, milligrams per liter, mm, millimeters. Dash indicates no data available]

\begin{tabular}{|c|c|c|c|c|}
\hline Compound & $\log K_{\text {ow }}$ & $\begin{array}{l}\text { Solubility } \\
\text { (mg/L) }\end{array}$ & $\begin{array}{c}\text { Vapor pressure } \\
\text { (mm of } \mathrm{Hg})\end{array}$ & Refs. \\
\hline $\begin{array}{l}\text { Dichloromethane } \\
\text { Chloroform } \\
\text { Carbon tetrachloride } \\
1,2 \text {-Dichloroethane } \\
1,1,1 \text {-Trichloroethane } \\
1,1,2,2 \text {-Tetrachloroethane } \\
1,2-\text { Ibromoethane } \\
\text { Vinyl chloride } \\
\text { Trichloroethylene } \\
1,1,2,2 \text {-Tetrachloroethylene } \\
\text { Bromoform } \\
1,2 \text {-Dichloropropane } \\
\text { Benzene } \\
\text { Toluene } \\
\text { o-Xylene } \\
\text { Chlorobenzene } \\
\text { 1,2-Dichlorobenzene } \\
1,4-\text { Dichlorobenzene } \\
1,2,4-\text { Trichlorobenzene } \\
\text { Ethyl benzene } \\
\text { Nitrobenzene } \\
\text { Fluorobenzene } \\
\text { Bromobenzene } \\
\text { Iodobenzene }\end{array}$ & $\begin{array}{l}- \\
1.97 \\
2.64 \\
- \\
- \\
- \\
- \\
- \\
2.29 \\
2.60 \\
- \\
- \\
2.13 \\
2.69 \\
2.77 \\
2.84 \\
3.38 \\
3.38 \\
4.02 \\
3.15 \\
1.85 \\
2.27 \\
2.99 \\
3.25\end{array}$ & $\begin{array}{r}20,000 \\
7,950 \\
800 \\
8,450 \\
1,360 \\
3,230 \\
3,520 \\
2,700 \\
1,100 \\
400 \\
3,190 \\
3,570 \\
1,780 \\
470 \\
175 \\
448 \\
148 \\
79 \\
19 \\
152 \\
1,900 \\
1,540 \\
446 \\
340\end{array}$ & $\begin{array}{c}349 \\
160 \\
90 \\
61 \\
100 \\
5 \\
11 \\
2.660 \\
57.9 \\
14 \\
5.6 \\
42 \\
76 \\
22 \\
5 \\
8.8 \\
1.5 \\
0.6 \\
- \\
7 \\
0.15 \\
- \\
3.3 \\
-\end{array}$ & $\begin{array}{l}1 \\
1,2 \\
1,2 \\
1,3 \\
1,3 \\
1,3 \\
1,3 \\
4,1 \\
5 \\
1,2 \\
1 \\
1,3 \\
1,2,6 \\
1,2 \\
1 \\
1,2 \\
1,3 \\
1,2 \\
1,7 \\
1,7 \\
1 \\
2 \\
1,2 \\
2\end{array}$ \\
\hline
\end{tabular}

1. Verschueren (1983)

2. Chiou and others (1977)

3. Chiou and others (1979)

4. Dilling (1977)

5. Callahan and others (1979)

6. Mackay (1977)

7. Chiou, Porter, and Schmedding (1983)

Other researchers similarly have noted the importance of volatilization. Helz and Hsu (1978) determined that evaporative losses were the primary cause of the attenuation of halogenated aliphatic hydrocarbons discharged into the Back River estuary in Maryland. Hill and others (1976) found that the rate of bulk exchange of gaseous vinyl chloride between water and air is about twice that of oxygen, and they concluded that volatilization probably is the most important process in its distribution. Within an 8-d period, Jensen and Rosenberg (1975) observed 80 percent removal of trichloroethylene from an open aquarium kept in the light. Concentrations of chloroform, 1,1,1-trichloroethane, and tetrachloroethylene were decreased by 40 to 50 percent over the same period. When the same compounds were incubated in closed systems (both light and dark), compound disappearance typically was less than 5 percent, indicating that solute volatilization was the most important fate process. Simi- larly, Wakeham and others (1983) stated that volatilization appeared to be the major process responsible for the removal of a variety of aromatic and chlorinated aromatic hydrocarbons from seawater.

Using theoretical considerations, Cadena and others (1984) presented a model to predict the aqueous concentrations of volatile organic contaminants (compounds having Henry's law constants greater than $1.6 \times 10^{-4}$ atm $-\mathrm{m}^{3} / \mathrm{mol}$ ) in streams as a function of traveltime and stream-reaeration coefficient. The derived relationship is given by

$$
\mathrm{C} / \mathrm{C}_{\mathrm{i}}=\exp \left(-\mathrm{K}_{2} \mathrm{t}\left(\mathrm{K} / \mathrm{K}^{\prime}\right)\right)
$$

where $C / C_{i}$ is the ratio of the concentration of the contaminant at traveltime $t$ to its initial concentration, $K_{2}$ is the stream reaeration constant, and $\mathrm{K} / \mathrm{K}^{\prime}$ is the ratio of the overall transfer coefficient for the volatile contaminant 
Table 30. Evaporation times for 50 and 90 percent removal of chlorinated aliphatic hydrocarbons [ 1 milligram per liter] at $25^{\circ} \mathrm{C}, 200$ revolutions per minute of stirring, and a depth of 6.5 centimeters

[From Dilling and others, 1975]

Time (minutes) for evaporation from water

Compound 50 percent 90 percent

Chlorome thane

Dichloromethane

Chloroform

Carbon tetrachloride

Chloroethane

1,1-Dichloroethane

1,2-Dichloroethane

1,1,1-Trichloroethane

1,1,2-Trichloroethane

1,1,1,2-Tetrachloroethane

1,1,2,2-Tetrachloroe thane

Pentachloroethane

Hexachloroethane

Vinyl chloride

1,1-Dichloroethylene

cis-Dichloroethylene

trans-Dichloroethylene

Trichloroe thylene

Tetrachloroethylene

1,1,2,3-Tetrachloropropane

$1,2,2,3$-Tetrachloropropane

3-Chloropropene

2-Chloropropene

1-Chloropropene

2,3-D1chloropropene

1,3-Dichloropropene

(cis and trans)

1,2,3-Trichloropropene

\begin{tabular}{rr}
27 & 91 \\
19 & 60 \\
20 & 68 \\
29 & 97 \\
21 & 79 \\
22 & 109 \\
29 & 96 \\
20 & 65 \\
21 & 102 \\
43 & $>120$ \\
56 & $>120$ \\
48 & $>140$ \\
45 & $>120$ \\
26 & 96 \\
22 & 89 \\
18 & 64 \\
24 & 83 \\
21 & 63 \\
25 & 86 \\
51 & $>120$ \\
47 & $>120$ \\
27 & 89 \\
29 & 110 \\
16 & 59 \\
20 & 68 \\
31 & 98 \\
49 & $>140$ \\
& \\
\hline &
\end{tabular}

to the overall transfer coefficient of a tracer compound. The value of $K_{2}$ is given by

$$
\mathrm{K}_{2}=5.015 \mathrm{v}^{0.969} / \mathrm{L}^{1.673} \text {, }
$$

where $v$ is stream velocity $(\mathrm{m} / \mathrm{s})$ and $L$ is mean stream depth. The value of $K_{2}$ can be corrected for temperature by multiplying $\mathrm{K}_{2}$ at $20^{\circ} \mathrm{C}$ by $(1.0238)^{\mathrm{T} \cdot 20}$, where $\mathrm{T}$ is stream temperature in degrees Celsius. Ratios of $K / K^{\prime}$ are presented in table $\mathbf{3 1}$ for a variety of halogenated aliphatic and MAH's.

Cadena and others (1984) verified their model by a pilot study using benzene and chlorobenzene at a variety of concentrations and reaeration rates. Figure 21 presents the results of their model applied to a hypothetical contamination problem in the Rio Grande River in New Mexico. The concentrations of both methylene chloride and dichlorobenzene are predicted to be below 10 percent of their initial concentration within $60 \mathrm{~km}$ from the point of discharge. The authors state that other halogenated aliphatic and MAH's also are likely to volatilize at similar rates, inasmuch as methylene chloride and dichlorobenzene represent the extremes in volatility of the compounds tested in this study.

Once volatilized from solution, many halogenated aliphatic and MAH's are degraded photolytically in the atmosphere. In laboratory experiments simulating atmospheric conditions, photolysis half-lives for vinylidene chloride, cis- and trans-dichloroethylene, trichloroethylene, and vinyl chloride ranged from 5 to $12 \mathrm{~h}$ under bright sunlight and in the presence of nitric oxide (Dilling and others, 1976). Half-lives for chlorobenzene, tetrachloroethylene, and 1,1,2-trichloroethane were slightly longer, ranging from 20 to $40 \mathrm{~h}$. Methylene chloride and 1,1,1trichloroethane, however, were resistant to photolysis, with respective half-lives of $>250$ and $>1,700 \mathrm{~h}$ reported. While the aqueous photodecomposition of many of the halogenated aliphatic and MAH's will not be considerable because of rapid volatilization, atmospheric photodecomposition of these compounds may be their ultimate fate (Hill and others, 1976; Helz and Hsu, 1978).

Analysis of available data suggests that some of the halogenated aliphatic and MAH's can be biologically and (or) chemically degraded in surface-water systems, but

Table 31. Ratios of overall transfer coefficients for selected aliphatic and monocyclic aromatic hydrocarbons $(K)$ to overall transfer coefficients for oxygen $\left(\mathrm{K}^{\prime}\right)$

[From Cadena and others, 1984]

Compound

$\mathrm{K} / \mathrm{K}^{\prime}$

1,4-Dichlorobenzene

0.45

1,2-Dichlorobenzene

.46

1,3-Dichlorobenzene

.46

Chlorobenzene

.49

1,1,2-Trichloroethane

.49

Tetrachloroethylene

.50

Carbon tetrachloride

.51

Benzene

.53

Trichlorofluoromethane

.54

Chloroform

.55

1,1-Dichloroethane

.55

1,2-Dichloropropane

.57

1,2-Dfchlorothane

.58

Dichlorodifluoromethane $\quad .58$

Acrylonitrile $\quad .59$

Chloroethane .61

Dichloromethane $\quad .62$

Vinyl chloride $\quad .66$

Methylene chloride $\quad .73$ 


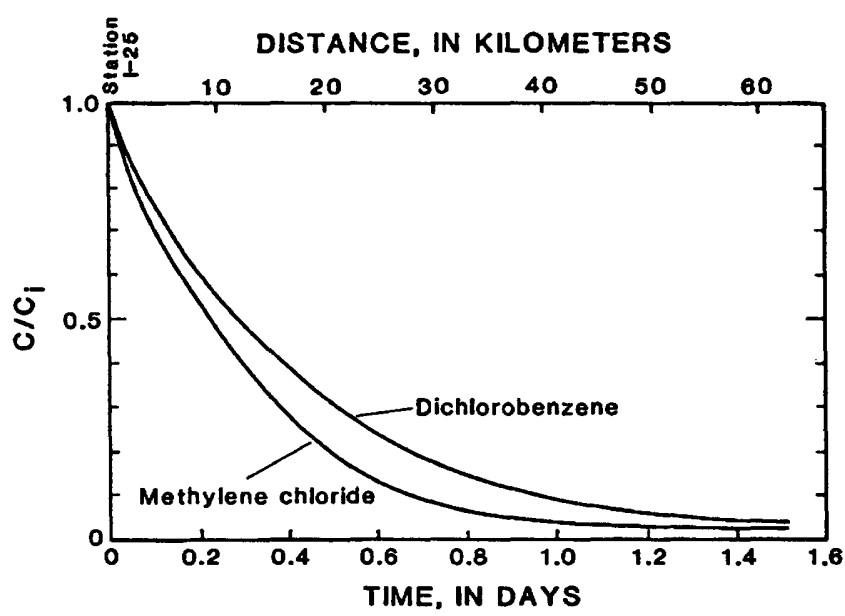

Figure 21. Graph of predicted volatilization rates of methylene chloride and dichlorobenzene in the Rio Grande River, N. Mex. $C / C_{1}$ is the ratio of the concentration of the contaminant at travel time t to its initial concentration. [Reprinted with permission from Journal of the Water Pollution Control Federation, v. 56 , p. 460 (1984).]

degradation rates are slow compared with volatilization rates for these compounds. Helz and Hsu (1978) noted that many halogenated aliphatic compounds were rapidly volatilized from a Maryland estuary. However, they also observed nonconservative downstream mixing of the contaminants during winter, when the river was ice covered and substrate evaporation was minimal. They concluded that some biological or chemical degradation also was occurring. Wakeham and others (1983) also reported that volatilization was the primary fate process for aromatic hydrocarbons in seawater, but they noted that summer biodegradation of these compounds can also be an important process. In closed systems that were incubated in the dark, Jensen and Rosenberg (1975) observed slow degradation of 1,1,2-trichloroethane and 1,1,2,2-tetrachloroethylene. Other compounds, such as vinyl chloride, are highly resistant to biological or chemical degradation in natural surface waters (Hill and others, 1976).

Because of their high solubilities and low octanolwater partition coefficients, the majority of the halogenated aliphatic and MAH's will not strongly partition into sediment organic matter or biological lipid reservoirs. However, some of the chlorinated benzenes have been observed to bioaccumulate. Könemann and van Leeuwen (1980) found that the increasing octanol-water partition coefficients of the chlorobenzenes correlated with increased BCF's. Guppies exposed to aqueous chlorobenzene concentrations exhibited lipid-normalized BCF's ranging from 1,800 (1,4-dichlorobenzene) to 72,000 (1,2,3,5-tetrachlorobenzene). Oliver and Niimi (1983) observed a similar bioconcentration trend for the chlorobenzenes accumulated by rainbow trout, with BCF's as high as 4,100 reported for 1,3,5-trichlorobenzene. Lower BCF's were reported for the less chlorinated benzenes. Sediments rich in organic matter also can accumulate appreciable amounts of tri- and tetrachlorobenzenes. Chiou, Porter, and Schmedding (1983) reported organicmatter-normalized sorption coefficients of 500 and 190 for 1,2,4-trichlorobenzene and 1,4-dichlorobenzene partitioned between water and a Woodburn silt loam soil having 1.9 percent organic-matter content. In contrast, the distribution coefficient for chlorobenzene was only 50 .

Based on their tendency to rapidly volatilize from solution, aliphatic and MAH's are not persistent environmental contaminants in surface-water systems. Secondary fate processes include biological and chemical degradation, but these rates are slow relative to evaporative loss rates. With the possible exception of some of the highly chlorinated benzenes, sorption and bioaccumulation are not important fate mechanisms.

\section{Environmental Distribution}

Aliphatic and MAH's are natural components of oil deposits and commonly find their way into surface waters as a result of discharges from refineries, waste oil disposal, and accidental spills. Municipal wastewater discharges also have been recognized as sources of aliphatic and MAH discharges (Barrick, 1982). Chlorinated aliphatic hydrocarbons are commonly found in chlorinated water and wastewater effluents and in industrial discharges. Chlorinated benzenes may enter the environment as a result of their use as solvents, heat-transfer fluids, flame retardants, or chemical intermediates or as waste products of the electro-industry (Jan and Malnersic, 1980).

Point discharges have contributed large amounts of aliphatic and MAH's to surface waters. Barrick (1982) determined that primary sewage effluent from Seattle discharges an average of $475 \mathrm{Mg} / \mathrm{yr}$ of aliphatic hydrocarbons into central Puget Sound. Eganhouse and Kaplan (1982) similarly noted that southern California treatment plants discharge hydrocarbons into coastal waters at an annual rate of $17,400 \mathrm{Mg}$. Brooks and others (1981) documented concentrations of aliphatic hydrocarbons with 5 to 14 carbon atoms to be as high as $400 \mu \mathrm{g} / \mathrm{L}$ as the result of an oil well blowout in the Gulf of Mexico. Middleditch and Basile (1980) have reported that oil platforms in the northwest portion of the gulf routinely discharge $200 \mathrm{~g} / \mathrm{d}$ of alkanes. Halogenated aliphatic and MAH's such as methylene chloride ( 3 to $8 \mathrm{ppm}$ ), toluene (13 to $20 \mathrm{ppm})$, and chlorobenzenes $(0.50 \mathrm{ppm})$ have been detected in the effluents of chemical-manufacturing plants (Jungclaus and others, 1978; Sheldon and Hites, 1979). Because of the volatility of the halogenated aliphatic and MAH's, however, these effluent concentrations are usually rapidly reduced to much lower levels. 
Because of the large quantities of halogenated aliphatic and MAH's produced annually in the United States, these compounds are ubiquitous contaminants in surface waters. Their aqueous concentrations, however, are usually in the parts-per-billion range as a result of their tendency to volatilize into the atmosphere. Higher concentrations usually are limited to specific discharge points. While Brooks and others (1981) reported volatile hydrocarbon residues as high as $400 \mu \mathrm{g} / \mathrm{L}$ in the vicinity of an oil-well blowout, residues 6 and $12 \mathrm{mi}$ down plume were reduced to 63 and $4 \mu \mathrm{g} / \mathrm{L}$, respectively. Oliver and Nicol (1982) reported low concentrations of chlorobenzenes in the Great Lakes, with the highest mean concentration being observed for 1,4-dichlorobenzene ( $45 \mathrm{ng} / \mathrm{L}$ ) in Lake Ontario. Parts-per-trillion residues have also been reported by Schwarzenbach and others (1979) in Lake Zurich, Switzerland. Concentrations of 1,4-dichlorobenzene and tetrachloroethylene in the lake's upper basin were 10 and $40^{\prime} \mathrm{ng} / \mathrm{L}$, respectively.

With the possible exception of some of the chlorobenzenes, biological residues of the aliphatic and the MAH's are generally in the parts-per-billion range. Ferrario and others (1985) detected a variety of chlorinated aliphatic and MAH's in clams and oysters from Lake Pontchartrain, La. Detectable concentrations ranged from $0.04 \mathrm{ppb}$ for chlorobenzene to $310 \mathrm{ppb}$ for 1,1,1trichloroethane. Jan and Malnersic (1980) reported total chlorobenzene residues in fish from Yugoslavian surface waters to range from $1.8 \mathrm{ppm}$ (expressed on a fat basis) near industrial areas to $0.2 \mathrm{ppm}$ near agricultural and wooded areas. Oliver and Nicol (1982) also quantified the concentrations of a variety of chlorobenzenes in trout from the Great Lakes. Again, residues were in the parts-per-billion range, varying from 0.05 (1,2,3,5-tetrachlorobenzene) to $12 \mathrm{ppb}(1,2,3,4-$ tetrachlorobenzene).

Similar to biological residues, sediment residues of halogenated aliphatic and MAH's are typically in the parts-per-billion range. Chlorobenzene residues in the surficial sediments of Lake Ontario have been reported to range from 1 to $320 \mathrm{ppb}$ (Oliver and Nicol, 1982). Lower concentrations were reported for Lakes Superior, Huron, and Erie. Chlorobenzenes sorbed to suspended sediments in the Niagara River also had concentrations in the parts-per-billion range, with the highest concentration reported for 1,4-dichlorobenzene (160 ppb) (Oliver and Charlton, 1984). Benzene (21 ppb) and chloroform (18 $\mathrm{ppb}$ ) had the highest concentrations of a variety of chlorinated aliphatic and MAH's detected in the sediments of Lake Pontchartrain, La. (Ferrario and others, 1985). In a study of the effects of an industrial discharge on a stream, Jungclaus and others (1978) found that effluent toluene and methylene chloride concentrations of 13 to 20 and 3 to $8 \mathrm{ppm}$, respectively, caused no detectable residues of either compound in the stream sediment.
Few data were found in the reviewed literature with regard to spatial or temporal contamination trends in the United States; however, based on production and use data, some general conclusions can be drawn. The production of halogenated aliphatic and MAH's increased significantly until the late 1970's, when production of many of the compounds either slowed or declined (table 27). Therefore, temporal trends in surface-water contamination are likely to mirror production. Sediment-core data from the Great Lakes confirm this hypothesis. Oliver and Nicol (1982) reported that chlorobenzene residues in Great Lakes sediments increased rapidly from about 1940 (6- to 7-cm sediment core depth) to the early 1970's (1- to 2 -cm sediment core depth). Surficial sediment residues (0- to 1-cm sediment core depth), however, were generally lower than residues at a $1-$ to $2-\mathrm{cm}$ depth, paralleling the decreased production of chlorobenzenes in the late 1970's. Despite this decline, surficial sediment residues were still higher than sediment residues at the 2- to $3-\mathrm{cm}$ depth (1965-71).

Halogenated aliphatic and MAH's are found principally in industrial and municipal wastewater effluents, and, as a result, significant environmental residues of these contaminants are most commonly found near industrial areas (Jan and Malnersic, 1980). Surface waters draining agricultural or forested areas are less likely to have significant residues of halogenated aliphatic and MAH's than are densely populated and industrialized areas. Nonhalogenated aliphatic and MAH's also are commonly found in coastal waters near oil-drilling and oil-production areas because of their presence in natural oil.

\section{PHTHALATE ESTERS}

\section{Uses, Production, and Properties}

The phthalate esters are derivatives of phthalic acid (the ortho isomer of benzene dicarboxylic acid) and are characterized by the following structure:

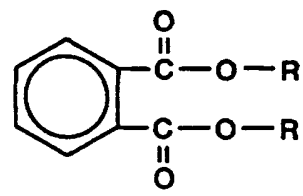

where $\mathbf{R}$ is either an alkyl or aryl group. Structural diagrams of some of the phthalate esters are presented in figure 22 .

The phthalate esters are manufactured by the oxidation of either naphthalene or o-xylene to produce phthalic anhydride, which is subsequently combined with the desired alcohol (Peakall, 1975). Phthalate esters are used extensively as plasticizers to produce useful products from polymers of vinyl chloride, propylene, ethylene, and 


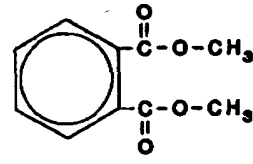

o-Dimethyl phthalate

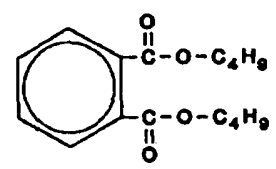

DI-n-butyl phthalate

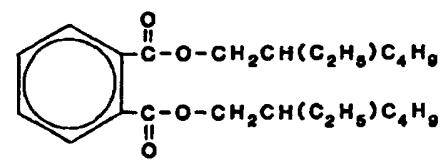

Bis(2-ethylhexyl) phthalate

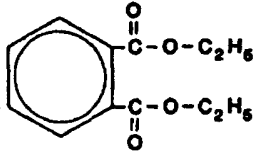

Diethyl phthalate

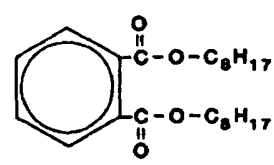

Di-n-octyl phthalate

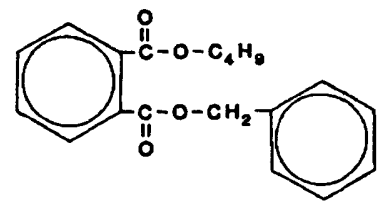

Butyl benzyl phthalate
Figure 22. Structural diagrams of some common phthalate esters.

styrene. Commonly, their contribution to the weight of the plastic is second only to the weight of the polymer itself (Mathur, 1974). Uses of plastics include home construction, appliances, furnishings, automobiles, apparel, and food containers and wrappings. Table 32 documents the relative use of phthalate esters for these various products in the United States, along with the small proportion of nonplasticizer use. The amount of solid waste generated from these uses has been estimated to be in excess of 12 billion kg annually in the United States (Mathur, 1974).

The manufacture of phthalate esters in the United States has increased rapidly over the last $25 \mathrm{yr}$. Production from 1961 to 1970 increased at an average annual rate of 10 percent (Peakall, 1975). Total annual production of phthalate esters in the United States reached nearly $5 \times 10^{8} \mathrm{~kg}$ in 1978 and has continued to increase (Giam and others, 1978). World production has been estimated to be three to four times the U.S. production, and some of the leading foreign manufacturers of phthalate esters include Japan, the U.S.S.R., and Germany (Peakall, 1975). Of the various esters of phthalic acid, bis(2ethylhexyl) phthalate is one of the most widely used, with 158.8 million $\mathrm{kg}$ produced in the United States in 1970 (Mathur, 1974). As a result of their large-scale production, phthalates are frequently identified as contaminants in the water, sediment, and biota of surface-water systems.

The phthalate esters are relatively stable, colorless liquids of medium viscosity and low volatility. Table 33 presents some of the physicochemical properties of the phthalate esters.
Table 32. Uses of phthalate esters in the United States [From Peakall, 1975]

Percentage

of total use

A. As plasticizers

$\begin{array}{lr}\text { Bullding and construction } & \\ \text { Wire and cable } & 21 \\ \text { Flooring } & 17 \\ \text { Swimming pool liners } & 2 \\ \text { Miscellaneous } & 4 \\ \text { Home furnishings } & \\ \text { Furniture upholstery } & 10 \\ \text { Wall coverings } & 4 \\ \text { Houseware } & 3 \\ \text { Miscellaneous } & 13 \\ \text { Cars (upholstery, tops, etc.) } & 8 \\ \text { Wearlng apparel } & 3 \\ \text { Food wrapping and closures } & 3 \\ \text { Medical tubing and intravenous bags } & 94 \\ \quad \text { Total as plastleizers } & \end{array}$

B. As nonplasticizers

Pesticide carriers

OIls

Insect repellent

Total as nonplasticizers

21
17
2
4

10
4
3
6
13
8
3
3
94

A dash indicates that exact data are not available.

\section{Environmental Fate}

The reviewed literature contained only sparse information on the environmental fate of the phthalate esters, and most studies.were limited to bis(2-ethylhexyl) phthalate. Based on the available data, however, biodegradation, sorption, and bioaccumulation appear to be important fate-determining processes.

Phthalate esters have been metabolized by both isolated and mixed bacterial cultures, undergoing primary and ultimate biodegradation by enzyme-catalyzed hydrolysis. Of the group, bis(2-ethylhexyl) and di-n-octyl phthalate have been determined to be the most resistant to biodegradation, but data indicate that even these two compounds can be at least partially degraded (Tabak and others, 1981). Mathur and Rouatt (1975) isolated a bacterium, Serratia marcescens Bizio, capable of using both bis(2-ethylhexyl) phthalate and di-n-octyl phthalate as sole sources of carbon and energy. The primary degradation product of these phthalates appeared to be o-phthalic acid. Fairbanks and others (1985) observed the degradation of bis(2-ethylhexyl) phthalate to $\mathrm{CO}_{2}$ in sludge-amended soils. Half-lives ranged from 8 to $72 \mathrm{~d}$, and after $146 \mathrm{~d}, 76$ to 93 percent of the phthalate ester was degraded to $\mathrm{CO}_{2}$. A strain of Enterobacter aerogenes, isolated from the inside of plastic tubing used as an outlet for deionized water, degraded dimethyl phthalate as a sole carbon source (Perez and others, 1977). The culture 
Table 33. Solubilities and vapor pressures of selected phthalate esters $[\mathrm{mg} / \mathrm{L}$, milligrams per liter, $\mathrm{mm}$, millimeters]

\begin{tabular}{lccc}
\hline Compound & $\begin{array}{c}\text { Solubility } \\
(\mathrm{mg} / \mathrm{L})\end{array}$ & $\begin{array}{c}\text { Vapor pressure } \\
(\mathrm{mm} \text { of } \mathrm{Hg})\end{array}$ & Reference \\
\hline Dimethyl phthalate & $5000\left(20^{\circ} \mathrm{C}\right)$ & $0.01\left(20^{\circ} \mathrm{C}\right)$ & 1 \\
Diethyl phthalate & $896\left(25^{\circ} \mathrm{C}\right)$ & $.05\left(70^{\circ} \mathrm{C}\right)$ & 1 \\
Di-n-butyl phthalate & $13\left(20^{\circ} \mathrm{C}\right)$ & $.10\left(115^{\circ} \mathrm{C}\right)$ & 1 \\
Di-n-octyl phthalate & $3\left(25^{\circ} \mathrm{C}\right)$ & $.20\left(150^{\circ} \mathrm{C}\right)$ & 1 \\
Bis(2-ethylhexyl) phthalate & $0.4\left(25^{\circ} \mathrm{C}\right)$ & $2 \times 10^{-7}\left(20^{\circ} \mathrm{C}\right)$ & 1 \\
Butyl benzyl phthalate & 2.9 & $8.6 \times 10^{-6}\left(20^{\circ} \mathrm{C}\right)$ & 1,2 \\
\hline
\end{tabular}

1. Callahan and others (1979)

2. Verschueren (1983)

degraded a dimethyl phthalate concentration of $1,000 \mathrm{ppm}$ to less than $400 \mathrm{ppm}$ in $41 \mathrm{~d}$. Engelhardt and Wallnofer (1975) determined that a variety of microorganisms were capable of degrading di-n-butyl, di-n-octyl, bis(2ethylhexyl), and dimethyl phthalates and suggested that mixed microbial populations can readily metabolize phthalate esters. Their proposed pathway for the degradation of di-n-butyl phthalate by different soil microorganisms is presented in figure 23 .

As a result of their low solubilities, some of the phthalate esters strongly partition into the lipid reservoirs of aquatic organisms and sediment organic matter. Table 34 documents BCFs for bis(2-ethylhexyl), di-n-octyl, and di-n-butyl phthalates for a variety of aquatic organisms (Sanborn and others, 1975; Callahan and others, 1979). The data indicate that all three compounds exhibit significant bioaccumulation. The BCF's range from 130 to 100,000 , with variations reflecting differences in organism lipid content, compound solubility, and duration of exposure. Few sorption data are available for the phthalate esters. However, Matsuda and Schnitzer (1971) presented data indicating that a variety of dialkyl phthalates can partition into dissolved fulvic acid, significantly enhancing their apparent solubilities. Using batch sorption studies with solution/soil ratios ranging from 5 to 300 , Fairbanks and others (1985) noted that as much as 87 percent of the bis(2-ethylhexyl) phthalate added to centrifuge tubes was sorbed to the glass. Of the amount remaining, 96 to 99 percent was sorbed to the soil, suggesting that significant sorption to sediments may occur in natural systems. Because phthalate esters have been frequently detected in surface-water sediments and biota, it is likely that both bioaccumulation and sorption will influence their environmental fate.
Table 34. Selected bioconcentration factors (BCF's) of phthalate esters in aquatic systems

[From Callahan and others, 1979, and Sanborn and others, 1975]

\begin{tabular}{llcr}
\hline Phthalate ester & Aquatic organism & $\begin{array}{c}\text { Exposure } \\
\text { time (days) }\end{array}$ & \multicolumn{1}{c}{ BCF } \\
\hline Bis(2-ethylhexyl) & Fish & - & 130 \\
Bis(2-ethylhexyl) & Sowbug & 14 & 230 \\
Bis(2-ethylhexy1) & Fathead minnow & 28 & 800 \\
Bis(2-ethylhexyl) & Scud & 14 & 13,400 \\
Bis(2-ethylhexyl) & Snail & - & 21,000 \\
Bis(2-ethylhexyl) & Mosquito 1arvae & - & 100,000 \\
Di-n-octyl & Daphnia & 33 & 2,600 \\
Di-n-octy1 & Fish & 33 & 9,400 \\
Di-n-octyl & Algae & 33 & 28,500 \\
Di-n-butyl & Waterflea & 14 & 5,000 \\
Di-n-butyl & Scud & 14 & 6,700 \\
\hline
\end{tabular}

Nonbiological hydrolysis, volatilization, and photolysis do not appear to be significant fate-determining processes for the phthalate esters. Estimated hydrolytic half-lives range from $3.2 \mathrm{yr}$ for dimethyl phthalate to 2,000 yr for bis(2-ethylhexyl) phthalate (Callahan and others, 1979). Evaporative losses of phthalate esters from surface waters also are minor because of their relatively low vapor pressures. Fairbanks and others (1985), for example, detected no volatilization of bis(2-ethylhexyl) phthalate applied to three sludge-amended soils. Finally, 

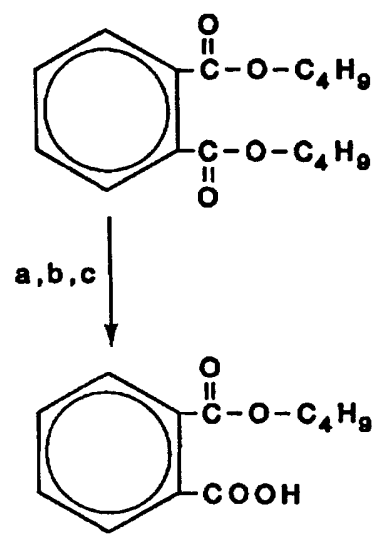

c

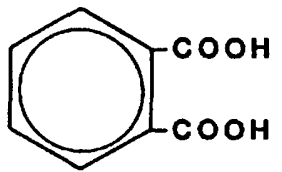

c

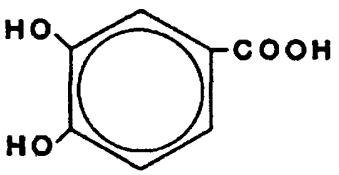

c

further

degradation

Figure 23. Structural diagrams showing degradation of di-n-butyl phthalate (DBP), mono-n-butyl phthalate, and phthalic acid by different microorganisms: (a) organisms isolated with DBP as carbon source for enrichment, (b) stock cultures, (c) bacteria isolated from phthalic acid enrichment medium. [Reprinted with permission from Bulletin of Environmental Contamination and Toxicology, v. 13, p. 344 (1975). Copyright 1975 by Springer-Verlag New York, Inc.]

although no data were found on the photodecomposition of phthalate esters in aquatic systems, it is unlikely that they are degraded photolytically since they do not possess significant absorption maximums in the ultraviolet and visible regions of the electromagnetic spectrum (Callahan and others, 1979).

\section{Environmental Distribution}

Reported environmental levels of anthropogenically produced phthalate esters may be inaccurate because of the possible natural origins of these compounds and sample contamination by plastic sample containers. There is strong evidence that phthalate esters have natural as well as anthropogenic origins. Ortho-phthalic acid has been detected in wood and in the oxidation products of lignin, and as the product of the chemical and biological oxidation of compounds, such as naphthalene and its derivatives (Mathur, 1974). Phthalides also appear to be common constituents of plants, with phthalates serving as intermediates in biochemical pathways. Mathur (1974) has stated that, because phthalates and aliphatic alcohols are present in plants, it is reasonable to assume that phthalate esters are synthesized naturally in the environment. Additionally, phthalate esters in plastic sample containers can easily contaminate natural water, sediment, or biological samples. For example, phthalate esters have been found in extracts of the lining of plastic bags and in uncontaminated sand shaken in the bag (Mathur, 1974). As a result, reported environmental residues of phthalate esters may not simply reflect the anthropogenic origins of this group of compounds.

Peakall (1975) has ranked the uses of phthalate esters according to likelihood of escape into the environment. Nonplasticizer uses, such as pesticide carriers, insect repellent, cosmetics, fragrances, and oils, have the highest likelihood of escape, because the phthalate ester is not encased in a polymer matrix. Phthalate ester plasticizers used directly in contact with water pose the second-greatest risk of escaping to the environment and include swimming-pool liners, garden hoses, and medical uses. Other plasticizer uses that involve only contact with air are the least likely to result in phthalate ester loss to the environment. Additionally, phthalate esters have been reported in industrial discharges. Sheldon and Hites (1979) reported concentrations of dibutyl, butyl benzyl, and bis(2-ethylhexyl) phthalate in an industrial effluent of 50,40 , and $200 \mathrm{ppb}$, respectively.

Phthalate esters have been detected in numerous coastal- and inland-water samples. Giam and others (1978) reported concentrations of di-n-butyl phthalate as high as $0.471 \mathrm{ppb}$ and concentrations of bis(2-ethylhexyl) phthalate as high as $0.316 \mathrm{ppb}$ in water samples from the Gulf of Mexico. Both of these compounds also have been detected in the Tama River near Tokyo, Japan, with concentrations ranging from 0.4 to $6.8 \mathrm{ppb}$ (Morita and others, 1974). Jungclaus and others (1978) reported even higher concentrations in a small, freshwater river; concentrations of bis(2-ethylhexyl) phthalate ranged from 1 to 50 $\mathrm{ppb}$, and concentrations of di-n-octyl phthalate ranged from 1 to $20 \mathrm{ppb}$. Sheldon and Hites (1979) also reported the presence of aqueous phthalate esters, with concentrations in the Delaware River near Philadelphia as high as $0.6 \mathrm{ppb}$ for butyl benzyl phthalate and $1.0 \mathrm{ppb}$ for bis(2-ethylhexyl) phthalate. Similarly, maximum bis(2ethylhexyl) phthalate concentrations of 1.98 and $3.10 \mathrm{ppb}$ 
were reported by Thuren (1986) in water samples from the Rivers Svartan and Ronnebyan, respectively, in southern Sweden.

Sediment residues of phthalate esters also have been reported frequently, with detected concentrations usually ranging from a few parts per billion to a fraction of a part per million. In a study of the Chester River in Maryland, Peterson and Freeman (1984) reported maximum sediment residues of diethyl, diallyl, diisobutyl, dibutyl, dihexyl, bis(2-ethylhexyl), and di-n-octyl phthalate of $44,5.5,27.6,900,6.4,4,800$, and $62 \mathrm{ppb}$, respectively. The maximum concentrations of dibutyl phthalate (69 $\mathrm{ppb}$ ) and bis(2-ethylhexyl) phthalate (248 ppb) found in sediment samples from the Gulf Coast and Mississippi River Delta were slightly lower (Giam and others, 1978). Much higher sediment concentrations were reported by Jungclaus and others (1978) and Van Luik (1984). The former study detected both bis(2-ethylhexyl) and di-noctyl phthalate at concentrations ranging from 250 to $56,000 \mathrm{ppb}$ in sediment samples collected downstream from a chemical manufacturing plant's discharge. The study by Van Luik (1984), which analyzed sediments from the Calumet Sag Channel (Ill.), determined that the average sediment concentration of bis(2-ethylhexyl) phthalate was $29,800 \mathrm{ppb}$, with a high value of $63,770 \mathrm{ppb}$.

Laboratory studies have indicated that phthalate esters can bioaccumulate, and these results have been confirmed in field studies identifying significant residues of phthalate esters in aquatic organisms. Despite aqueous bis(2-ethylhexyl) phthalate concentrations of $0.316 \mathrm{ppb}$ or less, biota from the Gulf of Mexico contained concentrations ranging from 1 to $135 \mathrm{ppb}$ (Giam and others, 1978). DeVault (1985) detected high concentrations of both bis(2-ethylhexyl) and di-n-butyl phthalate in two fish from the Menominee and Kinnickinnic Rivers in Wisconsin. Unfortunately, no aqueous concentrations were reported. The ubiquity of phthalate esters is evidenced by the data of Stalling and others (1973), who detected residues of bis(2-ethylhexyl) phthalate in fish collected throughout the United States. Concentrations ranged from 0.2 to 10 ppm and appeared highest near industrialized areas.

\section{POLYCHLORINATED DIBENZO-P-DIOXINS}

\section{Uses, Production, and Properties}

The polychlorinated dibenzo-p-dioxins (PCDD's) are characterized by the following structure:

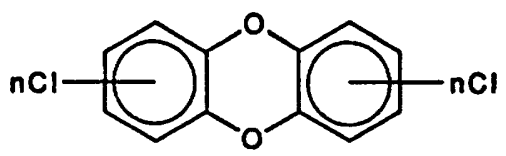

Chlorination of the molecule can produce a total of 75 chlorinated species, ranging from monochlorodibenzo-pdioxin to octachlorodibenzo-p-dioxin.

Although not deliberately manufactured and having no commercial use, PCDD's are produced inadvertently during the manufacture of 2,4,5-trichlorophenol (2,4,5-T) from 1,2,4,5-tetrachlorobenzene (fig. 24). Because 2,4,5$T$ is used in the production of a variety of pesticides along with tetra- and pentachlorophenol, PCDD's have been found as contaminants in many of these compounds. Table 35 documents the detected residues of tetra-, hexa-, hepta-, and octachlorodibenzo-p-dioxin in several pesti-

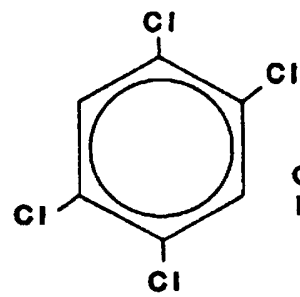

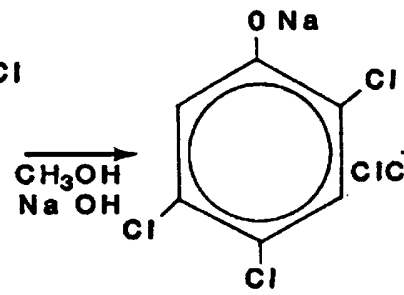

$$
2
$$

1,2,4,5-Tetrachlorobenzene

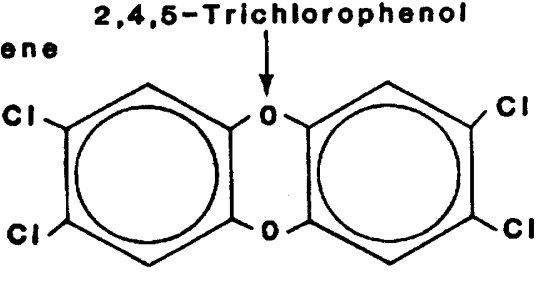

TCDD

Figure 24. Structural diagrams showing formation of 2,3,7,8-tetrachlorodibenzo-p-dioxin (TCDD) as a byproduct in the synthesis of 2,4,5-trichlorophenoxyacetic acid (2,4,5-T). [Reprinted with permission from Journal of Environmental Quality, v. 7, p. 172 (1973). Copyright 1973 by the American Society of Agronomy, Crop Science Society of America, and Soil Science Society of America.] 
Table 35. Chlorinated dibenzo-p-dioxins found in commercial pesticides [From Helling and others, 1973]

\begin{tabular}{|c|c|c|c|c|c|c|}
\hline \multirow[b]{2}{*}{ Pesticide } & \multicolumn{4}{|c|}{$\begin{array}{c}\text { Chlorodibenzo-p-dioxin } \\
\text { detected }\end{array}$} & \multicolumn{2}{|c|}{ Samoles } \\
\hline & $\overline{\text { Tetra- }}$ & Hexa- & Hepta- & Octa- & Contaminated & Tested \\
\hline $2,4,5-T$ & $\star \star$ & ** & - & - & 23 & 42 \\
\hline Silvex & * & - & - & - & 1 & 7 \\
\hline $2,4-D$ & - & * & - & - & 1 & 24 \\
\hline $2,4-D B$ & - & - & - & - & 0 & 3 \\
\hline 2,4-DEP & - & - & - & - & 0 & 2 \\
\hline Dichlorprop & - & - & - & - & 0 & 1 \\
\hline Erbon & - & - & - & ** & 1 & 1 \\
\hline Sesone & - & * & - & - & 1 & 1 \\
\hline Dicamba & - & - & - & - & 0 & 8 \\
\hline \multicolumn{7}{|l|}{ Chlorophenols } \\
\hline $\operatorname{Tr} i-$ & - & * & * & * & 4 & 6 \\
\hline Tetra- & - & $* *$ & ** & $\star \star$ & 3 & 3 \\
\hline Penta- & - & ** & ** & $* *$ & 10 & 11 \\
\hline Others & - & ** & ** & * & 5 & 22 \\
\hline $\begin{array}{l}\text { * Concentra } \\
\text { per milli } \\
\text { * Concentra } \\
-\quad \text { Concentra } \\
\text { DMPA, ron } \\
\text { hexachlor } \\
\text { residues }\end{array}$ & $\begin{array}{l}\text { on of at } \\
\text { (ppm) } \\
\text { on of at } \\
\text { on was } 1 \\
1 \text {, and } t \\
\text { hene, ne }\end{array}$ & $\begin{array}{l}\text { least } \\
\text { least } \\
\text { ess thar } \\
\text { etradif } \\
\text { matocide }\end{array}$ & $\begin{array}{l}\text { e sampl } \\
\text { e sampl } \\
\text { the } 0.5 \\
\text { had } \mathrm{ch} \\
\text { and } \mathrm{ni}\end{array}$ & $\begin{array}{l}\text { was b } \\
\text { was } g \\
\text { ppm de } \\
\text { corodio } \\
\text { rofen }\end{array}$ & $\begin{array}{l}\text { reen } 0.5 \text { and } 10 \\
\text { ter than } 10 \\
\text { tion } 1 \text { imit } \\
\text { residues; chl } \\
\text { no detectable }\end{array}$ & $\begin{array}{l}\text { parts } \\
\text { oroneb, }\end{array}$ \\
\hline
\end{tabular}

cides that were manufactured between 1950 and 1970 . Although the extent of contamination is likeiy to vary with manufacturer, one company produced 2,4,5-T from 1966 to 1968 that typically contained $10 \mathrm{ppm}$ of $2,3,7,8-$ tetrachlorodibenzo-p-dioxin (TCDD). Of 42 samples of 2,4,5-T tested, 23 contained detectable residues of PCDD's. One analyzed sample of pentachlorophenol contained nearly $1,000 \mathrm{ppm}$ of both hepta- and octachlorodibenzo-p-dioxin (Helling and others, 1973). More recent commercial production of such compounds as 2,4,5-T has resulted in much lower residues, with TCDD concentrations usually less than $0.1 \mathrm{ppm}$ (Isensee and Jones, 1975).

PCDD's are extremely toxic compounds. They were first identified as environmental contaminants in 1970 as a result of a report by the Office of Science and Technol- ogy noting that mice given a relatively large dose of the herbicide 2,4,5-T during early pregnancy produced an abnormally high number of deformed offspring (Helling and others, 1973). Analysis of the 2,4,5-T given to the mice revealed that it contained approximately $27 \mathrm{ppm}$ of TCDD. Subsequent studies have shown that PCDD's have very high mammalian toxicities. Table 36 reports the single oral doses of some PCDD's required to kill 50 percent of the exposed animals $\left(\mathrm{LD}_{50}\right)$. TCDD appears to be the most toxic of the PCDD's, with an $\mathrm{LD}_{50}$ of just 2 $\mu \mathrm{g} / \mathrm{kg}$ for guinea pigs. TCDD $\mathrm{LD}_{s 0}$ values of $10 \mu \mathrm{g} / \mathrm{kg}$ for rabbits and $0.6 \mu \mathrm{g} / \mathrm{kg}$ for guinea pigs have also been documented (Isensee and Jones, 1975).

Some of the less severe effects of PCDD exposure to humans include changes in skin color, skin rashes, excessive hair growth, tingling and numbness of the arms 
Table 36. Single oral doses of dioxins necessary to kill 50 percent of exposed animals $\left(L_{50}\right)$

[ $\mu \mathrm{g} / \mathrm{kg}$ bw, micrograms per kilogram of body weight. From Kriebel, 1981]

\begin{tabular}{clr}
\hline Dibenzo-p-dioxin & Animal & $\begin{array}{c}\mathrm{LD}_{50} \\
(\mu \mathrm{g} / \mathrm{kg} \mathrm{bw})\end{array}$ \\
\hline $\begin{array}{c}\text { 2,3,7,8- } \\
\text { tetrachloro- }\end{array}$ & $\begin{array}{l}\text { Guinea pig } \\
\text { Rat (male) }\end{array}$ & 2 \\
& $\begin{array}{l}\text { Rabbit } \\
\text { Mouse }\end{array}$ & 115 \\
$1,2,3,7,8-$ & 284 \\
pentachloro- & Guinea pig & 3 \\
$1,2,3,4,7,8-$ & Mouse & 338 \\
hexachloro- & Guinea pig & 73 \\
& Mouse & 825 \\
\hline
\end{tabular}

and legs, and liver damage (Kriebel, 1981). TCDD exposure has also been linked to certain cases of birth defects. Pregnant women living near Alsea, Oreg., experienced a significant increase in the number of spontaneous abortions during the months of June and July from 1972 to 1977. From March to June of each of these years, herbicides, including 2,4,5-T, were routinely applied to nearby forests (Kriebel, 1981). Similarly, many Vietnam veterans claim that PCDD's in Agent Orange (approximately a 1:1 mixture of 2,4,5-T and 2,4-D) applied to Vietnamese forests have caused birth defects in their children (Kriebel, 1981). These examples indicate that even the low residues of PCDD's found in certain herbicides may cause adverse health effects owing to the high toxicity of the PCDD's.

Inasmuch as PCDD's are not deliberately manufactured, only gross estimates of production can be made. Based on a combined annual production figure of 30,000 $t$ for 2,4,5-T, and tri-, tetra-, and pentachlorophenol in the United States, and assuming that the production of each kilogram of the technical grade formulation results in the production of $1 \mathrm{mg}$ of PCDD, then approximately $30 \mathrm{~kg}$ are produced each year from these sources. Similarly, more than 40,000 t of Agent Orange were sprayed over the jungles of Southeast Asia, with the formulation having a mean TCDD concentration greater than $1.9 \mathrm{mg} / \mathrm{kg}$ (Crosby and Wong, 1977).

Although PCDD's are produced as byproducts in the manufacture of trichlorophenol, their properties and environmental behavior more closely resemble those of the chlorinated insecticides. As a group, they are sparingly soluble, lipophilic compounds of relatively long environmental persistence. Increased chlorination correlates with decreased solubility and increased lipophilicity.
Table 37. Bioconcentration factors (BCF's) of 2,3,7,8-tetrachlorodibenzo-p-dioxin (TCDD) for a variety of aquatic organisms

[From Isensee and Jones, 1975]

\begin{tabular}{lcc} 
Organism & Exposure time, days & BCF \\
\hline Algae & 30 & $2,000-18,600$ \\
Duckweed & 30 & $1,200-5,000$ \\
Snails & 30 & $1,400-47,100$ \\
Daphnids & 30 & $7,800-48,000$ \\
Mosquito fish & 3 & $1,000-63,300$ \\
Catfish & 6 & $2,000-27,900$
\end{tabular}

TCDD, which has been the subject of most of the research on PCDD's, has a solubility of about 3 to $5 \mathrm{ppb}$ (Biddinger and Gloss, 1984) and an octanol-water partition coefficient of $4.24 \times 10^{6}$ (Marple and others, 1986).

\section{Environmental Fate}

Almost all the published data on the fate of the PCDD's is limited to TCDD. As a result, any conclusions about the environmental fate of the PCDD's are at best qualitative.

As a result of their relatively low solubilities, the PCDD's are likely to strongly sorb to sediments and to bioaccumulate in aquatic organisms. Chemical and biological degradation processes appear very slow, making the PCDD's persistent environmental contaminants. Few data are available regarding the volatilization of PCDD's from surface-water systems.

Extremely low concentrations of PCDD's can cause significant residues in surface-water biota. By contaminating aquatic microcosms with TCDD sorbed to sediment, Isensee and Jones (1975) found that BCF's for a variety of organisms ranged from 1,000 to 63,300 . After $30 \mathrm{~d}$ of exposure, equilibrium aqueous concentrations of TCDD as low as $50 \mathrm{pg} / \mathrm{L}$ caused TCDD concentrations in daphnids to be as great as $2.4 \mu \mathrm{g} / \mathrm{L}$ (corresponding to a BCF of 48,000). Other bioconcentration data from their study are summarized in table 37 . Callahan and others (1979) have reported that mosquito larvae bioaccumulated TCDD to concentrations 2,800 to 9,200 times greater than the aqueous concentration. BCF's determined for brine shrimp and silversides were 1,600 and 54, respectively. Unfortunately, no bioaccumulation data were found for the other PCDD's. Based on the strong tendency of TCDD to bioconcentrate, however, it is likely that other PCDD's of equal or greater chlorination will also be readily bioaccumulated. 
Available data based on studies of TCDD indicate that the PCDD's strongly partition into sediment organic matter. The solubility of TCDD ( 3 to $5 \mathrm{ppb}$ ) is approximately equal to the solubility of DDT, which has been documented as having sorption coefficients $\left(K_{d}\right)$ greater than $10^{4}$ and organic carbon/organic matter normalized sorption coefficients $\left(\mathrm{K}_{\mathrm{oc} / \mathrm{om}}\right)$ greater than $10^{6}$ (table 7 ). Helling and others (1973) have noted that TCDD applied to fields coincident with 2,4,5-T application will not undergo significant leaching by runoff. Only transport due to soil erosion would be likely. Ward and Matsumura (1978) confirmed the conclusions of Helling and others (1973) in a study employing anaerobic sediment-water microcosms dosed with radio-labeled TCDD. They found that typically 93 to 96 percent of the recovered radioactivity was from the sediment and speculated that much of the remaining TCDD was associated with dissolved organic matter. Similar results also were reported by Isensee and Jones (1975), who observed that 85 to 99 percent of the TCDD originally added to a model ecosystem remained in the sediment after a 39-d period.

PCDD's appear to be highly resistant to both chemical and biological degradation. In a laboratory sediment-water system incubated under anaerobic conditions, the half-life of TCDD was found to be approximately $600 \mathrm{~d}$ (Ward and Matsumura, 1978). Similarly, Helling and others (1973) reported that TCDD applied to moist soils exhibited half-lives of approximately 1 yr in the laboratory. TCDD half-lives in soil greater than $10 \mathrm{yr}$ also have been documented (Moore and Ramamoorthy, 1984).

There is some evidence that the PCDD's can be chemically degraded by photolysis; however, photolytic decomposition rates will probably be unable to compete with sorption and bioaccumulation rates in surface-water systems. Crosby and Wong (1977) demonstrated that TCDD dissolved in organic solvents and exposed to natural sunlight on leaves and glass plates was rapidly photodegraded, with half-lives of less than $6 \mathrm{~h}$. The organic solvent was believed to serve as a hydrogen donor, because in its absence photolytic degradation was greatly reduced. Longer half-lives were observed for TCDD on soils, and this was attributed to upper soil particles shading lower soil particles. The soil's protective effect against the photolytic degradation of TCDD also has been noted by Plimmer (1978). In surface-water systems, the rapid sorption of TCDD to sediments greatly reduces the amount of light reaching the TCDD molecules, thereby reducing the rate of photodecomposition. This is confirmed by an experiment by Ward and Matsumura (1978), who compared the degradation of TCDD in sedimentwater microcosms incubated in the dark with identically prepared microcosms incubated in the light. After $39 \mathrm{~d}$, the average recovery of TCDD from the "dark" microcosms was 93.29 percent and the average recovery of TCDD from the "light" microcosm was 89.45 percent, indicating the lack of a significant photolytic influence. In aquatic systems, it is likely that PCDD's will be rapidly sorbed to sediments or bioaccumulated by aquatic organisms.

\section{Environmental Distribution}

Because PCDD's are byproducts of any manufacturing process that involves the production or use of trichlorophenol, they are commonly discharged to surface waters in effluents from chemical manufacturing plants, leather tanneries, kraft-pulp mills, wood-processing plants, or sewage-treatment plants (Moore and Ramamoorthy, 1984). For example, VanNess and others (1980) analyzed a series of industrial effluents and determined that 5 of the 20 samples contained detectable amounts of TCDD, with concentrations ranging up to $100 \mathrm{ppt}$. PCDD's also enter the environment in conjunction with the application of pesticides, as discharges from chemical disposal sites, and from fly ash from municipal incinerators. Table 38 gives estimates of the input of TCDD's into the Canadian environment from a variety of sources.

There is some evidence that PCDD's can be produced by the combustion of trichlorophenol or its derivatives. Small quantities of TCDD have been produced by burning 2,4,5-T under conditions simulating a forest fire (Kriebel, 1981), and it has been estimated that as much as $1 \mu \mathrm{g}$ of PCDD's will be produced for every square meter of forest that burns immediately after a herbicide treatment. Additionally, 2,4,6-trichlorophenol applied to dried leaves and allowed to burn resulted in a residual TCDD concentration of $2,100 \mathrm{ppm}$, about 100,000 times greater than the TCDD concentration in the original aliquot of trichlorophenol (Kriebel, 1981).

Upon entering surface-water systems, PCDD's strongly partition from water into sediments and biota. As a result, aqueous residues of PCDD's are generally below detectable limits, even with a significant input of PCDD's to the system. Despite low aqueous concentrations, sediment and biological residues of PCDD's have been reported in the parts-per-trillion to parts-per-billion range.

VanNess and others (1980) analyzed soil samples from a trichlorophenol-manufacturing plant. Eighty-five percent of the soil samples contained detectable residues of TCDD, with concentrations ranging from $<20 \mathrm{ppt}$ to $600 \mathrm{ppb}$. O'Keefe and others (1984) detected a TCDD concentration of $10 \mathrm{ppt}$ in a sediment sample collected from the lower Hudson River (N.Y.). Two other samples from the lower Hudson, however, contained TCDD concentrations of less than 7.3 ppt. Kriebel (1981) summarized the results of a study by Dow Chemical Company that reported PCDD residues in soils from a variety of locations in the United States, including soils from the grounds of one of Dow's own chemical-manufacturing plants. The ranges of the detectable concentrations are 
Table 38. Estimated annual inputs of polychlorinated dibenzo-p-dioxins to the Canadian environment from major sources

[From Moore and Ramamoorthy, 1984]

Annual inputs, in kilograms

\begin{tabular}{|c|c|c|c|c|c|}
\hline Source & $\begin{array}{l}\text { British } \\
\text { Columbia }\end{array}$ & Prairies & Ontario & Quebec & Maritimes \\
\hline $\begin{array}{l}\text { Pentachlorophenol } \\
\text { usage }\end{array}$ & 570 & 360 & 350 & 110 & 130 \\
\hline 2,4-D usage & .3 & 8.9 & $<.1$ & $<.1$ & $<.1$ \\
\hline $\begin{array}{l}\text { Precipitated fly } \\
\text { ash }\end{array}$ & $<.1$ & $<.1$ & 1.6 & 5.1 & $<.1$ \\
\hline Alrborne fly ash & $<.1$ & 1.5 & 2.2 & 2.2 & .6 \\
\hline Total & 570 & 370 & 354 & 117 & 131 \\
\hline
\end{tabular}

presented in table 39. Most of the detectable concentrations were less than $3 \mathrm{ppb}$, with the exception of soil samples taken from the Dow plant, which were highly contaminated with isomers of tetra-, hexa-, hepta-, and octachlorodibenzo-p-dioxin. Based on these data, contaminated soils carried into surface waters by runoff can be a significant source of sediment TCDD residues.

Because of the high toxicity of PCDD's, and particularly TCDD, numerous researchers have documented biological residues of these compounds in edible fish. As a result of the heavy application of Agent Orange to South Vietnamese forests, carp and catfish sampled downstream from the sprayed areas contained average TCDD residues ranging from 70 to $810 \mathrm{ppt}$ (Kriebel, 1981; Moore and Ramamoorthy, 1984). TCDD residues as high as $57 \mathrm{ppt}$ have even been detected in the fat of some Vietnam veterans (Kriebel, 1981). Table 40 summarizes the detected residues of TCDD in a variety of fish from both fresh and marine waters. Although few studies have reported on the more highly chlorinated dioxins, they have also been detected in aquatic organisms. Concentrations as high as 388 (octa-), 304 (hepta-), 203 (hexa-), and 80 (penta-) ppt have been found in carp from the Niagara River (Moore and Ramamoorthy, 1984).

\section{POLYCYCLIC AROMATIC HYDROCARBONS}

\section{Uses, Production, and Properties}

The polycyclic (or polynuclear) aromatic hydrocarbons (PAH's) are a large group of environmentally important compounds. Although little is known about their toxicities, several of the PAH's have been identified as carcinogens or mutagens. As a group, the PAH's are structurally characterized by two or more fused-ring compounds based on benzene, with properties intermediate between benzene and olefinic hydrocarbons (Harrison and others, 1975). Two aromatic rings are considered to be fused when carbon atoms from each ring are shared. The environmentally significant PAH's have from two (naphthalene) to seven (coronene) rings. Structural diagrams of some of these compounds are given in figure 25 .

PAH's originate from both natural and anthropogenic sources; however, it is believed that their occurrence in aquatic systems is due primarily to anthropogenic inputs (Cossa and others, 1983). PAH's are produced mainly by high-temperature $\left(>700^{\circ} \mathrm{C}\right)$ pyrolytic reactions such as municipal incineration or forest fires. Their residues also have been detected in fossil fuels and wood-preservative sludges (table 41).

A few of the simpler PAH's are produced commercially. Naphthalene is used in several chemical manufacturing processes to produce moth balls, pesticides, fungicides, dyes, wetting agents, synthetic resins, cutting fluids, solvents, and lubricants (Verschueren, 1983). Commercial production of petroleum naphthalene in the United States was $4.9 \times 10^{4} \mathrm{t}$ in $1976,4.7 \times 10^{4} \mathrm{t}$ in 1980 , and $6.5 \times 10^{4} \mathrm{t}$ in 1981 (Moore and Ramamoorthy, 1984). The production of chloronaphthalenes (used in automobile capacitors and as oil additives for fabric dyeing and engine cleaning) is much less, with U.S. production probably less than 270 $t$ per year (Moore and Ramamoorthy, 1984). Commercial uses of other PAH's such as anthracene, acenaphthene, and phenanthrene are small and limited primarily to dye and plastics manufacturing (Verschueren, 1983). Pyrolitic 
Table 39. Residues of chlorodibenzo-p-dioxins (micrograms per kilogram) in soil samples from various locations in the United States

[From Kriebel, 1981]

Range of detectable concentrations

\begin{tabular}{lcccc} 
Location & Tetra- & Hexa- & Hepta- & Octa- \\
\hline $\begin{array}{l}\text { In and around } \\
\text { Dow Chemical plant }\end{array}$ & $1-120$ & $7-280$ & $70-3200$ & $490-20,000$ \\
Metropolitan area & $.005-.03$ & $.03-.3$ & $.1-3$ & $.4-22$ \\
Urban area & nd & $.03-1.2$ & $.03-2$ & $.05-2$ \\
Rural area & nd & nd & 0.05 & 0.2 \\
\hline
\end{tabular}

nd - no sample exceeded the limit of detection

Table 40. Mean and maximum concentrations of detected residues of 2,3,7,8tetrachlorodibenzo-p-dioxin in a variety of freshwater and marine fish [ppt, parts per trillion]

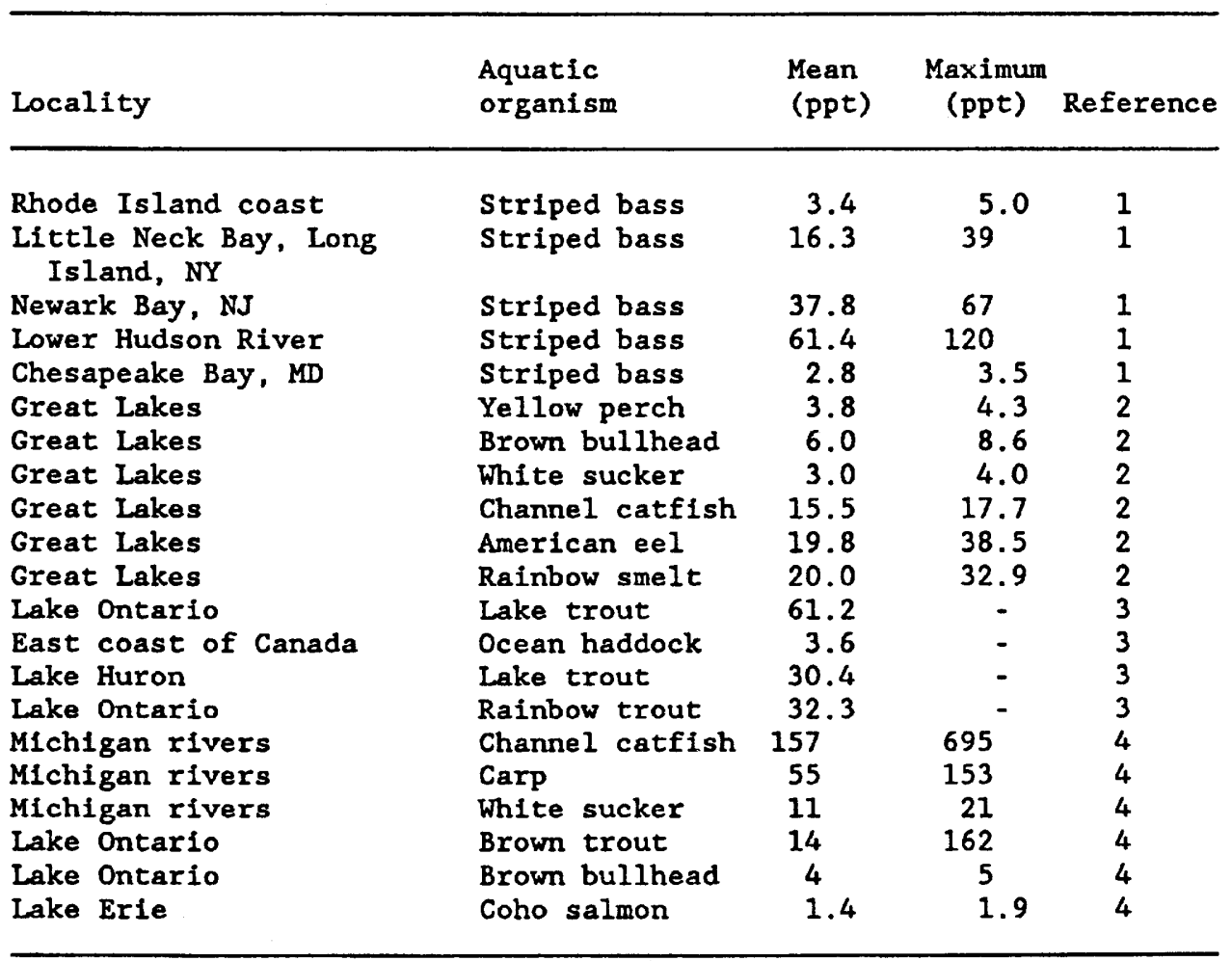

1. $0^{\prime}$ Keefe and others (1984)

2. Ryan and others (1984)

3. Ryan and others (1983)

4. Moore and Ramamoorthy (1984) 


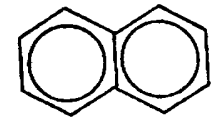

Naphthalene

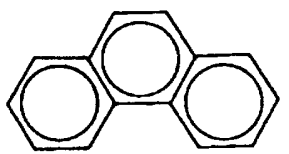

Phenanthrene

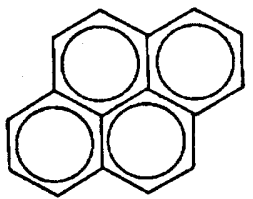

Pyrene

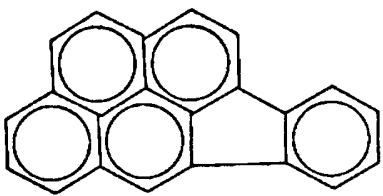

Indeno(1,2,3-cd)pyrene

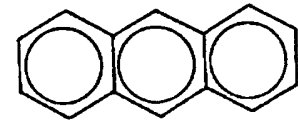

Anthracene

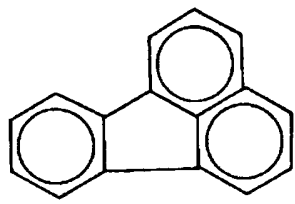

Fluoranthene

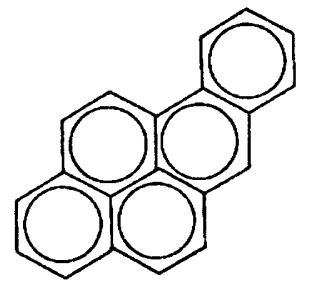

Benzo(a)pyrene

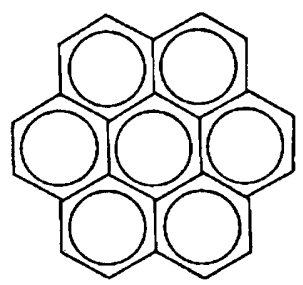

Coronene
Figure 25. Structural diagrams of selected polycyclic aromatic hydrocarbons.

sources are probably the major input of PAH's to the environment. It has been estimated, on the basis of data from 1966 to 1969, that the global emission of benzo(a)pyrene from anthropogenic sources is about 4.6 million $\mathrm{kg} / \mathrm{yr}$ (Edwards, 1983). Table 42 lists the sources and approximate amounts of benzo(a)pyrene emitted to the atmosphere.

In general, the PAH's are compounds having relatively low solubilities and vapor pressures and high octanol-water partition coefficients. These properties vary with the number of compound rings, as indicated in table 43. As the number of rings increases, compound solubility and vapor pressure generally decrease, whereas the octanol-water partition coefficient increases. Acute toxicity is greatest for the low-molecular-weight PAH's, such as naphthalene, and increases with alkyl substitution (Van Luik, 1984). Benzo(a)pyrene is perhaps the most highly carcinogenic compound of the group, but other compounds, such as benzo(b)fluoranthene, benzo(j)fluoran- thene, benzo(a)anthracene, chrysene, and indeno(1,2,3cd)pyrene, also have been recognized as carcinogens (Harrison and others, 1975).

\section{Environmental Fate}

The PAH's are persistent surface-water contaminants. Because of their low solubilities and high octanolwater partition coefficients, they strongly partition from water into biota and particulate and dissolved organic matter. As a result, even low aqueous concentrations can result in environmentally significant sediment and biological residues. There is some evidence that PAH's can be photolytically degraded in the water column, but the importance of this process in natural systems is likely to be small because of the strong sorption of PAH's to sediments. The ultimate fate of the PAH's probably is sorption to sediments followed by slow biodegradation. Other transport and transformation processes, such as volatilization and hydrolysis, are not important fate processes.

Several laboratory studies have investigated the sorption of PAH's to sediments. Gardner and others (1979) exposed sand and salt marsh sediment to crude oil containing small amounts of anthracene, fluoranthene, benzo(a)anthracene, and benzo(a)pyrene. Sorption of all four compounds was extensive, with the sediments having the highest organic-matter content sorbing the greatest amount of PAH's. PAH concentrations as high as 10 $\mathrm{mg} / \mathrm{kg}$ also have been reported in rapid-sand-filter solids (Harrison and others, 1975). In a study comparing anthracene sorption to organic matter (yeast cells) and mineral particulate matter (powdered calcite), Herbes (1977) observed that the particulate organic matter rapidly sorbed the anthracene in solution, with equilibrium reached in minutes. In the presence of a $250-\mathrm{mg} / \mathrm{L}$ yeast-cell concentration, 72 percent of an initial anthracene concentration of $0.02 \mu \mathrm{g} / \mathrm{L}$ was sorbed by the organic matter. In contrast, the concentration of calcite required to sorb just 30 percent of the initial anthracene concentration was $300 \mathrm{~g} / \mathrm{L}$, indicating that anthracene is sorbed by partitioning into organic matter and that adsorption to mineral surfaces is relatively insignificant. Hassett and others (1980) also noted the importance of organic matter in the sorption of dibenzothiophene to several soils and sediments. Laboratory-measured sorption coefficients ranged from 5.8 to 388 .

The sediment-water partition coefficients normalized for organic-carbon content $\left(\mathrm{K}_{\mathrm{oc}}\right)$ for a variety of the PAH's can be calculated from solubility data using the empirical relation derived by Banwart and others (1982):

$$
\log \mathrm{K}_{\mathrm{oc}}=-0.686 \log \mathrm{S}+4.273 \text {, }
$$

where $S$ is compound solubility, in milligrams per liter. The relation was developed from data from Karickhoff 
Table 41. Residues of polycyclic aromatic hydrocarbons (PAH's) in oils, gasoline, bitumen, and sludge [In parts per million except for wood preservative sludge, which is in grams per liter of raw sludge; $\mathrm{km}$, kilometer. Dash indicates no data available. From Verschueren, 1983]

\begin{tabular}{|c|c|c|c|c|c|c|c|}
\hline \multirow[b]{2}{*}{ Compound } & \multicolumn{7}{|c|}{ Residue, in } \\
\hline & Gasoline & Crude oil & Bitumen & $\begin{array}{l}\text { Hood preserv- } \\
\text { at ive sludge }\end{array}$ & Fresh & $\begin{array}{c}\text { Motor oi } \\
\text { Used } \\
(5,000 \mathrm{~km})\end{array}$ & $\begin{array}{l}\text { Used } \\
(10,000 \mathrm{~km})\end{array}$ \\
\hline Anthracene & $1.55 \cdot 2.59$ & $\cdot$ & - & - & - & $\cdot$ & - \\
\hline Benzo(a)anthracene & $0.04-0.27$ & $1.7 \cdot 2.3$ & $0.13 \cdot 0.86$ & 5.18 & $\cdot$ & $\cdot$ & $\cdot$ \\
\hline Benzo(b)fluoranthene & $0.16-3.9$ & $<1.0$ & $0.40-1.60$ & $\cdot$ & 0.08 & $45-82$ & $56-141$ \\
\hline Benzo( $j$ )fluoranthene & 0.009 & $<1.0$ & $\cdot$ & 0.31 & $\cdot$ & - & $\cdot$ \\
\hline Benzo(k)fluoranthene & 0.009 & $<1.3$ & $0.34-1.41$ & $\cdot$ & - & - & $\cdot$ \\
\hline Benzo(g, $h, i)$ perylene & $0.32 \cdot 9$ & $<1.6$ & $1.37 \cdot 5.50$ & $\cdot$ & 0.12 & $109-208$ & $153-289$ \\
\hline Benzo(a)pyrene & $0.13-8.28$ & $0.4 \cdot 2.8$ & $\cdot$ & - & $0.02-0.1$ & $83.2 \cdot 162$ & $110-242$ \\
\hline Chrysene & $0.05 \cdot 2.96$ & $6.9-17.5$ & $1.64-5.14$ & - & 0.56 & $86-190$ & $129-237$ \\
\hline Coronene & $0.06-1.9$ & $\cdot$ & $\cdot$ & - & 0.00 & $25 \cdot 37$ & $28 \cdot 63$ \\
\hline Dibenz $(a, h)$ anthracene & 0.167 & - & $\cdot$ & 0.07 & - & $\cdot$ & $\cdot$ \\
\hline Fluoranthene & $0.70 \cdot 7.56$ & $2.9 \cdot 5.0$ & - & 26.47 & 0.11 & $109 \cdot 173$ & $129-270$ \\
\hline Fluorene & - & - & $\cdot$ & 6.61 & $\cdot$ & $\cdot$ & $\cdot$ \\
\hline Indeno $(1,2,3-\mathrm{cd})$ pyrene & $0.04-2.88$ & $\cdot$ & - & - & 0.03 & $34-59$ & $47 \cdot 83$ \\
\hline Phenanthrene & $15.7-20.5$ & $26 \cdot 70$ & $\cdot$ & - & $\cdot$ & - & $\cdot$ \\
\hline Pyrene & $1.55-17.1$ & $3.5-4.5$ & $0.17 \cdot 0.80$ & 24.2 & 0.29 & $286 \cdot 450$ & $330-700$ \\
\hline
\end{tabular}

and others (1979) and Banwart and others (1980), along with original sorption data for three nitrogen-heterocyclic compounds. Table 44 presents the calculated values of $\mathrm{K}_{\mathrm{oc}}$ for some of the PAH's along with experimentally determined $K_{o c}$ values for additional PAH's from Karickhoff and others (1979). The $K_{o c}$ values indicate that a sediment sample having only 0.1 percent organiccarbon content may have an equilibrium benzo(a)pyrene concentration of $8.6 \times 10^{5} \times 0.001$, or 860 times greater than the compound's concentration in the surrounding water. Means and others $(1980,1982)$ also determined $\mathrm{K}_{\mathrm{oc}}$ values for several PAH's sorbed to 14 sediment and soil samples. Mean values for the 14 samples ranged from 517 (anthracene-9-carboxylic acid) to $1.8 \times 10^{6}$ (3methylcholanthrene). These data indicate the strong tendency of benzo(a)pyrene and other PAH's of similarly low solubilities to partition into sediment organic matter.

In addition to their tendency to sorb to sediments, PAH's also accumulate in the lipid reservoirs of aquatic organisms, with BCF's generally increasing as compound solubility decreases. This observation is confirmed by the data of Southworth and others (1978b), who studied the bioaccumulation of seven PAH's by Daphnia pulex. They determined that the octanol-water partition coefficients of the PAH's were good estimators of BCF's, with laboratory-measured BCF's ranging from 100 for naph- thalene to 10,000 for benzo(a)anthracene. Casserly and others (1983) also found that BCF's increase with decreasing solubility. Exposure of the alga Selenastrum capricornutum to aqueous residues of naphthalene, phenanthrene, and pyrene resulted in BCF's of 12,600, 24,000, and 36,300 , respectively. BCF's as great as 10,000 also have been documented for PAH's bioaccumulated by fish (Mackay, 1982a). Table 45 lists BCF's determined for a variety of PAH's. For a given compound, differences in BCF's determined for different organisms are at least partially attributable to differences in the lipid contents of the organisms. For a given compound, BCF's will increase with increasing lipid content of the aquatic organism.

In aqueous systems, PAH's are photodegraded by reactions with oxygen resulting in the formation of quinones (Smith and others, 1978). Although several laboratory experiments have documented short photolytic half-lives for PAH's in distilled water samples, photodecomposition in natural systems may be relatively insignificant owing to the strong partitioning of PAH's into particulate and dissolved organic matter. Smith and others (1978) measured photolytic half-lives of several hours for benzo(a)anthracene and benzo(a)pyrene in oxygensaturated distilled water exposed to sunlight. However, when half-lives were similarly determined in natural waters or in distilled water containing dissolved humic 
Table 42. Estimated annual benzo(a)pyrene (BaP) emissions to the atmosphere

[kg, kilogram. Values in parentheses are percentages of the total emission. From Edwards, 1983]

\begin{tabular}{lcc}
\hline & \multicolumn{2}{c}{ Concentration (kg X 10") } \\
\cline { 2 - 3 } Sources & United states & Global \\
\hline Heating and power & $0.43(36.8)^{\star}$ & $2.36(51.6)^{\star}$ \\
Industrial processes & $.18(15.4)^{\star *}$ & $.95(20.8)^{\star *}$ \\
Enclosed incineration & $.03(2.6)$ & $.09(2.0)$ \\
Coal refuse burning & $.31(26.5)$ & $.62(13.6)$ \\
Forest and agricultural fires & $.13(11.1)$ & $.38(8.3)$ \\
Other refuse burning & $.07(6.0)$ & $.13(2.8)$ \\
Trucks and buses & $.01(0.8)$ & $.03(0.7)$ \\
Automobiles & $.01(0.8)$ & $.01(0.2)$ \\
\cline { 2 - 2 } Total & 1.17 & 4.57 \\
\hline
\end{tabular}

* 91 percent from coal and 8 percent from wood

** 99 percent from coke production acids, photolysis was significantly retarded. The low absorbance of the natural water used indicated that light screening alone probably was not responsible for the differences in photolysis rates. Partition of the two PAH's into the dissolved organic matter, however, may have altered the reactivity of the molecules and thereby reduced the photolysis rates. Photolytic degradation of PAH's may be an important fate process only when the PAH's are present in oil slicks or in shallow, low-turbidity waters with low dissolved-organic-matter content (Callahan and others, 1979).

Several studies have documented the biodegradation of PAH's. Low-molecular-weight PAH's, such as naphthalene, acenaphthene, and acenaphthylene, have been rapidly degraded in laboratory cultures, with greater than 90 percent degradation of initial concentrations of 5 to $10 \mathrm{mg} / \mathrm{L}$ occurring within $7 \mathrm{~d}$ (Tabak and others, 1981). PAH's of higher molecular weights, such as fluoranthene, benzo(a)anthracene, chrysene, benzo(a)pyrene, and anthracene, however, are much more resistant to biodegradation. For example, Smith and others (1978) were unable to develop a microbial culture capable of degrading benzo(a)pyrene or benzo(a)anthracene when they were present as sole carbon sources. Figure 26 presents a proposed degradation pathway for phenanthrene by soil pseudomonads that is typical for three-ring PAH's (Harrison and others, 1975).

Table 43. Experimentally determined octanol-water partition coefficients $\left(\mathrm{K}_{\text {ow }}\right)$, solubilities, and vapor pressures of selected polycyclic aromatic hydrocarbons (PAH's) [mg/L, milligrams per liter, mm, millimeters. From Callahan and others, 1979]

\begin{tabular}{lcccc}
\hline PAH & $\begin{array}{c}\text { Number of } \\
\text { rings }\end{array}$ & Log $\mathrm{K}_{\text {ow }}$ & $\begin{array}{c}\text { Solubilityo } \\
(\mathrm{mg} / \mathrm{L} \text { at } 25 \mathrm{C})\end{array}$ & $\begin{array}{c}\text { Vapor pressure } \\
\left(\mathrm{mm} \text { of } \mathrm{Hg} \text { at } 20^{\mathrm{C}}\right)\end{array}$ \\
\hline $\begin{array}{l}\text { Naphthalene } \\
\text { Phenanthrene }\end{array}$ & 2 & 3.37 & 34.4 & 0.0492 \\
Anthracene & 3 & 4.46 & 1.00 & $6.8 \times 10^{-4}$ \\
Pyrene & 3 & 4.45 & 0.045 & $1.95 \times 10^{-4}$ \\
Benzo(a) anthracene & 4 & 5.61 & 0.014 & $5.85 \times 10^{-7}$ \\
Benzo(k) fluoranthene & 4 & nd & nd & $9.59 \times 10^{-11}$ \\
Chrysene & 4 & nd & 0.14 & $\mathrm{nd}$ \\
Benzo(a) pyrene & 4 & 5.61 & 0.002 & $5 \times 10^{-9 *}$ \\
Benzo(ghi)perylene & 6 & 6.04 & 0.0038 & nd \\
\hline
\end{tabular}

* - vapor pressure determined at $25^{\circ} \mathrm{C}$. nd - no data avallable. 
Table 44. Calculated and experimental sediment-water sorption coefficients normalized for organic carbon $\left(K_{o c}\right)$ for a variety of polycyclic aromatic hydrocarbons (PAH's)

\begin{tabular}{|c|c|c|}
\hline PAH & ${ }_{\text {Solubillty }}^{\star}{ }_{\text {(milligrams per iltar) }}$ & ${ }_{\text {oc }}^{\mathrm{R}}$ \\
\hline Naphthalene & 34.4 & $1.3 \times 10^{3}$ (E) \\
\hline Phenanthrene & 1.00 & $2.3 \times 10^{4}$ (E) \\
\hline Fluoranthene & .265 & $4.7 \times 10^{4}$ (c) \\
\hline Pyrene & .14 & $8.4 \times 10^{4}$ (E) \\
\hline Anthracene & .045 & $2.6 \times 10^{4}$ (E) \\
\hline Benzo (a) anthracene & .014 & $3.5 \times 10^{5}$ (c) \\
\hline Benzo (a)pyrene & .0038 & $8.6 \times 10^{8}$ (C) \\
\hline Chrysene & .002 & $1.3 \times 10^{\circ}$ (C) \\
\hline Benzo (ghi) perylene & .00026 & $5.4 \times 10^{\circ}$ (C) \\
\hline \multicolumn{3}{|c|}{$\begin{array}{l}\text { C - Calculated according to Banwart and others (1982). } \\
\text { E - Experimental values are from Karickhoff and others } \\
\text { (1979). } \\
\text { * - All solubility data are fron Callahan and others (1979) } \\
\text { except for fluoranthene, which is from Harrison and } \\
\text { others (1975). }\end{array}$} \\
\hline
\end{tabular}

There is evidence that PAH's are slowly biodegraded after they have been sorbed to sediments. Gardner and others (1979) exposed fine sand, medium sand, and marsh sediment to crude oil enriched with benzo(a)pyrene, benzo(a)anthracene, anthracene, and fluoranthene. Based on initial PAH concentrations ranging from 7.6 to $73.9 \mu \mathrm{g} / \mathrm{g}$ dry sediment, the percent degradation per week of the four PAH's ranged from 0.84 to 3.5 percent, with benzo(a)pyrene having the slowest degradation rate. The authors also noted that the presence of a polychaete worm, Capitella capitata, enhanced the degradation of the PAH's either by improving the sediment conditions for microbial degradation or by metabolically degrading the PAH's themselves. In a similar study, Varanasi and others (1985) determined that over a 4-week period, PAH's, including benzo(a)pyrene, present in sediments were not significantly degraded. However, benzo(a)pyrene was metabolized by both shrimp and fish exposed to the contaminated sediment. These studies indicate that a possible fate of PAH's in surface-water systems is sorption to sediments followed by slow biodegradation.

Based on their relatively low vapor pressures (table 43), PAH's are not expected to volatilize from water at a significant rate, and this observation has been confirmed in laboratory studies. Southworth (1979) predicted the

Table 45. Bioconcentration factors (BCF's) for selected polycyclic aromatic hydrocarbons [Dash indicates no data available]

\begin{tabular}{|c|c|c|c|c|}
\hline Compound & Organism & $\begin{array}{l}\text { Exposure } \\
\text { time (days) }\end{array}$ & $\mathrm{BCF}$ & Reference \\
\hline Naphthalene & Daphnia pulex & 1 & 131 & 1 \\
\hline Naphthalene & S. capricornutum & 1 & 12,500 & 2 \\
\hline Naphthalene & Fish & - & 427 & 3 \\
\hline Chloronaphthalenes & Grass shrimp & 3 & $50-300$ & 4 \\
\hline Acenaphthene & Fish & - & 389 & 3 \\
\hline Phenanthrene & Daphnia pulex & 1 & 325 & 1 \\
\hline Phenanthrene & s, capricornutum & 1 & 23,800 & 2 \\
\hline Phenanthrene & Fish & - & 2,630 & 3 \\
\hline 2-Chlorophenanthrene & Fish & - & 4,266 & 3 \\
\hline 2-Methylphenanthrene & Fish & - & 3,020 & 3 \\
\hline Anthracene & Daphnia pulex & 1 & 917 & 1 \\
\hline Anthracene & Fish & - & 912 & 3 \\
\hline 9-Methylanthracene & Daphnia pulex & 1 & 4,583 & 1 \\
\hline 9-Methylanthracene & Fish & - & 4,571 & 3 \\
\hline Pyrene & Daphnia pulex & 1 & 2,702 & 1 \\
\hline Pyrene & S. capricornutum & 1 & 36,300 & 2 \\
\hline Pyrene & Fish & - & 2,692 & 3 \\
\hline Fluorene & Fish & - & 1,288 & 3 \\
\hline Benzo (a) anthracene & Daphnia pulex & 1 & 10,109 & 1 \\
\hline Benzo (a) anthracene & Fish & - & 10,000 & 3 \\
\hline Benzo(a)pyrene & Fish & - & 22 & 4 \\
\hline Benzo (a) pyrene & Snail & - & 3,000 & 4 \\
\hline Perylene & Daphnia pulex & 1 & 7,191 & 1 \\
\hline
\end{tabular}

1. Southworth and others (1978b) 3. Mackay (1982a)

2. Casserly and others (1983) 4. Biddinger and Gloss (1984) 


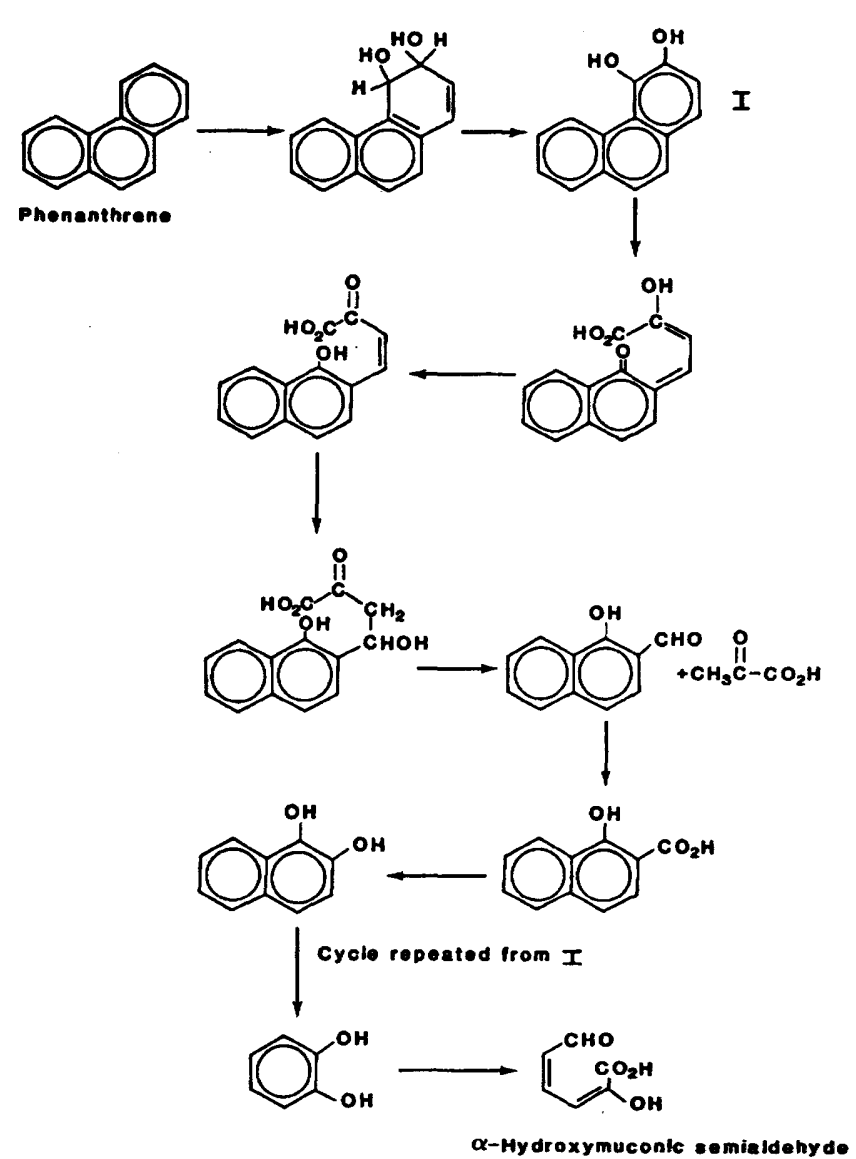

Figure 26. Structural diagrams showing proposed degradation pathway of phenanthrene by soil pseudomonads. [Reprinted with permission from Water Research, v. 9, p. 337 (1975). Copyright 1975 by Pergamon Press Ltd.]

volatilization rates of several PAH's and determined that volatilization would not be a significant attenuation method in streams with depths greater than $1 \mathrm{~m}$ and average velocities less than $1 \mathrm{~m} / \mathrm{s}$. In a stream $1.0 \mathrm{~m}$ deep at $25^{\circ} \mathrm{C}$, predicted volatilization half-lives of benzo(a)anthracene and benzo(a)pyrene were greater than $100 \mathrm{~h}$ for current and wind velocities up to 1 and $4 \mathrm{~m} / \mathrm{s}$, respectively. Similarly, volatilization half-lives of benzo(a)pyrene and benzo(a)anthracene in aqueous solutions stirred at a fast rate have been determined to be 22 and 89 $\mathrm{h}$, respectively (Smith and others, 1978). The presence of sediments will likely increase these experimental half-lives as a result of PAH sorption.

The structure of PAH's, for the most part, prevents hydrolytic degradation, and this process is not expected to be an important fate process in surface-water systems (Callahan and others, 1979).

\section{Environmental Distribution}

PAH's enter surface-water systems in a variety of ways, including atmospheric deposition, surface runoff and soil leaching, industrial discharges, and municipal wastewater effluents. Heit and others (1984) presented data indicating that fluoranthene is atmospherically deposited in remote lakes in Rocky Mountain National Park. Similarly, Heit (1985) determined that atmospheric deposition is the prime source of PAH's for Cayuga Lake, N.Y. Runoff into the Delaware River estuary between Trenton and Philadelphia has been found to contain both particulate and dissolved quantities of petroleum hydrocarbons, many of which were identified as PAH's (Whipple and Hunter, 1979). Naphthalene concentrations ranging from 1 to $4 \mathrm{mg} / \mathrm{L}$ have been reported by Jungclaus and others (1978) in the wastewater of a specialty chemicals manufacturing plant. Barrick (1982) estimated that approximately $1 \mathrm{t}$ per year of 3- to 7-ring PAH's are discharged to Puget Sound from Seattle's primary municipal wastewater effluents. Likewise, Eganhouse and Kaplan (1982) determined that southern California's wastewater-treatment plants annually discharge more than $17,400 t$ tons of aliphatic and aromatic hydrocarbons to coastal waters.

The origin of PAH residues in surface waters commonly can be determined by the ratio of the concentration of parent hydrocarbons to their methyl isomers. PAH's of petroleum origin consist of homologous series in which the methyl and higher alkyl-substituted isomers greatly outnumber the parent compounds (Pancirov and Brown, 1977). In contrast, PAH's of pyrolitic origin (such as the combustion of fossil fuel or wood) contain predominantly the parent hydrocarbons (Pancirov and Brown, 1977). Therefore, PAH's in a water, sediment, or biota sample having a high concentration of pyrene relative to methylpyrene are likely to be of pyrolytic origin, while PAH's in samples having a high methylpyrene concentration relative to pyrene are likely a result of direct contamination from petroleum or petroleum-derived products. The limitation of this reasoning is the assumption that both the parent hydrocarbon and its methyl isomer have the same aquatic fates. If, for example, pyrene is biodegraded at a faster rate than methylpyrene, the initial parent/methyl isomer ratio will be upset.

Because of their relatively low solubilities, PAH's are usually found only at low aqueous concentrations in surface waters. Sheldon and Hites (1979), for example, measured aqueous methylnaphthalene concentrations of 0.02 and $0.2 \mu \mathrm{g} / \mathrm{L}$ at two locations in the Delaware River estuary. Similarly, Stainken and Frank (1979) detected 2to 5-ring PAH's at concentrations ranging from 2 to 20 $\mu \mathrm{g} / \mathrm{L}$ in the bottom waters of Raritan Bay (N.J.). Downstream from a chemical manufacturing plant's effluent, Jungclaus and others (1978) reported low concentrations of naphthalene ( 6 to $10 \mu \mathrm{g} / \mathrm{L}$ ) in river water. Harrison and others (1975) have also reported low aqueous concentrations of PAH's. Their maximum reported concentration 
Table 46. Sediment residues of polycyclic aromatic hydrocarbons $[\mu \mathrm{g} / \mathrm{kg}$, micrograms per kilogram. Dash indicates no data available]

\begin{tabular}{|c|c|c|c|c|}
\hline Compound & Locality & $\begin{array}{l}\text { Mean } \\
(\mu \mathrm{g} / \mathrm{kg})\end{array}$ & $\begin{array}{c}\operatorname{Max} \\
(\mu \mathrm{g} / \mathrm{kg})\end{array}$ & Reference \\
\hline Benzo(a)pyrene & $\begin{array}{l}\text { Adirondack acid lake } \\
\text { region, } \mathrm{NY}\end{array}$ & 409 & 690 & 1 \\
\hline Benzo (a)pyrene & Western U.S. lakes & 38,000 & 305,000 & 2 \\
\hline Benzo (a)pyrene & Lake George, NY & - & 30 & 3 \\
\hline Benzo (a)pyrene & Casco Bay, ME & 122 & 805 & 4 \\
\hline Phenanthrene & $\begin{array}{l}\text { Adirondack acid lake } \\
\text { region, } N Y\end{array}$ & 239 & 324 & 1 \\
\hline Phenanthrene & Lake George, NY & - & 150 & 3 \\
\hline Pyrene & Lake George, NY & - & 150 & 3 \\
\hline Pyrene & Calumet-Sag Channel & 6,300 & 10,000 & 5 \\
\hline Fluoranthene & Lake George, NY & - & 160 & 3 \\
\hline Fluoranthene & Rocky Mountain lakes & 165 & 375 & 6 \\
\hline Perylene & $\begin{array}{l}\text { Adirondack acid lake } \\
\text { region, NY }\end{array}$ & 443 & 605 & 1 \\
\hline Perylene & Lake George, NY & 16 & - & 3 \\
\hline Perylene & Cayuga Lake, NY & 207 & 510 & 7 \\
\hline $\begin{array}{l}\text { Benzo }(g, h, 1)- \\
\text { perylene }\end{array}$ & $\begin{array}{l}\text { Adirondack acid lake } \\
\text { region, NY }\end{array}$ & 830 & 1,356 & 1 \\
\hline $\begin{array}{l}\text { Benzo }(k) \text { fluor- } \\
\text { anthene }\end{array}$ & Casco Bay, ME & 77.8 & 193 & 4 \\
\hline Anthracene & $\begin{array}{l}\text { Adirondack acid lake } \\
\text { region, NY }\end{array}$ & 27 & 32 & 1 \\
\hline Benzo (a) anthracene & Lake George, NY & - & 30 & 3 \\
\hline $\begin{array}{l}\text { Dibenzo }(a, c / a, h)- \\
\text { anthracene }\end{array}$ & Cayuga Lake, NY & 54 & 120 & 7 \\
\hline Indeno $(c, d)$ pyrene & $\begin{array}{l}\text { Adirondack acid lake } \\
\text { region, NY }\end{array}$ & 805 & 1,294 & 1 \\
\hline Coronene & $\begin{array}{l}\text { Adirondack acid lake } \\
\text { region, } \mathrm{NY}\end{array}$ & 495 & 801 & 1 \\
\hline $\begin{array}{l}\text { Acenaphthene } \\
\text { Chrysene/ } \\
\text { triphenylene }\end{array}$ & $\begin{array}{l}\text { Casco Bay, } \mathrm{ME} \\
\text { Cayuga Lake, NY }\end{array}$ & $\begin{array}{l}293 \\
176\end{array}$ & $\begin{array}{r}1,150 \\
605\end{array}$ & $\begin{array}{l}4 \\
7\end{array}$ \\
\hline $\begin{array}{l}\text { 1. Heit and others } \\
\text { 2. Heit ( } 1979 \text { ) } \\
\text { 3. Heit and others } \\
\text { 4. Larsen and other }\end{array}$ & $\begin{array}{l}(1981) \\
(1980) \\
\text { rs }(1983)\end{array}$ & $\begin{array}{l}\text { Luik (198 } \\
t \text { and othe } \\
t(1985)\end{array}$ & s $(1984)$ & \\
\hline
\end{tabular}

for any of the PAH's in several European rivers was only $0.76 \mu \mathrm{g} / \mathrm{L}$.

As a result of their generally low aqueous solubilities and high octanol-water partition coefficients, PAH's will strongly partition into sediment-associated organic matter, and, consequently, sediments act as a reservoir for PAH's. Although aqueous PAH concentrations in surface waters are typically in the parts-per-trillion to low partsper-billion range, sediment PAH concentrations can be several orders of magnitude higher. For example, Jungclaus and others (1978) detected significant residues of phenanthrene ( 0.2 to $25 \mathrm{ppm}$ ), fluorene ( 2 to $10 \mathrm{ppm}$ ), acenaphthylene ( 0.2 to $5 \mathrm{ppm})$, and pyrene ( 0.5 to 75 $\mathrm{ppm}$ ) in the sediment of a river downstream from a chemical manufacturing plant's discharge. Aqueous res- idues of these same compounds, however, were not detected. Table 46 presents documented residues of a variety of PAH's in sediment samples collected from U.S. surface waters. Benzo(a)pyrene concentrations greater than $300 \mathrm{ppm}$ have been detected in the sediments of Lake Hansen, Los Angeles, and numerous researchers have reported sediment PAH concentrations ranging from $10 \mathrm{ppb}$ to $10 \mathrm{ppm}$.

In addition to strongly partitioning into sediment organic matter, PAH's also accumulate in the lipid reservoirs of aquatic organisms. Table 47 presents mean and maximum reported concentrations of PAH's in aquatic organisms and illustrates that residues greater than 400 ppb have been reported. The data in table 47 from Brown and Pancirov (1979) are concentrations of PAH in fish 
Table 47. Residues of polycyclic aromatic hydrocarbons in biota [ $\mu \mathrm{g} / \mathrm{kg}$, micrograms per kilogram. Dash indicates no data available]

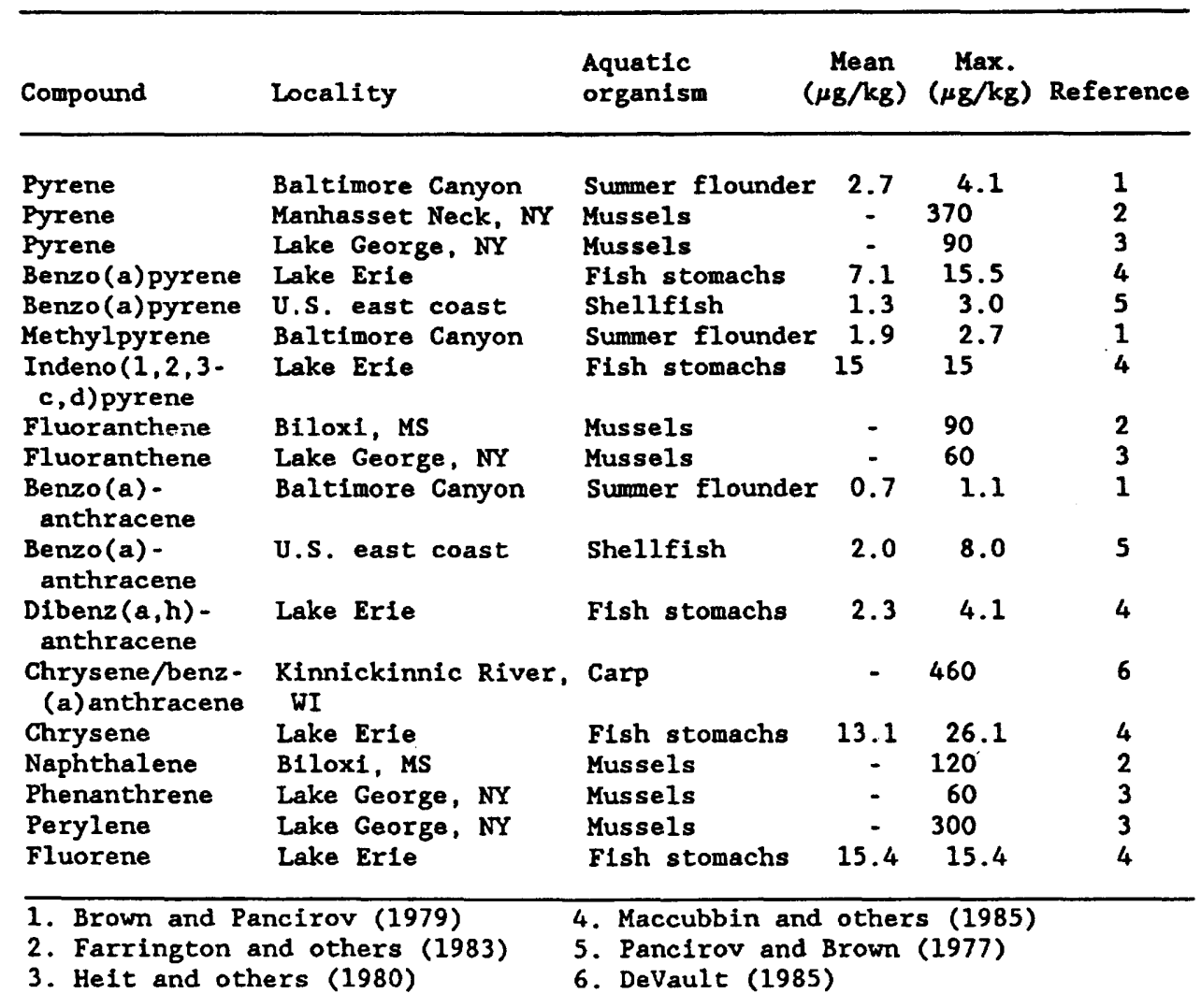

from the Baltimore Canyon area off the coast of New Jersey and Delaware. Despite the lack of any oil or gas production in the area, biological residues of PAH's were still found at significant concentrations (up to $4.1 \mathrm{ppb}$ ), indicating their strong tendency to bioaccumulate.

Although no studies have addressed temporal contamination trends of PAH's in surface waters across the Nation, several localized studies have reported data indicating that PAH residues in sediments have been increasing over time. In a study of two New York lakes, Heit and others (1981) analyzed sediment cores for a variety of PAH's. They determined that with the exception of perylene, anthropogenically derived PAH concentrations decreased with increasing sediment depth until a background concentration was reached at a depth at which sediment was estimated to be about $30 \mathrm{yr}$ old. Hurtt and Quinn (1979) examined PAH residues in sediment cores collected from Narragansett Bay, R.I., and also discovered that PAH residues steadily decreased with sediment core depth, with concentrations stabilizing at a depth of 20-25 cm. Likewise, Heit and others (1984) observed that the highest fluoranthene concentrations in Rocky Mountain National Park occurred in the surficial sediments of four lakes. Lower concentrations were observed in deeper sediments. Finally, Bates and others (1984) noted that
PAH concentration changes in the sediments of the central main basin of Puget Sound, Wash., paralleled the urbanization of Seattle.

Several studies have also investigated regional PAH contamination trends and determined that the highest PAH residues are typically found near highly populated, industrialized areas. Larsen and others (1983) reported strongly regional PAH contamination trends in the sediments of Casco Bay, Maine. In general, total PAH concentrations in the bay's upper and middle sections were less than $900 \mathrm{ppb}$. Sediment samples from stations near the metropolitan area of Portland, however, had total PAH concentrations in excess of $2,000 \mathrm{ppb}$. Heit (1979) noted similar results after collecting and analyzing sediment samples from a variety of western lakes for residues of benzo(a)pyrene. The highest concentrations of the carcinogenic PAH were found in Lake Hansen, which is located in the urban environment of Los Angeles. Farrington and others (1983) sampled mussels from 62 locations along the Atlantic and Pacific coasts of the United States and analyzed them for PAH residues. Again, mussels sampled from stations near urban areas had elevated PAH concentrations relative to mussels from stations near rural, sparsely populated areas. 


\section{SUMMARY}

This report critically reviews the scientific literature with regard to the processes influencing the occurrence and distribution of manmade organic compounds in surface-water systems. The distribution and concentration of organic compounds in surface-water systems are affected by sorption, bioaccumulation, photolysis, hydrolysis, biodegradation, and volatilization.

In aqueous systems, nonionic organic compounds are sorbed by partitioning between water and the sediment-associated organic matter. Adsorption does not contribute significantly to sorption owing to the competitive advantage polar water molecules have for surface adsorption sites. Sediments having high organic-matter contents exhibit the greatest sorption capacity for nonionic organic compounds, and compounds having low aqueous solubilities exhibit the strongest tendency to partition into sediment organic matter. Ionic organic compounds may be able to compete successfully with polar water molecules for surface adsorption sites and, therefore, may be sorbed by an adsorption process.

Organic compounds can similarly partition into the lipid reservoirs of aquatic organisms, and available data indicate that the extent of bioaccumulation depends primarily on an organism's lipid content rather than its position in the aquatic food chain. The popular concept of biomagnification in aqueous systems is not well supported by the scientific literature.

Photolysis, hydrolysis, and biodegradation act to reduce the concentration of an organic compound by either a chemical or a biological transformation. Volatilization also reduces the solute's concentration in the surface-water system, but does so by physically partitioning the solute into the atmosphere. The rates of all four processes are commonly modeled by first-order kinetics, in which the rate of transformation and (or) transport is proportional to the solute's concentration in the water. Both the compound and environmental parameters that influence these processes are discussed.

Data regarding production and use, environmental fate, and environmental distribution are presented for eight groups of anthropogenic organic compounds. Polychlorinated biphenyls (PCB's) and chlorinated insecticides, despite almost complete cessation of their production more than $10 \mathrm{yr}$ ago, remain at significant concentrations in the sediments and biota of surface waters across the United States and around the world. Their low solubilities cause them to strongly partition into particulate organic matter and biological lipid reservoirs. They are extremely persistent organic contaminants and are highly resistant to biodegradation, photolysis, and hydrolysis. Although their vapor pressures are relatively low, their unusually high activities in water permit them to be volatilized from solution and transported atmospherically.
In natural systems, aqueous concentrations of PCB's and chlorinated insecticides are typically low (in the parts-pertrillion range), but sediment and biological concentrations in the parts-per-million range have been reported. Regionally, the highest PCB residues are commonly found in waters near highly populated, industrial areas, while the highest chlorinated insecticide residues are often found in surface waters draining agricultural areas. Surface-water residues of PCB's and chlorinated insecticides in the United States appear to be slowly decreasing, and this is attributable to North American bans on production and use of most of these compounds.

Organophosphorus and carbamate insecticides have seen widespread use in recent years as replacements for many of the chlorinated insecticides. They are readily degraded by both chemical and biological processes, and, as a result, they are among the least environmentally persistent pesticides. Their generally high aqueous solubilities prevent significant partitioning into organic phases, and, therefore, the organophosphorus and carbamate insecticides do not tend to accumulate in sediments or biota. When present in surface-water systems, their highest concentrations are typically found in aqueous samples, but these residues typically do not persist for prolonged periods.

Herbicides, characterized by high aqueous solubilities and low vapor pressures, have been increasingly applied to major crops in the United States, with atrazine and 2,4-D being the most extensively used. Similar to the organophosphorus and carbamate insecticides, the herbicides are relatively nonpersistent environmental contaminants that are readily biodegraded or chemically attenuated by photolytic or hydrolytic reactions. Herbicide bioaccumulation and sorption to sediments is minor, with the possible exception of the dinitroaniline and bipyridylium herbicides. In natural systems, herbicide residues are generally found in the aqueous phase. Aquatic herbicides are applied directly to water bodies, and their residues are therefore greatest immediately following application. Terrestrial herbicides are transported to surface waters primarily in the dissolved phase of surface runoff, and, consequently, residues of these herbicides are usually greatest if a heavy rain immediately follows application of the herbicide. In view of the increasing use of herbicides in the United States, it is unlikely that herbicide residues in surface waters will decrease in the near future.

Phenols are a widely used group of compounds manufactured primarily by the organic chemical and pesticide industries. As a group, the phenols are of generally high solubility. However, increasing chlorination of the molecule results in decreased solubility and increased octanol-water partition coefficients. Phenols are attenuated primarily by biodegradation and photolysis. Sorption to sediments is generally minor, inasmuch as the relatively high solubility of phenols prevents substantial 
partitioning of the solute into sediment-associated organic matter and the negative charge of particle surfaces minimizes adsorption of phenolate anions. Sediments having high organic-matter contents, however, have been observed to sorb appreciable amounts of the highly chlorinated phenols because of their lower solubilities. Similarly, phenols are not readily bioaccumulated, with the exception of the highly chlorinated phenols such as pentachlorophenol. Phenols commonly enter surface waters in industrial or municipal effluents, and chlorination of these effluents can convert phenol to mono-, di-, or even trichlorophenol isomers. Despite their large-scale production, phenolic residues in surface waters usually are not found at concentrations greater than $1 \mathrm{ppm}$.

Halogenated aliphatic and monocyclic aromatic hydrocarbons are industrial chemicals that have a variety of uses, including solvent degreasers, refrigerants, and styrene and dye manufacturing. They are highly soluble in water, and their primary fate in natural waters is volatilization followed by atmospheric photolysis. While many of these compounds have been biologically and chemically degraded in the laboratory, the degradation rates are generally not fast enough to compete successfully with volatilization from the water body. Sorption to sediments and bioaccumulation are not important fate processes, with the possible exception of the chlorinated benzenes. Because of the large quantities of halogenated aliphatic and monocyclic aromatic hydrocarbons produced annually, they are ubiquitous surface-water contaminants. Sediment, biological, and aqueous environmental residues, however, rarely exceed the parts-per-billion range. Spatially, halogenated aliphatic and monocyclic aromatic hydrocarbons are typically found near industrial and highly populated areas. Temporally, there is some evidence that environmental residues have decreased slightly since the late 1970's, paralleling a similar decrease in production of these compounds in the United States.

Phthalate esters represent a relatively new class of environmental pollutants. They are extensively used as plasticizers to produce useful products from polymers of vinyl chloride. As a result of their low solubilities and nonionic nature, they tend to strongly partition into particulate organic matter and biological lipid reservoirs. Therefore, aqueous residues exceeding $50 \mathrm{ppb}$ rarely have been reported, whereas sediment and biological residues exceeding $1 \mathrm{ppm}$ have been reported. Reported environmental levels of phthalate esters should be viewed with caution, however, because there is strong evidence that they may be produced naturally. Additionally, environmental samples can be contaminated with phthalate esters by the use of plastic sampling containers. The ultimate fate of phthalate esters in surface waters appears to be biodegradation.

Although not deliberately manufactured and having no commercial use, polychlorinated dibenzo-p-dioxins
(PCDD's) enter the environment as impurities in compounds whose production involves the use of 2,4,5trichlorophenol. These compounds include many pesticides and both tetra- and pentachlorophenol. Although the quantity of PCDD's produced each year is probably very small, they are extremely persistent contaminants that have been shown to be highly toxic to laboratory animals (particularly 2,3,7,8-tetrachlorodibenzop-dioxin). PCDD's strongly sorb to sediments and soils, and erosion of soil treated with PCDD-contaminated pesticides is a likely input of PCDD's to surface-water systems. PCDD's also strongly partition into biological lipid reservoirs, and aqueous concentrations as low as $\mathbf{5 0}$ $\mathrm{pg} / \mathrm{L}$ have resulted in biological concentrations as great as $2.4 \mu \mathrm{g} / \mathrm{L}$. There is some evidence that PCDD's can be degraded photolytically; however, the majority of PCDD's in surface waters will probably be unavailable for photolysis owing to their rapid sorption to sediments. The highest PCDD residues in surface-water systems are found in the sediments and biota, with reported concentrations typically in the parts-per-trillion to parts-perbillion range.

Polycyclic aromatic hydrocarbons (PAH's) are produced by high-temperature pyrolytic reactions, such as municipal incineration, forest fires, and fuel combustion. Their residues also have been detected in fossil fuels and wastewater sludges. Important environmental-fate processes include sorption and bioaccumulation, and the ultimate fate of PAH's in surface-water systems may be sorption to sediments followed by slow biodegradation. Photolytic degradation of PAH's has been demonstrated in laboratory studies, but in natural systems it is uncertain if photolysis is a significant fate process owing to the rapid sorption of PAH's to sediments. Because of their low solubilities, aqueous residues of PAH's in natural systems are typically low relative to sediment and biological concentrations. Based on sediment core data, PAH residues in surface-water systems appear to be increasing with time, and concentrations seem to parallel industrialization both temporally and spatially.

\section{SELECTED REFERENCES}

Abdullah, M.I., Ringstad, O., and Kveseth, N.J., 1982, Polychlorinated biphenyls in the sediments of the Inner Oslofjord: Water, Air, and Soil Pollution, v. 18, p. 485-497.

Acree, J., Beroza, M., and Bowman, M.C., 1963, Codistillation of DDT with water: Journal of Agricultural Food Chemistry, v. 11, p. 278-283.

Adams, R.S., 1973, Factors influencing soil adsorption and bioactivity of pesticides: Residue Reviews, v. 47, p. 1-45.

Addison, R.F., Paterson, S., and Mackay, Donald, 1983, The predicted environmental distribution of some PCB replacements: Chemosphere, v. 12 , no. 6 , p. 827-834.

Agarwal, H.C., Mittal, P.K., Menon, K.B., and Pillai, M.K.K., 1986, DDT residues in the river Jamuna in Delhi, India: Water, Air, and Soil Pollution, v. 28, p. 89-104. 
Agarwal, H.C., Saxena, D.M., and Lal, Rup, 1982, Accumulation and metabolism of DDT and its metabolites by Tetrahymena: Water, Air, and Soil Pollution, v. 18, p. 441-447.

Akhavein, A.A., and Linscott, D.L., 1968, The dipyridilium pesticides: Paraquat and diquat: Residue Reviews, v. 23, p. 98-140.

Alexander, Martin, 1985, Biodegradation of organic chemicals: Environmental Science and Technology, v. 18, no. 2, p. 106-111.

Alexander, M., and Aleem, M.I.H., 1961, Effect of chemical structure on microbial decomposition of aromatic herbicides: Agricultural and Food Chemistry, v. 9, no. 1, p. 44-47.

Allison, L.E., 1965, Organic carbon, in Black, C., Evans, D., White, J., Ensminger, L., and Clark, F., eds., Methods of soil analysis, pt. 2: Madison, Wis., American Society of Agronomy, p. 1367-1378.

Almgren, Mats, Grieser, Franz, Powell, J.R., and Thomas, J.K., 1979, A correlation between the solubility of aromatic hydrocarbons in water and micellar solutions, with their normal boiling points: Journal of Chemical and Engineering Data, v. 24, no. 4, p. 285-287.

Al-Omar, M.A., Al-Ogaily, N.H., and Shebil, Dia-Aldin, 1986, Residues of organochlorine insecticides in fish from polluted water: Bulletin of Environmental Contamination and Toxicology, v. 36, p. 109-113.

Anderson, R.L., 1985, Environmental effects on metsulfuron and chlorsulfuron bioactivity in soil: Journal of Environmental Quality, v. 14 , no. 4 , p. 517-521.

Andrilenas, P.A., 1974, Farmers' use of pesticides in 1971-Quantities: U.S. Department of Agriculture Agricultural Economic Report 252, 56 p.

Anjum, F., and Qadri, S.S.H., 1986, In vivo metabolism of fenitrothion (o,o-dimethyl-o-(4-nitro-m-tolyl) phosphorothioate) in fresh water teleost (Tilapia mossambica): Bulletin of Environmental Contamination and Toxicology, v. 36, p. 140-145.

Ansari, G.A.S., James, G.P., Hu, L.A., and Reynolds, E.S., 1986, Organochlorine residues in adipose tissue of residents of the Texas Gulf Coast: Bulletin of Environmental Contamination and Toxicology, v. 36, p. 311-316.

Arbuckle, W.B., 1983, Estimating activity coefficients for use in calculating environmental parameters: Environmental Science and Technology, v. 17, no. 9, p. 537-542.

Aslanzadeh, Jaber, and Hedrick, H.G., 1985, Search for mirexdegrading soil microorganisms: Soil Science, v. 139, no. 4, p. 369-374.

Averitt, W.K., and Gangstad, E.O., 1976, Dissipation of residues of 2,4-D in static water: Journal of Environmental Quality, v. 5, no. 2, p. $145-147$.

Avnimelech, Y., Yamamato, M., and Menzel, R.G., 1983, Evaluating the release of soluble components from sediments: Journal of Environmental Quality, v. 12, no. 1, p. 86-91.

Bailey, G.W., and White, J.L., 1965, Herbicides: A compilation of their physical, chemical and biological properties: Residue Reviews, v. 10, p. 97-121.

Bailey, G.W., White, J.L., and Rothberg, T., 1968, Adsorption of organic herbicides by montmorillonite: Role of $\mathrm{pH}$ and chemical character of adsorbate: Soil Science Society of America Proceedings, v. 32, p. 222-234.

Baird, R.B., Kuo, C.L., Shapiro, J.S., and Yanko, W.A., 1974, The fate of phenolics in wastewater determinations by direct injection GLC and Warburg respirometry: Archives of Environmental Contamination and Toxicology, v. 6, p. 165-178.

Baker, E.T., and Feely, R.A., 1978, Chemistry of oceanic particulate matter and sediments: Science, v. 200, p. 533-535.

Baker, J.E., Eisen reich, S.J., Johnson, T.C., and Halfman, B.M., 1985, Chlorinated hydrocarbon cycling in the benthic nepheloid layer of Lake Superior: Environmental Science and Technology, v. 19, no. 9, p. 854-861.
Banerjee, Sujit, 1984, Solubility of organic mixtures in water: Environmental Science and Technology, v. 18, no. 8, p. 587-591.

-1985, Calculation of water solubility of organic compounds with UNIFAC-derived parameters: Environmental Science and Technology, v. 19, no. 4, p. 369-370.

Banerjee, Sujit, Howard, P.H., Rosenberg, A.M., Dombrowski, A.E., Sikka, Harish, and Tullis, D.L., 1984, Development of a general kinetic model for biodegradation and its application to chlorophenols and related compounds: Environmental Science and Technology, v. 18 , no. 6 , p. 416-422.

Banerjee, Sujit, Sugatt, R.H., and O'Grady, D.P., 1984, A simple method for determining bioconcentration parameters of hydrophobic compounds: Environmental Science and Technology, v. 18, no. 2 , p. 79-81.

Banerjee, Sujit, Yalkowsky, S.H., and Valvani, S.C., 1980, Water solubility and octanol/water partition coefficients of organics; Limitations of the solubility-partition coefficient correlation: Environmental Science and Technology, v. 14, no. 10, p. 1227-1229.

Banwart, W.L., Hasset, J.J., Wood, S.G., and Means, J.C., 1982, Sorption of nitrogen-heterocyclic compounds by soils and sediments: Soil Science, v. 133, p. 42-47.

Banwart, W.L., Khan, A., and Hassett, J.J., 1980, Effect of sample pretreatment on sorption of acetophenone by soils and sediments: Journal of Environmental Science and Health, v. B15, p. 165-179.

Barber, R.T., and Warlen, S.M., 1979, Organochlorine insecticide residues in deep sea fish from $2500 \mathrm{~m}$ in the Atlantic Ocean: Environmental Science and Technology, v. 13, no. 9, p. 1146-1148.

Barbera, J.C., Lopez, F.J., Hernandez, F., Medina, J., and Pastor, A., 1986, Gas chromatographic determination of organochlorine pesticides; Contamination of dicofol, fenson, and tetradifon in fish and natural waters of a wet area beside the Mediterranean Sea: Bulletin of Environmental Contamination and Toxicology, v. 36, p. 211-218.

Barker, J.L., 1984, Organochlorine pesticide and polychlorinated biphenyl residues at four trophic levels in the Schuylkill River, Pennsylvania, in Meyer, E.L., ed., Selected papers in the hydrologic sciences 1984: U.S. Geological Survey Water-Supply Paper 2262, p. 25-31.

Barrick, R.C., 1982, Flux of aliphatic and polycyclic aromatic hydrocarbons to central Puget Sound for Seattle (Westpoint) primary sewage effluent: Environmental Science and Technology, v. 16, p. 682-692.

Bates, T.S., Hamilton, S.E., and Cline, J.D., 1984, Vertical transport and sedimentation of hydrocarbons in the central main basin of Puget Sound, Washington: Environmental Science and Technology, v. 18 , no. 5, p. 299-305.

Baum, S.J., 1982, Introduction to organic and biological chemistry: New York, Macmillan, $560 \mathrm{p}$.

Belluck, David, and Felsot, Allan, 1981, Bioconcentration of pesticides by egg masses of the caddisfly, Triaenodes tardus milne: Bulletin of Environmental Contamination and Toxicology, v. 26, p. 299-306.

Benefield, L.D., and Randall, C.W., 1980, Biological process design for wastewater treatment: Englewood Cliffs, N.J., Prentice-Hall, 515 p.

Berner, R.A., 1980, Early diagenesis: A theoretical approach: Princeton, N.J., Princeton University Press, 241 p.

Bevenue, Arthur, 1976, The "bioconcentration" aspects of DDT in the environment: Residue Reviews, v. 61, p. 37-112.

Biddinger, G.R., and Gloss, S.P., 1984, The importance of trophic transfer in the bioaccumulation of chemical contaminants in aquatic ecosystems: Residue Reviews, v. 91, p. 103-145.

Bilby, R.E., and Likens, G.E., 1979, Effects of hydrologic fluctuations on the transport of fine particulate organic carbon in a small stream: Limnology and Oceanography, v. 24, no. 1, p. 69-75. 
Birmingham, B.C., and Colman, Brian, 1983, Potential phytotoxicity of diquat accumulated by aquatic plants and sediments: Water, Air, and Soil Pollution, v. 19, p. 123-131.

Blair, W.R., Olson, G.J., Brinckman, F.E., and Iverson, W.P., 1982, Accumulation and fate of tri-n-butyltin cation in estuarine bacteria: Microbial Ecology, v. 8, p. 241-251.

Bobra, A., Mackay, Donald, and Shiu, W.Y., 1979, Distribution of hydrocarbons among oil, water and vapor phases during oil dispersant toxicity tests: Bulletin of Environmental Contamination and Toxicology, v. 23, p. 558-565.

Boehm, P.D., and Quinn, J.G., 1973, Solubilization of hydrocarbons by the dissolved organic matter in sea water: Geochimica et Cosmochimica Acta, v. 37, p. 2459-2477.

Bopp, R.F., Simpson, H.J., Olsen, C.R., and Kostyk, N., 1981, Polychlorinated biphenyls in sediments of the tidal Hudson River, New York: Environmental Science and Technology, v. 15, no. 2, p. 210-216.

Bopp, R.F., Simpson, H.J., Olsen, C.R., Trier, R.M., and Nostyk, N., 1982, Chlorinated hydrocarbons and radionuclide chronologies in sediments of the Hudson River and estuary, New York: Environmental Science and Technology, v. 16, no. 10, p. 666-676.

Borighem, G., and Vereecken, J., 1978, Study of the biodegradation of phenol in river water: Ecological Modelling, v. 4, p. 51-59.

Bouchard, D.C., and Lavy, T.L., 1985, Hexazinone adsorptiondesorption studies with soil and organic adsorbents: Journal of Environmental Quality, v. 14, no. 2, p. 181-186.

Bovey, R.W., Burnett, Earl, Richardson, Clarence, Merkle, M.G., Baur, J.R., and Knisel, W.G., 1974, Occurrence of 2,4,5-T and picloram in surface runoff water in the blacklands of Texas: Journal of Environmental Quality, v. 3, no. 1, p. 61-64.

Bowman, B.T., and Sans, W.W., 1985a, Partitioning behavior of insecticides in soil-water systems: I. Adsorbent concentration effects: Journal of Environmental Quality, v. 14, no. 2, p. 265-269.

-1985b, Partitioning behavior of insecticides in soil-water systems: II. Desorption hysteresis effects: Journal of Environmental Quality, v. 14, no. 2, p. 270-273.

Boyle, E.A., Edmond, J.M., and Sholkovitz, E.R., 1977, The mechanism of iron removal in estuaries: Geochimica et Cosmochimica Acta, v. 41, p. 1313-1324.

Bradley, J.R., Sheets, T.J., and Jackson, M.D., 1972, DDT and toxaphene movement in surface water from cotton plots: Journal of Environmental Quality, v. 1, no. 1, p. 102-105.

Brooks, J.M., Wiesenburg, D.A., Burke, R.A., and Kennicutt, M.C., 1981 , Gaseous and volatile hydrocarbon inputs from a subsurface oil spill in the Gulf of Mexico: Environmental Science and Technology, v. 15, no. 8, p. 951-959.

Brown, D.S., and Flagg, E.W., 1981, Empirical prediction of organic pollutant sorption in natural sediments: Journal of Environmental Quality, v. 10, no. 3, p. 382-386.

Brown, M.P., Werner, M.B., Sloan, R.J., and Simpson, K.W., 1985, Polychlorinated biphenyls in the Hudson River: Environmental Science and Technology, v. 19, no. 8, p. 656-661.

Brown, R.A., and Pancirov, R.J., 1979, Polynuclear aromatic hydrocarbons in Baltimore Canyon fish: Environmental Science and Technology, v. 13, no. 7, p. 878-879.

Buchel, K.H., 1983, Chemistry of pesticides: New York, John Wiley and Sons, $518 \mathrm{p}$.

Bunce, N.H., and Kumar, Y., 1978, An assessment of the impact of solar degradation of PCB's in the aquatic environment: Chemosphere, v. 2, p. 155-164.

Burkhard, L.P., Andren, A.W., and Armstrong, D.E., 1985, Estimation of vapor pressures for polychlorinated biphenyls: A comparison of eleven predictive methods: Environmental Science and Technology, v. 19 , no. 6 , p. $500-507$.

Burns, N.M., and Rosa, F., 1980, In situ measurement of the settling velocity of organic carbon particles and 10 species of phyto- plankton: Limnology and Oceanography, v. 25 , no. 5 , p. 855-864.

Buser, Hans-Rudolf, 1986, Polybrominated dibenzofurans and dibenzo-p-dioxins: Thermal reaction products of polybrominated diphenyl ether flame retardants: Environmental Science and Technology, v. 20 , no. 4 , p. 404-408.

Cadena, Fernando, Eiceman, G.A., and Vandiver, V.J., 1984, Removal of volatile organic pollutants from rapid streams: Journal of the Water Pollution Control Federation, v. 56, no. 5, p. 460-463.

Call, D.J., Brooke, L.T., Kent, R.J., Poirier, S.H., Knuth, M.L., Shubat, P.J., and Slick, E.J., 1984, Toxicity, uptake, and elimination of the herbicides alachlor and dinoseb in freshwater fish: Journal of Environmental Quality, v. 13, no. 3, p. 493-498.

Callahan, M.A., Slimak, M.W., Gabel, N.W., May, I.P., Fowler, C.F., Freed, J.R., Jennings, Patricia, Durfee, R.L., Whitmore, F.C., Maestri, Bruno, Mabey, W.R., Holt, B.R., and Gould, Constance, 1979, Water-related environmental fate of 129 priority pollutants: U.S. Environmental Protection Agency, EPA-440/4-79-029a,b.

Campbell, J.R., and Luthy, R.G., 1985, Prediction of aromatic solute partition coefficients using the UNIFAC group contribution model: Environmental Science and Technology, v. 19, p. 980-985.

Campbell, J.R., Luthy, R.G., and Carrondo, M.J.T., 1983, Measurement and prediction of distribution coefficients for wastewater aromatic solutes: Environmental Science and Technology, v. 17, no. $10,582-589$.

Canton, J.H., Greve, P.A., Slooff, W., and van Esch, G.J., 1975, Toxicity, accumulation and elimination studies of hexachlorocyclotexane $(\mathrm{HCH})$ with freshwater organisms of different trophic levels: Water Research, v. 9, p. 1163-1169.

Canton, J.H., van Esch, G.J., Greve, P.A., and van Hellemond, A.B.A.M., 1977, Accumulation and elimination of hexachlorocyclohexane (HCH) by the marine algae Chlamydomonas and Dunaliella: Water Research, v. 11, p. 111-115.

Carlson, D.J., 1983, Dissolved organic materials in surface microlayers: Temporal and spatial variability and relation to sea state: Limnology and Oceanography, v. 28, no. 3, p. 415-431.

Caron, G., Suffet, I.H., and Belton, Tom, 1985, Effect of dissolved organic carbon on the environmental distribution of nonpolar organic compounds: Chemosphere, v. 14, no. 8, p. 993-1000.

Carranza de Storani, M.M., Rosas, S.B., and Ghittoni, N.E., 1986, Alterations in lipid composition of membranes from Rhizobium meliloti exposed to parathion: Bulletin of Environmental Contamination and Toxicology, v. 36, p. 267-270.

Carter, C.W., and Suffet, I.H., 1982, Binding of DDT to dissolved humic materials: Environmental Science and Technology, v. 16, no. 11 , p. $735-740$.

Casserly, D.M., Davis, E.M., Downs, T.D., and Guthrie, R.K., 1983, Sorption of organics by Selenastrum capriconutum: Water Research, v. 17, no. 11, p. 1591-1594.

Champion, D.R., and Olsen, S.R., 1971, Adsorption of DDT on solid particles: Soil Science Society of America Proceedings, v. 35, p. 887-891.

Chapman, B.M., 1982, Numerical simulation of the transport and speciation of nonconservative chemical reactants in rivers: Water Resources Research, v. 18, no. 1, p. 155-167.

Chase, R.R.P., 1979, Settling behavior of natural organic particulates: Limnology and Oceanography, v. 24, no. 3, p. 417-426.

Chau, A.S.Y., and Lee, H.B., 1980, Analytical reference materials. III. Preparation and homogeneity test of large quantities of wet and dry sediment reference materials for long term polychlorinated biphenyl quality control studies: Journal of the Official Association of Analytical Chemists, v. 63, no. 5, p. 947-951.

Chiou, C.T., 1981, Partition coefficient and water solubility in environmental chemistry, in Saxena, J., and Fisher, F. eds., Hazard assessment of chemicals: Current developments: New York, Academic Press, v. 1, p. 117-153. 
1985, Partition coefficients of organic compounds in lipidwater systems and correlations with fish bioconcentration factors: Environmental Science and Technology, v. 19, no. 1, p. 57-62.

Chiou, C.T., and Freed, V.H., 1977, Environmental Science and Technology, v. 11, p. 1220.

Chiou, C.T., Freed, V.H., Peters, L.J., and Kohnert, R.L., 1980, Evaporation of solutes from water: Environment International, $v$. 3, p. 231-236.

Chiou, C.T., Freed, V.H., Schmedding, D.W., and Kohnert, R.L., 1977, Partition coefficient and bioaccumulation of selected organic chemicals: Environmental Science and Technology, v. 11, no. 5, p. 475-478.

Chiou, C.T., Kohnert, R.L., Freed, V.H., and Tonkyn, R.G., 1983, Predictions of evaporative loss rates of solutes in stagnant and turbulent waters in relation to rates of reference materials: Environment International, v. 9, p. 13-17.

Chiou, C.T., Malcolm, R.L., Brinton, T.I., and Kile, D.E., 1986, Water solubility enhancement of some organic pollutants and pesticides by dissolved humic and fulvic acids: Environmental Science and Technology, v. 20, no. 5, p. 502-508.

Chiou, C.T., and Manes, M., 1980, On the validity of the codistillation model for the evaporation of pesticides and other solutes from water solution: Environmental Science and Technology, v. 14, p. 1253-1254.

Chiou, C.T., Peters, L.J., and Freed, V.H., 1979, Physical concept of soil-water equilibria for nonionic organic compounds: Science, v. 206, p. 831-832.

1981, Science, v. 213 , p. 684.

Chiou, C.T., Porter, P.E., and Schmedding, D.W., 1983, Partition equilibria of nonionic organic compounds between soil organic matter and water: Environmental Science and Technology, v. 17, no. 4, p. 227-231.

Chiou, C.T., Porter, P.E., and Shoup, T.D., 1984, Environmental Science and Technology, v. 18, no. 4, p. 295.

Chiou, C.T., Schmedding, D.W., and Block, J.H., 1981, Correlation of water solubility with octanol-water partition coefficient: Journal of the Pharmaceutical Sciences, v. 70, no. 10, p. 1176-1177.

Chiou, C.T., Schmedding, D.W., Block, J.H., and Manes, M., 1982, Substituent contribution to the partition coefficients of substituted benzenes in solvent-water mixtures: Journal of Pharmaceutical Sciences, v. 71, no. 11, p. 1307-1309.

Chiou, C.T., Schmedding, D.W., and Manes, Milton, 1982, Partitioning of organic compounds in octanol-water systems: Environmental Science and Technology, v. 16, no. 1, p. 4-10.

Chiou, C.T., and Shoup, T.D., 1985, Soil sorption of organic vapors and effects of humidity on sorptive mechanism and capacity: Environmental Science and Technology, v. 19, no. 12, p. 1196-1200.

Chiou, C.T., Shoup, T.D., and Porter, P.E., 1985, Mechanistic roles of soil humus and minerals in the sorption of nonionic organic compounds from aqueous and organic solutions: Organic Geochemistry, v. 8, no. 1, p. 9-14.

Choi, W.W., and Chen, K.Y., 1976, Association of chlorinated hydrocarbons with fine particles and humic substances in nearshore surficial sediments: Environmental Science and Technology, v. 10, no. 8, p. 782-786.

Christman, R.F., and Gjessing, E.T., 1983, Priorities in humic research, in Christman, R., and Gjessing, E., eds., Aquatic and terrestrial humic materials: Ann Arbor, Mich., Ann Arbor Science Publishers, p. 517-528.

Chu, J.P., and Kirsch, E.J., 1972, Metabolism of pentachlorophenol by an axenic bacterial culture: Applied Microbiology, v. 23, no. 5, p. 1033-1035.

Clark, J.R., Patrick, J.M., Moore, J.C., and Forester, Jerrold, 1986, Accumulation of sediment-bound PCBs by fiddler crabs: Bulletin of Environmental Contamination and Toxicology, v. 36, p. 571-578.

Clayton, J.R., Pavlou, S.P., and Breitner, N.F., 1977, PCB's in coastal marine zooplankton; Bioaccumulation by equilibrium partitioning: Environmental Science and Technology, v. 11, no. 7, p. 676-682.

Coates, J.T., and Elzerman, A.W., 1986, Desorption kinetics for selected PCB congeners from river sediments: Journal of Contaminant Hydrology, v. 1, p. 191-210.

Cole, R.H., Frederick, R.E., Healy, R.P., and Rolan, R.G., 1984, Preliminary findings of the priority pollutant monitoring project of the nationwide urban runoff program: Journal of the Water Pollution Control Federation, v. 56, no. 7, p. 898-908.

Collier, T.K., Gruger, E.H., and Varanasi, Usha, 1985, Effect of Aroclor 1254 on the biological fate of 2,6-dimethylnaphthalene in Coho salmon (Oncorhynchus kisutch): Bulletin of Environmental Contamination and Toxicology, v. 34, p. 114-120.

Connolly, J.P., Armstrong, N.E., and Miksad, R.W., 1983, Adsorption of hydrophobic pollutants in estuaries: American Society of Engineers, Journal of the Environmental Engineering Division, v. 109, no. EE1, p. 17-35.

Connor, M.S., 1984a, Fish/sediment concentration ratios for organic compounds: Environmental Science and Technology, v. 18, no. 1, p. 31-35.

-1984b, Comparison of the carcinogenic risks from fish vs. groundwater contamination by organic compounds: Environmental Science and Technology, v. 18, no. 8, p. 628-631.

Conrad, Ralf, and Seiler, Wolfgang, 1985, Characteristics of abiological carbon monoxide formation from soil organic matter, humic acids, and phenolic compounds: Environmental Science and Technology, v. 19 , no. 12 , p. 1165-1169.

Cossa, D., Picard-Berube, M., and Gouygou, J.P., 1983, Polynuclear aromatic hydrocarbons in mussels from the estuary and northwestern Gulf of St. Lawrence, Canada: Bulletin of Environmental Contamination and Toxicology, v. 31, p. 41-47.

Criddle, C.S., McCarty, P.L., Elliott, M.C., and Barker, J.F., 1986, Reduction of hexachloroethane to tetrachloroethylene in groundwater: Journal of Contaminant Hydrology, v. 1, p. 133-142.

Crosby, D.G., and Wong, A.S., 1977, Environmental degradation of 2,3,7,8-tetrachlorodibenzo-p-dioxin (TCDD): Science, v. 195, p. 1337-1338.

Curl, R.L., and Keoleian, G.A., 1984, Implicit-adsorbate model for apparent anomalies with organic adsorption on natural adsorbents: Environmental Science and Technology, v. 18, no. 12, p. 916-922.

Czuczwa, J.M., McVeety, B.D., and Hites, R.A., 1984, Polychlorinated dibenzo-p-dioxins and dibenzofurans in sediments from Siskiwit Lake, Isle Royale: Science, v. 226, no. 4674, p. 568-569.

Dahchour, A., Bitton, G., Coste, C.M., and Bastide, J., 1986, Degradation of the herbicide propanil in distilled water: Bulletin of Environmental Contamination and Toxicology, v. 36, p. 556-562.

Dao, T.H., Lavy, T.L., and Dragun, J., 1983, Rationale of the solvent selection for soil extraction of pesticide residues: Residue Reviews, v. 87, p. 91-104.

Davani, B., Ingram, J., Gardea, J.L., and Eiceman, G.A., 1986, Organic compounds in soils and sediments from unlined waste disposal pits for natural gas production and processing: Water, Air, and Soil Pollution, v. 27, p. 267-276.

Davis, J.A., 1982, Adsorption of natural dissolved organic matter at the oxide/water interface: Geochimica et Cosmochimica Acta, v. 46, p. 2381-2393.

DeLaune, R.D., Gambrell, R.P., and Reddy, K.S., 1983, Fate of pentachlorophenol in estuarine sediment: Environmental Pollution (Ser. B), v. 6, p. 297-308. 
DeLaune, R.D., and Salinas, L.M., 1985, Fate of 2,4-D entering a freshwater aquatic environment: Bulletin of Environmental Contamination and Toxicology, v. 35, p. 564-568.

Delfino, J.J., 1979, Toxic substances in the Great Lakes: Environmental Science and Technology, v. 13, no. 12, p. 1462-1468.

DePinto, J.V., Young, T.C., and Martin, S.C., 1980, Aquatic sediments: Journal of the Water Pollution Control Federation, v. 52, no. 6, p. 1656-1670.

1981, Aquatic sediments: Journal of the Water Pollution Control Federation, v. 53, no. 6, p. 999-1007.

1982, Aquatic sediments: Journal of the Water Pollution Control Federation, v. 54, no. 6, p. 855-862.

1983, Aquatic sediments: Journal of the Water Pollution Control Federation, v. 55, no. 6, p. 822-829.

DeVault, D.S., 1985, Contaminants in fish from Great Lakes harbors and tributary mouths: Archives of Environmental Contamination and Toxicology, v. 14, p. 587-594.

Dhamotharan, S., Gulliver, J.S., and Stefan, H.G., 1981, Unsteady one-dimensional settling of suspended sediment: Water Resources Research, v. 17, no. 4, p. 1125-1132.

Dietrich, A.M., Millington, D.S., and Christman, R.F., 1983, Specific identification of organic pollutants in Haw River water using gas chromatography/mass spectrometry: Raleigh, University of North Carolina Water Resources Research Institute Report 206, 91 p.

Dietrich, W.E., 1982, Settling velocity of natural particles: Water Resources Research, v. 18, no. 6, p. 1615-1626.

Dilling, W.L., 1977, Interphase transfer processes. II. Evaporation rates of chloromethanes, ethanes, ethylenes, propanes, and propylenes from dilute aqueous solutions. Comparisons with theoretical predictions: Environmental Science and Technology, v. 11 , no. 4 , p. $405-409$.

Dilling, W.L., Bredeweg, C.J., and Tefertiller, N.B., 1976, Organic photochemistry: Simulated atmospheric photodecomposition rates of methylene chloride, 1,1,1-trichloroethane, trichloroethylene, tetrachloroethylene, and other compounds: Environmental Science and Technology, v. 10, no. 4, p. 351-356.

Dilling, W.L., Tefertiller, N.B., and Kallos, G.J., 1975, Evaporation rates and reactivities of methylene chloride, chloroform, 1,1,1trichloroethane, trichloroethylene, tetrachloroethylene, and other chlorinated compounds in dilute aqueous solutions: Environmental Science and Technology, v. 9, no. 9, p. 833-838.

Di Salvo, L.H., Guard, H.E., and Hunter, Leon, 1975, Tissue hydrocarbon burden of mussels as potential monitor of environmental hydrocarbon insult: Environmental Science and Technology, v. 9, no. 3 , p. $247-251$

Di Toro, D.M., and Horzempa, L.M., 1982, Reversible and resistant components of $\mathrm{PCB}$ adsorption-desorption isotherms: Environmental Science and Technology, v. 16, no. 9, p. 592-602.

Di Toro, D.M., Horzempa, L.M., Casey, M.M., and Richardson, W., 1982, Reversible and resistant components of PCB adsorptiondesorption; Adsorbent concentration effects: Journal of Great Lakes Research, v. 8, no. 2, p. 336-349.

Di Toro, D.M., Jeris, J.S., and Ciarcia, Daniel, 1985, Diffusion and partitioning of hexachlorobiphenyl in sediments: Environmental Science and Technology, v. 19, no. 12, p. 1169-1175.

Drake, E.H., and Motto, H.L., 1982, An analysis of the effect of clay and organic matter content on the cation exchange capacity of New Jersey soils: Soil Science, v. 133, no. 5, p. 281-288.

Drifmeyer, J.E., Rosenberg, C.L., and Heywood, M.A., 1980, Chlordecone (kepone) accumulation on estuarine plant detritus: Bulletin of Environmental Contamination and Toxicology, v. 24, p. 364-368.

Drivas, P.J., 1982, Calculation of evaporative emissions from multicomponent liquid spills: Environmental Science and Technology, v. 11 , no. 4 , p. $405-409$.

Duce, R.A., Quinn, J.G., Olney, C.E., Piotrowicz, S.R., Ray, B.J., and
Wade, T.L., 1972, Enrichment of heavy metals and organic compounds in the surface microlayer of Narragansett Bay, Rhode Island: Science, v. 176, p. 161-163.

Duinker, J.C., 1980, Suspended matter in estuaries: Adsorption and desorption processes, in Olausson, E., and Cato, I., eds, Chemistry and biochemistry of estuaries: New York, John Wiley and Sons, p. 121-145.

Duinker, J.C., Hillebrand, M.T.J., Palmork, K.H., and Wilhelmsen, S., 1980, An evaluation of existing methods for quantitation of polychlorinated biphenyls in environmental samples and suggestions for an improved method based on measurement of individual components: Bulletin of Environmental Contamination and Toxicology, v. 25, p. 956-964.

Dyer, K.R., 1972, Sedimentation in estuaries, in Barnes, R., and Green, J., eds, The estuarine environment: London, Applied Science Publishers, p. 10-33.

Dzombak, D.A., and Luthy, R.G., 1984, Estimating adsorption of polycyclic aromatic hydrocarbons on soils: Soil Science, v. 137, no. 5, p. 297.

Eberhardt, L.L., Gilbert, R.O., Hollister, H.L., and Thomas, J.M., 1976, Sampling for contaminants in ecological systems: Environmental Science and Technology, v. 10, no. 9, p. 917-925.

Eckert, J.M., and Sholkovitz, E.R., 1976, The flocculation of iron, aluminum and humates from river water by electrolytes: Geochimica et Cosmochimica Acta, v. 40, p. 847-848.

Edwards, N.T., 1983, Polycyclic aromatic hydrocarbons (PAHs) in the terrestrial environment-A review: Journal of Environmental Quality, v. 12, no. 4, p. 427-441.

Edzwald, J.K., Upchurch, J.B., and O'Melia, C.R., 1974, Coagulation in estuaries: Environmental Science and Technology, v. 8, no. 1, p. 58-63.

Eganhouse, R.P., and Kaplan, I.R., 1982, Extractable organic matter in municipal wastewaters. 1. Petroleum hydrocarbons: Temporal variations and mass emission rates to the ocean: Environmental Science and Technology, v. 16, no. 3, p. 180-186.

Eichers, T.R., Andrilenas, P.A., and Anderson, T.W., 1978, Farmers' use of pesticides in 1976: U.S. Department of Agriculture, Agricultural Economic Report 418, 58 p.

Eichers, T.R., Andrilenas, P.A., Blake, Helen, Jenkins, Robert, and Fox, A.S., 1970, Quantities of pesticides used by farmers in 1966: U.S. Department of Agriculture, Agricultural Economic Report $179,61 \mathrm{p}$.

Eichholz, G.G., Craft, T.F., and Galli, A.N., 1967, Trace element fractionation by suspended matter in water: Geochimica et Cosmochimica Acta, v. 31, p. 737-745.

Eidt, D.C., Sosiak, A.J., and Mallet, V.N., 1984, Partitioning and short-term persistence of fenitrothion in New Brunswick (Canada) headwater streams: Archives of Environmental Contamination and Toxicology, v. 13, p. 43-52.

Eisenreich, S.J., Elzerman, A.W., and Armstrong, D.E., 1978, Enrichment of micronutrients, heavy metals, and chlorinated hydrocarbons in wind-generated lake foam: Environmental Science and Technology, v. 12, no. 4, p. 413-417.

Eisenreich, S.J., Hollod, G.J., and Johnson, T.C., 1979, Accumulation of PCBs in surficial Lake Superior sediments. Atmospheric deposition: Environmental Science and Technology, v. 13, no. 5, p. 569-573.

Eisenreich, S.J., Hollod, G.J., Johnson, T.C., and Evans, J., 1980, Polychlorinated biphenyl and other microcontaminant-sediment interactions in Lake Superior, in Baker, Robert, ed., Contaminants and sediments, v. 1: Ann Arbor, Mich., Ann Arbor Science Publishers, p. 67-94.

Eisma, D., 1981, Suspended matter as a carrier for pollutants in estuaries and the sea, in Geyer, R., ed., Marine environmental pollution, pt. 2, Dumping and mining: Amsterdam, Elsevier Scientific Publishing Co., p. 281-295. 
Elder, D.L., and Bowden, S.W., 1977, Polychlorinated biphenyls: Penetration into the deep ocean by zooplankton fecal pellet transport: Science, v. 197, p. 459-461.

Elder, J.F., and Mattraw, H.C., Jr., 1984, Accumulation of trace elements, pesticides, and polychlorinated biphenyls in sediments and the clam Corbicula manilensis of the Apalachicola River, Florida: Archives of Environmental Contamination and Toxicology, v. 13, p. $453-469$.

El-Dib, M.A., and Aly, O.A., 1976a, Persistence of some phenylamide pesticides in the aquatic environment-I. Hydrolysis: Water Research, v. 10, p. 1047-1050.

-1976b, Persistence of some phenylamide pesticides in the aquatic environment-II. Adsorption on clay minerals: Water Research, v. 10, p. 1051-1053.

-1976c, Persistence of some phenylamide pesticides in the aquatic environment-III. Biological degradation: Water Research, v. 10, p. 1055-1059.

Engelhardt, G., Wallnofer, P.R., and Hutzinger, O., 1975, The microbial metabolism of di-n-butyl phthalate and related dialkyl phthalates: Bulletin of Environmental Contamination and Toxicology, v. 13. no. 3, p. 342-347.

Ertel, J.R., and Hedges, J.I., 1983, Bulk chemical and spectroscopic properties of marine and terrestrial humic acids, melanoidins and catechol-based synthetic polymers, in Christman, R., and Gjessing, E., eds., Aquatic and terrestrial humic materials: Ann Arbor, Mich., Ann Arbor Science Publishers, p. 143-163.

Fairbanks, B.C., O'Connor, G.A., and Smith, S.E., 1985, Fate of di-2-(ethylhexyl)phthalate in three sludge-amended New Mexico soils: Journal of Environmental Quality, v. 14, no. 4, p. 479-483.

Farrington, J.W., Goldberg, E.D., Risebrough, R.W., Martin, J.H., and Bowen, V.T., 1983, U.S. "mussel watch" 1976-1978: An overview of the trace-metal, DDE, PCB, hydrocarbon, and artificial radionuclide data: Environmental Science and Technology, v. 17, no. 8 , p. $490-496$.

Faust, S.D., and Suffet, I.H., 1966, Recovery, separation, and identification of organic pesticides from natural and potable waters: Residue Reviews, v. 15, p. 45-111.

Feltz, H.R., 1980, Significance of bottom material data in evaluating water quality, in Baker, Robert, ed., Contaminants and sediments, v. 1: Ann Arbor, Mich., Ann Arbor Science Publishers, p. 271-287.

Feng, T.H., 1972, Bottom deposits: Journal of the Water Pollution Control Federation, v. 44, no. 6, p. 1092-1101.

Ferrario, J.B., Lawler, G.C., DeLeon, I.R., and Laseter, J.L., 1985, Volatile organic pollutants in biota and sediments of Lake Pontchartrain: Bulletin of Environmental Contamination and Toxicology, v. 34, p. 246-255.

Fishel, D.K., 1984, Water-quality and chemical loads of the Susquehanna River at Harrisburg, Pennsylvania, April 1980 to March 1981: U.S. Geological Survey Water-Resources Investigations Report 83-4164, 90 p.

Fisher, J.S., Pickral, J., and Odum, W.E., 1979, Organic detritus particles: Initiation of motion criteria: Limnology and Oceanography, v. 24, no. 3, p. 529-532.

Foess, G.W., and Feng, T.H., 1971, Bottom deposits: Journal of the Water Pollution Control Federation, v. 43, no. 6, p. 1257-1266.

Forstner, U., and Wittman, G., 1979, Metal pollution in the aquatic environment: New York, Springer-Verlag, 486 p.

Fortner, A.R., and Sick, L.V., 1985, Simultaneous accumulations of naphthalene, a PCB mixture, and benzo(a)pyrene, by the oyster, Crassostrea vinginica: Bulletin of Environmental Contamination and Toxicology, v. 34, p. 256-264.

Fox, L.E., 1983a, Geochemistry of humic acid during estuarine mixing, in Christman, R., and Gjessing, E., eds., Aquatic and terrestrial humic materials: Ann Arbor, Mich., Ann Arbor Science Publishers, p. $407-427$. 1983b, The removal of dissolved humic acid during estuarine mixing: Estuarine, Coastal and Shelf Science, v. 16, p. 431-440.

Frank, R., Braun, H.E., Van Hove Holdrinet, M., Sirons, G.J., and Ripley, B.D., 1982, Agriculture and water quality in the Canadian Great Lakes basin: V. Pesticide use in 11 agricultural watersheds and presence in stream water, 1975-1977: Journal of Environmental Quality, v. 11, no. 3, p. 497-505.

Frank, R., Thomas, R.L., Braun, H.E., Gross, D.L., and Davies, T.T., 1981, Organochlorine insecticides and PCB in surficial sediments of Lake Michigan (1975): Journal of Great Lakes Research, v. 7, no. 1, p. 42-50.

Frank, R., Thomas, R.L., Braun, H.E., Rasper, J., and Dawson, R., 1980 , Organochlorine insecticides and PCB in the surficial sediments of Lake Superior (1973): Journal of Great Lakes Research, v. 6 , no. 2, p. 113-120.

Frank, R., Thomas, R.L., Holdrinet, M.V.H., and Damiani, V., 1980, PCB residues in bottom sediments collected from the Bay of Quinte, Lake Ontario, 1972-73: Journal of Great Lakes Research, v. 6, no. 4, p. 371-376.

Frank, R., Thomas, R.L., Holdrinet, M., Kemp, A.L.W., and Braun, H.E., 1979, Organochlorine insecticides and PCB in surficial sediments (1968) and sediment cores (1976) from Lake Ontario: Journal of Great Lakes Research, v. 5, no. 1, p. 18-27.

Fredenslund, Aage, Jones, R.L., and Prausnitz, J.M., 1975, Groupcontribution estimation of activity coefficients in nonideal liquid mixtures: American Institute of Chemical Engineering Journal, v. 21, no. 6, p. 1086-1099.

Freeman, D.H., and Cheung, L.S., 1981, A gel partitioning model for organic desorption from a pond sediment: Science, v. 214, p. 790-792.

Frissel, M.J., and Bolt, G.H., 1962, Interaction between certain ionizable organic compounds (herbicides) and clay minerals: Soil Science, v. 94, p. 284-291.

Fu, Jaw-Kwei, and Luthy, R.G., 1986, Effect of organic solvent on sorption of aromatic solutes onto soils: Journal of Environmental Engineering, v. 112, no. 2, p. 346-366.

Fuhrer, G.J., 1984, Chemical analyses of elutriates, native water, and bottom material from the Chetco, Rogue, and Columbia Rivers in western Oregon: U.S. Geological Survey Open-File Report 84-133, 57 p.

Fuhrer, G.J., and Rinella, F.A., 1983, Analyses of elutriates, native water, and bottom material in selected rivers and estuaries in western Oregon and Washington: U.S. Geological Survey OpenFile Report 82-922, 157 p.

Gambrell, R.P., Reddy, C.N., Collard, Vicki, Green, Gloria, and Patrick, W.H., Jr., 1984, The recovery of DDT, kepone, and permethrin added to soil and sediment suspensions incubated under controlled redox potential and $\mathrm{pH}$ conditions: Journal of the Water Pollution Control Federation, v. 56, no. 2, p. 174-182.

Gardner, W.S., Lee, R.F., Tenore, K.R., and Smith, L.W., 1979, Degradation of selected polycyclic aromatic hydrocarbons in coastal sediments: Importance of microbes and polychaete worms: Water, Air, and Soil Pollution, v. 11, p. 339-347.

Garten, C.T., and Trabalka, J.R., 1983, Evaluation of models for predicting terrestrial food chain behavior of xenobiotics: Environmental Science and Technology, v. 17, no. 10, p. 590-595.

Gauger, W.K., MacDonald, J.M., Adrian, N.R., Matthees, D.P., and Walgenbach, D.D., 1986, Characterization of a streptomycete growing on organophosphate and carbamate insecticides: Archives of Environmental Contamination and Toxicology, v. 15, p. 137-141.

Gay, F.B., and Frimpter, M.H., 1985, Distribution of polychlorinated biphenyls in the Housatonic River and adjacent aquifer, Massachusetts: U.S. Geological Survey Water-Supply Paper 2266, 26 p. 
Giam, C.S., Chan, H.S., Neff, G.S., and Atlas, E.L., 1978, Phthalate ester plasticizers: A new class of marine pollutant: Science, v. 199, p. 419-421.

Gibbs, R.J., 1977, Clay mineral segregation in the marine environment: Journal of Sediment Petrology, v. 47, p. 237-243.

Gibson, W.P., and Burns, R.G., 1977, The breakdown of malathion in soil and soil components: Microbial Ecology, v. 3, p. 219-230.

Gillette, Robert, 1971, DDT: In field and courtroom a persistent pesticide lives on: Science, v. 174, p. 1108-1110.

Gilliom, R.J., 1985, Pesticides in rivers of the United States, in National Water Summary 1984: U.S. Geological Survey Water-Supply Paper 2275, p. 85-92.

Gilliom, R.J., Alexander, R.B., and Smith, R.A., 1985, Pesticides in the Nation's rivers, 1975-1980, and implications for future monitoring: U.S. Geological Survey Water-Supply Paper 2271, 26 p.

Given, C.J., and Dierberg, F.E., 1985, Effect of $\mathrm{pH}$ on the rate of aldicarb hydrolysis: Bulletin of Environmental Contamination and Toxicology, v. 34, p. 627-633.

Glooschenko, W.A., Capocianco, J., Coburn, J., and Glooschenko, V., 1981, Geochemical distribution of trace metals and organchlorine contaminants of a Lake Ontario shoreline marsh: Water, Air, and Soil Pollution,.v. 15, p. 197-213.

Glotfelty, D.E., Taylor, A.W., Isensee, A.R., Jersey, J., and Glenn, S., 1984, Atrazine and simazine movement to Wye River estuary: Journal of Environmental Quality, v. 13, no. 1, p. 115-121.

Gmehling, Jurgen, Rasmussen, Peter, and Fredenslund, Aage, 1982, Vapor-liquid equilibria by UNIFAC group contribution. Revision and extension. 2: Industrial Engineering Chemical Process Design and Development, v. 21, p. 118-127.

Goerlitz, D.F., and Law, L.M., 1974a, Determination of chlorinated insecticides in suspended sediment and bottom material: Journal of the Association of Analytical Chemists, v. 57, no. 1, p. 176-181. 1974b, Distribution of chlorinated hydrocarbons in stream bottom material: Geological Survey Journal of Research, v. 2, no. 5 , p. 541-543.

Gooch, J.A., and Hamdy, M.K., 1983, Uptake and concentration factor of Arochlor 1254 in aquatic organisms: Bulletin of Environmental Contamination and Toxicology, v. 31, p. 445-452.

Grant, B.F., 1976, Endrin toxicity and distribution in freshwater: A review: Bulletin of Environmental Contamination and Toxicology, v. 15 , no. 3 , p. $283-290$.

Graveel, J.G., Sommers, L.E., and Nelson, D.W., 1986, Decomposition of benzidine, naphtylamine, and p-toluidine in soils: Journal of Environmental Quality, v. 15, no. 1, p. 53-59.

Green, R.E., Goswami, K.P., Mukhtar, M., and Young, H.Y., 1977, Herbicides from cropped watersheds in stream and estuarine sediments in Hawaii: Journal of Environmental Quality, v. 6, no. 2, p. 145-154.

Green, T., and Houk, D.F., 1979, The removal of organic surface films by rain: Limnology and Oceanography, v. 24, no. 5, p. 966-970.

Green, W.J., Lee, G.F., Jones, R.A., and Palit, Ted, 1983, Interaction of clay soils with water and organic solvents; Implications for the disposal of hazardous wastes: Environmental Science and Technology, v. 17 , no. 5 , p. 278-282.

Greenberg, M., Anderson, R., Keene, J., Kennedy, A., and Page, G., 1982, Empirical test of the association between gross contamination of wells with toxic substances and surrounding land use: Environmental Science and Technology, v. 16, no. 1, p. 14-19.

Greig, R.A., Schurman, Susan, Pereira, José, and Naples, Patricia, 1983, Metals and PCB concentrations in windowpane flounder from Long Island Sound: Bulletin of Environmental Contamination and Toxicology, v. 31, p. 257-262.

Greig, R.A., and Sennefelder, George, 1985, Metals and PCB concentrations in mussels from Long Island Sound: Bulletin of Environmental Contamination and Toxicology, v. 35, p. 331-334.

Grimes, D.J., and Morrison, S.M., 1975, Bacterial bioconcentration of chlorinated hydrocarbon insecticides from aqueous systems: Microbial Ecology, v. 2, p. 43-59.

Grover, R., and Hance, R.J., 1970, Effect of ratio of soil to water on adsorption of linuron and atrazine: Soil Science, v. 109, no. 2, p. 136-138.

Gschwend, P.M., and $\mathrm{Wu}$, Shian-chee, 1985, On the constancy of sediment-water partition coefficients of hydrophobic organic pollutants: Environmental Science and Technology, v. 19, no. 1, p. 90-96.

Gunkel, G., and Streit, B., 1980, Mechanisms of bioaccumulation of a herbicide (atrazine, s-triazine) in a freshwater mollusc (Ancylus fluviatilis mull.) and a fish (Coregonus fera jurine): Water Research, v. 14, p. 1573-1584.

Guthrie, M.A., Kirsch, E.J., Wukasch, R.F., and Grady, C.P.L., 1984, Pentachlorophenol biodegradation-II: Water Research, v. 18, no. 4 , p. $451-461$

Haines, T.A., 1983, Organochlorine residues in Brook Trout from remote lakes in the northeastern United States: Water, Air, and Soil Pollution, v. 20, p. 47-54.

Haley, T.J., 1984, Pentachlorobiphenyls: Dangerous Properties of Industrial Materials Report, v. 4, no. 6, p. 2-17.

Hamaker, J.W., 1975, The interpretation of soil leaching experiments, in Haque, R., and Freed, V., eds., Environmental dynamics of pesticides: New York, Plenum Press Publishers, p. 115-133.

Hamaker, J.W., and Thompson, J.M., 1972, Adsorption, in Goring, C., and Hamaker, J.W., eds., Organic chemicals in the soil environment, v. 1: New York, Marcel Dekker, p. 51-132.

Hamelink, J.L., Waybrant, R.C., and Ball, R.C., 1971, A proposal: Exchange equilibria control the degree chlorinated hydrocarbons are biologically magnified in lentic environments: Transactions of the American Fisheries Society, v. 100, p. 207-211.

Hansch, Corwin, Quinlan, J.E., and Lawrence, G.L., 1968, The linear free-energy relationship between partition coefficients and the aqueous solubility of organic liquids: Journal of Organic Chemistry, v. 33, no. 1, p. 347-350.

Haque, R., and Freed, V.H., 1974, Behavior of pesticides in the environment: Residue Reviews, v. 52, p. 89-111.

Haque, R., Schmedding, D.W., and Freed, V.H., 1974, Aqueous solubility, adsorption, and vapor behavior of polychlorinated biphenyl Aroclor 1254: Environmental Science and Technology, v. 8, no. 2, p. 139-142.

Harris, C.R., and Miles, J.R.W., 1975, Pesticide residues in the Great Lakes region of Canada: Residue Reviews, v. 57, p. 27-81.

Harrison, R.M., Perry, R., and Wellings, R.A., 1975, Polynuclear aromatic hydrocarbons in raw, potable and waste waters: Water Research, v. 9, p. 331-346.

Harrold, D.E., and Young, J.C., 1982, Extraction of priority pollutants from solids: American Society of Civil Engineers, Journal of the Environmental Engineering Division, v. 108, no. EE6, p. 1211-1227.

Hassett, J.J., 1980, Sorption properties of sediments and energy related pollutants: U.S. Environmental Protection Agency, EPA600/3-80-041, $132 \mathrm{p}$.

Hassett, J.J., and Anderson, M.A., 1979, Association of hydrophobic organic compounds with dissolved organic matter in aquatic systems: Environmental Science and Technology, v. 13, no. 12, p. 1526-1529.

1982, Effects of dissolved organic matter on adsorption of hydrophobic organic compounds by river- and sewage-borne particles: Water Research, v. 16, p. 681-686.

Hassett, J.J., Banwart, W.L., and Griffin, R.A., 1983, Correlation of compound properties with sorption characteristics of nonpolar compounds by soils and sediments: Concepts and limitations, in Francis, C., and Auerbach, S., eds., Environment and solid wastes: Ann Arbor Mich., Ann Arbor Science Publishers, p. 161-178. 
Hassett, J.J., Means, J.C., Banwart, W.L., Wood, S.G., Ali, S., and Khan, A., 1980, Sorption of dibenzothiophene by soils and sediments: Journal of Environmental Quality, v. 9, no. 2, p. 184-186.

Hattula, M.L., 1974, Some aspects of the recovery of chlorinated residues (DDT-type compounds and PCB) from fish tissue by using different extraction methods: Bulletin of Environmental Contamination and Toxicology, v. 12, no. 3, p. 301-307.

Hayes, M.H.B., Pick, M.E., and Toms, B.A., 1975, Interactions between clay minerals and bipyridylium herbicides: Residue Reviews, v. 57, p. 1-25.

Heit, Merrill, 1979, Concentrations of benzo(a)pyrene in the sediments of six Western United States lakes: Water, Air, and Soil Pollution, v. 11, p. 447-454.

1985, The relationship of a coal fired power plant to the levels of polycyclic aromatic hydrocarbons (PAH) in the sediment of Cayuga Lake: Water, Air, and Soil Pollution, v. 24, p. 41-61.

Heit, Merrill, Klusek, Catherine, and Baron, Jill, 1984, Evidence of deposition of anthropogenic pollutants in remote Rocky Mountain lakes: Water, Air, and Soil Pollution, v. 22, p. 403-416.

Heit, Merrill, Klusek, C.S., and Miller, K.M., 1980, Trace element, radionuclide, and polynuclear aromatic hydrocarbon concentrations in Unionidae mussels from northern Lake George: Environmental Science and Technology, v. 14, no. 4, p. 465-468.

Heit, Merrill, Tan, Y., Klusek, Catherine, and Burke, J.C., 1981, Anthropogenic trace elements and polycyclic aromatic hydrocarbon levels in sediment cores from two lakes in the Adirondack acid lake region: Water, Air, and Soil Pollution, v. 15, p. 441-464.

Helling, C.S., 1976, Dinitroaniline herbicides in soils: Journal of Environmental Quality, v. 5, no. 1, p. 1-15.

Helling, C.S., Isensee, A.R., Woolson, E.A., Ensor, P.D.J., Jones, G.E., Plimmer, J.R., and Kearney, P.C., 1973, Chlorodioxins in pesticides, soils, and plants: Journal of Environmental Quality, v. 2, no. 2, p. 171-178.

Helwig, D.D., and Hora, M.E., 1983, Polychlorinated biphenyl, mercury, and cadmium concentrations in Minnesota snapping turtles: Bulletin of Environmental Contamination and Toxicology, v. 30, p. $186-190$.

Helz, G.R., and Hsu, R.Y., 1978, Volatile chloro- and bromocarbons in coastal waters: Limnology and Oceanography, v. 23 , no. 5 , p. 858-869.

Herbes, S.E., 1977, Partitioning of polycyclic aromatic hydrocarbons between dissolved and particulate phases in natural waters: Water Research, v. 11, p. 493-496.

Hermann, R.B., 1972, Theory of hydrophobic bonding. II. The correlation of hydrocarbon solubility in water with solvent cavity surface area: Journal of Physical Chemistry, v. 76 , no. 19 , p. 2754-2759.

Hesselberg, R.J., and Nicholson, L.W., 1981, Influence of PCBs in water on uptake and elimination of DDT and DDE by Lake Trout: Journal of Environmental Quality, v. 10, no. 3, p. 315-318.

Hickman, G.T., and Novak, J.T., 1984, Acclimation of activated sludge to pentachlorophenol: Journal of the Water Pollution Control Federation, v. 56, no. 4, p. 364-369.

Hildebrand, J.H., 1968, A criticism of the term "hydrophobic bond": Journal of Physical Chemistry, v. 72, no. 5, p. 1841-1842.

1979, Is there a "hydrophobic effect"?: Proceedings of the National Academy of Science, v. 76, no. 1, p. 194.

Hill, J., Kollig, H.P., Paris, D.F., Wolfe, N.L., and Zepp, R.G., 1976, Dynamic behavior of vinyl chloride in aquatic ecosystems: U.S. Environmental Protection Agency, EPA-600/3-76-001, $59 \mathrm{p}$.

Hill, N.P., McIntyre, A.E., Perry, R., and Lester, J.N., 1986, Behaviour of chlorophenoxy herbicides during the activated sludge treatment of municipal waste water: Water Research, v. 20, no. 1, p. 45-52.

Hiraizumi, Y., Takahashi, M., and Nishimura, H., 1979, Adsorption of PCBs onto sea bed sediment, marine plankton, and other adsorb- ing agents: Environmental Science and Technology, v. 13, no. 5, p. 580-584.

Hochreiter, J.J., Jr., 1982, Chemical-quality reconnaissance of the water and surficial bed material in the Delaware River estuary and adjacent New Jersey tributaries, 1980-81: U.S. Geological Survey Water-Resources Investigations Report 82-36, 41 p.

Hoeppel, R.E., and Westerdahl, H.E., 1983, Dissipation of 2,4-D DMA and BEE from water, mud, and fish at Lake Seminole, Georgia: Water Resources Bulletin, v. 19, no. 2, p. 197-204.

Horowitz, A.J., 1984, A primer on trace metal-sediment chemistry: U.S. Geological Survey Open-File Report 84-709, 82 p.

Horzempa, L.M., and Di Toro, D.M., 1983a, The extent of reversibility of polychlorinated biphenyl adsorption: Water Research, v. 17, no. 8, p. 851-859.

$1983 \mathrm{~b}, \mathrm{PCB}$ partitioning in sediment-water systems; The effect of sediment concentration: Journal of Environmental Quality, $\mathbf{v .}$ 12 , no. 3 , p. $373-380$.

Howells, D.H., and Zielinski, Paul, 1982, Control of water pollution from toxics: Southeast U.S.: American Society of Civil Engineers, Journal of the Environmental Engineering Division, v. 108, no. EE5, p. 1045-1061.

Huang, J.C., 1971, Effect of selected factors on pesticide sorption and desorption in the aquatic system: Journal of the Water Pollution Control Federation, v. 20, p. 1739-1748.

Huggett, R.J., Nichols, M.M., and Bender, M.E., 1980, Kepone contamination of the James River estuary, in Baker, Robert, ed., Contaminants and sediments, v. 1: Ann Arbor, Mich., Ann Arbor Science Publishers, p. 33-52.

Hunt, C.D., 1983, Incorporation and deposition of $\mathrm{Mn}$ and other trace metals by flocculent organic matter in a controlled marine ecosystem: Limnology and Oceanography, v. 28, no. 2, p. 302-308.

Hunt, J.R., 1982, Particle dynamics in seawater; Implications for predicting the fate of discharged particles: Environmental Science and Technology, v. 16, no. 6, p. 303-309.

Hunter, K.A., and Liss, P.S., 1982, Organic matter and the surface charge of suspended particles in estuarine waters: Limnology and Oceanography, v. 27, no. 2, p. 322-335.

Hunter, R.G., Randolph, J.C., and Carroll, J.H., 1980, Polychlorinated biphenyls in the sediments and fish of an Oklahoma stream: Environmental Pollution (Ser. B), v. 1, p. 233-240.

Hurtt, A.C., and Quinn, J.G., 1979, Distribution of hydrocarbons in Narragansett Bay sediment cores: Environmental Science and Technology, v. 13, no. 7, p. 829-836.

Hutzinger, S., Safe, S., and Zitko, V., 1974, The chemistry of PCBs: Boca Raton, Fla., CRC Press, 269 p.

Isaacson, P.J., 1985, Sorption of phenol vapors and influence of ring substitution: Soil Science, v. 140, no. 3, p. 189-193.

Isaacson, P.J., and Frink, C.R., 1984, Nonreversible sorption of phenolic compounds by sediment fractions: The role of sediment organic matter: Environmental Science and Technology, v. 18, no. 1 , p. $43-48$

Isensee, A.R., and Jones, G.E., 1975, Distribution of 2,3,7,8,tetrachloro-dibenzo-p-dioxin (TCDD) in aquatic model ecosystem: Environmental Science and Technology, v. 9, no. 7, p. 668-672.

Ishiwatari, Ryoshi, 1985, Geochemistry of humic substances in lake sediments, in Aiken, George, McKnight, Diane, Wershaw, Robert, and MacCarthy, Patrick, eds., Humic substances in soil, sediment, and water: New York, John Wiley and Sons, p. 147-180.

Jackson, T.A., 1975, Humic matter in natural waters and sediments: Soil Science, v. 119, no. 1, p. 56-64.

Jaffe, P.R., 1986, Modeling sorbing chemicals: Considering the nonsingular adsorption/desorption isotherm: Journal of Environmental Science and Health, v. A21, no. 1, p. 55-69.

Jaffe, P.R., Parker, F.L., and Wilson, D.J., 1982, Distribution of toxic substances in rivers: American Society of Civil Engineers, Journal 
of the Environmental Engineering Division, v. 108, no. EE4, p. 639-649.

Jan, J., and Malnersic, S., 1980, Chlorinated benzene residues in fish in Slovenia (Yugoslavia): Bulletin of Environmental Contamination and Toxicology, v. 24, p. 824-827.

Jensen, Soren, and Rosenberg, Rutger, 1975, Degradability of some chlorinated aliphatic hydrocarbons in sea water and sterilized water: Water Research, v. 9, p. 651-659.

Johnsen, R.E., 1976, DDT metabolism in microbial systems: Residue Reviews, v. 61, p. 1-28.

Jones, T.W., Kemp, W.M., Stevenson, J.C., and Means, J.C., 1982, Degradation of atrazine in estuarine water/sediment systems and soils: Journal of Environmental Quality, v. 11, no.4, p. 632-638.

Joschek, J.I., and Miller, S.I., 1966, Photooxidation of phenol, cresols, and dihydroxybenzenes: Journal of the American Chemical Society, v. 88, no. 14 , p. 3273-3281.

Josephson, Julian, 1982, Humic substances: Environmental Science and Technology, v. 16, no. 1, p. 20A-24A.

Jungclaus, G.A., Lopez-Avila, Viorica, and Hites, R.A., 1978, Organic compounds in an industrial wastewater: A case study of their environmental impact: Environmental Science and Technology, v. 12 , no. 1 , p. 88-96.

Juo, A.S.R., and Oginni, O.O., 1978, Adsorption and desorption of paraquat in acid tropical soils: Journal of Environmental Quality, v. 7 , no. 1 , p. 9-12.

Kaiser, K.L.E., 1978, The rise and fall of mirex: Environmental Science and Technology, v. 12, no. 5, p. 520-528.

Kane, J.E., 1967, Organic aggregates in surface waters of the Ligurian Sea: Limnology and Oceanography, v. 12, p. 287-294.

Karickhoff, S.W., 1980, Sorption kinetics of hydrophobic pollutants in natural sediments, in Baker, Robert, ed., Contaminants and sediments: Ann Arbor, Mich., Ann Arbor Science Publishers, p. 193-205.

-1981, Semi-empirical estimation of sorption of hydrophobic pollutants on natural sediments and soils: Chemosphere, v. 10, no. 8, p. 833-846.

1984, Organic pollutant sorption in aquatic systems: Proceedings of the American Society of Civil Engineers, Journal of the Hydraulic Engineering Division, v. 110, no. 6, p. 707-735.

Karickhoff, S.W., and Brown, D.S., 1978, Paraquat sorption as a function of particle size in natural sediments: Journal of Environmental Quality, v. 7, no. 2, p. 246-252.

-1979, Determination of octanol/water distribution coefficients, water solubilities, and sediment/water partition coefficients for hydrophobic organic pollutants: U.S. Environmental Protection Agency, EPA-600/4-79-932.

Karickhoff, S.W., Brown, D.S., and Scott, T.A., 1979, Sorption of hydrophobic pollutants on natural sediments: Water Research, v. 13, p. 241-248.

Karydis, M., 1980, Uptake of hydrocarbons by the marine diatom Cyclotella cryptica: Microbial Ecology, v. 5, p. 287-293.

Kearney, P.C., Woolson, E.A., Plimmer, J.R., and Isensee, A.R., 1969, Decontamination of pesticides in soils: Residue Reviews, v. 29, p. 137-149.

Keith, L.H., and Telliard, W.A., 1979, Priority pollutants-I. A perspective view: Environmental Science and Technology, v. 13, no. 4 , p. $416-423$.

Kenaga, E.E., 1975a, Guidelines for environmental study of pesticides: Determination of bioconcentration potential: Residue Reviews, $\mathbf{v}$. 44, p. 73-114.

1975b, Partitioning and uptake of pesticides in biological systems, in Haque, R., and Freed, V.H., eds., Environmental dynamics of pesticides: New York, Plenum Press, p. 217-273.

1980, Correlation of bioconcentration factors of chemicals in aquatic and terrestrial organisms with their physical and chemical properties: Environmental Science and Technology, v. 14, no. 5, p. 553-556.

Kenaga, E.E., and Goring, C.A.I., 1980, Relationship between water solubility, soil sorption, octanol-water partitioning, and concentration of chemicals in biota, in Eaton, J.G., Parish, P.R., and Hendricks, A.C., eds., Aquatic toxicology: American Society for Testing and Materials, ASTM STP 707, p. 78-115.

Khan, S.U., 1972a, Adsorption of pesticide by humic substances. A review: Environmental Letters, v. 3, no. 1, p. 1-12.

1972b, The retention of hydrophobic organic compounds by humic acid: Geochimica et Cosmochimica Acta, v. 36, p. 745-754.

1974a, Adsorption of bipyridylium herbicides by humic acid: Journal of Environmental Quality, v. 3, no. 3, p. 202-206.

1974b, Adsorption of 2,4-D from aqueous solution by fulvic acid-clay complex: Environmental Science and Technology, v. 8, no. 3, p. 236-238.

1974c, Humic substances reactions involving bipyridylium herbicides in soil and aquatic environments: Residue Reviews, v. 52, p. 1-26.

1978, The interaction of organic matter with pesticides, in Schnitzer, Morris, and Khan, S.U., eds., Soil organic matter: New York, Elsevier Scientific Publishing Co., p. 137-171.

1980, Role of humic substances in predicting fate and transport of pollutants in the environment, in Haque, R., ed., Dynamics, exposure, and hazard assessment of toxic chemicals: Ann Arbor, Mich., Ann Arbor Scientific Publishers, p. 215-230.

Kim, C.J., and Maier, W.J., 1986, Acclimation and biodegradation of chlorinated organic compounds in the presence of alternate substrates: Journal of the Water Pollution Control Federation, v. 58 , no. 2, p. 157-164.

Klauda, R.J., Peck, T.H., and Rice, G.K., 1981, Accumulation of polychlorinated biphenyls in Atlantic Tomcod (Microgadus tomcod) collected from the Hudson River estuary, New York: Bulletin of Environmental Contamination and Toxicology, v. 27, p. 829-835.

Knackmuss, H.J., and Hellwig, M., 1978, Utilization and cooxidation of chlorinated phenols by Pseudomonas sp. B 13: Archives of Microbiology, v. 117, p. 1-7.

Knap, A.H., and Williams, P.J., 1982, Experimental studies to determine the fate of petroleum hydrocarbons from refinery effluent on an estuarine system: Environmental Science and Technology, $v$. 16 , no. 1, p. $1-4$.

Kobylinski, G.J., and Livingston, R.J., 1975, Movement of mirex from sediment and uptake by the hogchoker, Trinectes maculatus: Bulletin of Environmental Contamination and Toxicology, v. 14, no. 6 , p. 692-698.

Könemann, Hans, and van Leeuwen, Kees, 1980, Toxikinetics in fish: Accumulation and elimination of six chlorobenzenes by guppies: Chemosphere, v. 9, p. 3-19.

Koskinen, W.C., and Cheng, H.H., 1983, Effects of experimental variables on 2,4,5-T adsorption-desorption in soil: Journal of Environmental Quality, v. 12, no. 3, p. 325-330.

Kozak, J., Weber J.B., and Sheets, T.J., 1983, Adsorption of prometryn and metolachlor by selected soil organic matter fractions: Soil Science, v. 136, no. 2, p. 94-101.

Kriebel, David, 1981, The dioxins: Toxic and still troublesome: Environment, v. 23 , no. 1 , p. 6-13.

Krom, M.D., and Sholkovitz, E.R., 1977, Nature and reactions of dissolved organic matter in the interstitial waters of marine sediments: Geochimica et Cosmochimica Acta, v. 41, p. 1565-1573.

Kuehl, D.W., Durhan, E., Butterworth, B., and Linn, D., 1984, Identification of polychlorinated planar chemicals in fishes from major watersheds near the Great Lakes: Environment International, v. 10 , no. 1 , p. $45-49$. 
Kuntz, K.W., and Warry, N.D., 1983, Chlorinated organic contaminants in water and suspended sediments of the lower Niagara River: Journal of Great Lakes Research, v. 9, no. 2, p. 241-248.

Kuznetsov, S.I., 1975, The role of microorganisms in the formation of lake bottom deposits and their diagenesis: Soil Science, v. 119, no. 1, p. 81-88.

Kyle, B.G., 1981, Science, v. 213, p. 683-684.

LaFleur, K.S., 1979, Sorption of pesticides by model soils and agronomic soils: Rates and equilibria: Soil Science, v. 127, no. 2, p. 94-101.

Lake, J.L., Rogerson, P.F., and Norwood, C.B., 1981, A polychlorinated dibenzofuran and related compounds in an estuarine ecosystem: Environmental Science and Technology, v. 15, no. 5, p. 549-553.

Lal, D., 1977, The oceanic microcosm of particles: Science, v. 198, no. 4321, p. 997-1009.

Landner, L., Lindstrom, K., Karlsson, M., Nordin, J., and Sorensen, L., 1977 , Bioaccumulation in fish of chlorinated phenols from Kraft pulp mill bleachery effluents: Bulletin of Environmental Contamination and Toxicology, v. 18, no. 6, p. 663-673.

Landrum, P.F., Nlhart, S.R., Eadle, B.J., and Gardner, W.S., 1984, Reverse-phase separation method for determining pollutant binding to Aldrich humic acid and dissolved organic carbon of natural waters: Environmental Science and Technology, v. 18, no.3, p. 187-192.

Lappalainen, K.M., 1982, Convection in bottom sediments and its role in material exchange between water and sediments: Hydrobiologia, v. 86 , no. $1 / 2$, p. $105-108$.

Larsen, P.F., Gadbois, D.F., Johnson, A.C., and Doggett, L.F., 1983, Distribution of polycyclic aromatic hydrocarbons in the surficial sediments of Casco Bay, Maine: Bulletin of Environmental Contamination and Toxicology, v. 30, p. 530-535.

Larsson, P., 1983, Transport of C-14 labelled PCB compounds from sediment to water and from water to air in laboratory model systems: Water Research, v. 17, no. 10, p. 1317-1326.

Laska, A.L., Bartell, C.K., and Laseter, J.L., 1976, Distribution of hexachlorobenzene and hexachlorobutadiene in water, soil, and selected aquatic organisms along the lower Mississippi River, Louisiana: Bulletin of Environmental Contamination and Toxicology, v. 15 , no. 5 , p. 535-542.

Leenheer, J.A., 1981, Comprehensive approach to preparative isolation and fractionation of dissolved organic carbon from natural waters and wastewaters: Environmental Science and Technology, v. 15 , no. 5 , p. $578-587$.

Leenheer, J.A., and Huffman, E.W.D., 1976, Classification of organic solutes in water by using macroreticular resins: U.S. Geological Survey Journal of Research, v. 4, no. 6, p. 737-751.

Leenheer, J.A., and Stuber, H.A., 1981, Migration through soil of organic solutes in an oil-shale process water: Environmental Science and Technology, v. 15, no. 12, p. 1467-1475.

Leistra, M., Dekker, A., and van der Burg, A.M.M., 1984, Leaching of oxidation products of aldicarb from greenhouse soils to water courses: Archives of Environmental Contamination and Toxicology, v. 13, p. $327-334$.

Leo, A., Hansch, C., and Elkins, D., 1971, Partition coefficients and their uses: Chemical Reviews, v. 71, no. 6, p. 525-616.

Lerman, A., Lal, D., and Dacey, M.F., 1974, Stokes' settling and chemical reactivity of suspended particles in natural waters, in Gibbs, R., ed., Suspended solids in water: New York, Plenum Press, p. 17-47.

Leung, S.T., Bulkley, R.V., and Richard, J.J., 1982, Pesticide accumulation in a new impoundment in Iowa: Water Resources Bulletin, v. 18 , no. 3 , p. $485-493$.

Li, G.C., and Felbeck, G.T., 1972, Atrazine hydrolysis as catalyzed by humic acids: Soil Science, v. 114, no. 3, p. 201-209.
Lietman, P.L., Ward, J.R., and Behrendt, T.E., 1983, Effects of specific land uses on nonpoint sources of suspended sediment, nutrients, and herbicides; Pequea Creek Basin, Pennsylvania, 1979-1980: U.S. Geological Survey Water-Resources Investigations Report 83-4113, 88 p.

Lorenzen, C.J., Welschmeyer, N.A., Copping, A.E., and Vernet, M., 1983, Sinking rates of organic particles: Limnology and Oceanography, v. 28 , no. 4 , p. $766-769$.

Lotse, E.G., Graetz, D.A., Chesters, Gordon, Lee, G.B., and Newland, L.W., 1968, Lindane adsorption by lake sediments: Environmental Science and Technology, v. 2, no. 5, p. 353-357.

Lurry, D.L., 1983, Analyses of native water, bottom material, elutriate samples, and dredged material from selected southern Louisiana waterways and selected areas in the Gulf of Mexico, 1979-1981: U.S. Geological Survey Open-File Report 82-690, 105 p.

Lush, D.L., and Hynes, H.B.N., 1973, The formation of particles in freshwater leachates of dead leaves: Limnology and Oceanography, v. 18 , p. $968-977$.

Mabey, W.R., and Mill, T., 1978, Critical review of hydrolysis of organic compounds in water under environmental conditions: Journal of Physical and Chemical Reference Data, v. 7, p. 383.

Mabey, W.R., Smith, J.H., Podoll, R.T., Johnson, H.L., Mill, T., Chou, T.-W., Gates, J., Partridge, I.W., Jaber, H., and Vandenberg, D., 1982, Aquatic fate process data for organic priority pollutants: U.S. Environmental Protection Agency, EPA 440/4-81-014, 434 p.

Maccubbin, A.E., Black, P., Trzeciak, L., and Black, J.J., 1985, Evidence for polynuclear aromatic hydrocarbons in the diet of bottom-feeding fish: Bulletin of Environmental Contamination and Toxicology, v. 34, p. 876-882.

MacIntyre, F., 1974, The top millimeter of the ocean: Scientific American, v. 203, p. 62-77.

MacIntyre, W.G., and Smith, C.L., 1984, Environmental Science and Technology, v. 18, no. 4, p. 295-297.

Mackay, Donald, 1977: Environmental Science and Technology, v. 13, no. 11 , p. 1219.

1979, Finding fugacity feasible: Environmental Science and Technology, v. 13 , no. 10 , p. 1218-1223.

1982a, Correlation of bioconcentration factors: Environmental Science and Technology, v. 16, no. 5, p. 274-278.

1982b, Effects of surface films on air-water exchange rates: Journal of Great Lakes Research, v. 8, no. 2, p. 299--306.

Mackay, D.M., Ball, W.P., and Durant, M.G., 1986, Variability of aquifer sorption properties in a field experiment on groundwater transport of organic solutes: Methods and preliminary results: Journal of Contaminant Hydrology, v. 1, p. 119-132.

Mackay, Donald, Bobra, A., Chan, D.W., and Shiu, W.Y., 1982, Vapor pressure correlations for low-volatility environmental chemicals: Environmental Science and Technology, v. 16, no. 10, p. 645-649.

Mackay, Donald, Bobra, A., Shiu, W.Y., and Yalkowsky, S.H., 1980, Relationships between aqueous solubility and octanol-water partition coefficients: Chemosphere, v. 9, p. 701-711.

Mackay, Donald, and Leinonen, P.J., 1975, Rate of evaporation of low-solubility contaminants from water bodies to atmosphere: Environmental Science and Technology, v. 9, no. 13, p. 1178-1180.

Mackay, Donald, Mascarenhas, R., Shiu, W.Y., Valvani, S.C., and Yalkowsky, S.H., 1980, Aqueous solubility of polychlorinated biphenyls: Chemosphere, v. 9, p. 257-264.

Mackay, Donald, and Paterson, Sally, 1981, Calculating fugacity: Environmental Science and Technology, v. 15, no. 9, p. 1006-1014.

1982, Fugacity revisited: Environmental Science and Technology, v. 16 , no. 12 , p. $654 \mathrm{~A}-660 \mathrm{~A}$.

1983, Fugacity models of indoor exposure to volatile chemicals: Chemosphere, v. 12, no. 2, p. 143-154. 
Mackay, Donald, Paterson, Sally, and Joy, Michael, 1983, A quantitative water, air, sediment interaction (QWASI) fugacity model for describing the fate of chemicals in rivers: Chemosphere, v. 12, no. 9/10, p. 1193-1208.

Mackay, Donald, and Shiu, W.Y., 1977, Aqueous solubility of polynuclear aromatic hydrocarbons: Journal of Chemical and Engineering Data, v. 22, no. 4, p. 399-402.

Mackay, Donald, Shiu, W.Y., and Sutherland, R.J., 1979, Estimating volatilization and water column diffusion rates of hydrophobic contaminants, in Haque, R., ed., Dynamics, exposure and hazard assessment of toxic chemicals: Ann Arbor, Mich., Ann Arbor Science Publishers, p. 127-142.

Mackay, Donald, and Wolkoff, A.W., 1973, Rate of evaporation of low-solubility contaminants from water bodies to atmosphere: Environmental Science and Technology, v. 7, no. 7, p. 611-614.

Mackay, Donald, and Yeun, A.T.K., 1983, Mass transfer coefficient correlations for volatilization of organic solutes from water: Environmental Science and Technology, v. 17, no. 4, p. 211-217.

Madhun, Y.A., Young, J.L., and Freed, V.H., 1986, Binding of herbicides by water-soluble organic materials from soil: Journal of Environmental Quality, v. 15, no. 1, p. 64-68.

Maier-Bode, H., and Hartel, K., 1981, Linuron and Monolinuron: Residue Reviews, v. 77, p. 1-294.

Malcolm, R.L., 1985, Geochemistry of stream fulvic and humic substances, in Aiken, George, McKnight, Diane, Wershaw, Robert, and MacCarthy, Patrick, eds., Humic substances in soil, sediment, and water: New York, John Wiley and Sons, p. 181-210.

Maqueda, C., Perez Rodriguez, J.L., Martin, F., and Hermosin, M.C., 1983, A study of the interaction between chlordimeform and humic acid from a typic chromoxerert soil: Soil Science, v. 136, no. 2, p. 75-81.

Marinucci, A.C., and Bartha, R., 1982, Accumulation of the polycliorinated biphenyl Arochlor 1242 from contaminated detritus and water by the saltmarsh detritivore, Uca pugnax: Bulletin of Environmental Contamination and Toxicology, v. 29, p. 326-333.

Marple, Leland, Berridge, Bernard, and Throop, Lewis, 1986, Measurement of the water-octanol partition coefficient of 2,3,7,8tetrachlorodibenzo-p-dioxin: Environmental Science and Technology, v. 20, no. 4, p. 397-399.

Martel, J.M., Rickert, D.A., and Siegel, F.R., 1975, PCB's in suburban watershed, Reston, Va.: Environmental Science and Technology, v. 9, no. 9, p. 872-875.

Mathur, S.P., 1974, Phthalate esters in the environment: Pollutants or natural products?: Journal of Environmental Quality, v. 3, no. 3, p. 189-197.

Mathur, S.P., and Rouatt, J.W., 1975, Utilization of the pollutant di-2-ethylhexyl phthalate by a bacterium: Journal of Environmental Quality, v. 4, no. 2, p. 273-275.

Matsuda, Keiichiro, and Schnitzer, Morris, 1971, Reactions between fulvic acid, a soil humic material, and dialkyl phthalates: Bulletin of Environmental Contamination and Toxicology, v. 6, no. 3, p. 200-204.

Matsumoto, Genki, 1983, Comparative study on organic constituents in polluted and unpolluted inland aquatic environments--V-Organic carbons and hydrocarbons in sediments: Water Research, v. 17 , no. 7 , p. $823-830$.

Matsumoto, Genki, and Hanya, Takahisha, 1981, Comparative study on organic constituents in polluted and unpolluted inland aquatic environments--I--Features of hydrocarbons for polluted and unpolluted waters: Water Research, v. 15, p. 217-224.

McCall, P.J., Laskowski, D.A, Swann, R.L., and Dishburger, H.J., 1983, Estimation of environmental partitioning of organic chemicals in model ecosystems: Residue Reviews, v. 85, p. 231-243.

McElroy, A.D., Chiu, S.Y., Nebgen, J.W., Aleti, A., and Vandegrift, A.E., 1975, Water pollution from nonpoint sources: Water Research, v. 9, p. 675-681.
McFall, J.A., Huang, W.Y., and Laseter, J.L., 1979, Organics at the air-water interface of Lake Pontchartrain: Bulletin of Environmental Contamination and Toxicology, v. 22, p. 80-87.

McMurtrey, K.D., Wildman, N.J., and Tai, Han, 1983, Pyrolysis gas chromatography-mass spectrometry of polychlorinated biphenyls on sediment: Bulletin of Environmental Contamination and Toxicology, v. 31, p. 734-737.

Means, J.C., and Wijayaratne, R., 1982, Role of natural colloids in the transport of hydrophobic pollutants: Science, v. 215, p. 968-970.

Means, J.C., Wood, S.G., Hassett, J.J., and Banwart, W.L., 1980, Sorption of polynuclear aromatic hydrocarbons by sediments and soils: Environmental Science and Technology, v. 14, no. 12, p. 1524-1528.

-1982, Sorption of amino- and carboxy-substituted polynuclear aromatic hydrocarbons by sediments and soils: Environmental Science and Technology, v. 16, no. 2, p. 93-98.

Metcalf, R.L., 1972, Agricultural chemicals in relation to environmental quality: Insecticides today and tomorrow: Journal of Environmental Quality, v. 1, no. 1, p. 10-14.

Metcalf, R.L., and Pitts, J.N., 1969, Outline of environmental sciences: Advances in Environmental Sciences, v. 1, p. 1-23.

Metcalf, R.L., Sanborn, J.R., Lu, P.Y., and Nye, Donald, 1975, Laboratory model ecosystem studies of the degradation and fate of radiolabeled tri-, tetra-, and pentachlorobiphenyl compared with DDE: Archives of Environmental Contamination and Toxicology, v. 3, no. 2, p. 151-165.

Meyers, P.A., Leenheer, M.J., Eadie, B.J., and Maule, S.J., 1984, Organic geochemistry of suspended and settling particulate matter in Lake Michigan: Geochimica et Cosmochimica Acta, v. 48, p. 443-452.

Michael, P.R., Adams, W.J., Werner, A.F., and Hicks, O., 1984, Surveillance of phthalate esters in surface waters and sediments of the United States: Environmental Toxicology and Chemistry, v. 3, p. 377-389.

Middleditch, B.S., and Basile, Brenda, 1980, Alkanes in benthic organisms from the Buccaneer oil field: Bulletin of Environmental Contamination and Toxicology, v. 24, p. 945-952.

Miles, J.R.W., 1976, Insecticide residues on stream sediments in Ontario, Canada: Pesticide Monitoring Journal, v. 10, no. 3, p. 87-91.

Miller, C.T., and Weber, W.J., 1986, Sorption of hydrophobic organic pollutants in saturated soil systems: Journal of Contaminant Hydrology, v. 1, p. 243-261.

Miller, M.M., Wasik, S.P., Huang, Guo-Lan, Shiu, Wan-Ying, and Mackay, Donald, 1985, Relationships between octanol-water partition coefficient and aqueous solubility: Environmental Science and Technology, v. 19, no. 6, p. 522-529.

Miller, R.W., and Faust, S.D., 1972, Sorption from aqueous solution by organo-clays: II. Thermodynamics of 2,4-D sorption by various organo-clays: Environmental Letters, v. 2, no. 4, p. 183-194.

Miller, Stanton, 1983, Photochemistry of natural water systems: Environmental Science and Technology, v. 17, no. 12, p. 568a-570a.

Milner, C.R., and Goulder, R., 1986, The abundance, heterotrophic activity and taxonomy of bacteria in a stream subject to pollution by chlorophenols, nitrophenols and phenoxyalkanoic acids: Water Research, v. 20 , no. 1 , p. $85-90$.

Mingelgrin, U., and Gerstl, Z., 1983, Reevaluation of partitioning as a mechanism of nonionic chemicals adsorption in soils: Journal of Environmental Quality, v. 12, no. 1, p. 1-11.

Mix, M.C., and Schaffer, R.L., 1979, Benzo(a)pyrene concentrations in mussels (Mytilus edulis) from Yaquina Bay, Oregon during June 1976-May 1978: Bulletin of Environmental Contamination and Toxicology, v. 23, p. 677-684.

Miyazaki, Tomoyuki, Yamagishi, Tatsunori, and Matsumoto, Masao, 1984, Residues of 4-chloro-1-(2,4-dichlorophenoxy)-2- 
methoxybenzene(triclosan methyl) in aquatic biota: Bulletin of Environmental Contamination and Toxicology, v. 32, p. 227-232.

Moore, J.W., and Ramamoorthy, S., 1984, Organic chemicals in natural waters-Applied monitoring and impact assessment: New York, Springer-Verlag, $289 \mathrm{p}$.

Moore, N.W., 1975, A synopsis of the pesticide problem: Advances in Ecological Research (Academic Press), v. 4, p. 75-129.

Moore, R.M., Burton, J.D., Williams, P.J., and Young, M.L., 1979, The behavior of dissolved organic material, iron, and manganese in estuarine mixing: Geochimica et Cosmochimica Acta, v. 43, p. 919-926.

Morgan, R.P., and Sommer, S.E., 1979, Polychlorinated biphenyls in Baltimore Harbor sediments: Bulletin of Environmental Contamination and Toxicology, v. 22, p. 413-419.

Morin, R., Gaboury, G., and Mamarbachi, G., 1986, Fenitrothion and aminocarb residues in water and balsam fir foliage following spruce budworm spraying programs in Quebec, 1979 to 1982 : Bulletin of Environmental Contamination and Toxicology, v. 36, p. 622-628.

Morita, M., Nakamura, H., and Mimura, S., 1974, Phthalic acid esters in water: Water Research, v. 8, p. 781-788.

Morris, R.J., and Calvert, S.E., 1975, Fatty acid uptake by marine sediment particles: Geochimica et Cosmochimica, v. 39, p. 377-381.

Mount, M.E., and Oehme, F.W., 1981, Carbaryl: A literature review: Residue Reviews, v. 80, p. 1-65.

Mowrer, Jacques, Calambokidis, John, Musgrove, Nancy, Drager, Bruce, Beug, M.W., and Herman, S.G., 1977, Polychlorinated biphenyls in cottids, mussels, and sediment in southern Puget Sound, Washington: Bulletin of Environmental Contamination and Toxicology, v. 18., no. 5, p. 588-594.

Muir, D.C.G., Grift, N.P., Blouw, A.P., and Lockhart, W.L., 1980, Persistence of fluridone in small ponds: Journal of Environmental Quality, v. 9, no. 1, p. 151-156.

Mulholland, P.J., 1981, Formation of particulate organic carbon in water from a southeastern swamp-stream: Limnology and Oceanography, v. 26, no. 4, p. 790-795.

Mulholland, P.J., and Kuenzler, E.J., 1979, Organic carbon export from upland and forested wetland watersheds: Limnology and Oceanography, v. 24 , no. 5 , p. 960-966.

Mulla, M.S., and Mian, L.S., 1981, Biological and environmental impacts of the insecticides malathion and parathion on nontarget biota in aquatic ecosystems: Residue Reviews, v. 78, p. 101-137.

Mulla, M.S., Mian, L.S., and Kawecki, J.A., 1981, Distribution, transport and fate of the insecticides malathion and parathion in the environment: Residue Reviews, v. 81, p. 1-172.

Mullin, M.M., 1965, Size fractionation of particulate organic carbon in the surface waters of the western Indian Ocean: Limnology and Oceanography, v. 10, p. 459-462.

Munson, T.O., 1976, A note on toxaphene in environmental samples from the Chesapeake Bay region: Bulletin of Environmental Contamination and Toxicology, v. 16, no. 4, p. 491-494.

Murphy, P.G., 1971, The effect of size on the uptake of DDT from water by fish: Bulletin of Environmental Contamination and Toxicology, v. 6, no. 1, p. 20-23.

Murphy, T.J., and Rzeszutko, C.P., 1977, Precipitation inputs of PCBs to Lake Michigan: Journal of Great Lakes Research, v. 3, no. 3-4, p. 305-312.

Murthy, N.B.K., Kaufman, D.D., and Fries, G.F., 1979, Degradation of pentachlorophenol (PCP) in aerobic and anaerobic soil: Journal of Environmental Science and Health, v. B14, no. 1, p. 1-14.

Nadeau, R.J., and Davis, R.A., 1976, Polychlorinated biphenyls in the Hudson River (Hudson Falls-Fort Edward, New York State): Bulletin of Environmental Contamination and Toxicology, v. 16, no. 4 , p. $436-444$.

Nagy, E., Mudroch, P., Mudroch, A., and Thomas, R.L., 1984,
Hydrocarbons in the surficial sediments of Lakes St. Clair, Erie, and Ontario: Environmental Geology and Water Science, v. 6, no. 1, p. 31-37.

Narine, D.R., and Guy, R.D., 1982, Binding of diquat and paraquat to humic acid in aquatic environments: Soil Science, v. 133, no. 6, p. 356-363.

Nau-Ritter, G.M., and Wurster, C.F., 1983, Sorption of PCBs to clay particulates and effects of desorption on phytoplankton: Water Research, v. 17, p. 383-387.

Nau-Ritter, G.M., Wurster, C.F., and Rowland, R.G., 1982, Partitioning of $\mathrm{PCB}$ between water and particulates with various organic contents: Water Research, v. 16, p. 1615-1618.

Neely, W.B., Branson, D.R., and Blau, G.E., 1974, Partition coefficient to measure bioconcentration potential of organic chemicals in fish: Environmental Science and Technology, v. 8, no. 13, p. 1113-1115.

Nelson, C.R., and Hites, R.A., 1980, Aromatic amines in and near the Buffalo River: Environmental Science and Technology, v. 14, no. 9, p. 1147-1149.

Nemethy, G., Scheraga, H.A., and Kauzmann, W., 1968, Journal of Physical Chemistry, v. 72, no. 5, p. 1842.

Nigg, H.N., Henry, J.A., and Stamper, J.H., 1983, Regional behavior of pesticide residues in the United States: Residue Reviews, v. 85, p. 257-276.

Niimi, A.J., 1979, Hexachlorobenzene (HCB) levels in Lake Ontario salmonids: Bulletin of Environmental Contamination and Toxicology, v. 23, p. 20-24.

Niimi, A.J., and Cho, C.Y., 1983, Laboratory and field analysis of pentachlorophenol (PCP) accumulation by salmonids: Water Research, v. 17, no. 12, p. 1791-1795.

Niimi, A.J., and McFadden, C.A., 1982, Uptake of sodium pentachlorophenate (NaPCP) from water by rainbow trout (Saimo gairdneri) exposed to concentrations in the $\mathrm{ng} /$ range: Bulletin of Environmental Contamination and Toxicology, v. 28, p. 11-19.

Nkedi-Kizza, P., Rao, P.S.C., and Hornsby, A.G., 1985, Influence of organic cosolvents on sorption of hydrophobic organic chemicals by soils: Environmental Science and Technology, v. 19, no. 10, p. 975-979.

Nkedi-Kizza, P., Rao, P.S.C., and Johnson, J.W., 1983, Adsorption of Diuron and 2,4,5-T on soil particle-size separates: Journal of Environmental Quality, v. 12, no. 2, p. 195-197.

Norris, L.A., 1981, The movement, persistence, and fate of the phenoxy herbicides and TCDD in the forest: Residue Reviews, v. 80, p. 66-126.

Novak, J.T., 1974, Temperature-substrate interactions in biological treatment: Journal of Water Pollution Control Federation, v. 46, no. 8, p. 1984-1994.

Novotny, Vladimir, 1980, Delivery of suspended sediment and pollutants from nonpoint sources during overland flow: Water Resources Bulletin, v. 16, no. 6, p. 1057-1065.

O'Connor, D.J., and Connolly, J.P., 1980, The effect of concentration of adsorbing solids on the partition coefficient: Water Research, $v$. 14, p. 1517-1523.

O'Connor, D.J., Mueller, J.A., and Farley, K.J., 1983, Distribution of Kepone in the James River es uary: Journal of Environmental Engineering, v. 109, no. 2, p. 396-413.

Ogner, Gunnar, and Schnitzer, Morris, 1970, Humic substances: Fulvic acid-dialkyl phthalate complexes and their role in pollution: Science, v. 170, p. 317-318.

Ogram, A.V., Jessup, R.E., Ou, L.T., and Rao, P.S.C., 1985, Effects of sorption on biological degradation rates of 2,4-(dichlorophenoxy)acetic acid in soils: Applied and Environmental Microbiology, v. 49 , no. 3 , p. $582-587$.

Ogura, N., 1970, On the presence of $0.1-0.5$ micron dissolved organic matter in seawater: Limnology and Ocea nography,v. 15, p. 476-478. 
O'Keefe, P., Hilker, D., Meyer, C., Aldous, K., Shane, L., Donnelly, R., Smith, R., Sloan, R., Skinner, L., and Horn, E., 1984, Tetrachlorodibenzo-p-dioxins and tetrachlorodibenzofurans in Atlantic coast striped bass and in selected Hudson River fish, waterfowl and sediments: Chemosphere, v. 13, no. 8, p. 849-860.

O'Keefe, P.W., Hilker, D.R., Smith, R.M., Aldous, K.M., Donnelly, R.J., Long, D., and Pope, D.H., 1986, Nonaccumulation of chlorinated dioxins and furans by goldfish exposed to contaminated sediment and flyash: Bulletin of Environmental Contamination and Toxicology, v. 36, p. 452-459.

Oliver, B.G., and Charlton, M.N., 1984, Chlorinated organic contaminants on settling particulates in the Niagara River vicinity of Lake Ontario: Environmental Science and Technology, v. 18, no. 12, p. 903-908.

Oliver, B.G., and Nicol, K.D., 1982, Chlorobenzenes in sediments, water, and selected fish from Lakes Superior, Huron, Erie, and Ontario: Environmental Science and Technology, v. 16, no. 8, p. 532-536.

Oliver, B.G., and Niimi, A.J., 1983, Bioconcentration of chlorobenzenes from water by rainbow trout: Correlations with partition coefficients and environmental residues: Environmental Science and Technology, v. 17, no. 5, p. 287-291.

1985, Bioconcentration factors of some halogenated organics for rainbow trout: Limitations in their use for prediction of environmental residues: Environmental Science and Technology, v. 19 , no. 9 , p. $842-849$.

Olsen, C.R., Cutshall, N.H. and Larsen, I.L., 1982, Pollutant-particle associations and dynamics in coastal marine environments: $A$ review: Marine Chemistry, v. 11, p. 501-535.

O'Melia, C.R., 1980, Aquasols; The behavior of small particles in aquatic systems: Environmental Science and Technology, v. 14, no. 9, p. 1052-1060.

Oschwald, W.R., 1972, Sediment-water interactions: Journal of Environmental Quality, v. 1, no. 4, p. 360-366.

Page, G.W., 1981, Comparison of groundwater and surface water for patterns and levels of contamination by toxic substances: Environmental Science and Technology, v. 15, no. 12, p. 1475-1481.

Page, G.W., and Greenberg, Michael, 1982, Maximum contaminant levels for toxic substances in water: A statistical approach: Water Resources Bulletin, v. 18, no. 6, p. 955-963.

Pancirov, R.J., and Brown, R.A., 1977, Polynuclear aromatic hydrocarbons in marine tissues: Environmental Science and Technology, v. 11, no. 10, p. $989-992$.

Parejko, Ronald, Johnston, Raymond, and Keller, Robert, 1975, Chlorohydrocarbons in Lake Superior lake trout (Salvelinus namaycush): Bulletin of Environmental Contamination and Toxicology, v. 14, no. 4, p. 480-488.

Parejko, Ronald, and Wu, C.J., 1977, Chlorohydrocarbons in Marquette Fish Hatchery lake trout (Salvelinus namaycush): Bulletin of Environmental Contamination and Toxicology, v. 17, no. 1, p. 90-97.

Paris, D.F., and Lewis, D.C., 1973, Chemical and microbial degradation of 10 selected pesticides in aquatic systems: Residue Reviews, v. 45 , p. 96-114.

Paris, D.F., Lewis, D.L., and Barnett, J.T., 1977, Bioconcentration of toxaphene by microorganisms: Bulletin of Environmental Contamination and Toxicology, v. 17, no. 5, p. 564-572.

Parker, B.L., Brammer, J.D., Whalon, M.E., and Berry, W.O., 1976, Chronic oil contamination and aquatic organisms with emphasis on diptera: Status and bibliography: Water Resources Bulletin, v. 12 , no. 2, p. 291-305.

Parris, G.E., 1980, Covalent binding of aromatic amines to humates; 1. Reactions with carbonyls and quinones: Environmental Science and Technology, v. 14, no. 9, p. 1099-1106.

Pavlou, S.P., and Dexter, R.N., 1979, Distribution of PCBs in estuarine ecosystems; Testing the concept of equilibrium partitioning in the marine environment: Environmental Science and Technology, v. 13 , no. 1 , p. $65-71$

Pavlou, S.P., Dexter, R.N., Anderson, D.E., Quinlan, E.A., and Hom, W., 1980, Release, distribution, and impacts of PCBs induced by dredged material disposal activities at a deepwater estuarine site: Proceedings of the fifth meeting on Management of Bottom Sediments Containing Toxic Substances, U.S. Environmental Protection Agency, EPA 600/9-80-044, p. 129-174.

Pavlou, S.P., and Hom, W., 1976, Interlaboratory calibration results from chlorinated hydrocarbon analyses in marine sediments: Marine Chemistry, v. 4, p. 155-163.

Peakall, D.B., 1975, Phthalate esters: Occurrence and biological effects: Residue Reviews, v. 54, p. 1-39.

Pearlman, R.S., Yalkowsky, S.H., and Banerjee, Sujit, 1984, Water solubilities of polynuclear aromatic and heteroaromatic compounds: Journal of Physical and Chemical Reference Data, v. 13, no. 2, p. 555-562.

Peck, D.E., Corwin, D.L., and Farmer, W.J., 1980, Adsorptiondesorption of diuron by freshwater sediments: Journal of Environmental Quality, v. 9, no. 1, p. 101-106.

Pepe, M.G., and Byrne, J.J., 1980, Adhesion binding of $2,2^{\prime}, 4,4^{\prime}, 5,5^{\prime}$ hexachlorobiphenyl to glass and plastic: A possible source of error for PCB analysis: Bulletin of Environmental Contamination and Toxicology, v. 25, p. 936-940.

Perez, J.A., Hernandez, M.A., Ruiz, R.A., and Brown, P.J., 1977, The utilization of the plasticizer dimethyl phthalate by an isolated strain of Enterobacter aerogenes: Bulletin of Environmental Contamination and Toxicology, v. 18, no. 1, p. 104-107.

Peterle, T.J., 1969, DDT in antarctic snow: Nature, v. 224, p. 620-622.

Peterson, J.C., and Freeman, D.H., 1984, Variations of phthalate ester concentrations in sediments from the Chester River, Maryland: International Journal of Environmental and Analytical Chemistry, v. 18 , p. $237-252$.

Petrocelli, S.R., Hanks, A.R., and Anderson, Jack, 1973, Uptake and accumulation of an organochlorine insecticide (dieldrin) by an estuarine mollusc, Rangia cuneata: Bulletin of Environmental Contamination and Toxicology, v. 10, no. 5, p. 315-320.

Pfaender, F.K., Shuman, M.S., Dempsey, Herbert, and Harden, C.W., 1977, Monitoring heavy metals and pesticides in the Cape Fear river basin of North Carolina: Raleigh, University of North Carolina Water Resources Research Institute Report 126, 151 p.

Pfister, R.M., Dugan, P.R., and Frea, J.I., 1969, Microparticulates: Isolation from water and identification of associated chlorinated pesticides: Science, v. 172, p. 878-879.

Picer, N., Picer, M., and Strohal, P., 1977, The interaction of DDT with suspended particles in sea water: Water, Air, and Soil Pollution, v. 8, p. $429-440$.

Pierce, D.P., Williamson, K.J., and Nelson, P.O., 1981, Partitioning of trace organics in sediments: Proceedings of the American Society of Civil Engineers, Environmental Engineering Division, v. 107, no. EE5, p. 1100-1105.

Pierce, R.H., Brent, C.R., Williams, H.P., and Reeves, S.G., 1977, Pentachlorophenol distribution in a freshwater ecosystem: Bulletin of Environmental Contamination and Toxicology, v. 18, p. 251-258.

Pierce, R.H., Olney, C.E., and Felbeck, G.T., 1974, p,p'-DDT adsorption to suspended particulate matter in sea water: Geochimica et Cosmochimica Acta, v. 38, p. 1061-1073.

Pionke, H.B., and Chesters, G., 1973, Pesticide-sediment-water interactions: Journal of Environmental Quality, v. 2, no. 1, p. 29-45.

Plimmer, J.R., 1978, Photolysis of TCDD and trifluralin on silica and soil: Bulletin of Environmental Contamination and Toxicology, v. 20, p. 87-92.

Poirrier, M.A., Bordelon, B.R., and Laseter, J., 1972, Adsorption and concentration of dissolved carbon-14 DDT by coloring colloids in 
surface waters: Environmental Science and Technology, v. 6, no. 12, p. 1033-1035.

Pollock, G.A., and Kilgore, W.W., 1978, Toxaphene: Residue Reviews, v. 69 , p. 87-143.

Powers, C.F., Sanville, W.D., and Stay, F.S., 1976, Aquatic sediments: Journal of the Water Pollution Control Federation, v. 48, no. 6, p. 1433-1439.

Powers, C.F., Sanville, W.D., Stay, F.S., and Schuytema, G.S., 1977, Aquatic sediments: Journal of the Water Pollution Control Federation, v. 49, no. 6, p. 1307-1316.

Powers, C.F., Stay, F.S., and Sanville, W.D., 1975, Aquatic sediments: Journal of the Water Pollution Control Federation, v. 47, no. 6, p. 1611-1617.

Presley, B.J., and Trefry, J.H., 1980, Sediment-water interactions and the geochemistry of interstitial waters, in Olausson, E., and Cato, I., eds., Chemistry and biogeochemistry of estuaries: New York, John Wiley and Sons, p. 187-226.

Preston, M.R., and Riley, J.P., 1982, The interactions of humic compounds with electrolytes and three clay minerals under simulated estuarine conditions: Estuarine, Coastal and Shelf Science, v. 14 , p. 567-576.

Pritchard, P.H., 1984, Fate of environmental pollutants: Journal of the Water Pollution Control Federation, v. 56. no. 6, p. 718-725.

Puffer, Harold W., and Gossett, Richard W., 1983, PCB, DDT, and benzo(a)pyrene in raw and pan-fried white croaker (Genyonemus lineatus): Bulletin of Environmental Contamination and Toxicology, v. 30 , p. $65-73$.

Purdue, E.M., 1983, Association of organic pollutants with humic substances: Partitioning equilibria and hydrolysis kinetics, in Christman, R.F., and Gjessing, E.T., eds., Aquatic and terrestrial humic materials: Ann Arbor, Mich., Ann Arbor Science Publishers, p. 441-460.

- 1985, Acidic functional groups of humic substances, in Aiken, George, McKnight, Diane, Wershaw, Robert, and MacCarthy, Patrick, eds., Humic substances in soil, sediment, and water: New York, John Wiley and Sons, p. 493-526.

Qasim, S.R., Armstrong, A.T., Corn, John, and Jordan, B.L., 1980, Quality of water and bottom sediments in the Trinity River: Water Resources Bulletin, v. 16, no. 3, p. 522-531.

Rajagopal, B.S., Brahmaprakash, G.P., Reddy, B.R., Singh, U.D., and Sethunathan, N., 1984, Effect and persistence of selected carbamate pesticides in soil: Residue Reviews, v. 93, p. 1-207.

Ramamoorthy, S., 1985, Competition of fate processes in the bioconcentration of lindane: Bulletin of Environmental Contamination and Toxicology, v. 34, p. 349-358.

Rao, P.S.C., and Davidson, J.M., 1979, Adsorption and movement of selected pesticides at high concentrations in soils: Water Research, v. 13, p. 375-380.

Rao, P.S.C., Green, R.E., Balasubramanian, V., and Kanehiro, Y., 1974 , Field study of solute movement in a highly aggregated oxisol with intermittent flooding: II. Picloram: Journal of Environmental Quality, v. 3, no. 3, p. 197-201.

Rao, P.S.C., Hornsby, A.G., Kilcrease, D.P., and Nkedi-Kizza, P., 1985, Sorption and transport of hydrophobic organic chemicals in aqueous and mixed solvent systems: Model development and preliminary evaluation: Journal of Environmental Quality, v. 14, no. 3, p. 376-383.

Rashid, M.A., and King, L.H., 1970, Major oxygen-containing functional groups present in humic and fulvic acid fractions isolated from contrasting marine environments: Geochimica et Cosmochimica Acta, v. 34, p. 193-201.

Rathbun, R.E., and Tai, D.Y., 1982, Volatilization of organic compounds from streams: Proceedings of the American Society of Civil Engineers, Environmental Engineering Division, v. 108, no. EE5, p. 973-989.

-1984, Comparison of nonlinear least squares and log transfor- mation procedures for calculating volatilization coefficients: Chemosphere, v. 13 , no. 7, p. 715-730.

Ray, S., Jessop, B.M., Coffin, J., and Swetnam, D.A., 1984, Mercury and polychlorinated biphenyls in striped bass (Morone saxatilis) from two Nova Scotia rivers: Water, Air, and Soil Pollution, v. 21, p. 15-23.

Reinert, K.H., and Rodgers, J.H. Jr., 1984, Influence of sediment types on the sorption of endothall: Bulletin of Environmental Contamination and Toxicology, v. 32, p. 557-564.

Reinert, R.E., 1972, Journal of the Fish Research Board of Canada, v. 27, p. 1413.

Reutergardh, L., 1980, Chlorinated hydrocarbons in estuaries, in Olausson, E. and Cato, E., eds., Chemistry and biogeochemistry of estuaries: New York, John Wiley and Sons, p. 349-365.

Rhead, M.M., and Perkins, J.M., 1984, An evaluation of the relative importance of food and water as sources of $\mathrm{p}, \mathrm{p}^{\prime}$-DDT to the goldfish, Carassius auratus (1.): Water Research, v. 18, no. 6, p. 719-725.

Ricci, E.D., Hubert, W.A., and Richard, J.J., 1983, Organochlorine residues in sediment cores of a midwestern reservoir: Journal of Environmental Quality, v. 12, no. 3, p. 418-421.

Rice, C.P., Eadie, B.J., and Erstfeld, K.M., 1982, Enrichment of PCBs in Lake Michigan surface films: Journal of Great Lakes Research, v. 8, no. 2, p. 265-270.

Richardson, E.M., and Epstein, E., 1971, Retention of three insecticides on different size soil particles suspended in water: Soil Science Society of America Proceedings, v. 35, p. 884-887.

Rihan, T.I., Mustafa, H.T., Caldwell, George, Jr., and Frazier, Leroy, 1978, Chlorinated pesticides and heavy metals in streams and lakes of northern Mississippi water: Bulletin of Environmental Contamination and Toxicology, v. 20, p. 568-572.

Riley, G.A., 1963, Organic aggregates in seawater and the dynamics of their formation and utilization: Limnology and Oceanography, v. 8, p. $372-381$.

1970, Particulate organic matter in sea water: Advances in Marine Biology, v. 8, p. 1-118

Roberts, A.E., Hill, D.R., and Tifft, E.C., Jr., 1982, Evaluation of New York Bight lobsters for PCBs, DDT, petroleum hydrocarbons, mercury, and cadmium: Bulletin of Environmental Contamination and Toxicology, v. 29, p. 711-718.

Rodgers, P.W., and Swain, W.R., 1983, Analysis of PCB loading trends in Lake Michigan: Journal of Great Lakes Research, v. 9, no. 4, p. 548-558.

Rosales, M.T.L., and Escalona, R.L., 1983, Organochlorine residues in organisms of two different lagoons of northwest Mexico: Bulletin of Environmental Contamination and Toxicology, v. 30, p. 456-463.

Rosales, M.T.L., Escalona, R.L., Alarcon, R.M., and Zamora, V., 1985, Organochlorine hydrocarbon residues in sediments of two different lagoons of Northwest Mexico: Bulletin of Environmental Contamination and Toxicology, v. 35, p. 322-330.

Rossmann, R., and Siebel, E., 1977, Surficial sediment redistribution by wave energy; Element-grain size relationships: Journal of Great Lakes Research, v. 3, no.3-4, p. 258-262.

Routh, J.D., 1972, DDT residues in Salinas River sediments: Bulletin of Environmental Contamination and Toxicology, v. 7, p. 168-176.

Rudling, Lars, 1970, Determination of pentachlorophenol in organic tissues and water: Water Research, v. 4, p. 533-537.

Ryan, J.J., Lau, P.Y., Pilon, J.C., Lewis, Dave, McLeod, H.A., and Gervals, Adrian, 1984, Incidence and levels of 2,3,7,8-tetrachlorodibenzo-p-dioxin in Lake Ontario commercial fish: Environmental Science and Technology, v. 18, no. 9, p. 719-721.

Ryan, J.J., Pilon, J.C., Conacher, H.B.S., and Firestone, David, 1983, Interlaboratory study on determination of 2,3,7,8-tetrachlorodibenzo-p-dioxin in fish: Journal of the Association of Official Analytical Chemists, v. 66, no. 3, p. 700-707. 
Saar, R.A., and Weber, J.H., 1982, Fulvic acid: Modifier of metal-ion chemistry: Environmental Science and Technology, v. 16, no. 9, p. 510a-517a.

Sabljic, Aleksandar, and Protic, Miroslava, 1982, Relationship between molecular connectivity indices and soil sorption coefficients of polycyclic aromatic hydrocarbons: Bulletin of Environmental Contamination and Toxicology, v. 28, p. 162-165.

Sabourin, T.D., Stickle, W.B., Michot, T.C., Villars, C.E., Garton, D.W., and Mushinsky, H.R., 1984, Organochlorine residue levels in Mississippi River water snakes in southern Louisiana: Bulletin of Environmental Contamination and Toxicology, v. 32, p. 460-468.

Saeger, V.W., Hicks, O., Kaley, R.G., Michael, P.R., Mieure, J.P., and Tucker, E.S., 1979, Environmental fate of selected phosphate esters: Environmental Science and Technology, v. 13, no. 7, p. 840-844.

Salim, R., and Cooksey, B.G., 1981, The effect of centrifugation on the suspended particles of river waters: Water Research, v. 15, p. 835-839.

Sanborn, J.R., Metcalf, R.L., Yu, Ching-Chieh, and Lu, Po-Yung, 1975, Plasticizers in the environment: The fate of di-n-octyl phthalate (DOP) in two model ecosystems and upatke and metabolism of DOP by aquatic organisms: Archives of Environmental Contamination and Toxicology, v. 3, no. 2, p. 244-255.

Sanders, H.O., and Chandler, J.H., 1972, Biological magnification of a polychlorinated biphenyl (Aroclor 1254) from water by aquatic invertebrates: Bulletin of Environmental Contamination and Toxicology, v. 7, no. 5, p. 257-263.

Sanville, W.D., Lauer, W.L., Stay, F.S., Schuytema, G.S., and Powers, C.F., 1978, Aquatic sediments: Journal of the Water Pollution Control Federation, v. 50, no. 6, p. 1414-1424.

Sauer, T.C., 1980, Volatile liquid hydrocarbons in waters of the Gulf of Mexico and Caribbean Sea: Limnology and Oceanography, v. 25, no. 2, p. 338-351.

Sawhney, B.L., Frink, C.R., and Glowa, W., 1981, PCBs in the Housatonic River: Journal of Environmental Quality, v. 10, no. 4, p. 444-448.

Sayler, G.S., Shon, M., and Colwell, R.R., 1977, Growth of an estuarine Pseudomonas sp. on polychlorinated biphenyl: Microbial Ecology, v. 3, p. 24i-255.

Schaefer, C.H., Dupras, E.F., Jr., Stewart, R.J., Davidson, L.W., and Colwell, A.E., 1979, The accumulation and elimination of diflubenzuron by fish: Bulletin of Environmental Contamination and Toxicology, v. 21, p. 249-254.

Schaeffer, D.J., and Janardan, K.G., 1980, Abundance of organic compounds in water: Bulletin of Environmental Contamination and Toxicology, v. 24, p. 211-216.

Schellenberg, Kurt, Leuenberger, Christian, and Schwarzenbach, R.P., 1984, Sorption of chlorinated phenols by natural sediments and aquifer materials: Environmental Science and Technology, v. 18, no. 9 , p. $652-657$.

Schlagbauer, B.G.L., and Schlagbauer, A.W.J., 1972, The metabolism of carbamate pesticide $-A$ literature analysis: Residue Reviews, v. 42, p. 1-91.

Schnitzer, Morris, and Khan, S.U., 1972, Humic substances in the environment: New York, Marcel Dekker Inc., 317 p.

Schnoor, J.L., and McAvoy, D.C., 1981, Pesticide transport and bioconcentration model: Journal of the Environmental Engineering Division, American Society of Civil Engineers, v. 107, no. EE6, p. 1229-1246.

Schroeder, R.A., and Barnes, C.R., 1983a, Polychlorinated biphenyl concentrations in Hudson River water and treated drinking water at Waterford, New York: U.S. Geological Survey WaterResources Investigations Report 83-4188, 17 p.

1983b, Trends in polychlorinated biphenyl concentrations in Hudson River water five years after elimination of point sources:
U.S. Geological Survey Water-Resources Investigations Report 83-4206, 33 p.

Schwarzenbach, R.P., Molnar-Kubica, Eva, Giger, Walter, and Wakeham, S.G., 1979, Distribution, residence time, and fluxes of tetrachloroethylene and 1,4-dichlorobenzene in Lake Zurich, Switzerland: Environmental Science and Technology, v. 13, no. 11, p. 1367-1373.

Schwarzenbach, R.P., and Westall, J., 1981, Transport of nonpolar organic compounds from surface water to groundwater; Laboratory sorption studies: Environmental Science and Technology, v. 15 , no. 11 , p. $1360-1367$.

Scott, H.D., Wolf, D.C., and Lavy, T.L., 1982, Apparent adsorption and microbial degradation of phenol by soil: Journal of Environmental Quality, v. 11, no. 1, p. 107-112.

Scott, W.S., 1980, Analysis of bottom sediments in the vicinity of a proposed submarine cable: Bulletin of Environmental Contamination and Toxicology, v. 24, p. 766-773.

Seelye, J.G., Hesselberg, R.J., and Mac, M.J., 1982, Accumulation by fish of contaminants released from dredged sediments: Environmental Science and Technology, v. 16, no. 8, p. 459-464.

Seguchi, Koichiro, and Asaka, Shiro, 1981, Intake and excretion of diazinon in freshwater fishes: Bulletin of Environmental Contamination and Toxicology, v. 27, p. 244-249.

Seidler, J.J., Landau, Matthew, Dierberg, F.E., and Pierce, R.H., 1986, Persistence of pentachlorophenol in a wastewater-estuarine aquaculture system: Bulletin of Environmental Contamination and Toxicology, v. 36, p. 101-108.

Senesi, N., and Testini, C., 1980, Adsorption of some nitrogenated herbicides by soil humic acids: Soil Science, v. 130 , no. 6, p. 314-320.

Shackelford, W.M., and Keith, L.H., 1976, Frequency of organic compounds identified in water: U.S. Environmental Protection Agency, EPA 600/4-76-062.

Shannon, L.R., 1977, Accumulation and elimination of dieldrin in muscle tissue of channel catfish: Bulletin of Environmental Contamination and Toxicology, v. 17, no. 6, p. 637-644.

Sharom, M.S., Miles, J.R.W., Harris, C.R., and McEwen, F.L., 1980a, Behaviour of 12 pesticides in soil and aqueous suspensions of soil and sediment: Water Research, v. 14, p. 1095-1100.

-1980b, Persistence of 12 insecticides in water: Water Research, v. 14, p. 1089-1093.

Sharp, J.H., 1973, Size classes of organic carbon in seawater: Limnology and Oceanography, v. 18, p. 441-447.

Sheldon, L.S., 1979, Sources and movement of organic chemicals in the Delaware River: Environmental Science and Technology, v. 13, no. 5, p. 574-579.

Sheldon, L.S., and Hites, R.A., 1979, Organic compounds in the Delaware River: Environmental Science and Technology, v. 12, no. 10 , p. $1188-1194$.

Sheldon, R.W., 1968, Sedimentation in the estuary of the River Crouch, Essex, England: Limnology and Oceanography, v. 13, p. 72-83.

Sheldon, R.W., Evelyn, T.P.T., and Parsons, T.R., 1967, On the occurrence and formation of small particles in seawater: Limnology and Oceanography, v. 12, p. 367-375.

Sheldon, R.W., Prakash, A., and Sutcliffe, W.H., 1972, The size distribution of particles in the ocean: Limnology and Oceanography, v. 17 , p. $327-340$.

Sheldon, R.W., Sutcliffe, W.H., and Prakash, A., 1973, The production of particles in the surface waters of the ocean with particular reference to the Sargasso Sea: Limnology and Oceanography, v. 18 , no. 5 , p. $719-733$.

Sholkovitz, E.R., 1976, Flocculation of dissolved organic and inorganic matter during the mixing of river water and seawater: Geochimica et Cosmochimica Acta, v. 40, p. 831-845. 
1979, Chemical and physical processes controlling the chemical composition of suspended material in the River Tay estuary: Estuarine and Coastal Marine Science, v. 8, p. 523-545.

Sholkovitz, E.R., Boyle, E.A., and Price, N.B., 1978, The removal of dissolved humic acids and iron during estuarine mixing: Earth and Planetary Science Letters, v. 40, p. 130-136.

Sholkovitz, E.R., and Copland, D., 1982, The chemistry of suspended matter in Esthwaite Water, a biologically productive lake with seasonally anoxic hypolimnion: Geochimica et Cosmochimica Acta, v. 46 , p. $393-410$.

Sigleo, A.C., and Helz, G.R., 1981, Composition of estuarine colloidal material; Major and trace elements: Geochimica et Cosmochimica Acta, v. 45, p. 2501-2509.

Sigleo, A.C., Helz, G.R., and Zoller, W.H., 1980, Organic-rich colloidal material in estuaries and its alteration by chlorination: Environmental Science and Technology, v. 14, no. 6, p. 673-679.

Sigleo, A.C., Hoering, T.C., and Helz, G.R., 1982, Composition of estuarine colloidal material; Organic components: Geochimica et Cosmochimica Acta, v. 46, p. 1619-1626.

Simkins, Stephen, and Alexander, Martin, 1984, Models for mineralization kinetics with the variables of substrate concentration and population density: Applied and Environmental Microbiology, v. 47, no. 6, p. 1299-1306.

Simmons, M.S., Bialosky, D.I., and Rossman, R., 1980, PCB contamination in surficial sediments of northeastern Lake Michigan: Journal of Great Lakes Research, v. 6, no. 2, p. 167-171.

Simmons, M.S., and Kotz, K.T., 1982, Association studies of polybrominated biphenyls in aquatic systems: Bulletin of Environmental Contamination and Toxicology, v. 29, p. 58-63.

Skea, J.C., Simonin, H.A., Dean, H.J., Colquhoun, J.R., Spagnoli, J.J., and Veith, G.D., 1979, Bioaccumulation of Aroclor 1016 in Hudson River fish: Bulletin of Environmental Contamination and Toxicology, v. 22, p. 332-336.

Skea, J.C., Simonin, H.J., Jackling, S., and Symula, J., 1981, Accumulation and retention of mirex by brook trout fed a contaminated diet: Bulletin of Environmental Contamination and Toxicology, $v$. 27, p. 79-83.

Sloan, R.J., Simpson, K.W., Schroeder, R.A., and Barnes, C.R., 1983, Temporal trends toward stability of Hudson River PCB contamination: Bulletin of Environmental Contamination and Toxicology, v. 31, p. 377-385.

Smith, A.E., 1985, Identification of 2,4-dichloroanisole and 2,4dichlorophenol as soil degradation products of ring-labelled $\left[{ }^{14} \mathrm{C}\right] 2,4-\mathrm{D}$ : Bulletin of Environmental Contamination and Toxicology, v. 34, p. 150-157.

Smith, F.A., Sharma, R.P., Lynn, R.I., and Low, J.B., 1974, Mercury and selected pesticide levels in fish and wildlife of Utah: I. Levels of mercury, DDT, DDE, dieldrin and PCB in fish: Bulletin of Environmental Contamination and Toxicology, v. 12, no. 2, p. 218-223.

Smith, J.A., Harte, P.T., and Hardy, M.A., 1987, Trace metal and organochlorine residues in sediments of the Upper Rockaway River, New Jersey: Bulletin of Environmental Contamination and Toxicology, v. 39, p. 465-473.

Smith, J.A., and Novak, J.T., 1987, Biodegradation of chlorophenols in subsurface soils: Water, Air, and Soil Pollution, v. 33, p. 29-42.

Smith, J.H., Bomberger, D.C., and Haynes, D.L., 1980, Prediction of the volatilization rates of high-volatility chemicals from natural water bodies: Environmental Science and Technology, v. 14, no. 11, p. $1332-1337$.

- 1981, Volatilization rates of intermediate and low volatility chemicals from water: Chemosphere, v. 10, no. 3, p. 261-289.

Smith, J.H., Mabey, W.R., Bohonos, N., Holt, B.R., Lee, S.S., Chou, T.W., Bomberger, D.C., and Mill, T., 1978, Environmental pathways of selected chemicals in freshwater systems, Part II: Labo- ratory studies: U.S. Environmental Protection Agency, EPA600/7-78-074, 518 p.

Smith, J.H., Mackay, Donald, and Ng, C.W.K., 1983, Volatilization of pesticides from water: Residue Reviews, v. 85, p. 73-88.

Southworth, G.R., 1979, The role of volatilization in removing polycyclic aromatic hydrocarbons from aquatic environments: Bulletin of Environmental Contamination and Toxicology, v. 21, p. 507-514.

Southworth, G.R., Beauchamp, J.J., and Schmieder, P.K., 1978a, Bioaccumulation potential and acute toxicity of synthetic fuels effluents in freshwater biota: Azaarenes: Environmental Science and Technology, v. 12, no. 9, p. 1062-1066.

$-1978 \mathrm{~b}$, Bioaccumulation potential of polycyclic aromatic hydrocarbons in Daphnia pulex: Water Research, v. 12, p. 973-977.

Southworth, G.R., Herbes, S.E., Franco, P.J., and Giddings, J.M., 1985, Persistence of phenols in aquatic microcosms receiving chronic inputs of coal-derived oil: Water, Air, and Soil Pollution, v. 24, p. 283-296.

Southworth, G.R., Keffer, C.C., and Beauchamp, J.J., 1980, Potential and realized bioconcentration. A comparison of observed and predicted bioconcentration of azaarenes in the fathead minnow (Pimephales promelas): Environmental Science and Technology, $\mathbf{v}$. 14, no. 12, p. 1529-1531.

Southworth, G.R., and Keller, J.L., 1986, Hydrophobic sorption of polar organics by low organic carbon soils: Water, Air, and Soil Pollution, v. 28, p. 239-248.

Southworth, G.R., Parkhurst, B.R., and Beauchamp, J.J., 1979, Accumulation of acridine from water, food, and sediment by the fathead minnow, Pimephales promelas: Water, Air, and Soil Pollution, v. 12, p. 331-341.

Spehar, R.L., Veith, G.D., DeFoe, D.L., and Bergstedt, B.V., 1979, Toxicity and bioaccumulation of hexachlorocyclopentadiene, hexachloronorbornadiene and heptachloronorbornene in larval and early juvenile fathead minnows, Pimephales promelas: Bulletin of Environmental Contamination and Toxicology, v. 21, p. 576-583.

Spencer, W.F., Cliath, M.M., Farmer, W.J., and Shepherd, R.A., 1974, Volatility of DDT residues in soil as affected by flooding and organic matter applications: Journal of Environmental Quality, v. 3, no. 2, p. 126-129.

Spencer, W.F., Farmer, W.J., and Cliath, M.M., 1973, Pesticide volatilization: Residue Reviews, v. 49, p. 1-40.

Spigarelli, S.A., Thommes, M.M., and Prepejchal, William, 1983, Thermal and metabolic factors affecting PCB uptake by adult brown trout: Environmental Science and Technology, v. 17, no. 2, p. $88-94$.

Stainken, Dennis, 1979, Occurrence of extractable hydrocarbons in sediments from Raritan Bay, New Jersey: Bulletin of New Jersey Academy of Science, v. 24, no. 1, p. 6-11.

Stainken, Dennis, and Frank, Uwe, 1979, Analysis of Raritan Bay bottom sediments for polynuclear aromatic hydrocarbons: Bulletin of Environmental Contamination and Toxicology, v. 22, p. 480-487.

Stainken, Dennis, and Rollwagen, Janice, 1979, PCB residues in bivalves and sediments of Raritan Bay: Bulletin of Environmental Contamination and Toxicology, v. 23, p. 690-697.

Stalling, D.L., Hogan, J.W., and Johnson, J.L., 1973, Phthalate ester residues-Their metabolism and analysis in fish: Environmental Health Perspectives, v. 3, p. 159-173.

Stamer, J.K., Yorke, T.H., and Pederson, G.L., 1985, Distribution and transport of trace substances in the Schuylkill River basin from Berne to Philadelphia, Pennsylvania: U.S. Geological Survey Water-Supply Paper 2256-A, 45 p. 
Stanlake, G.J., and Finn, R.K., 1982, Isolation and characterization of a pentachlorophenol-degrading bacterium: Applied and Environmental Microbiology, v. 44, no. 6, p. 1421-1427.

Staples, C.A., Werner, A.F., and Hoogheem, T.J., 1985, Assessment of priority pollutant concentrations in the United States using storet database: Environmental Toxicology and Chemistry, v. 4, p. 131-142.

Steelink, Cornelius, 1985, Implications of elemental characteristics of humic substances, in Aiken, Georege, McKnight, Diane, Wershaw, Robert, and MacCarthy, Patrick, eds., Humic substances in soil, sediment, and water: New York, John Wiley and Sons, p. 457-476.

Steen, W.C., and Karickhoff, S.W., 1981, Biosorption of hydrophobic organic pollutants by mixed microbial populations: Chemosphere, v. 10, p. 27-32.

Steen, W.C., Paris, D.F., and Baughman, G.L., 1978, Partitioning of selected polychlorinated biphenyls to natural sediments: Water Research, v. 12, p. 655-657.

Stojanovic, B.J., Kennedy, M.V., and Shuman, F.L., 1972, Edaphic aspects of the disposal of unused pesticides, pesticide wastes and pesticide containers: Journal of Environmental Quality, v. 1, no. 1, p. 54-62.

Stumm, Werner, 1977, Chemical interaction in particle separation: Environmental Science and Technology, v. 11, no. 12, p. 1066-1070.

Sudhakar-Barik, and Sethunathan, N., 1978, Biological hydrolysis of parathion in natural ecosystems: Journal of Environmental Quality, v. 7, no. 3, p. 346-348.

Sugiura, Katsura, Washino, Tohoru, Hattori, Mitsuo, Sato, Eiji, and Goto, Miki, 1979, Accumulation of organochlorine compounds in fishes. Difference of accumulation factors by fishes: Chemosphere, v. 8, p. 359-364.

Sullivan, J.R., Delfino, J.J., Buelow, C.R., and Sheffy, T.B., 1983, Polychlorinated biphenyls in the fish and sediment of the Lower Fox River, Wisconsin: Bulletin of Environmental Contamination and Toxicology, v. 30, p. 58-64.

Swann, R.L., Laskowski, D.A., McCall, P.J., Vander Kuy, K., and Dishburger, H.J., 1983, A rapid method for the estimation of the environmental parameters octanol/water partition coefficient, soil sorption constant, water to air ratio, and water solubility: Residue Reviews, v. 85 , p. $17-28$.

Swanson, R.A., and Dutt, G.R., 1973, Chemical and physical processes that affect atrazine and distribution in soil systems: Soil Science Society of America Proceedings, v. 37, p. 872-876.

Tabak, H.H., Chambers, C.W., and Kabler, P.W., 1964, Microbial metabolism of aromatic compounds-I. Decomposition of phenolic compounds and aromatic hydrocarbons by phenol-adapted bacteria: Journal of Bacteriology, v. 87, no. 4, p. 910-919.

Tabak, H.H., Quave, S.A., Mashni, C.I., and Barth, E.F., 1981, Biodegradability studies with organic priority pollutant compounds: Journal of the Water Pollution Control Federation, v. 53, no. 10 , p. $1503-1518$.

Tahoun, S.A., and Mortland, M.M., 1966, Complexes of montmorillonite with primary, secondary, and tertiary amides: I. Protonation of amides on the surface of montmorillonite: Soil Science, v. 102, no. 4, p. 248-254.

Thomann, R.V., and Di Toro, D.M., 1983, Physico-chemical model of toxic substances in the Great Lakes: Journal of Great Lakes Research, v. 9, no. 4, p. 474-496.

Thuren, A., 1986, Determination of phthalates in aquatic environments: Bulietin of Environmental Contamination and Toxicology, v. 36, p. 33-40.

Thurman, E.M., 1984, Determination of aquatic humic substances in natural waters, in Thurman, E.M., ed., Selected papers in the hydrologic sciences 1984: U.S. Geological Survey Water-Supply Paper 2262, p. 47-52.
Tipping, E. and Woof, C., 1983, Seasonal variations in the concentration of humic substances in a soft-water lake: Limnology and Oceanography, v. 28, no. 1, p. 168-172.

Truhlar, J.F., and Reed, L.A., 1976, Occurrence of pesticide residues in four streams draining different land-use areas in Pennsylvania, 1969-71: Pesticides Monitoring Journal, v. 10, no. 3, p. 101-110.

Tschirley, F.H., 1986, Dioxin: Scientific American, v. 254, no. 2, p. 29-35.

Turk, J.T., 1980, Applications of Hudson River basin PCB-transport studies, in Baker, R.A., ed., Contaminants and sediments, v. 1: Ann Arbor, Mich., Ann Arbor Science Publishers, p. 171-183.

Turk, J.T., and Troutman, D.E., 1981, Polychlorinated biphenyl transport in the Hudson River, New York: U.S. Geological Survey Water-Resources Investigations Report 81-9, 16 p.

Turner, A.G., DiGiano, F.A., and DeRosa, P.M., 1984, A survey of potential population exposures to chemical contaminants present in unprotected surface water supplies in North Carolina: Raleigh, University of North Carolina Water Resources Research Institute Report 213, 72 p.

Uchrin, C.G., and Katz, Jack, 1985, Reversible and resistant components of hexachlorocyclohexane (lindane) sorption to New Jersey coastal plain aquifer solids: Journal of Environmental Science and Health, v. A20, no. 2, p. 205-218.

Uchrin, C.G., and Mangels, Gary, 1986, Chloroform sorption to New Jersey coastal plain ground water aquifer solids: Environmental Toxicology and Chemistry, v. 5, p. 339-343.

U.S. Department of Agriculture, 1983, Outlook and situation, October: U.S. Government Printing Office, 23 p.

U.S. Environmental Protection Agency, 1976, Criteria for water: Washington D.C., Office of Water Planning and Standards, 0.222-904, p. 193.

1977, Quality criteria for water, 1976: U.S. Government Printing Office, $256 \mathrm{p}$.

-1978, Environmental pathways of selected chemicals in freshwater systems, Pt. II, Laboratory studies: EPA-600/7-78-074, $404 \mathrm{p}$.

1979, Water related fate of 129 priority pollutants, v. I and II: EPA-440/4-79-029a,b.

1980a, Ambient water quality criteria for phenol: EPA440/5-80-066.

1980b, Water quality criteria documents; Availability: U.S. Federal Register, v. 45, no. 231, p. 79318-79379.

1981, Aquatic fate process data for organic priority pollutants: EPA-440/4-81-014, 432 p.

1982, Sampling protocols for collecting surface water, bed sediment, bivalves, and fish for priority pollutant analysis: Washington, D.C., Office of Water Regulations and Standards.

1982, Treatability manual, v. I, Treatability data: EPA600/2-82-001a.

Van Hove Holdrinet, Micheline, 1979, Confirmation of mirex and cistrans-chlordane in the presence of other organochlorine insecticides and polychlorinated biphenyls: Bulletin of Environmental Contamination and Toxicology, v. 21, p. 46-52.

Van Luik, A., 1984, Mined land reclamation using polluted urban navigable waterway sediments: II. Organics: Journal of Environmental Quality, v. 13, no. 3, p. 415-422.

Van Middelem, C.H., 1963, Parathion residues, on leafy crops: Residue Reviews, v. 2, p. 77-95.

VanNess, G.F., Solch, J.G., Taylor, M.L., and Tiernan, T.O., 1980, Tetrachlorodibenzo-p-dioxins in chemical wastes, aqueous effluents and soils: Chemosphere, v. 9, p. 553-563.

Varanasi, Usha, Reichert, W.L., Stein, J.E., Brown, D.W., and Sanborn, H.R., 1985, Bioavailability and biotransformation of aromatic hydrocarbons in benthic organisms exposed to sediment from an urban estuary: Environmental Science and Technology, $v$. 19 , no. 9 , p. 836-841. 
Veith, G.D., DeFoe, D.L., and Bergstedt, B.V., 1979, Journal of the Fish Resources Board of Canada, v. 36, p. 1040.

Verschueren, Karel, 1983, Handbook of environmental data on organic chemicals (2d ed.): New York, Van Nostrand Reinhold, $1,310 \mathrm{p}$.

Visser, S.A., Lamontagne, G., Zoulalian, V., and Tessier, A., 1977, Bacteria active in the degradation of phenols in polluted waters of the St. Lawrence River: Arhcives of Environmental Contamination and Toxicology, v. 6, p. 455-469.

Voice, T.C., Rice, C.P., and Weber, W.J., Jr., 1983, Effects of solids concentration on the sorptive partitioning of hydrophobic pollutants in aquatic systems: Environmental Science and Technology, $v$. 17 , no. 9 , p. $513-518$.

Voice, T.C., and Weber, W.J., Jr., 1983, Sorption of hydrophobic compounds by sediments, soils, and suspended solids-I. Theory and background: Water Research, v. 17, no. 10, p. 1433-1441.

-1985, Sorbent concentration effects in liquid/solid partitioning: Environmental Science and Technology, v. 19, no. 9, p. 789-796.

Wakeham, S.G., and Carpenter, Roy, 1976, Aliphatic hydrocarbons in sediments of Lake Washington: Limnology and Oceanography, v. 21, no. 5, p. 711-723.

Wakeman, S.G., Davis, A.C., and Karas, J.L., 1983, Mesocosm experiments to determine the fate and persistence of volatile organic compounds in coastal seawater: Environmental Science and Technology, v. 17, no. 10 , p. 611-617.

Walker, J.D., Colwell, R.R., Hamming, M.C., and Ford, H.T., 1975, Extraction of petroleum hydrocarbons from oil-contaminated sediments: Bulletin of Environmental Contamination and Toxicology, v. 13, no. 2, p. 245-248.

Walker, W.W., 1976, Chemical and microbiological degradation of malathion and parathion in an estuarine environment: Journal of Environmental Quality, v. 5, no. 2, p. 210-216.

Wallace, G.T., and Duce, R.A., 1978, Transport of particulate organic matter by bubbles in marine waters: Limnology and Oceanography, v. 23, no. 6, p. 1155-1167.

Wang, T., Lenahan, R., and Kanik, M., 1985, Impact of trichloroethylene contaminated groundwater discharged to the main canal and Indian River lagoon, Vero Beach, Florida: Bulletin of Environmental Contamination and Toxicology, v. 34, p. 578-586.

Wang, Wun-Cheng, 1975, Determination of cation-exchange capacity of suspended sediment: Water Resources Bulletin, v. 11, no. 5, p. 1052-1057.

Ward, C.T., and Matsumura, F., 1978, Fate of 2,3,7,8-tetrachlorodibenzo-p-dioxin (TCDD) in a model aquatic environment: Archives of Environmental Contamination and Toxicology, v. 7, p. 349-357.

Wasik, S.P., Miller, M.M., Tewari, Y.B., May, W.E., Sonnefeld, W.J., DeVoe, H., and Zoller, W.H., 1983, Determination of the vapor pressure, aqueous solubility, and octanol/water partition coefficient of hydrophobic substances by coupled generator column/ liquid chromatographic methods: Residue Reviews, v. 85, p. $29-42$.

Watkins, Jo, and Yarbrough, J.D., 1975, Aldrin and dieldrin uptake in insecticide-resistant and susceptible mosquitofish (Gambusia affinis): Bulletin of Environmental Contamination and Toxicology, $v$. 14 , no. 6 , p. $442-448$.

Wauchope, R.D., 1978, The pesticide content of surface waters draining from agricultural fields-A review: Journal of Environmental Quality, v. 7, no. 4, p. 459-472.

Wauchope, R.D., and Myers, R.S., 1985, Adsorption-desorption kinetics of atrazine and linuron in freshwater-sediment aqueous slurries: Journal of Environmental Quality, v. 14, no. 1, p. 132-136.

Weber, W.J., and Gould, J.P., 1966, Sorption of organic pesticides from aqueous solution, in Organic pesticides in the environment: American Chemical Society, Advances in Chemistry Series 60, p. 280-304.
Weber, J.B., Perry, P.W., and Upchurch, R.P., 1965, The influence of temperature and time on the adsorption of paraquat, diquat, 2,4-D, and prometone by clays, charcoal, and an anion-exchange resin: Soil Science Society of America Proceedings, v. 29, p. 678-688.

Weber, W.J., Sherrill, J.D., Pirbarazi, M., Uchrin, C.G., and Lo, T.Y., 1980, Transport and differential accumulation of toxic substances in river-harbor-lake systems, in Haque, R., ed., Dynamics, exposure, and hazard assessment of toxic chemicals: Ann Arbor, Mich., Ann Arbor Science Publishers, p. 191-213.

Weber, W.J., Voice, T.C., Pirbazari, M., Hunt, G.E., and Ulanoff, D.M., 1983, Sorption of hydrophobic compounds by sediments, soils and suspended soils-II. Sorbent evaluation studies: Water Research, v. 17, no. 10, p. 1443-1452.

Wegman, R.C.C., and van den Broek, H.H., 1983, Chlorophenols in river sediment in the Netherlands: Water Research, v. 17, p. 227-230.

Weinberger, Pearl, Greenhalgh, Roy, Moody, R.P., and Boulton, Bruce, 1982, Fate of fenitrothion in aquatic microcosms and the role of aquatic plants: Environmental Science and Technology, v. 16 , no. 8 , p. $470-473$.

Welch, K.J., Kuehl, D.W., Leonard, E.N., Veith, G.D., and Schoenthal, N.D., 1981, Background hydrocarbon residues in fishes from the great lakes and eastern Montana: Bulletin of Environmental Contamination and Toxicology, v. 26, p. 724-728.

Wershaw, R.L., 1986, A new model for humic materials and their interactions with hydrophobic organic chemicals in soil-water or sediment-water systems: Journal of Contaminant Hydrology, v. 1, p. $29-45$.

Wershaw, R.L., Burcar, P.J., and Goldberg, M.C., 1969, Interaction of pesticides with natural organic material: Environmental Science and Technology, v. 3, no. 3, p. 271-273.

Wershaw, R.L., and Pinckney, D.J., 1973, Determination of the association and dissociation of humic acid fractions by small angle X-ray scattering: U.S. Geological Survey Journal of Research, v. 1, no. 6, p. 701-707.

Whipple, William, and Hunter, J.V., 1979, Petroleum hydrocarbons in urban runoff: Water Resources Bulletin, v. 15, no. 4, p. 1096-1105.

White, R.J., Kim, H.T., and Kim, J.S., 1985, PCBs in striped bass collected from the Hudson River, New York, during fall, 1981: Bulletin of Environmental Contamination and Toxicology, v. 34, p. 883-889.

Whitman, W.G., 1923, Preliminary experimental confirmation of the two-film theory of gas absorption: Chemical and Metallurgical Engineering, v. 29, p. 146-154.

Wicklund, A., and Suffet, I.H., 1983, Boonton Reservoir study; Part I-Sampling and analysis of organic chemicals: Trenton, New Jersey Department of Environmental Protection, $120 \mathrm{p}$.

Wijayaratne, R.D., and Means, J.C., 1984, Affinity of hydrophobic pollutants for natural estuarine colloids in aquatic environments: Environmental Science and Technology, v. 18, no. 2, p. 121-123.

Wilbur, W.G. and Hunter, J.V., 1979, The impact of urbanization on the distribution of heavy metals in bottom sediments of the Saddle River: Water Resources Bulletin, v. 15, no. 3, p.790-800.

Wildish, D.J., Metcalfe, C.D., and McLeese, D.W., 1980, Flux of Aroclor 1254 between estuarine sediments and water: Bulletin of Environmental Contamination and Toxicology, v. 24, p. 20-26.

Wilson, A.J., and Forester, Jerrold, 1978, Persistence of Aroclor 1254 in a contaminated estuary: Bulletin of Environmental Contamination and Toxicology, v. 19, p. 637-640.

Wilson, J.T., Miller, G.D., Ghiorse, W.C., and Leach, F.R., 1986, Relationship between the ATP content of subsurface material and the rate of biodegradation of alkylbenzenes and chlorobenzene: Journal of Contaminant Hydrology, v. 1, p. 163-170. 
Winger, P.V., and Andreasen, J.K., 1985, Contaminant residues in fish and sediments from lakes in the Atchafalaya River Basin (Louisiana): Archives of Environmental Contamination and Toxicology, v. 14, p. 579-586.

Witkowski, P.J., Smith, J.A., Fusillo, T.V., and Chiou, C.T., 1987, A review of surface-water sediment fractions and their interactions with persistent manmade organic compounds: U.S. Geological Survey Circular 993, 39 p.

Wolfe, N.L., Zepp, R.G., Gordon, J.A., Baughman, G.L., and Cline, D.M., 1977, Kinetics of chemical degradation of malathion in water: Environmental Science and Technology, v. 11, no. 1, p. 88-93.

Wolfe, N.L., Zepp, R.G., and Paris, D.F., 1978, Use of structurereactivity relationships to estimate hydrolytic persistence of carbamate pesticides: Water Research, v. 12, p. 561-563.

Wood, L.W., Jones, P.A., and Richards, A., 1986, Possible sediment scavenging of chlordane and contamination of the aquatic biota in Belmont Lake, New York: Bulletin of Environmental Contamination and Toxicology, v. 36, p. 159-167.

Woodburn, K.B., Rao, P.S.C., Fukui, M., and Nkedi-Kizza, P., 1986, Solvophobic approach for predicting sorption of hydrophobic organic chemicals on synthetic sorbents and soils: Journal of Contaminant Hydrology, v. 1, p. 227-241.

Woodwell, G.M., Craig, P.P., and Johnson, H.A., 1971, DDT in the biosphere: Where does it go?: Science, v. 174, p. 1101-1107.

Wszolek, P.C., Lisk, D.J., Wachs, Timothy, and Youngs, W.D., 1979, Persistence of polychlorinated biphenyls and 1,1-dichloro-2,2bis(p-chlorophenyl)ethylene (p,p'-DDE) with age in lake trout after 8 years: Environmental Science and Technology, v. 13, no. 10, p. 1269-1271.

Wu, Shian-chee, and Gschwend, P.M., 1986, Sorption kinetics of hydrophobic organia compounds to natural sediments and soils: Environmental Science and Technology, v. 20, no. 7, p. 717-725.

Wu, T.L., Lambert, Laurie, Hastings, David, and Banning, Deborah, 1980, Enrichment of the agricultural herbicide atrazine in the microsurface water of an estuary: Bulletin of Environmental Contamination and Toxicology, v. 24, p. 411-414.

Yalkowsky, S.H., Valvani, S.C., and Mackay, Donald, 1983, Estimation of the aqueous solubility of some aromatic compounds: Residue Reviews, v. 85, p. 43-55.

Yamamoto, Yasuhiro, Suzuki, Manabu, Shimohara, Kenichi, and Akiyama, Takashi, 1980, Behaviour of $\mathrm{HCH}(1,2,3,4,5,6$ hexachlorocyclohexane) residue in the aquatic environment: Water Research, v. 14, p. 247-251.

Yaron, Bruno, 1978, Some aspects of surface interactions of clays with organophosphorous pesticides: Soil Science, v. 125 , no. 4, p. 210-216.

Yaron, Bruno, and Saltzman, Sarina, 1972, Influence of water and temperature on adsorption of parathion by soils: Soil Science Society of America Proceedings, v. 36, p. 583-586.

Yasuhara, A., Shiraishi, H., Tsujl, M., and Okuno, T., 1981, Analysis of organic substances in highly polluted river water by mass spectrometry: Environmental Science and Technology, v. 15, p. 570-573.

Yorke, T.H., Stamer, J.K, and Pederson, G.L., 1985, Effects of low-level dams on the distribution of sediment, trace metals, and organic substances in the lower Schuylkill River basin, Pennsylvania: U.S. Geological Survey Water-Supply Paper 2256-B, 53 p.

Zabawa, C.F., 1978, Microstructure of agglomerated suspended sediments in northern Chesapeake Bay estuary: Science, v. 202, p. 49-51.

Zafiriou, O.C., Joussot-Dubien, J., Zepp, R.G., and Zika, R.G., 1984, Photochemistry of natural waters: Environmental Science and Technology, v. 18, no. 12, p. 358a-371a.

Zepp, R.G., and Cline, D.M., 1977, Rates of direct photolysis in aquatic environment: Environmental Science and Technology, v. 11 , no. 4, p. 359-366.

Zierath, D.L., Hassett, J.J., Banwart, W.L., Wood, S.G. and Means. J.C., 1980, Sorption of benzidine by sediments and soils: Soil Science, v. 129 , no. 5, p. 277-281.

Zitko, V., 1971, Polychlorinated biphenyls and organochlorine pesticides in some freshwater and marine fishes: Bulletin of Environmental Contamination and Toxicology, v. 6, no. 5, p. 464-470.

Zsolnay, A., 1979, Coastal colloidal carbon: A study of its seasonal variation and the possibility of river input: Estuarine and Coastal Marine Science, v. 9, p. 559-567. 

